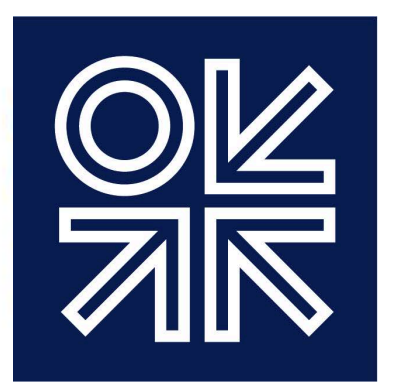

THE OXFORD

INSTITUTE

FOR ENERGY

STUDIES

July 2015

\title{
The Role of Gas in UK Energy Policy
}

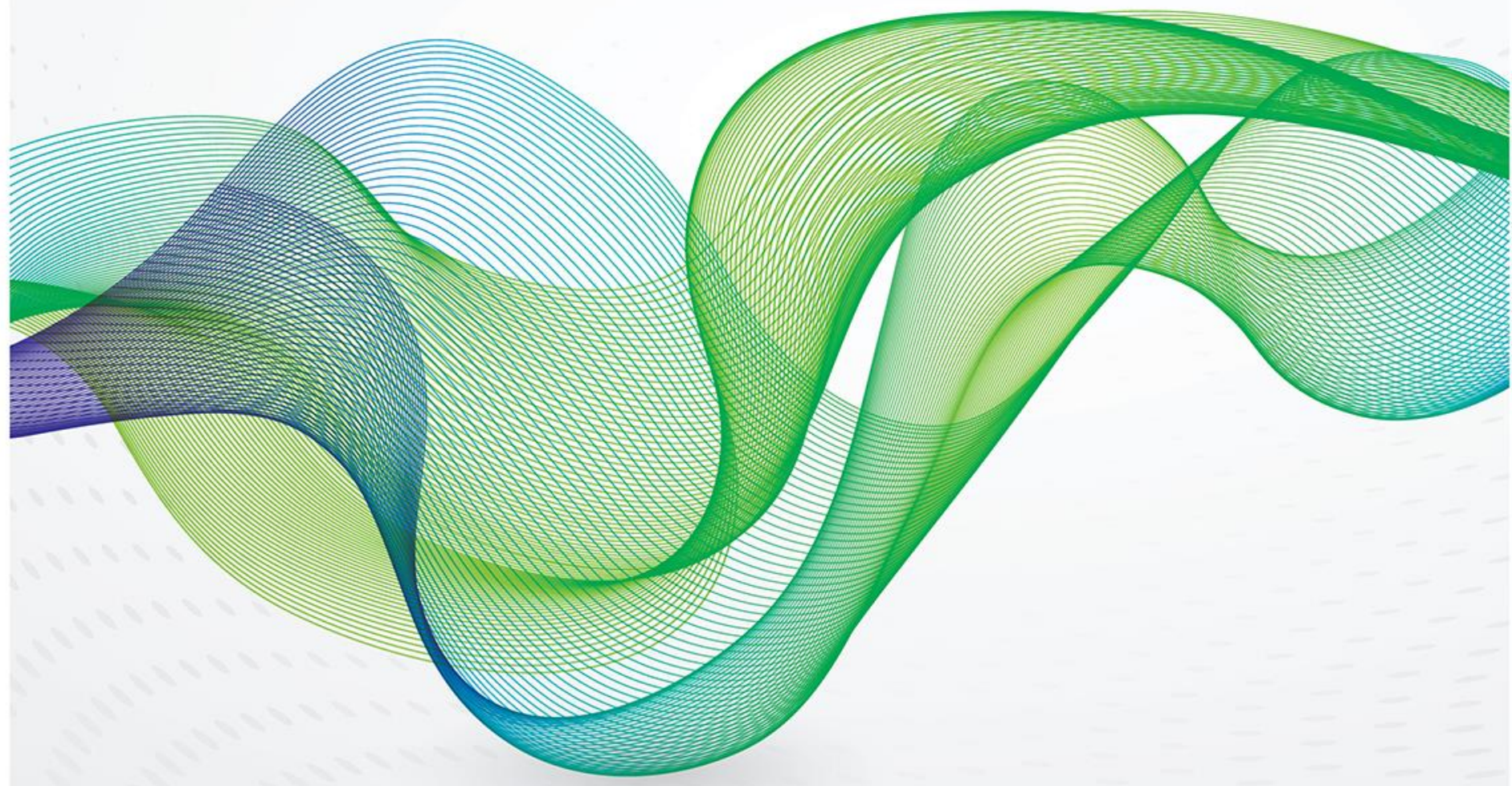



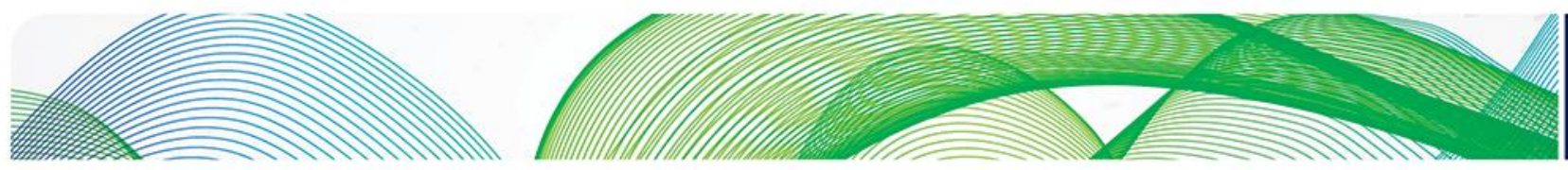

\section{O는}

The contents of this paper are the authors' sole responsibility. They do not necessarily represent the views of the Oxford Institute for Energy Studies or any of its members.

Copyright $\odot 2015$

Oxford Institute for Energy Studies

(Registered Charity, No. 286084)

This publication may be reproduced in part for educational or non-profit purposes without special permission from the copyright holder, provided acknowledgment of the source is made. No use of this publication may be made for resale or for any other commercial purpose whatsoever without prior permission in writing from the Oxford Institute for Energy Studies.

ISBN 978-1-78467-034-4 

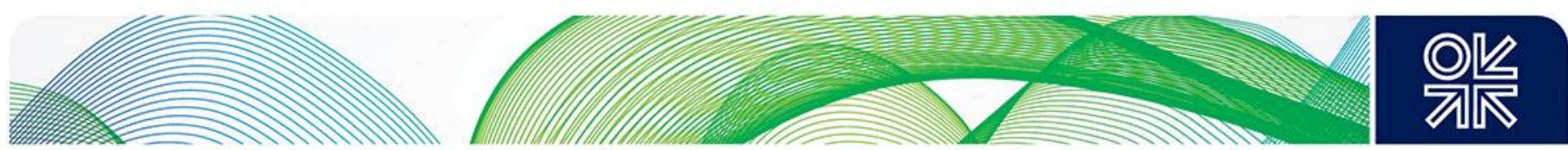

\section{Preface}

After Germany, the UK is Europe's largest gas market and in many ways encapsulates wider European policy concerns relating to gas and energy mix in general. The development of the North Sea secured gas at the core of the UK's energy mix, displacing coal and oil products in space heating and power generation sectors. The decline in indigenous production which began in 2001 has been rapid and to some, traumatic, despite the rapid establishment of import infrastructure and supply chains from diverse suppliers.

Despite the key contribution gas has made, in UK energy policy terms it is rarely referred to and in public discourse it is generally branded as a fossil fuel - undistinguished from coal which has double gas' footprint in power generation.

This paper by Chris Le Fevre takes a comprehensive view of the role of gas in the UK: its historic development and the future outlook and policy implications on both the supply and demand side. $\mathrm{He}$ explores the difficulties of the energy 'trilemma', i.e. how to achieve the three goals of 'affordability and competitiveness', sustainability' and 'security' when in practical terms these are at times mutually exclusive. Chris concludes that there is the danger that policy initiatives aimed at a particular part of the energy chain will fail to address the specific needs and opportunities presented by natural gas, and it is therefore essential that policy makers recognise and plan for the continuing large scale presence of gas in the energy mix. Without this recognition, the lead times involved may mean the gas-related components of the portfolio are not available when required. This is a particularly pressing issue for new generation gas-fired power plant. The recent capacity auctions have not incentivised any additional projects and this could lead to inadequate reserve margins of reliable generation.

It is therefore suggested that the development of an integrated natural gas strategy for the UK would go some way to addressing the challenges of the trilemma whilst reducing risks to the energy sector and the wider UK economy. Developing such a strategy would not involve a major change in direction or the establishment of a new task force or regulatory body. It would rather be a requirement for all government departments and agencies to consider policy implications where they are relevant to the natural gas sector.

The OIES Gas Programme while covering aspects of natural gas supply, demand, price formation, geopolitics and regulation on an international canvas, takes a keen interest in UK market developments. The UK was the first outside North America to liberalise its gas sector has thus served, thus far, as an example for international markets seeking to embark on a similar journey.

\section{Howard Rogers}

Oxford 2015 

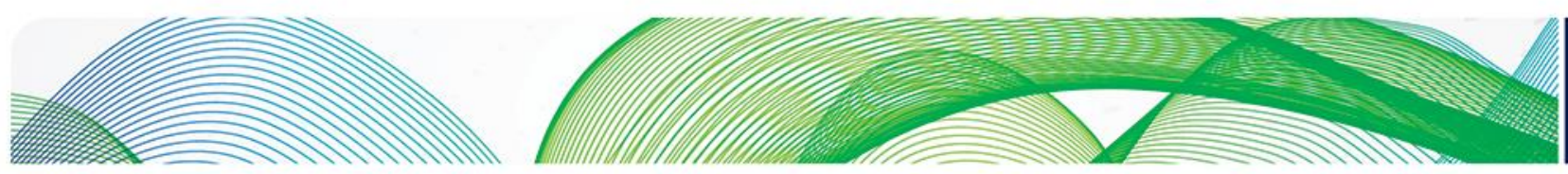

\section{O倸}

\section{Acknowledgements}

I would like to record my thanks for the help I have been given by many individuals in writing this paper. I received much valuable input from a range of experts in the field of UK gas - these include Simon Durk of National Grid, Peter Adams, Mike Bradshaw, David Cox and Ben Farrington. I am also most grateful to colleagues at the Oxford Institute of Energy Studies who have provided many valuable insights and suggestions. These include Malcolm Keay, John Elkins and Anouk Honore and I am particularly indebted to Jonathan Stern and Howard Rogers for their knowledge, advice and encouragement. I would also like to thank John Elkins for his diligence and skill in editing the final document and to Kate Teasdale for formatting and layout. Any remaining errors are fully my own. 


\section{Contents}

Preface .. ii

Acknowledgements .......................................................................................................................ii

1. Introduction ..........................................................................................................................

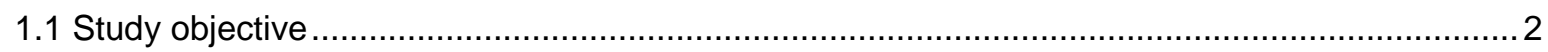

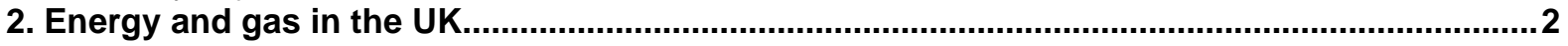

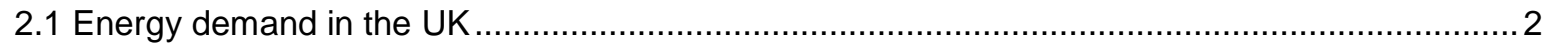

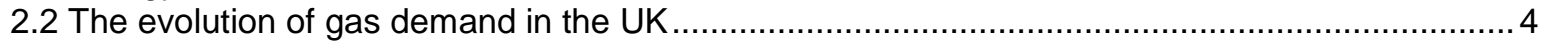

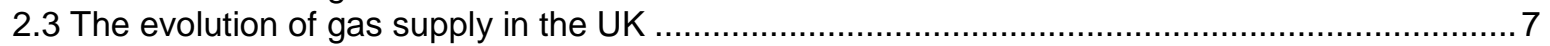

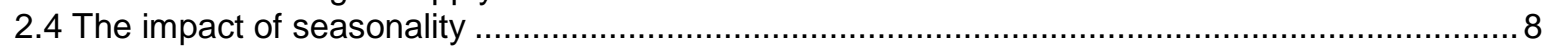

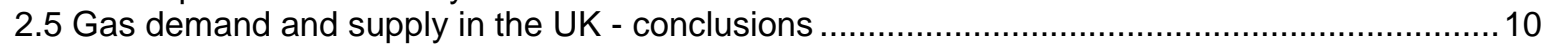

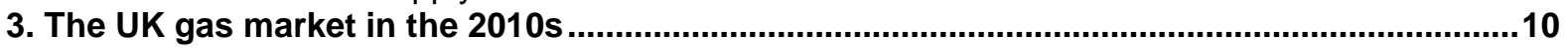

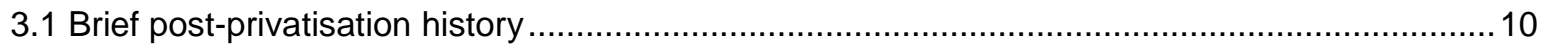

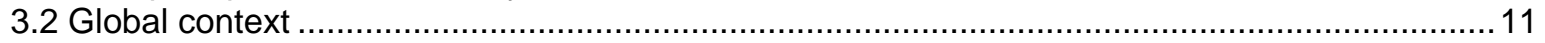

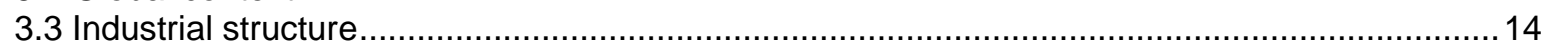

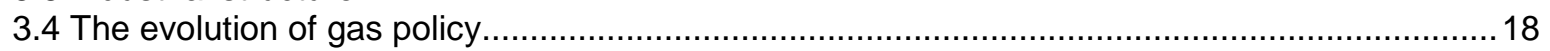

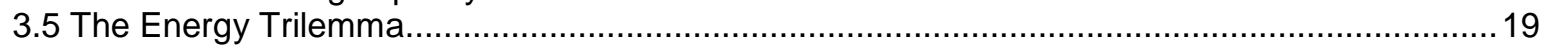

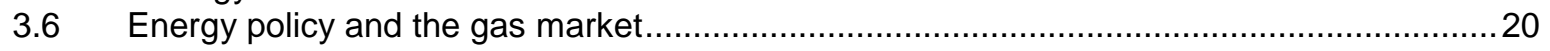

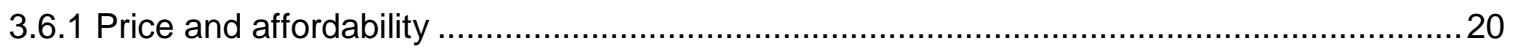

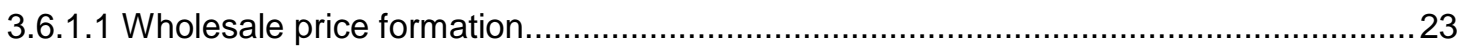

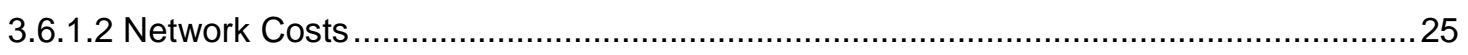

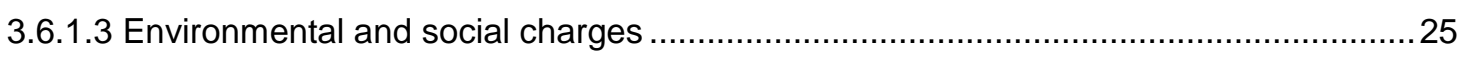

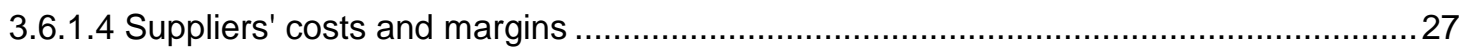

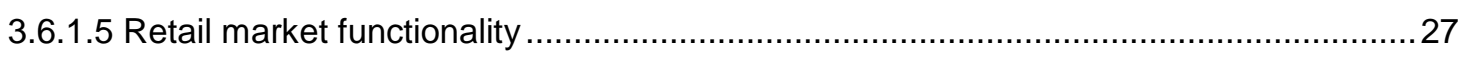

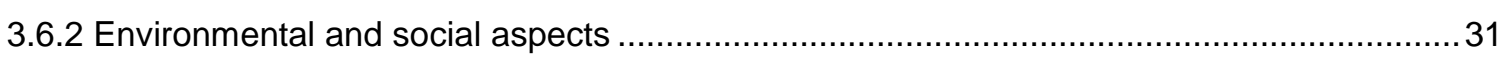

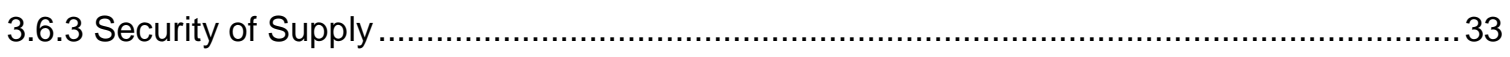

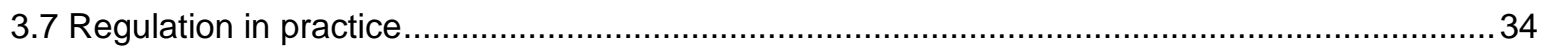

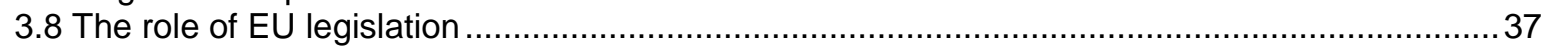

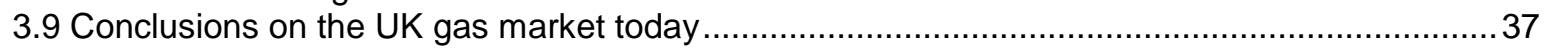

4. Outlook for the GB gas market and policy implications - demand ....................................38

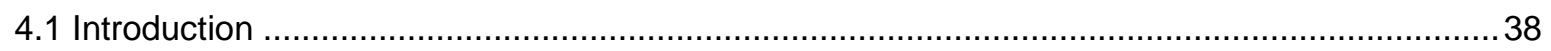

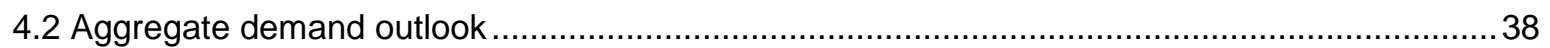

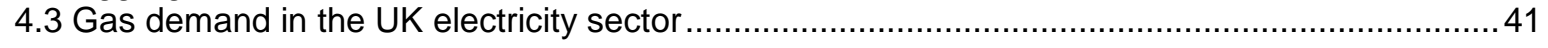

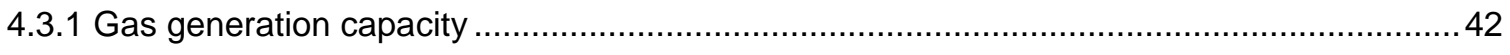

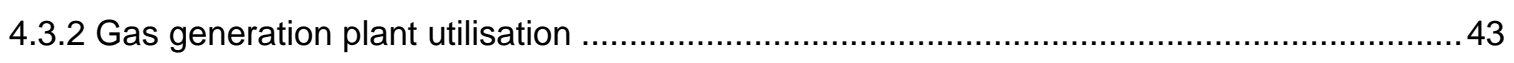

4.3.3 Generating plant merit order and profitability .......................................................... 45

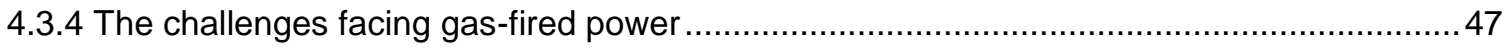

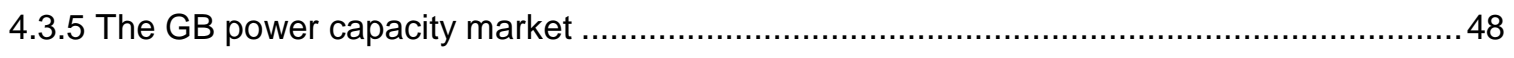

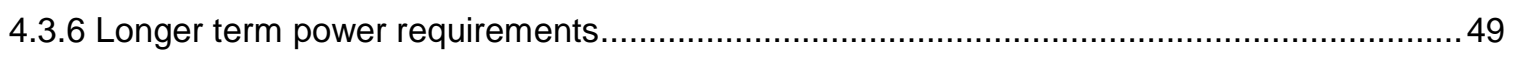

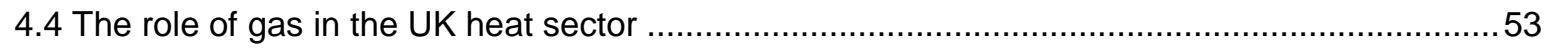

4.5 Conclusions on the demand outlook for the GB gas market and the policy implications ..........57

5. Outlook for the GB gas market and policy implications - supply .........................................57

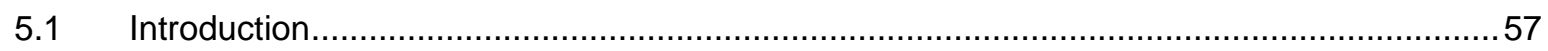



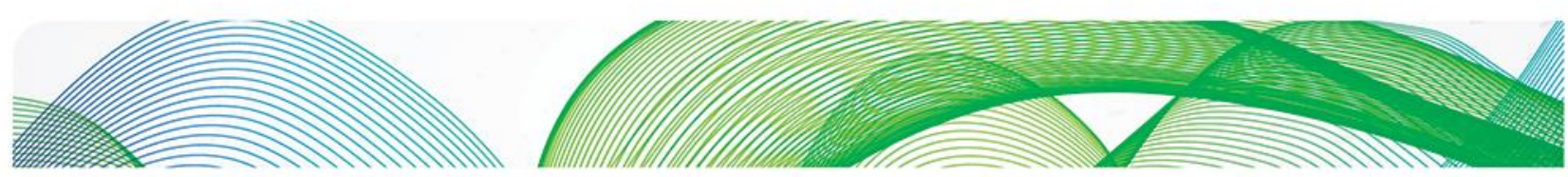

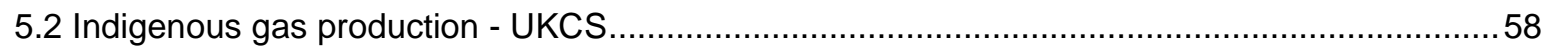

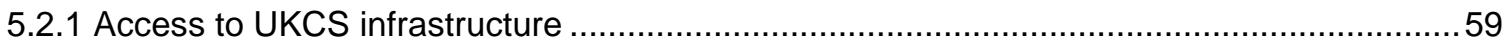

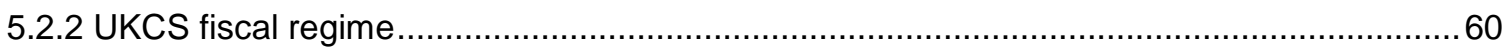

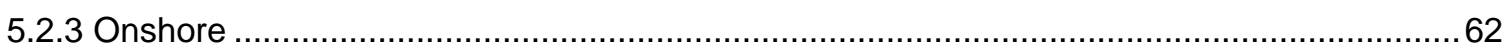

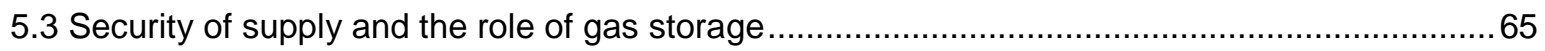

5.4 Conclusions on the supply outlook for the GB gas market and the policy implications .............71

6. Conclusions

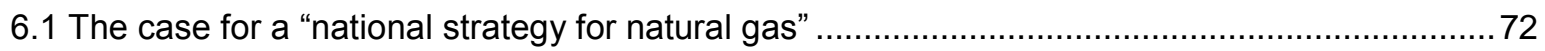

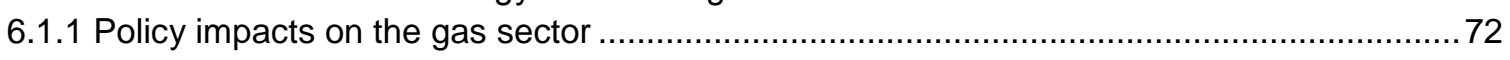

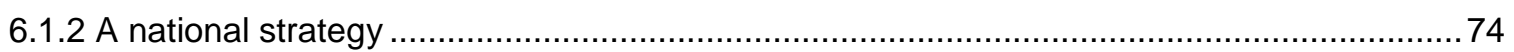

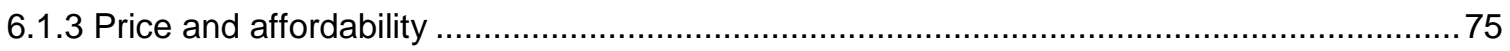

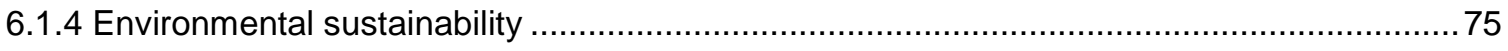

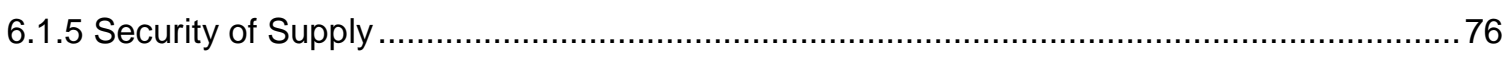

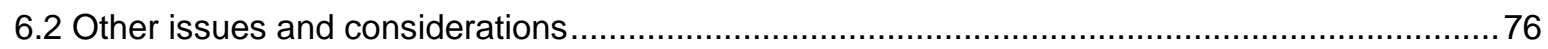

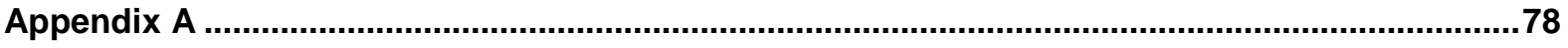

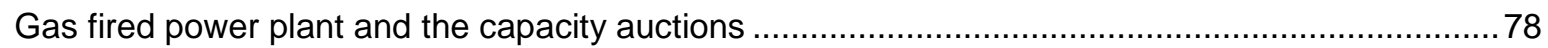

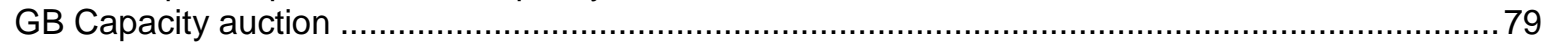

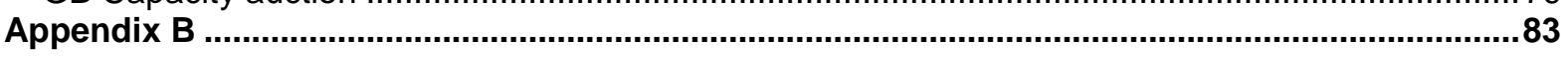

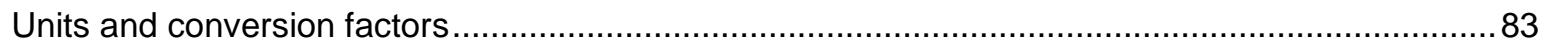

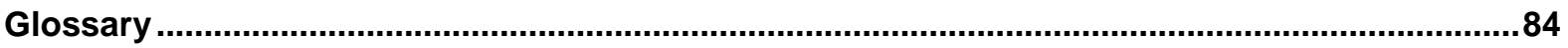

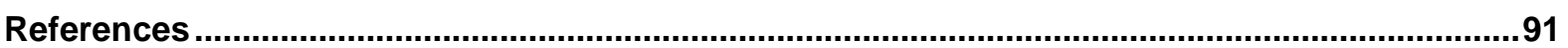

\section{Figures}

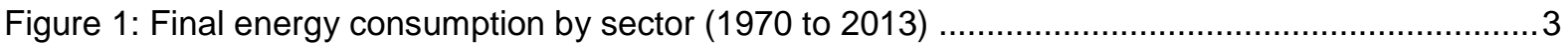

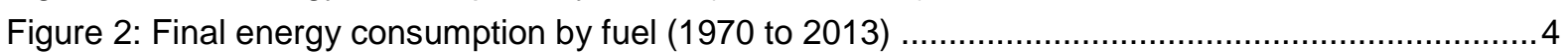

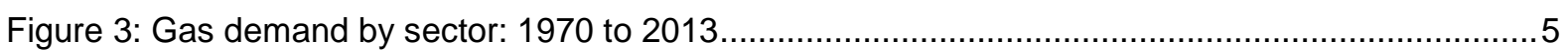

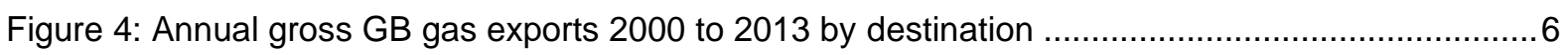

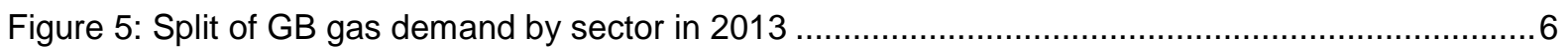

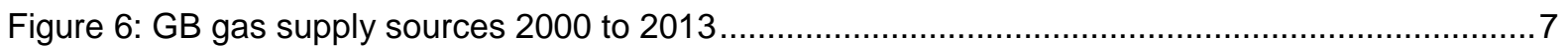

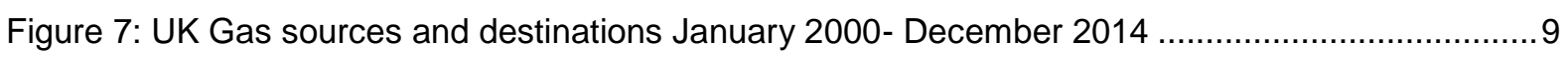

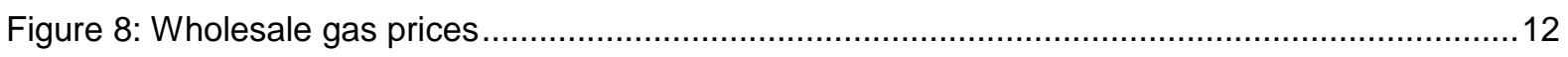

Figure 9: High level overview of gas industry structure and relationships ................................... 15

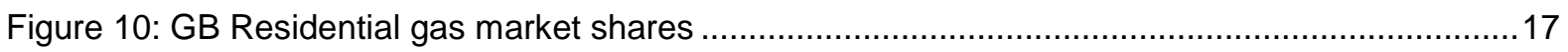

Figure 11: Index of UK residential retail prices and NBP wholesale price in pence/therm ................21

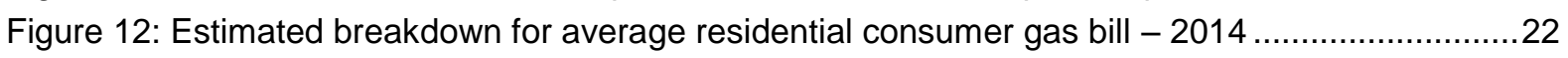

Figure 13: Components of average annual residential gas bill 2007 to 2013 (£) ............................23

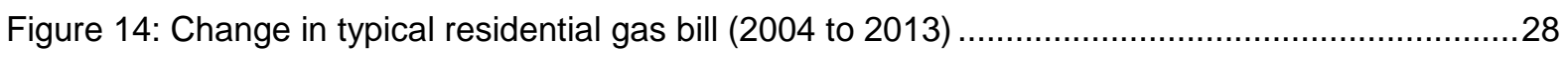

Figure 15: NBP prompt and forward prices January 2014 to March 2015 ...................................29

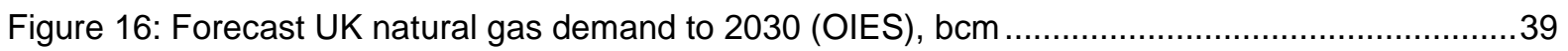

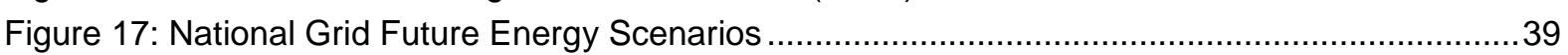

Figure 18: Forecast GB natural gas demand to 2035 (excluding exports) .....................................40

Figure 19: Historical and projected GB power demand .......................................................... 41

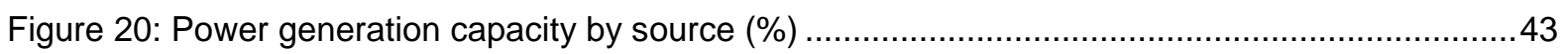



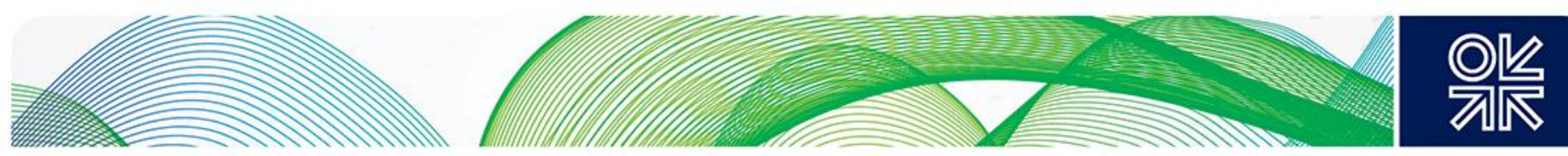

Figure 21: GB power generation load duration curve by source for 2009 (excluding hydro, pumped storage and interconnectors)

Figure 22: GB power generation load duration curve by source for 2014 (excluding hydro, pumped storage and interconnectors)

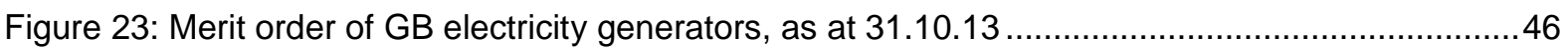

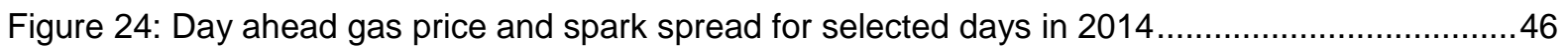

Figure 25: Year of commissioning of UK CCGT electricity generators............................................4

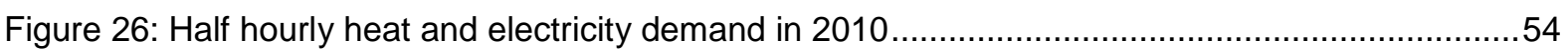

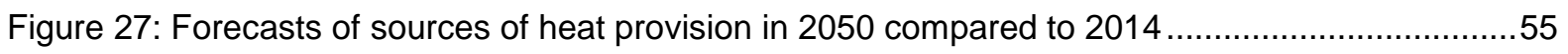

Figure 28: New development breakeven (levelised) costs for selected UK gas sources ....................58

Figure 29: Outcrop of main black shale formations in UK and selected oil and gas wells and gas fields

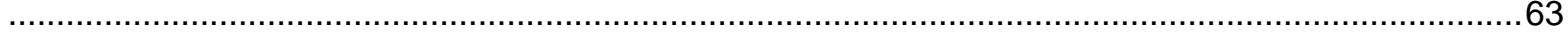

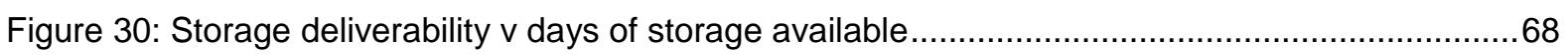

Figure A1: Supply demand curves for $2018 / 19$ capacity ............................................................... 81

\section{Tables}

Table 1: Major mid and downstream players in the GB gas market .............................................16

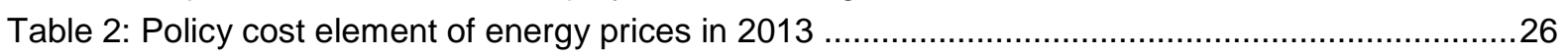

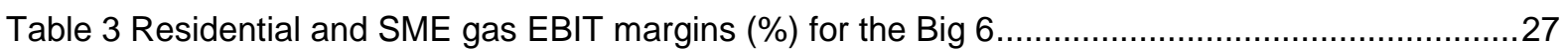

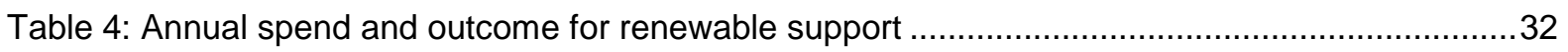

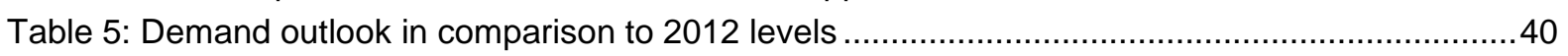

Table 6: Power stations in the UK by source of generation as at May 2014 .......................................42

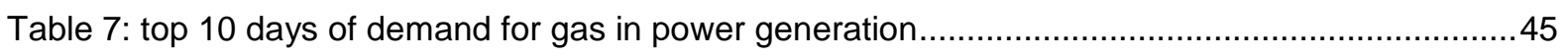

Table 8: Generating plant securing capacity agreements, December 2014 …................................. 49

Table 9: Alternative low carbon generation technologies - projected deployment.............................50

Table 10: Alternative generation technologies - cost estimates (£/MWh) ..........................................50

Table 11: Long term gas-fired power capacity and output by scenario ...............................................51

Table 12: Gas demand for gas-fired power by NG scenario $(\mathrm{bcm})$................................................52

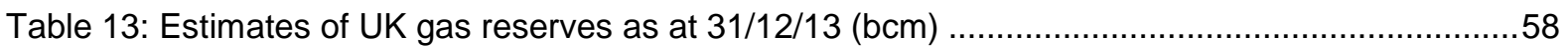

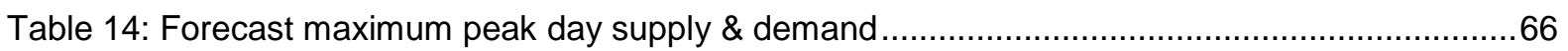

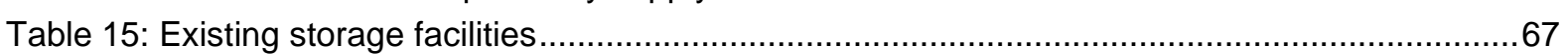

Table 16: Main GB supply sources; responsiveness and robustness ............................................... 70

Table 17: External factors meriting a review of supply security ........................................................ 71

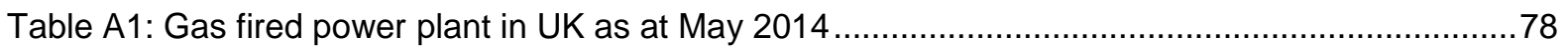

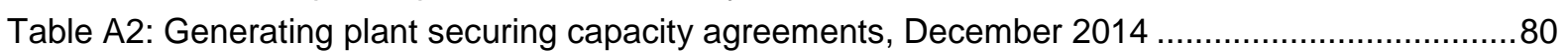

Table A3: Capacity bids in excess of $50 \mathrm{MW}$ that exited the auction ...............................................82 

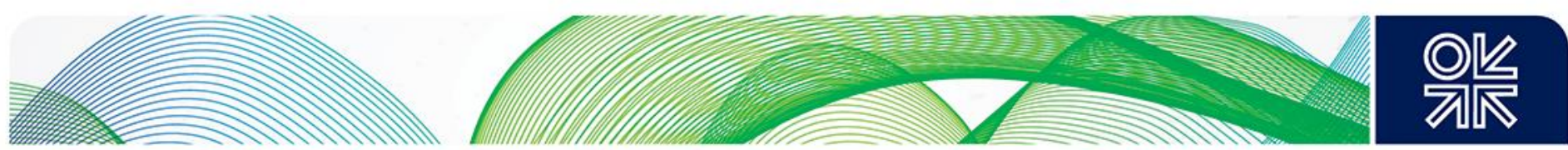

\section{Introduction}

UK$^{1}$ energy policy has often mystified outsiders. Politicians and policy makers talk grandly of solving the energy "trilemma" of affordability, environmental sustainability and security of supply. Many energy experts seem ensnared in endless debates regarding the minutiae of the electricity supply sector whilst in the real world coal displaces gas in power generation, prices rise and, if the media headlines are to be believed, gas and electricity supplies are in danger - the familiar 'lights going out' story.

Unlike the electricity sector, the GB gas market has remained relatively free of direct government intervention and it has retained many of the features that made it the most liberalised market outside North America since the mid 1990s. Furthermore whilst demand for gas has declined of late, rather than having grown in line with some expectations, it is still a large and vital part of the nation's energy mix; $48 \%$ of non transport consumption in 2013.

The last OIES paper on this issue ${ }^{2}$ noted that policy was primarily focussed on the Government's carbon reduction policy. However this policy failed to provide clarity over the role of specific fuels and it appeared that the role of natural gas would be to plug gaps and compensate for the lack (or slow development) of preferred low carbon generation technologies.

It is tempting to believe that little has changed, and that in the eyes of some gas is a "sunset fuel" requiring little proactive consideration. The relative lack of attention/intervention in the natural gas sector in part reflects its role of "presumed balancing factor" as a continuing feature of UK government energy policy. Given a long term vision of carbon free energy, the main focus of government has been on developing an electricity sector that will provide power through nuclear/renewable sources. In addition gas is often lumped together with other fuels: in the downstream sector with electricity; in power generation with coal (as a fossil fuel) and in the upstream with oil (as a hydrocarbon produced by E\&P companies).

There are, however, signs that the policy environment ${ }^{3}$ may be starting to change. Concerns from politicians, industry players and commentators and (to a greater or lesser degree) the public have emerged in a number of areas:

- The growing risk (whether real or perceived) of power shortages combined with a continuing reluctance of investors to extend the role of gas as a future power source;

- Public perceptions concerning the level of gas and electricity prices and profitability of energy companies (at times prompted by politicians);

- The cost and practicality of the decarbonisation of heat;

- The role, if any, of unconventional gas in boosting UK supplies;

- The danger of physical disruptions to UK/European gas supply as a result of increased import dependency coinciding with upheavals such as recent events in Ukraine.

The over-arching risk is that a lack of due consideration at the policy level of issues relating to the smooth operation of the GB gas market and gas' role in the GB power market, could result in:

a) policy-induced mitigation measures formulated too late given implementation lead times; and,

\footnotetext{
${ }^{1}$ Energy policy and most national statistics cover the United Kingdom of Great Britain and Northern Ireland though a number of areas considered in this report focus particularly on the situation in Great Britain. For example the energy regulator Ofgem covers Great Britain; Northern Ireland has a separate regulatory body.

${ }^{2}$ Elkins, (2010)

${ }^{3}$ But the policy environment has not impacted the political environment. In the 2015 general election despite limited mention in party manifestos there was hardly a mention of energy (or climate change) in the debate.
} 

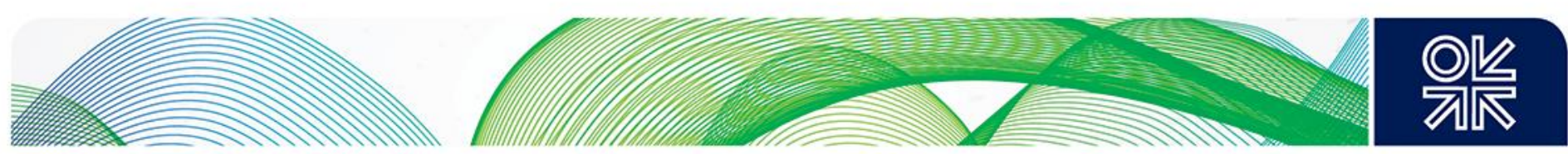

b) a knee-jerk response, post crisis, in ill thought-out intervention with unintended consequences.

c) This paper tries to assess how real this risk might be and what opportunities there are to make progress in ensuring an appropriate future for gas in the UK energy mix. The paper also seeks to highlight the risks that the gas industry might be facing in the present policy environment.

It is beyond the scope of this paper to provide a comprehensive review of the entire UK energy system. The view is from the gas industry perspective and so the focus is on the gas sector and how it interacts with other fuels and power technologies. The primary finding, which re-occurs throughout the analysis, is the benefit from accepting gas as a core element in the UK's long term energy strategy, and ensuring that policies are in place to ensure its adequate availability - whether as a source of heat or (with sufficient CCGT capacity in place) a means of power generation.

\subsection{Study objective}

Following from the issues raised in the introduction, relating to UK policy actions in the gas sector and more broadly for energy, the paper addresses two primary questions:

- How has UK energy policy since 2000 impacted on the gas sector ${ }^{4}$ ?

- Is there a case for an integrated natural gas strategy for the UK or, in other words, does the absence of such a strategy pose particular risks to the energy sector and the wider UK economy? If this is the case what specific policy initiatives might be directed at the gas market?

The paper also identifies three subsidiary questions:

1) How far has the consensus regarding the legitimacy of a privatised, market-led energy sector been eroded in the face of public concerns over costs and supply security?

2) How might policy evolve given concern over the effectiveness of markets and government intervention to reduce carbon emissions and what are the implications for the gas sector?

3) What role is gas likely to play in this future environment and what might be the impact of other factors such as indigenous shale gas or abundant international supplies?

Given the breadth of these subsidiary questions, the paper does not aim to provide definitive answers/solutions, but seeks to illustrate the dimensions of the issues and the dangers inherent in pursuing dogmatic approaches, which ignore the economic and physical realities of energy systems, and the timescales over which material change is possible.

\section{A note on units}

In general the units used by the source material are stated. Some of the gas demand data provided in TWh have been converted to $\mathrm{bcm}$ where appropriate and this has been done at the calorific value of $38.1 \mathrm{MJ} / \mathrm{m}^{3}$. Gas price data is generally provided in $\$ / \mathrm{mmbtu}$ or converted to this unit at the prevailing exchange rate. More detail on conversion factors is provided in Appendix $B$.

\section{Energy and gas in the UK}

\subsection{Energy demand in the UK}

Since the mid 2000s, primary energy demand in the UK has been trending down. In 2013 it was around 205 million tonnes of oil equivalent (mtoe), the lowest level for 25 years and $4 \%$ below the figure for 1970. The make-up of final energy consumption has changed dramatically over this period reflecting the decline of energy intensive industries as well as the impact of increased energy efficiency. For example, industry's share of consumption has dropped sharply from $40 \%$ to $16 \%$ between 1970 and 2013 whilst transport's share has doubled to $36 \%$. Households' share has edged up from $24 \%$ to $29 \%$ with other sectors remaining relatively unchanged.

\footnotetext{
${ }^{4}$ Whilst the focus is on policy developments since 2000 on occasions a longer historical perspective is taken
} 

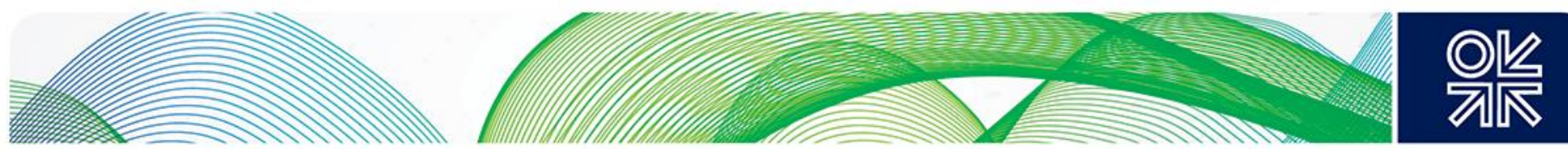

Figure 1: Final energy consumption by sector (1970 to 2013)

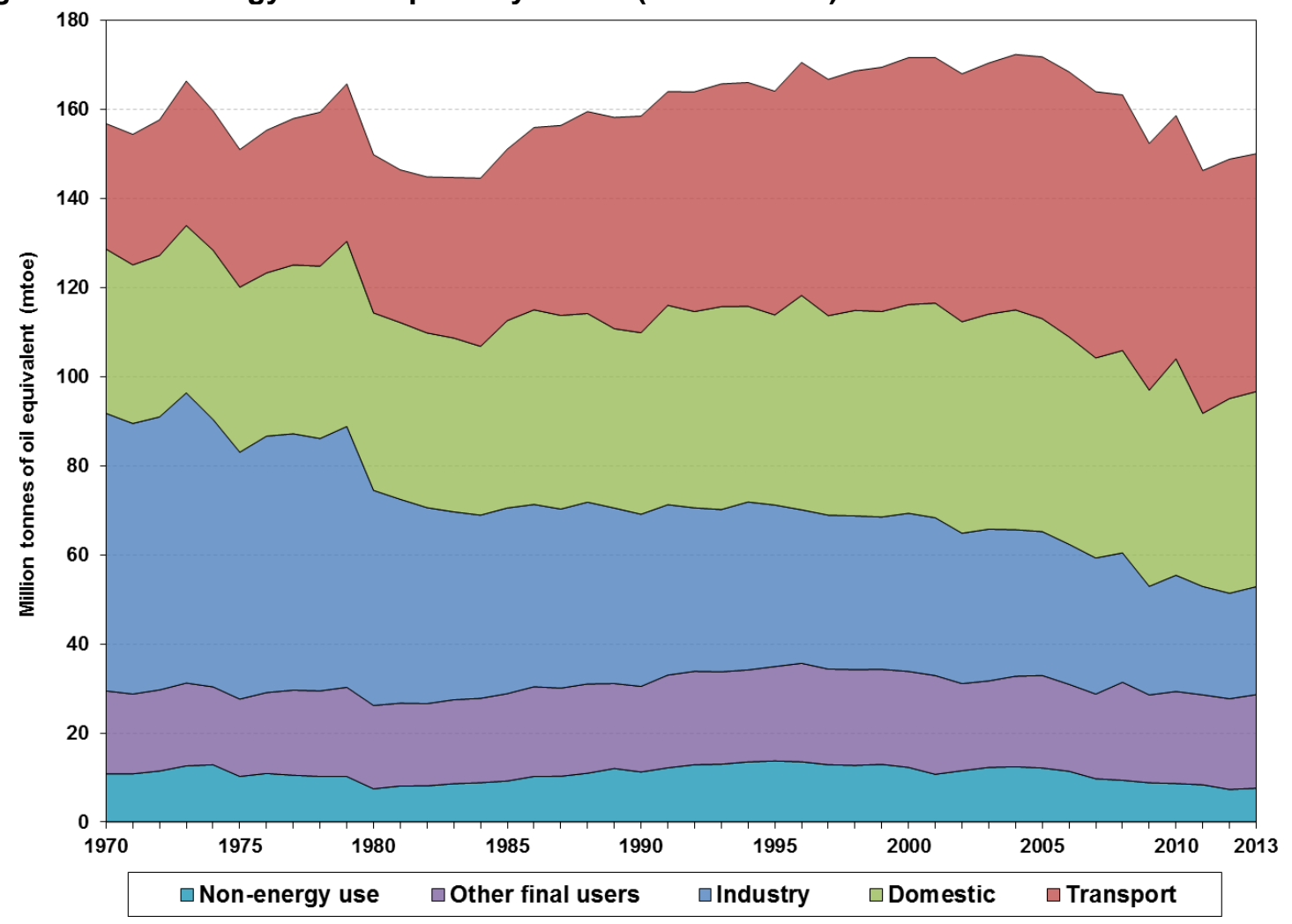

Source: DECC, Energy Consumption Statistics, 2014c

Over the last 40 years the fuels consumed to meet demand have also changed significantly. In 1970 primary fuel consumption was dominated by solid fuel (i.e. coal) and petroleum - $47 \%$ and $44 \%$ respectively. In 2013 coal accounted for $19 \%$ (most of which goes into power generation) and petroleum for $32 \%$. The share of natural gas has grown from $5 \%$ to $36 \%$ and nuclear and renewable energy from $5 \%$ to $13 \%$.

In terms of final energy consumption, demand has also fallen: 2013 consumption was $11 \%$ below the 2000 level and $3 \%$ below that of 1990. Natural gas has replaced solid and petroleum fuels in the heating sector and has accounted for 30 to $35 \%$ of final energy consumption since 1990 . Petroleum continues to dominate at over $40 \%$ due to its role in transportation whilst the share of electricity has grown to around $20 \%$. 

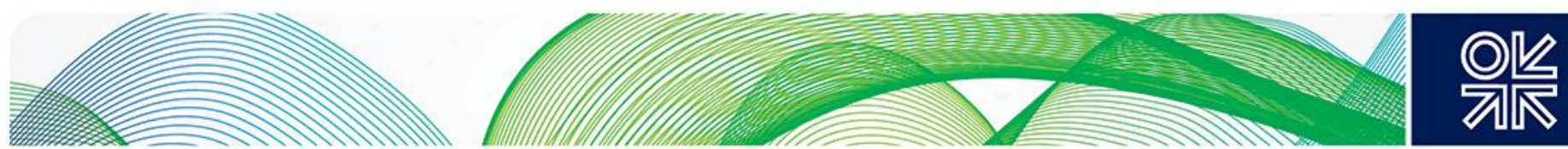

Figure 2: Final energy consumption by fuel (1970 to 2013)

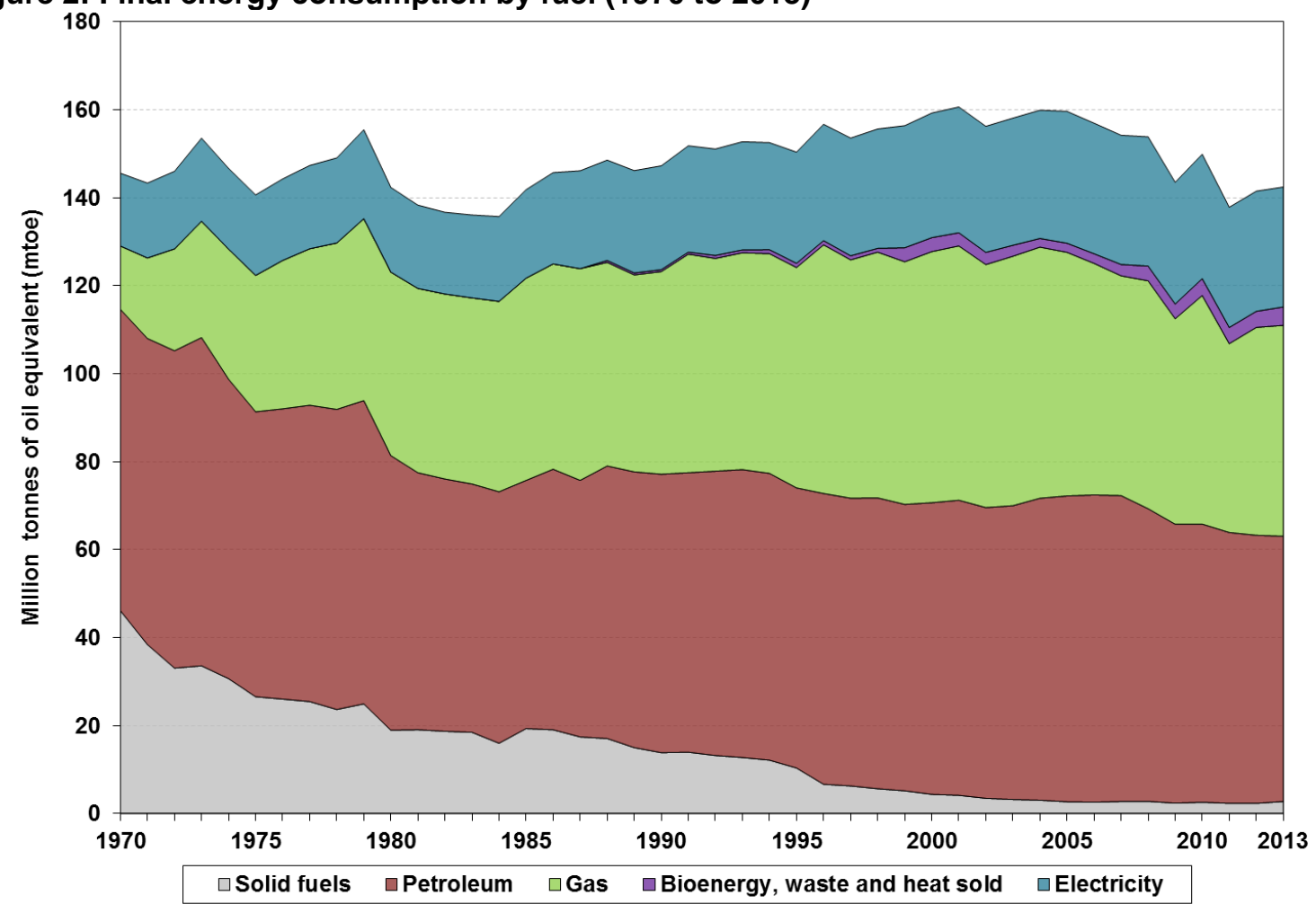

Source: DECC, Energy Consumption Statistics, 2014c

A more detailed consideration of gas supply and demand is contained in the next section.

\subsection{The evolution of gas demand in the UK}

Total gas demand (including town gas ${ }^{5}$ ) from 1970 to 2013 is shown in figure 3 . It is possible to determine three broad eras during this period

- 1970 to 1990 - strong growth in residential and industrial and commercial (I\&C) demand as UKCS gas grew increasingly accessible and natural gas became the fuel of choice for heating and many industrial applications. Natural gas's share in primary energy consumption grew from $5 \%$ in 1970 to $25 \%$ by $1990^{6}$.

- 1990 to 2000 - further strong growth primarily driven by the post-privatisation "dash for gas" in power generation accompanied by continued growth in residential and I\&C demand. In 2000 gas' share of primary energy consumption was $41 \%$ and $55 \%$ if the transport sector is excluded ${ }^{7}$.

- 2000 onwards - Natural gas's share in primary energy consumption rose to $43 \%$ by 2010 (58\% excluding transport). Since then it has fallen as a result of a combination of factors. These include a trend away from energy intensive manufacturing, improvements in energy efficiency, increased competition in power generation from coal and renewables and since 2008 a significant reduction in energy consumption as a result of the global economic crisis and consequent restructuring. The

\footnotetext{
${ }^{5}$ Whilst town gas production continued until 1988 volumes were insignificant after the mid 1970 s

${ }^{6}$ DECC $2014 \mathrm{C}$

${ }^{7}$ https://www.gov.uk/government/statistics/energy-consumption-in-the-uk chapter 1
} 

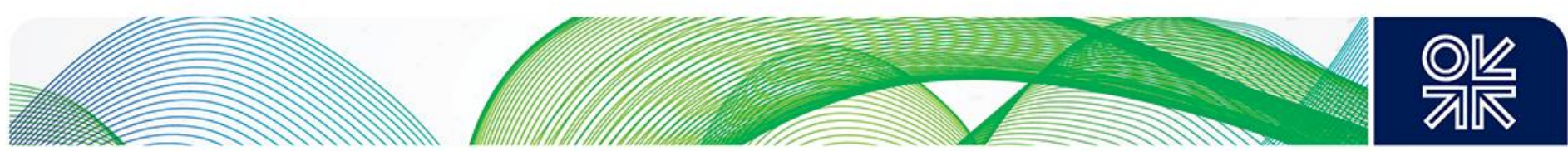

decline in demand was both absolute and relative with gas's share in primary energy consumption falling to $36 \%$ in 2013.

Figure 3: Gas demand by sector: 1970 to 2013

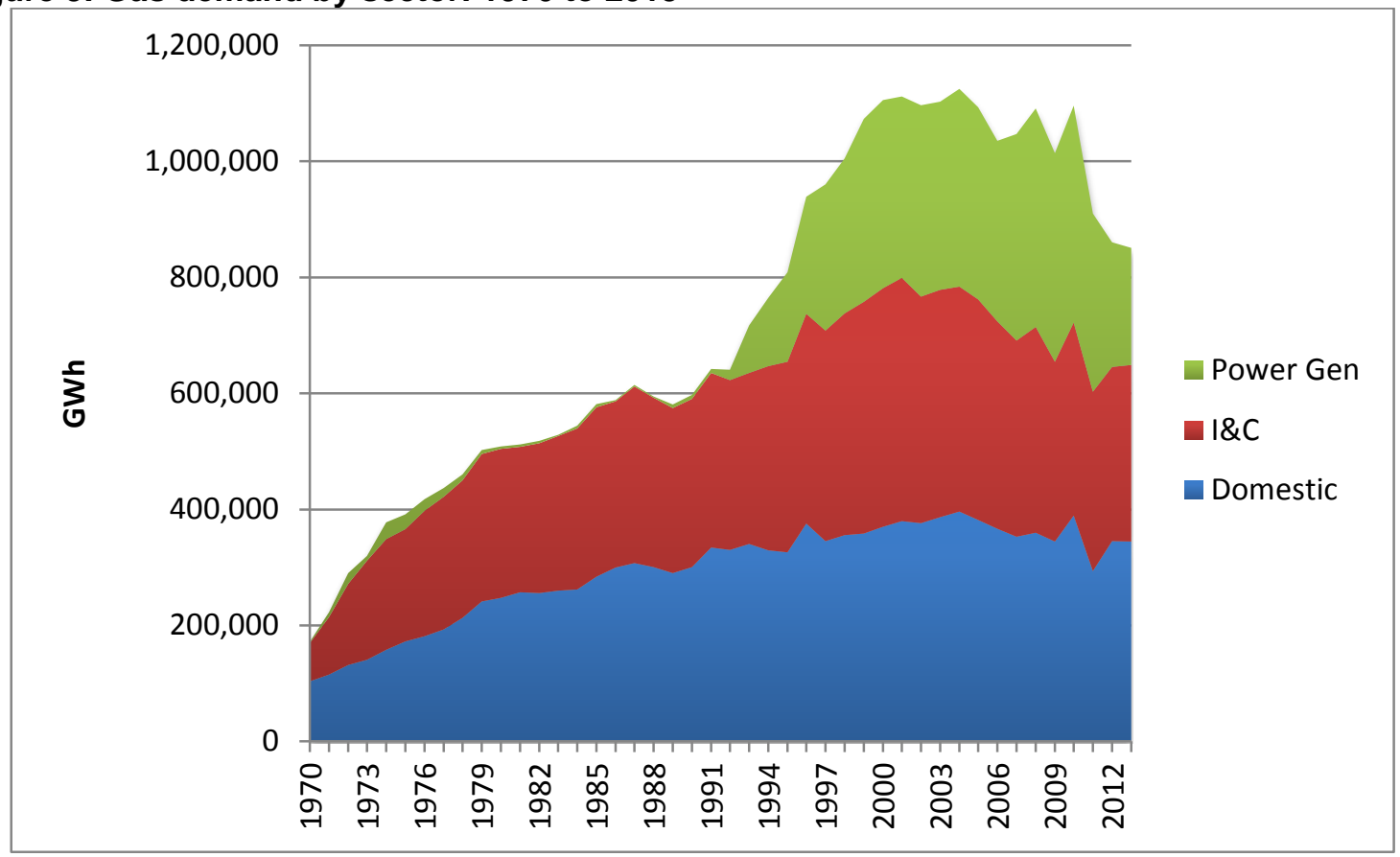

Source: DECC, Gas since 1882, https://www.gov.uk/government/statistical-data-sets/historical-gas-data-gasproduction-and-consumption-and-fuel-input-1882-to-2011

Whilst residential gas demand has fallen, the number of residential customers has continued to grow. In 2000 there were 20.49 million household consumers and 22.9 million in 2012 though unit consumption has declined from around $18 \mathrm{KWh}$ pa to $15 \mathrm{KWh}$ pa over this period. Reflecting the trend of reductions in the number of manufacturing consumers the number of non-residential users has fallen from 678,000 in 1990 to 271,000 in $2012^{8}$.

Whilst the UK is now a net importer of gas there is still a significant volume of exports to Ireland and, typically in the summer months, the European continent via the Interconnector UK (IUK). The volumes of the latter will vary significantly from year to year depending on price and demand factors. The pattern of UK exports since 2000 is shown in figure 4 which includes exports to the Netherlands from UKCS gas fields using the Dutch offshore pipeline system. 

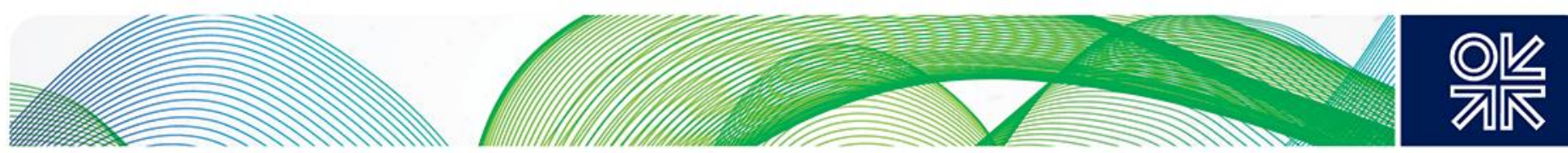

Figure 4: Annual gross GB gas exports 2000 to 2013 by destination

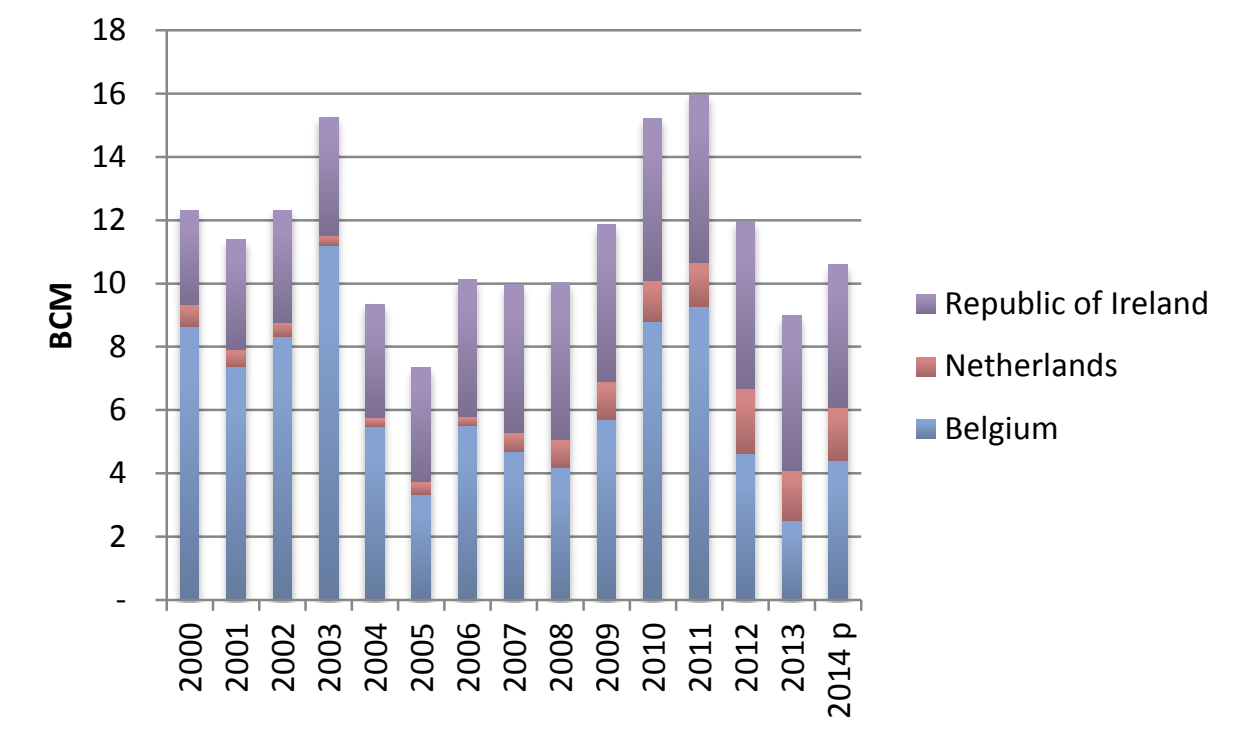

Source: DECC https://www.gov.uk/government/statistics/gas-section-4-energy-trends

The present shares of the three main demand sectors is shown in figure 5 which illustrates the dominant roles played by residential and power generation demand. The way these two sectors are expected to evolve is examined in detail in chapter 4.

Figure 5: Split of GB gas demand by sector in 2013

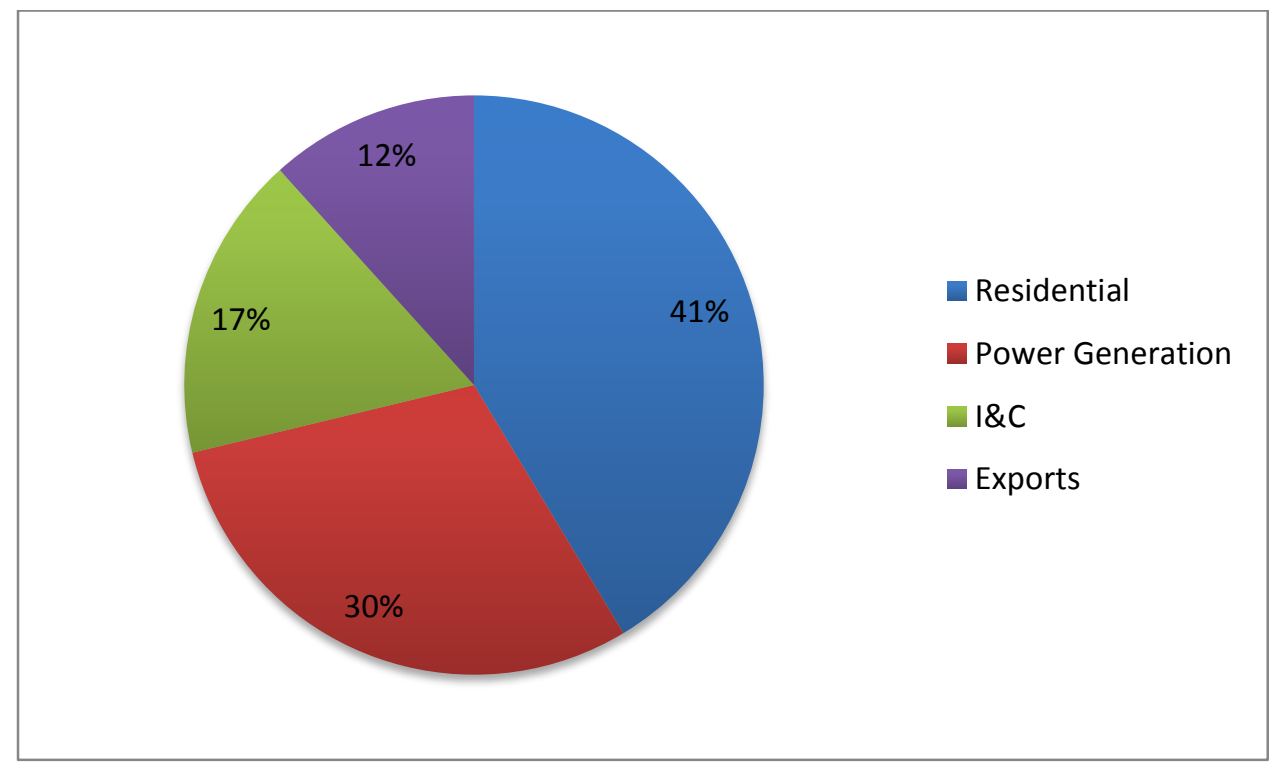

Source: National Grid (2014a)

Note: Historically National Grid has included exports from the UK as a category of 'demand'. This can be confusing to those who generally regard demand as synonymous with domestic consumption. 

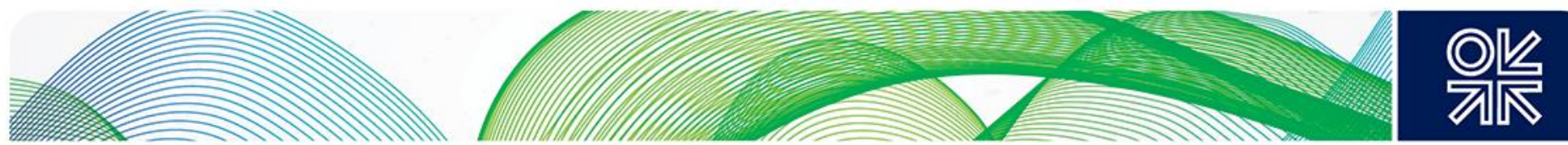

\subsection{The evolution of gas supply in the UK}

Between 1990 and 2002 the UK was largely self-sufficient in gas supplied from the UK Continental Shelf $(\text { UKCS })^{9}$. Production began to decline from 2000 and in the face of expected continued growth in demand a number of import projects were undertaken. These included new pipelines to bring gas from Norway and the Netherlands and LNG import terminals at Grain, Milford Haven and Teesside ${ }^{10}$.

Whilst the predicted growth in demand did not materialize the level of import dependency still increased to around $50 \%$ by 2011 after which it plateaued due to falling demand and a slower rate of decline in UKCS production. The new import capacity comprises both pipelines and LNG regas facilities. This configuration has allowed the UK to adopt the role of a transit market, especially in summer months when it is a significant exporter of gas via IUK, with price determining the direction of daily flows.

Figure 6 shows the make up of UK imports since 2000 and shows the role of Norway as the largest source of imports whilst volumes of LNG can vary significantly from year to year.

Figure 6: GB gas supply sources 2000 to 2013

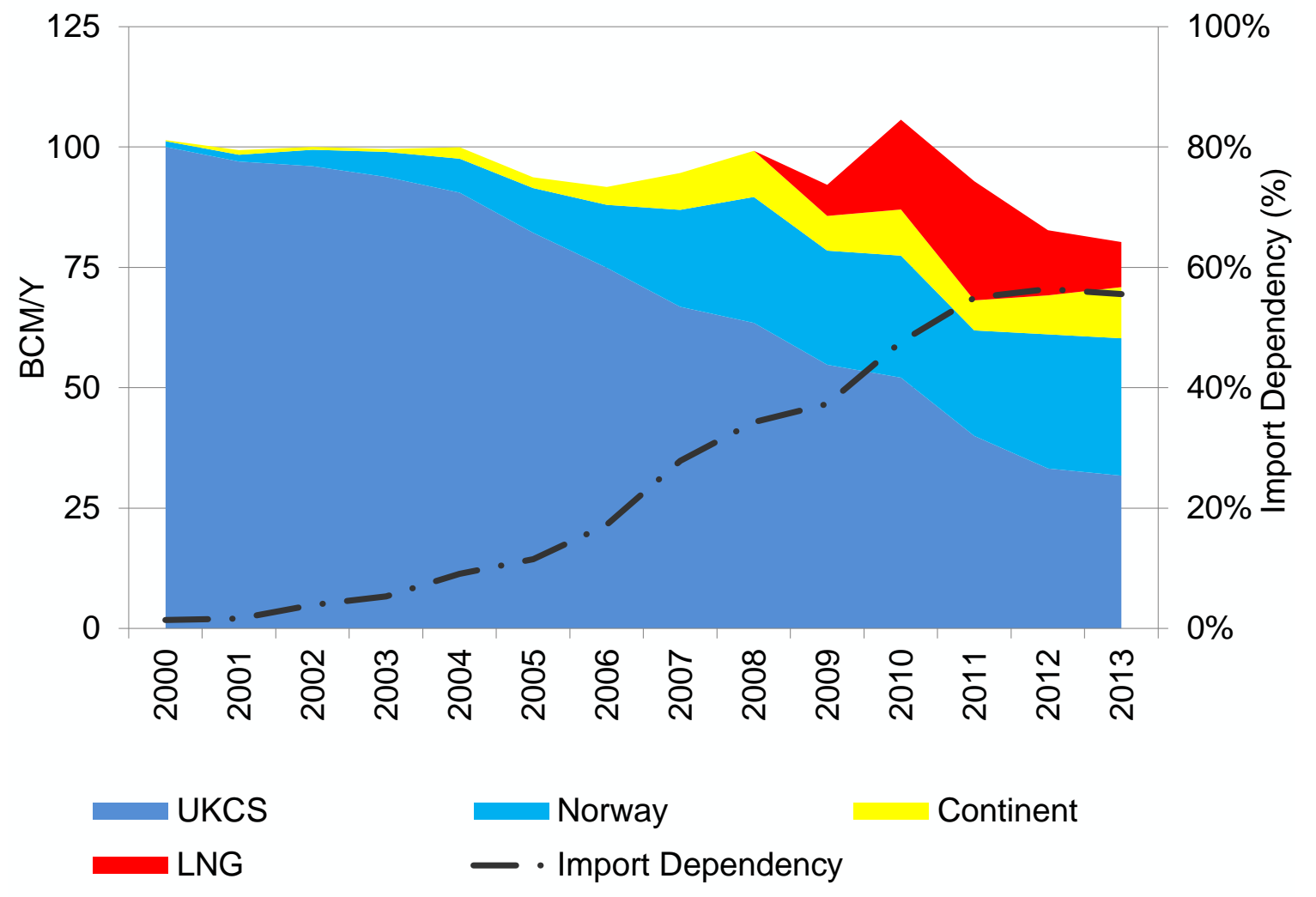

Source: National Grid (2014a)

\footnotetext{
${ }^{9}$ There have always been import flows from Norway. In the 1980 s these exceeded $20 \%$ of consumption reflecting the purchasing policy of British Gas which sought to manage UKCS depletion in a way that extended supplies from that source. See table 4.1.1 at

http://webarchive.nationalarchives.gov.uk/20130109092117/http://decc.gov.uk/en/content/cms/statistics/energy_stats/source/ga s/gas.aspx

10 The Teesside terminal has since closed
} 

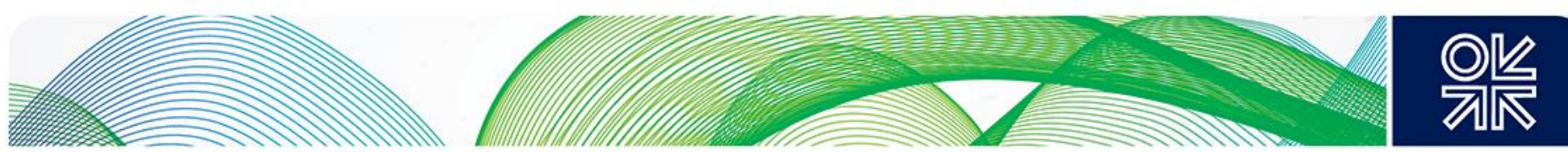

\subsection{The impact of seasonality}

The previous sections have examined the UK's supply and demand position from an annual perspective. However it is very important to remember that there are significant variations in demand within a year due to a number of factors. Ambient temperature is the most important in the UK as heating load is a major part of demand. Other factors such as levels of economic activity and variations in electricity demand (including the growing share of intermittent renewable generation) also have an impact.

To meet these requirements the GB system derives volume flexibility in supply from:

- UKCS production, import pipelines and LNG terminals

- Underground gas storage (UGS)

Figure 7 illustrates the source and destination of UK gas supply by month over the period January 2000 to December 2014. The seasonality of demand is clearly apparent, as is the range of sources used to replace the diminishing contribution of UKCS production. In particular the volumes of IUK and LNG imports have varied from year to year whilst storage also plays a key role in meeting seasonal demand peaks. It is also notable that IUK exports have continued to flow - at times even during the winter months - reflecting the important role of $\mathrm{GB}$ as a land bridge for transit gas imports to continental Europe.

The total supply capacity that is available is in excess of seasonal normal demand (SND) levels and this allows variation in the volumes delivered from alternative sources ${ }^{11}$. This variation reflects factors such as levels of demand in continental Europe, the price and availability of LNG shipments as well as conditions within the UK market.

Variations in daily demand are also a very important consideration and this is considered in section 5.3 .

\footnotetext{
${ }^{11}$ See DECC (2014b)
} 


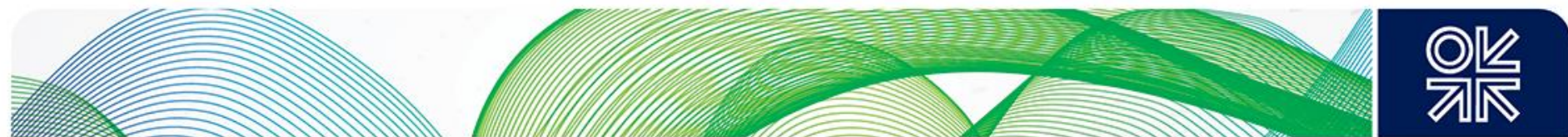

Figure 7: UK Gas sources and destinations January 2000- December 2014

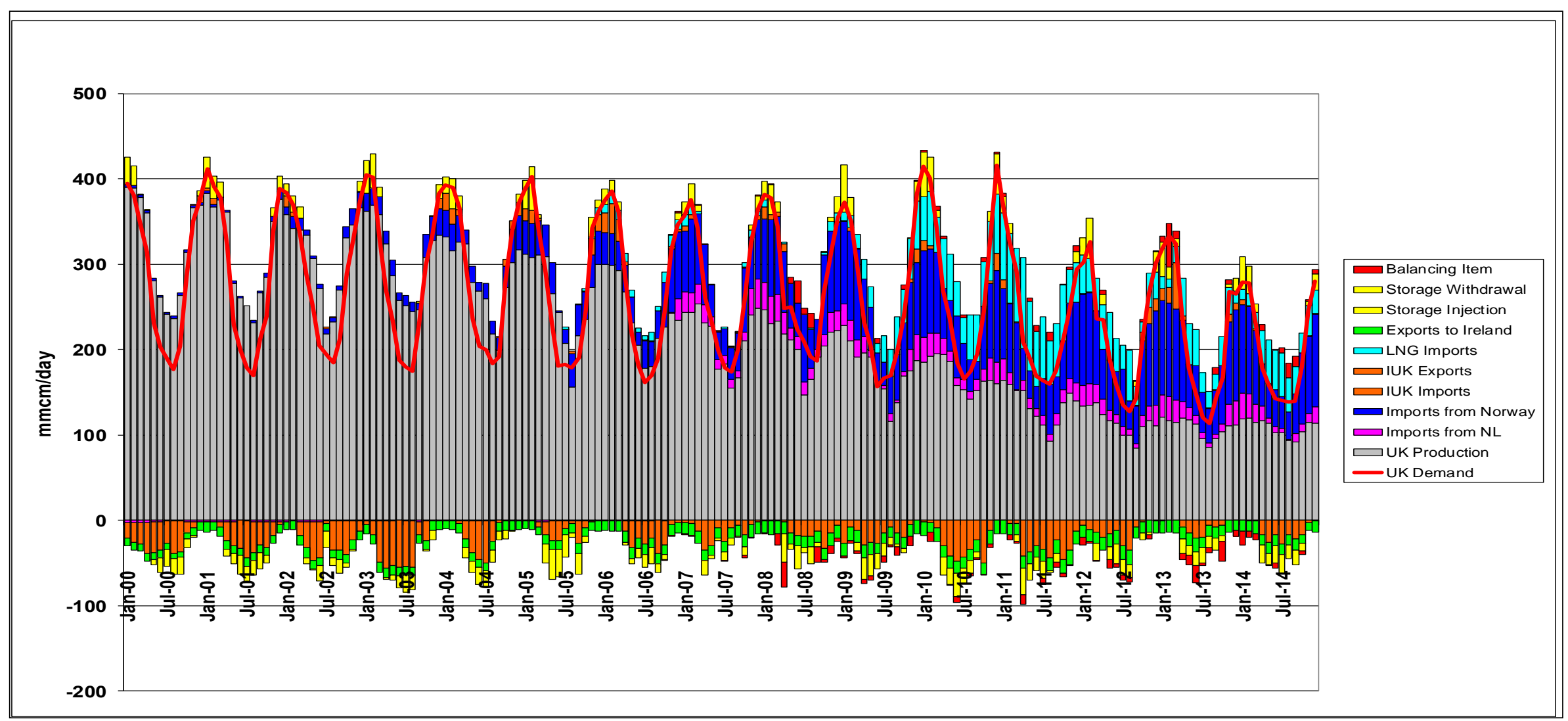

Sources: IEA Monthly Gas Data Service, DECC, Platts LNG Service, GIE Storage data. 

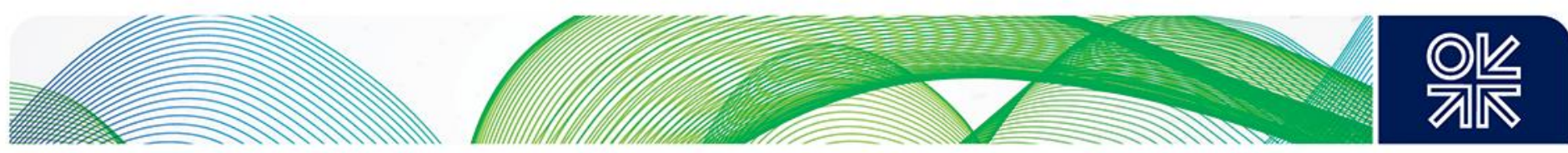

\subsection{Gas demand and supply in the UK - conclusions}

Whilst absolute levels of gas demand have fallen the fuel is still the most important component in the UK's non transport energy mix as it plays a vital role in residential heating and power generation. The number of homes heated by gas continues to grow though overall consumption, which is highly weather dependent from year to year, is falling due to higher energy efficiency from condensing boilers and insulation and from lower thermostat settings. The share of gas in power generation has fallen recently (primarily due to price competition from coal and an increase in the share of renewables) though as we shall see it still remains the key fuel for setting electricity prices.

Gas is also crucial in many industries. The trend away from energy intensive industry in the UK which was accelerated by the 2008 economic crisis - has continued and this has had a particular impact on gas consumption since 2000. Sectors such as steel and non-ferrous metal and chemicals have significantly reduced their energy consumption (DECC 2014e) though gas remains a crucial fuel in both these sectors as well as in many other manufacturing sectors such as glass, ceramics and food processing.

The range of sources of gas supply has grown dramatically in recent years as domestic production has fallen. This transition from an enclosed self-sufficient market to one exposed to the dynamics of global gas supply and demand has probably been the single most important factor shaping the UK gas market today. The main characteristics of this market are considered in the next chapter.

\section{The UK gas market in the 2010s}

\subsection{Brief post-privatisation history}

The UK can claim to host the world's oldest gas market, with public street lighting, based on town gas being demonstrated in London in $1806^{12}$. Most commentators however focus on the development of the market that followed the discovery of offshore natural gas in the North Sea in 1963. This precipitated a nationwide programme to convert the gas distribution network from town gas to natural gas coupled with the development of a number of beach terminals (receiving offshore production via pipeline) and the national gas transmission system (NTS). The advent of UK natural gas production led to a sustained growth of consumption to make it the world's third largest national gas market by $2000^{13}$.

As well as developing in size the UK market has also been at the forefront of market reforms. Competition was in theory possible under the 1982 Gas Act though it was only following the privatisation of British Gas in 1986 and the establishment of an independent regulator that market opening, slowly, began to gather momentum.

Some of the key milestones in this process were as follows:

- 1982 Oil and Gas Enterprise Act introduces the concept of competition

- 1986 British Gas privatised and regulator Ofgas established

- 1988 First MMC investigation of British Gas supply monopoly

- 1990 First gas transportation contract signed

- 1991 OFT investigation \& British Gas undertakings to assist competition

\footnotetext{
$12 \mathrm{http}: / /$ nationalgasmuseum.org.uk/the-history-of-gas/early-days/

${ }^{13} \mathrm{BP}$ (2015) annual consumption was $96.8 \mathrm{bcm}$ ahead of Canada which was $92.7 \mathrm{bcm}$
} 

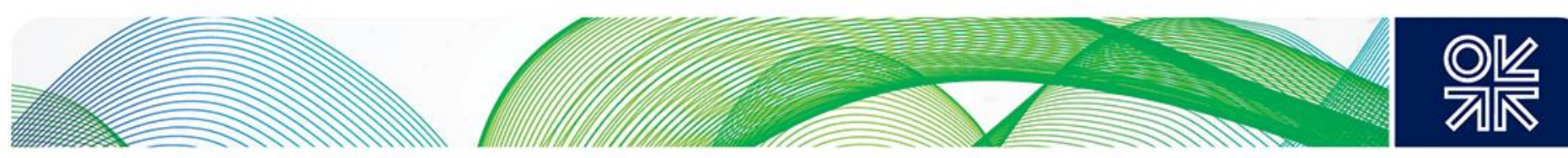

- 1992 Release gas sold by British Gas \& reduction in competitive threshold

- 1993 Second MMC investigation recommends partial break-up of British Gas

- 1993 British Gas share of industrial and commercial gas market falls to $70 \%$

- 1994 Transco established as a separate transmission and distribution unit within British Gas

- 1995 Heren Index published and gas trading commences ${ }^{14}$

- 1996 Network Code introduced \& residential competition commenced

- 1997 British Gas plc demerged into BG plc (Transco plus exploration and international activities) and Centrica plc (British Gas Trading and services plus the Morecambe gas field)

- 1998 Gas residential market fully open to competition

- 1998 Interconnector between Bacton \& Zeebrugge opens

- 1999 Ofgem created from merger of Ofgas and electricity regulator Offer

- 1999 Reform of Gas Trading Arrangements with the introduction of the on the day commodity market (OCM). Shippers take the lead in balancing their own positions.

- 2001 Transco demerged from BG plc into Lattice Group plc

- 2002 Lattice merges with electricity transmission company National Grid

- 2005 National Grid sells 4 gas distribution networks to third parties, 4 are retained

- 2005 LNG imports begin via Grain LNG terminal

- 2006 BBL pipeline between Netherlands and Bacton begins operation

- 2007 New pipeline (Langeled) from Norway to Easington commissioned

- 2008 Energy Act sets binding targets for renewable energy

- 2013 Energy Act paves the way for electricity market reform

- 2014 Wood Review calls for an upstream regulator to maximize production from the North Sea

2014 Ofgem refers the retail energy market to the Competition and Markets Authority (CMA)

By the end of the 1990s the GB gas market could justifiably be described as the most open and competitive outside North America. It is a notable feature of the liberalisation process that whilst there have been a number of minor changes the overall regulatory framework with regard to NBP trading and settlement remains largely unchanged ${ }^{15}$. This regulatory stability is noted by the $\mathrm{CMA}^{16}$ as an important factor in forming the basis for a liquid traded market. The development of the UK traded gas market and NBP is described in Heather (2010) ${ }^{17}$.

\subsection{Global context}

With the development of the Interconnector, BBL and LNG import terminals the UK gas market has become increasingly linked first to Continental Europe and then to the global gas market. This has had a major impact on price and security of supply considerations.

\footnotetext{
${ }^{14}$ See http://www.icis.com/resources/news/2015/03/20/9869776/guest-article-the-birth-of-the-esgm-and-the-heren-index/ for a personal account of the birth of gas trading and the Heren index.

${ }^{15}$ One interesting feature of this is the fact that original computer system for managing the overall processes - UKLink - is still in use though is due to be replaced in 2015

${ }^{16}$ CMA (2015f)

17 The Evolution and Functioning of the Traded Gas Market in Britain
} 

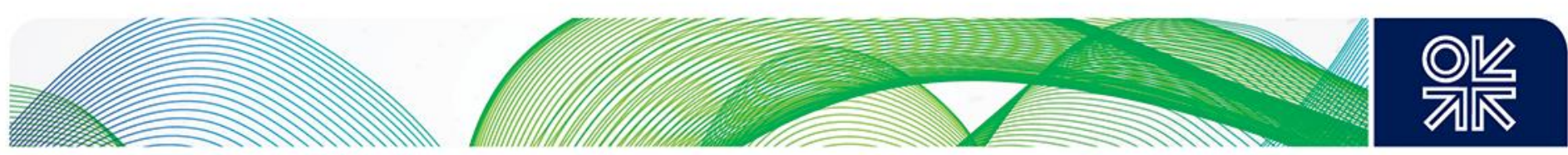

The evolution of NBP prices compared with those on the European continent and in the Asia Pacific market are shown in figure 8.

\section{Figure 8: Wholesale gas prices}

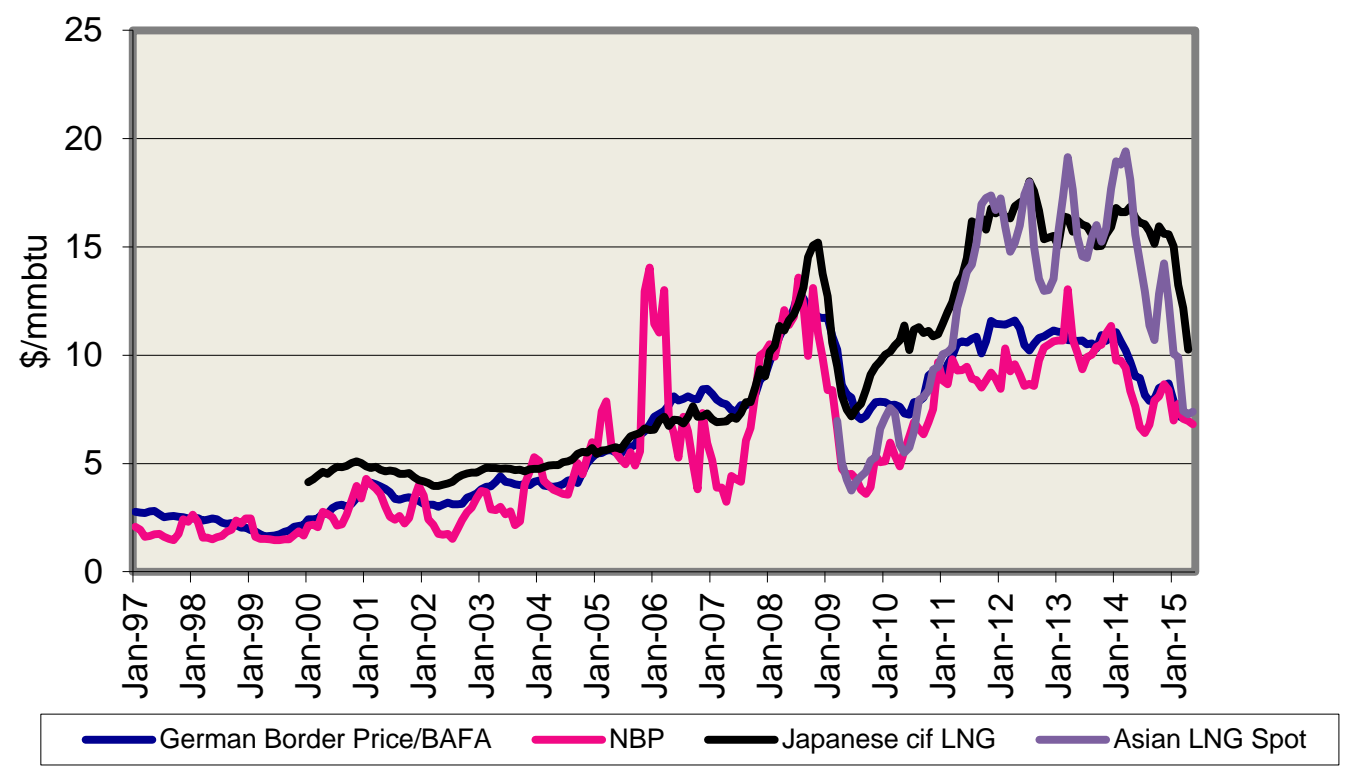

Source: Argus Global LNG Monthly, BAFA, Platts

As Stern and Rogers (2014) note NBP and continental oil linked prices (as represented by the German border price) were reasonably closely linked following the opening of the IUK in 1998. At the outset IUK operated mainly in export mode and the availability of an external market in which competing gas was largely priced through oil linked formulae had a significant influence on UK prices which had hitherto been priced solely on internal supply and demand fundamentals (see Stern (2012a)). In January 1998 spot prices were below $8 \mathrm{p} /$ therm $\left(\$ 1.31 / \mathrm{mmbtu}^{18}\right)$ increasing to $12 \mathrm{p} /$ therm $(\$ 2.04 / \mathrm{mmbtu})$ after IUK opening. Whilst these numbers are small in absolute terms compared to today's prices it should be remembered that at the time of IUK opening oil prices were still low ( $\$ 10$ to $\$ 15$ / barrel in 1998/99).

By 2000 oil prices had doubled to $\$ 30 /$ barrel and summer spot gas was trading at around $18 \mathrm{p} /$ therm $(\$ 2.66 / \mathrm{mmbtu})$. On the other hand the availability of IUK gas in the winter could in theory put a cap on UK prices during demand spikes if sufficient imported gas was available.

From 2004 NBP prices started to firm as UK supplies tightened and the 2005/6 peak occurred as a result of the closure of the Rough storage facility and lower availability of continental supplies than anticipated ${ }^{19}$. In addition the UK market still exhibited a marked seasonality in prices with the seasonal spreads exceeding at least $20 \mathrm{p} /$ therm $(\$ 3.50 / \mathrm{mmbtu})$. This seasonality was a major factor behind a large number of storage projects coming forward in the period 2003 to 2006. It can be seen from figure 8 that this price seasonality was not mirrored in continental prices where the lagged linkage to oil and oil product prices was the predominant driver.

As UK production began to decline in the early 2000s, the looming supply shortage precipitated a number of major pipeline and LNG import projects. The major developments were:

\footnotetext{
${ }^{18}$ At prevailing exchange rate of $£ 1=\$ 1.60$. All price conversions are at the exchange rate prevailing at the time.

${ }^{19}$ See https://www.ofgem.gov.uk/ofgem-publications/41806/14221-ofgem-winter-outlook-seminar-02-june-2006.pdf
} 

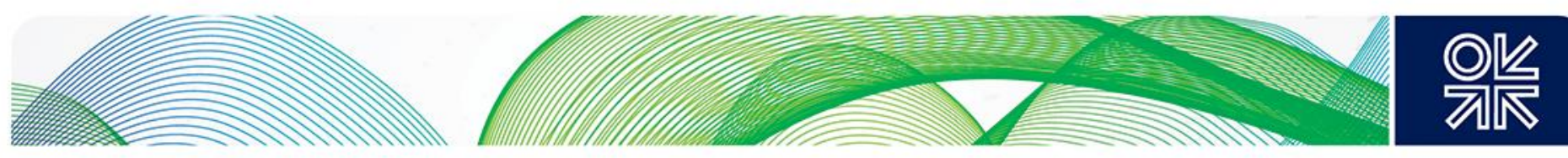

- Grain LNG commenced operation in 2005 with further capacity added in 2008 and $2010^{20}$

- South Hook LNG terminal started up in March 2009 as part of the Qatargas II project

- Dragon LNG terminal, located close to South Hook, received its first cargo in July 2009

- The Langeled pipeline bringing significant additional Norwegian supplies via the Easington terminal came on stream in 2007. UK prices once again became more closely related to continental prices.

- The BBL pipeline linking The Netherlands and Bacton started up in 2006.

Some of the capacity in the LNG terminals was linked to specific sources of gas supply - e.g. Qatar in the case of South Hook - or contracts as with purchases by Centrica from Petronas via the Dragon terminal. However, in other cases long term LNG terminal capacity holders were likely to utilise their slots for placing cargoes from their trading portfolio of LNG purchases. This meant that in many cases LNG would only flow to the UK when the price differentials with other markets - and the lucrative Japan, S Korea and Taiwan (JKT) markets in particular - were attractive. Furthermore it meant that if markets such as Japan required additional spot cargoes these would need to be priced in excess of the NBP spot price plus transportation. This led to particularly high prices during periods of high demand/supply tightness in both UK and JKT markets for example in the period prior to the 2008 recession when Japanese $L N G$ spot prices exceeded $\$ 20 / \mathrm{mmbtu}^{21}$. Figure 8 illustrates this trend as well as the fall in Asian spot LNG prices in 2015 to approximate parity with NBP levels.

Even where LNG was notionally contracted to the UK most of the contracts included diversion rights that enabled LNG to be switched elsewhere. The USA was one market that was seen as a potential destination for diverted UK cargoes, though of course this did not materialise because of the shale boom. Indeed the surge in UK LNG imports in 2010 and 2011 (see Figure 6) was partly due to diversions from the USA ${ }^{22}$. However the combination of the Japanese nuclear shut down following the Fukushima disaster in March 2011 and increased demand from South America created a general tightness in global LNG markets that restricted flows of LNG to the UK. This led to generally high prices and a flattening of seasonal spreads.

So whilst the UK is now fully exposed to global market developments the corollary is that with a deep and liquid UK traded market and the link to the continent the country was seen as an attractive destination for 'surplus' LNG. For some sellers a key consideration was the ability to sell uncontracted (spot) cargoes at the NBP to avoid undermining what had until late 2014 been much higher JKT prices though from late 2014 to mid-2015 the spread between NBP and JKT has collapsed due to higher volumes of spot LNG being available.

In addition to pricing issues the growing level of import dependency also created concerns over possible threats to security of supply (Rogers 2011). This concern arose from a combination of worries:

- The gas had further to travel and so was more susceptible to disruption,

- Many of the existing or potential supplying countries were deemed politically unstable and, under some circumstances, might be unable or unwilling to fulfil their supply obligations

- Other importing countries that did not have the same degree of market openness could ensure (through enforceable long term contracts) that they gained priority over the UK in sourcing gas when supply availability was tight.

\footnotetext{
${ }^{20} \mathrm{http}: / /$ www.cenex.co.uk/wp-content/uploads/2014/02/Low-Carbon-Truck-Workshop-1-Gas-Supply-Mechanisms.pdf

${ }^{21}$ Walker (2011)

${ }^{22}$ Bradshaw et al (2014)
} 

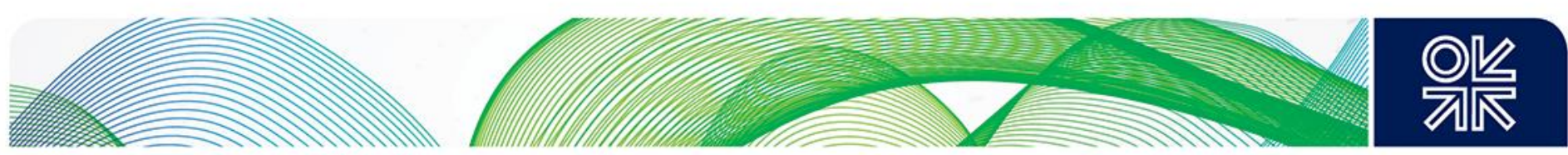

These concerns were amplified by events such as the Russia/Ukraine disputes ${ }^{23}$ and subsequent supply disruptions. National Grid planning assumptions were that Norwegian supplies to continental buyers with long term contracts in place would receive priority over sales to the UK - an assumption "broadly supported by feedback ... received through the consultation process" ${ }^{24}$. There was also a suggestion that public supply obligations that were present in some European countries meant that gas was held in storage to meet the potential needs of their own market rather than being available for export to the UK - despite the existence of higher prices. This led to the recognition that whilst the UK had plentiful supply capacity this did not mean it would always have plentiful physical gas supplies. This issue is considered further below.

\subsection{Industrial structure}

A critical aspect of the liberalisation of GB's energy market was the privatisation and subsequent unbundling of the incumbent gas and electricity companies and their infrastructure. This, coupled with introduction of competition in gas supply led to a multiplicity of players in the gas market that included upstream companies moving downstream, electricity suppliers moving horizontally into gas and a range of new entrants.

Today the GB gas market has a multiplicity of roles though there has been a considerable degree of consolidation in recent years amongst suppliers. The main roles are as follows:

- Gas producers - these comprise companies with UKCS acreage, producing and selling gas within the UK and non-UK producers selling gas into the UK via pipelines and LNG

- Gas pipeline companies - these are licensed entities that operate (and in most cases own) transmission (referred to as a TNO or TSO) and gas distribution networks (GDNO). The major transmission network is the National Transmission System (NTS) operated by National Grid. There are a number of DNOs and independent gas networks supplying new residential developments. There are also interconnectors with other networks in Belgium, The Netherlands and Ireland.

- Gas shippers/suppliers - these are licensed entities that buy and sell gas. Shippers move gas through the transportation system and trade in the wholesale market; suppliers sell gas to endusers. There are over 200 licensed gas shippers and 140 licensed gas suppliers - though some companies hold more than one license in each category 25

- Ancillary service providers - these cover activities such as gas storage, metering, connections and associated infrastructure provision. Whilst these are not generally licensed activities they are subject to regulatory oversight

The linkages between the various roles is shown in simplified form in figure 9 which also indicates those areas that are monopoly activities and those that are competitive.

\footnotetext{
${ }^{23}$ See Pirani et al (2009)

${ }^{24}$ National Grid (2009)

${ }^{25}$ For an up to date list of all licensed gas entities see https://www.ofgem.gov.uk/ofgem-publications/94566/externalgaslist-pdf
} 

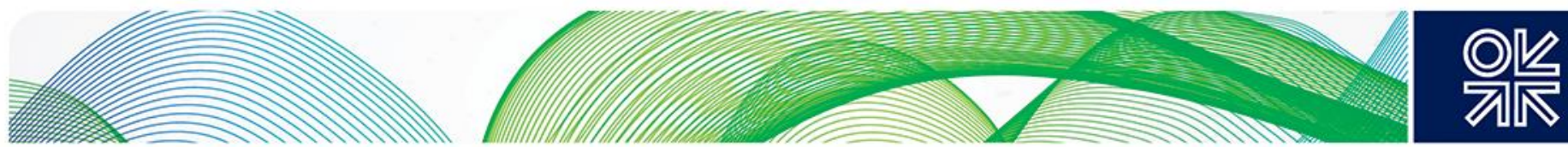

Figure 9: High level overview of gas industry structure and relationships

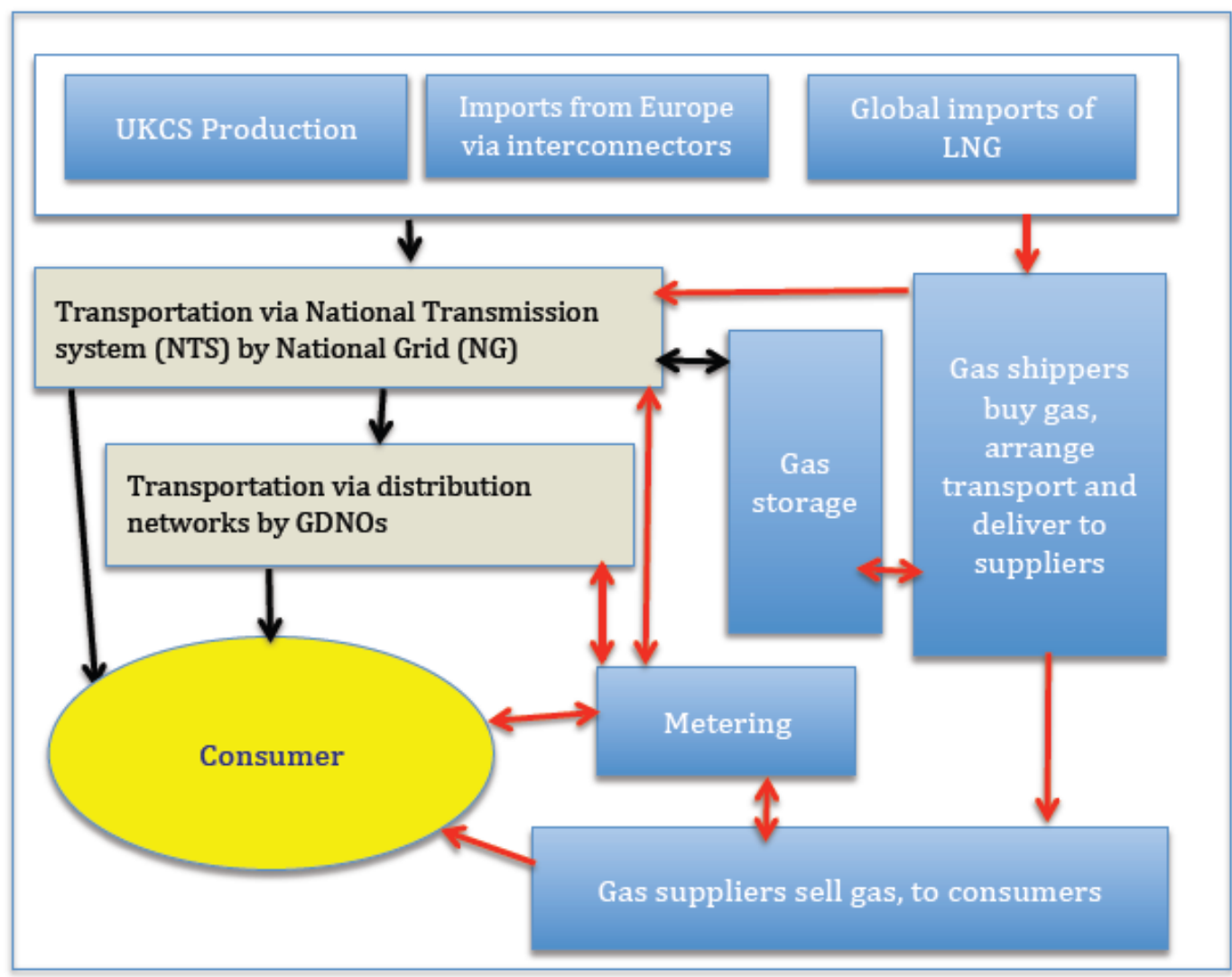

Competitive activities

Monopoly activities

Physical gas flow

Contractual/data linkages

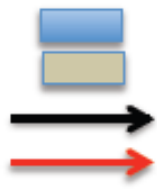

Source: Ofgem (2009). Note NCS is the Norwegian Continental Shelf. Not all linkages are shown.

Table 1 shows the main mid and downstream players and their main spheres of activities. This table excludes a number of suppliers who operate only in the industrial and commercial sector (see below). 

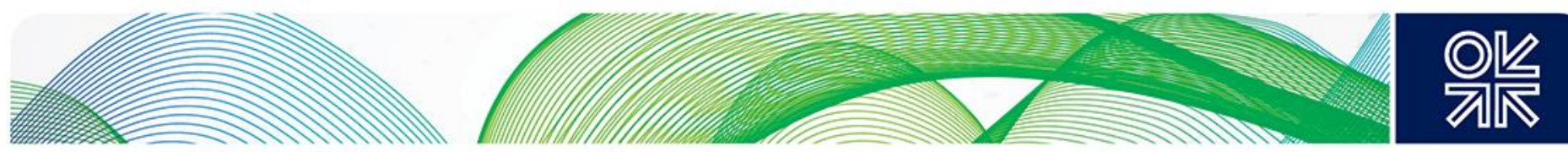

Table 1: Major mid and downstream players in the GB gas market

\begin{tabular}{|c|c|c|c|}
\hline Company & $\begin{array}{l}\text { Main UK gas } \\
\text { activities }\end{array}$ & Other areas of interest/operation & Ownership \\
\hline National Grid & $\begin{array}{l}\text { TSO,GDNO, LNG } \\
\text { terminal and metering }\end{array}$ & $\begin{array}{l}\text { In GB electricity transmission plus US gas } \\
\text { and electricity interests }\end{array}$ & $\begin{array}{l}\text { Listed company on } \\
\text { London Stock } \\
\text { Exchange (LSE) }\end{array}$ \\
\hline $\begin{array}{l}\text { Northern Gas } \\
\text { Networks }{ }^{26} \\
\text { (NGN) }\end{array}$ & GDNO & $\begin{array}{l}\text { CKI is part of Hutchison Whampoa and } \\
\text { has extensive global infrastructure } \\
\text { holdings. In the UK these include WWU, } \\
\text { UK power networks and Seabank Power }\end{array}$ & $\begin{array}{l}\text { CKI Hong Kong }{ }^{27} \\
\text { and NSW } \\
\text { (Australia) pension } \\
\text { fund }\end{array}$ \\
\hline $\begin{array}{l}\text { Wales and West } \\
\text { Utilities }^{28}\end{array}$ & GDNO & See above & CKI Hong Kong \\
\hline $\begin{array}{l}\text { Scottish \& } \\
\text { Southern Energy } \\
{ }^{29} \text { (SSE) }\end{array}$ & $\begin{array}{l}\text { Shipper, Supplier, } \\
\text { GDNO } \\
\text { Gas storage }\end{array}$ & $\begin{array}{l}\text { UK electricity generation, network } \\
\text { operation and supply }\end{array}$ & $\begin{array}{l}\text { Listed company on } \\
\text { LSE }\end{array}$ \\
\hline Centrica $^{30}$ & $\begin{array}{l}\text { Producer, Shipper, } \\
\text { Supplier, Gas storage } \\
\end{array}$ & $\begin{array}{l}\text { UK electricity generation, supply and } \\
\text { residential energy services, } \mathrm{N} \text { American } \\
\text { gas and electricity supply plus some } \\
\text { international gas assets }\end{array}$ & $\begin{array}{l}\text { Listed company on } \\
\text { LSE }\end{array}$ \\
\hline $\mathrm{RWE}^{31}$ & Shipper, Supplier & $\begin{array}{l}\text { UK electricity generation and supply. } \\
\text { Extensive gas and electricity interests in } \\
\text { Germany and throughout Europe }\end{array}$ & $\begin{array}{l}\text { Listed company on } \\
\text { German Stock } \\
\text { Exchanges }\end{array}$ \\
\hline $\mathrm{EON}^{32}$ & $\begin{array}{l}\text { Shipper, Supplier, Gas } \\
\text { storage, }\end{array}$ & $\begin{array}{l}\text { UK electricity generation and supply. } \\
\text { Extensive gas and electricity interests in } \\
\text { Germany and throughout Europe }\end{array}$ & $\begin{array}{l}\text { Listed company on } \\
\text { Frankfurt Stock } \\
\text { Exchange }\end{array}$ \\
\hline $\mathrm{EdF}^{33}$ & $\begin{array}{l}\text { Shipper, Supplier, Gas } \\
\text { storage, }\end{array}$ & $\begin{array}{l}\text { UK electricity generation (including } \\
\text { nuclear) and supply. Extensive electricity } \\
\text { interests globally though primarily in } \\
\text { France }\end{array}$ & $\begin{array}{l}84.5 \% \text { owned by } \\
\text { French government }\end{array}$ \\
\hline Scottish Power ${ }^{34}$ & $\begin{array}{l}\text { Shipper, Supplier, Gas } \\
\text { storage, }\end{array}$ & $\begin{array}{l}\text { UK electricity generation, networks and } \\
\text { supply }\end{array}$ & $\begin{array}{l}\text { Owned by Spanish } \\
\text { utility lberdrola }\end{array}$ \\
\hline $\begin{array}{l}\text { Engie } 35 \text { (formerly } \\
\text { GdF SUEZ) }\end{array}$ & $\begin{array}{l}\text { Producer, Shipper, } \\
\text { Supplier, Gas storage }\end{array}$ & $\begin{array}{l}\text { UK electricity generation. Extensive gas } \\
\text { and electricity interests globally particularly } \\
\text { in France and Belgium }\end{array}$ & $\begin{array}{l}33.3 \% \text { owned by } \\
\text { French government } \\
\text { most of remainder } \\
\text { publicly traded }\end{array}$ \\
\hline
\end{tabular}

Source: Company websites

Following the introduction of retail competition in residential gas supply a multiplicity of gas suppliers entered the market with over 50 different companies operating in the period 1997 to 2003. Kopp

\footnotetext{
${ }^{26}$ http://corporate.northerngasnetworks.co.uk/company-background/

${ }^{27} \mathrm{http}: / /$ www.cki.com.hk/english/about_CKI/cki_at_a_glance/index.htm

${ }^{28} \mathrm{http}: / /$ www.wwutilities.co.uk/WWUOverview.aspx?GroupKeyPos=02,

${ }^{29} \mathrm{http}: / /$ sse.com/whatwedo/

$30 \mathrm{http}: / /$ www.centrica.com/index.asp?pageid=16

${ }^{31}$ http://www.rwe.com/web/cms/en/1029638/rwe/about-rwe/profile/

32 http://www.eon.com/en/business-areas.html

${ }^{33}$ http://asia.edf.com/about-edf-group/activities-52189.html

${ }^{34}$ https://www.scottishpower.co.uk/about-us/

${ }^{35}$ http://www.gdfsuez.com/en/
} 

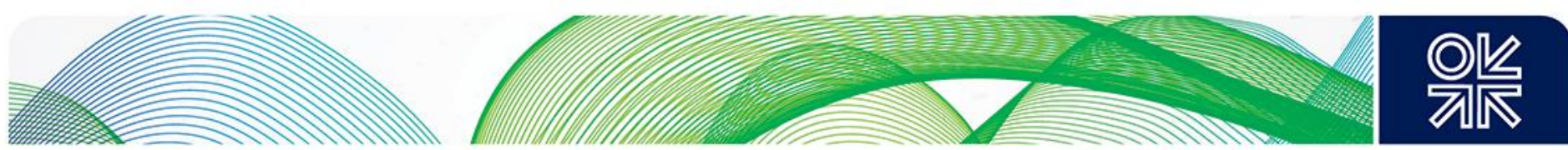

(2015) notes that in 2001 major European utilities entered the market and by 2004 the residential sector had become highly concentrated with just six companies serving the vast majority of consumers. This situation still prevails with the so called 'big 6' suppliers (Centrica trading as British Gas, E.ON, RWE, SSE, EdF and Scottish Power) dominating gas supply. These companies also have extensive interests in electricity; accounting for around 70\% of UK generation output in 2013 (CMA 2015d). Most also have substantial positions elsewhere in Europe though some are entering a phase of major restructuring ${ }^{36}$. The big 6 do not generally have the same level of vertical integration in gas as they do in electricity and some such as E.ON ${ }^{37}$ and RWE $^{38}$ are in the process of disposing of their upstream gas assets. It is also the case that many gas producers have abandoned their presence in downstream gas shipping and supply in favour of trading at hubs.

The evolution of market shares since 2005 is shown in figure 10. The dominant position of British Gas (Centrica) is evident, though its market share continues to decline. Most notable is the increase in the residential market share of smaller suppliers. This group had struggled to make inroads into the residential market for many years but their share is now over $5 \%$ in gas (and in electricity).

\section{Figure 10: GB Residential gas market shares}

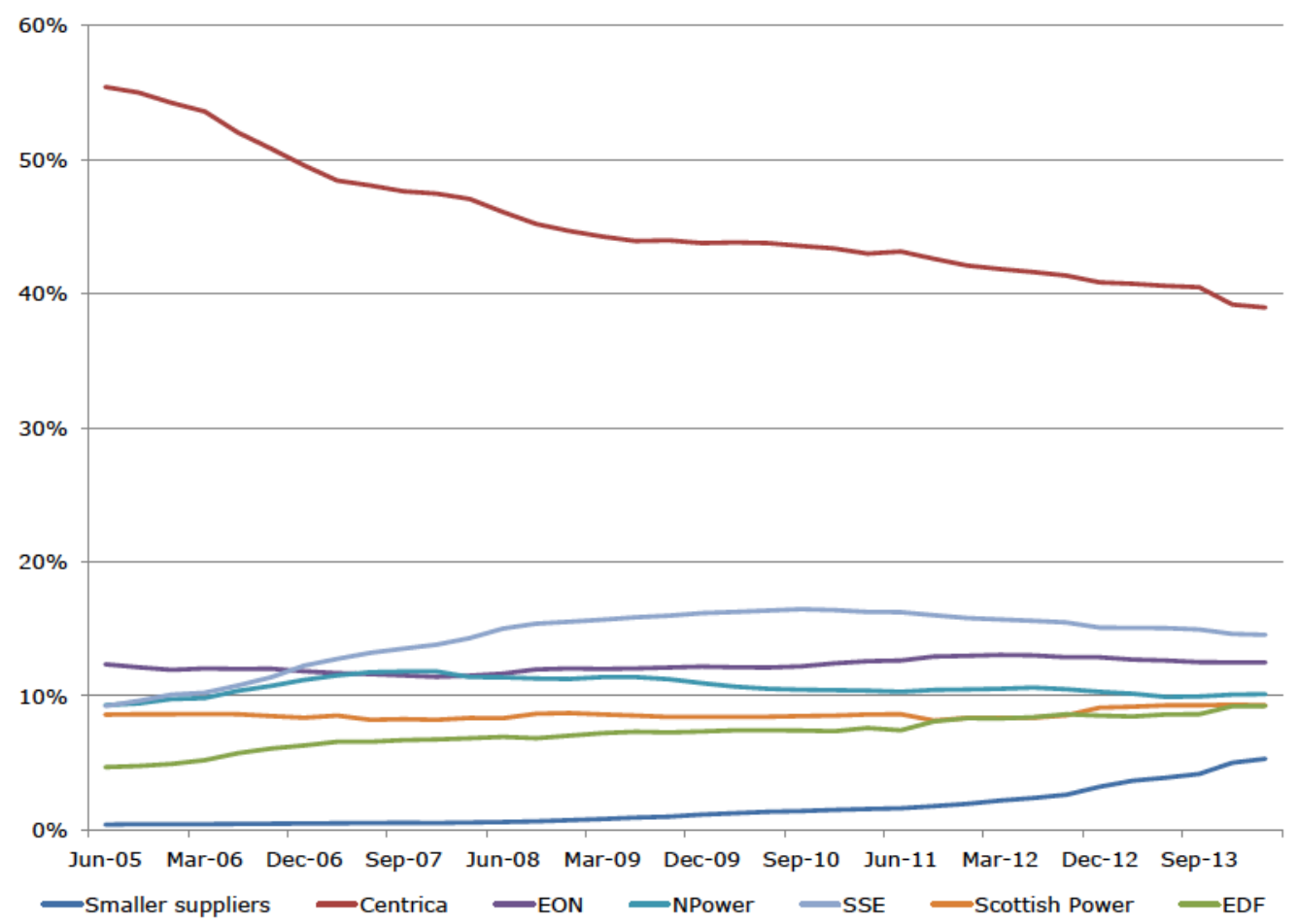

Source: Ofgem 2014a

Unlike the residential supply market the industrial and commercial sector has a greater variety of suppliers with a relatively limited presence of the "big 6". There are a number of players with a significant upstream presence such as Total (France), Statoil (Norway), ENI (Italy), and Gazprom (Russia) who apart from Total are majority state owned companies. In addition there are other European energy suppliers such as DONG ${ }^{39}$ (Denmark) and Wingas (Germany) as well as a number

\footnotetext{
${ }^{36}$ See Stern and Rogers (2014) for more details on the crisis facing midstream players

${ }^{37}$ http://uk.reuters.com/article/2014/11/30/uk-e-on-divestiture-idUKKCNOJE0TZ20141130

$38 \mathrm{http} / /$ www.rwe.com/web/cms/en/113648/rwe/press-news/press-release/?pmid=4012456

39 DONG acquired Shell's retail gas business Shell Gas Direct in 2012, http://uk.reuters.com/article/2012/05/01/energy-britainretail-idUKL5E8G11SJ20120501
} 

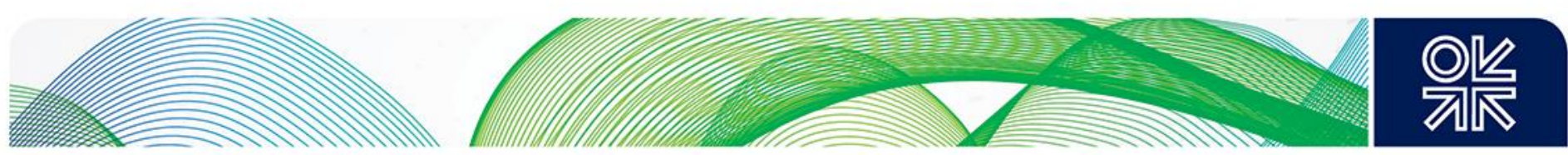

of independents such as Corona Energy and Contract Natural Gas ${ }^{40}$. The largest market share in 2014 was Total with $17.6 \%$ of the "large" business market followed by Gazprom, DONG and Corona with $12.8 \%, 11.8 \%$ and $11.0 \%$ respectively ${ }^{41}$. Most of these companies have developed their retail presence on the back of UK equity gas supplies. They will offer a range of options to buyers from fixed price contracts to those linked to the NBP. The businesses are typically structured in such a way that the retail unit operates at arm's length from the upstream with a trading and risk management function in place to limit exposure and exploit arbitrage opportunities. Suppliers who do not have an upstream presence will normally ensure retail sales contracts are matched back to back by NBP purchases to lock in the margin and remove downside risks.

\subsection{The evolution of gas policy}

A very high level review of UK government policy with regard to the gas industry since 1980 might discern two distinct phases. The early phase focussed on liberalisation and market opening with a switch to a more multi-layered approach evident from the turn of the century.

Much has been written about the liberalisation of the UK's energy market and there remains a wide range of views regarding the benefits and drawbacks from the policy ${ }^{42}$. The key drivers of liberalisation in the nation's gas market were threefold:

- Government policy of privatisation of state-owned industries coupled with the belief in the beneficial impact of private ownership ${ }^{43}$ on economic performance ${ }^{44}$

- Concern from some large gas users at high and discriminatory pricing by the incumbent British Gas

- Pressure from gas producers who wanted direct access to markets for their surplus gas supplies.

There followed what could in retrospect be termed a golden age for gas in the UK. The surplus in supplies led to very low prices and significant increases in the demand for gas - particularly for power generation. Regulation primarily focussed on reducing costs of transmission and distribution through progressively tighter periodic reviews and in introducing competition in supply at the residential consumer level. Security of supply did not need to be of concern and the Government view - that as long as the network operator had invested in sufficient capacity, the market would ensure that gas supplies were made available - was borne out by events.

At the beginning of the $21^{\text {st }}$ Century however the situation started to change.

- The supply overhang was removed by the construction of the interconnector between Bacton and Zeebrugge (IUK) which began operation in 1998 and, as described above, prices began to move, through arbitrage, towards continental European levels. Prices continued to strengthen thereafter and the social and economic impacts of high energy prices assumed increasing political prominence.

- Declining UKCS gas production and continuing growth in demand meant that the period of selfsufficiency was coming to an end and concerns over security of supply started to emerge. Worries that the liberalised market might not incentivise appropriate investments were accentuated by low oil prices depressing the level of UKCS activity and by events such as the energy crisis in California ${ }^{45}$ and the collapse of energy trader Enron. The Transco 2000 Ten Year Statement ${ }^{46}$

\footnotetext{
${ }^{40}$ Moss \& Buckley, (2014)

${ }^{41}$ See http://www.businessjuice.co.uk/wp-content/uploads/Supplier-Market-Share-PDF.pdf based on information from Cornwall Energy

${ }^{42}$ See for example Helm (2004) and Rutledge and Wright (2010)

${ }^{43}$ Parker (2009)

${ }^{44}$ And in addition to raise funds for the UK Treasury - see Heather (2010)

${ }^{45} \mathrm{See} \mathrm{http://www.pbs.org/wgbh/pages/frontline/shows/blackout/california/timeline.html} \mathrm{for} \mathrm{an} \mathrm{overview}$
} 

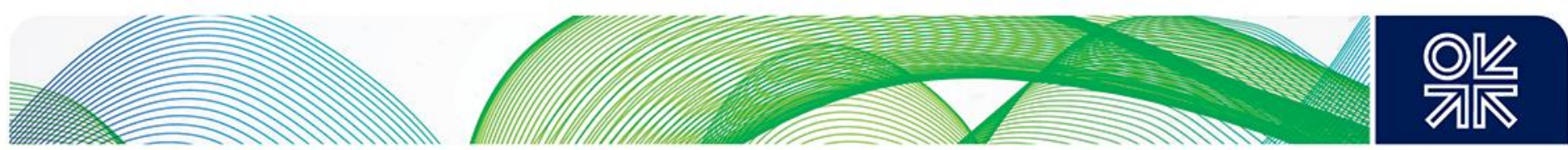

indicated the potential for a looming "supply crunch" though the company did expect supplies to materialise either from the Continent or Norway, though it was not sure which. LNG was not seen as a realistic option at that time.

- Government faced increasing pressure over the environmental implications of unfettered fossil fuel consumption and whilst gas had stronger environmental credentials than coal or oil it was at best treated equivocally when it came to formulating future policy.

- Growing disillusionment with market-based approaches following the financial and banking crisis and subsequent recession fed into a narrative of oligopolistic energy suppliers keeping prices and profits high at the expense of consumers with vulnerable customers particularly exposed. 47

- The role of the regulator came under increasing scrutiny with criticism from some quarters that the principle of independence had become eroded ${ }^{48}$ whilst the scope of regulation had become too widespread and interventionist. In particular the introduction of competition in areas such as metering and connections was seen as overly burdensome for industry with little or no benefit to consumers.

Overall energy issues (and prices in particular) have assumed a much higher profile with the public and successive governments and opposition parties have increased the level of rhetoric accordingly albeit sporadically.

\subsection{The Energy Trilemma}

In essence energy policy prescriptions revolve around satisfying three critical - and often incompatible - objectives:

- Keeping energy prices low (and having particular regard for poor and vulnerable consumers) "affordability and competitiveness";

- Reducing or mitigating the environmental impact of energy consumption - "sustainability";

- Ensuring stable and secure supplies - "security".

The innate challenge of meeting these three objectives is often referred to as the 'energy trilemma'.

The environmental mitigation objective is the one most clearly set out, primarily through the 2008 Climate Change $\mathrm{Act}^{49}$ together with EU legislation, both of which are discussed further below. The two other elements of the trilemma, however, tend to be subject to more ad hoc interventions. Furthermore Government policies designed to meet one objective can conflict with another. A desire to ensure secure supplies may lead to measures to encourage the development of indigenous fossil fuels which could make environmental targets harder to meet. Meeting environmental targets through requiring consumers to support high cost renewable energy in turn is likely to conflict with the affordability objectives. It is little wonder that policy makers have found it very difficult to construct a unifying theme that strikes a chord with the public - particularly when the level of dependence on fossil fuels continues to be so high.

\footnotetext{
46 Transco (2000)

${ }^{47}$ See for example Energy giants enjoyed $75 \%$ surge in profits as thousands died in freezing homes

http://www.mirror.co.uk/news/uk-news/fuel-poverty-energy-giants-surge-2851341 and Energy companies boost profits despite gas price cuts, warns energy watchdog

http://www.theguardian.com/business/2015/jan/29/energy-companies-boost-profits-despite-gas-price-cuts

${ }^{48}$ See for example Yarrow's submission to the CMA in Yarrow (2014)

49 UK Government (2008)
} 

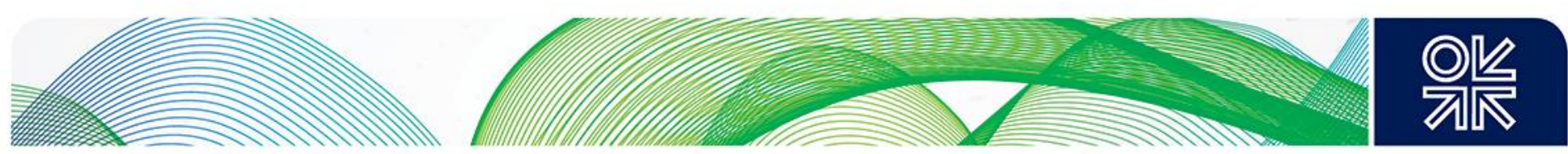

In implicit recognition of the lack of a clear overall policy framework and in order to provide greater certainty for all sectors (including the regulator) a Government review of economic regulation in $2011^{50}$ undertook to issue an annual Strategy and Policy Statement (SPS) for each regulated sector that would be in place for the life of a Parliament. The SPS for Ofgem ${ }^{51}$ sets out:

- The Government's strategic priorities for energy policy

- The particular policy outcomes required

- The roles and responsibilities of all those involved in implementation of the policy

The Energy Act $2013^{52}$ enshrined the requirement for a SPS and in its draft Strategy and Policy Statement ${ }^{53}$ the government set the following strategic priorities:

- "Helping households and businesses take control of their energy bills and keep their costs down" - primarily through transparent and competitive markets - though improved information from smart meters, community energy projects, increased coordination amongst EU member states, demand reduction measures and alleviation of fuel poverty should all play a role;

- "Unlocking investment in the UK's energy infrastructure that will support economic growth". This is primarily directed at investment in the electricity generation (renewable, nuclear and other low carbon sources) and connections sector plus greater interconnection with other countries' grids.

- "Playing a leading role in efforts to secure international action to reduce greenhouse gas emissions and tackle climate change." Primarily aimed at increasing investment in clean technologies and low carbon technologies.

The Government also recognised the importance of a "well-functioning and integrated EU internal market" to meet security of supply, decarbonisation and competitiveness/growth objectives ${ }^{54}$. This consultation closed in October 2014 and the responses ${ }^{55}$ are being analysed ${ }^{56}$.

Perhaps as a recognition of the criticism levelled at the lack of clear strategy the leaders of the three largest Westminster parties at that time issued a joint undertaking in February 2015 that included a commitment to agree carbon budgets in accordance with the Climate Change Act and to end the use of unabated coal for power generation ${ }^{57}$.

\subsection{Energy policy and the gas market}

How the policy regarding the three elements of price, environmental impact and security of supply impacts the gas market is considered in the following sections.

\subsubsection{Price and affordability}

After remaining relatively stable for many years, in 2004 retail gas and electricity prices started an apparently inexorable rise. Whilst some of this was due to increases in global oil and gas prices some studies (for example Wright (2006)) suggested that prices paid by residential consumers were higher due to higher mark-ups by suppliers than would have been the case under a single monopoly supplier. Further concerns were raised when residential prices failed to fall after the 2008 crash as global oil prices plummeted from nearly $\$ 150 / \mathrm{bbl}$ to below $\$ 50$. Figure 11 shows the evolution of average residential gas prices compared to the NBP wholesale price which suggests that residential

\footnotetext{
50 BIS (2011)

51 DECC (2011a)

52 UK Government (2013)

${ }^{53}$ DECC $(2014 \mathrm{~g})$

${ }^{54}$ DECC $(2014 \mathrm{~g})$

55 DECC (2015c)

${ }^{56}$ For latest position see https://www.gov.uk/government/consultations/strategy-and-policy-statement

57 http://www.green-alliance.org.uk/leaders_joint_climate_change_agreement.php
} 

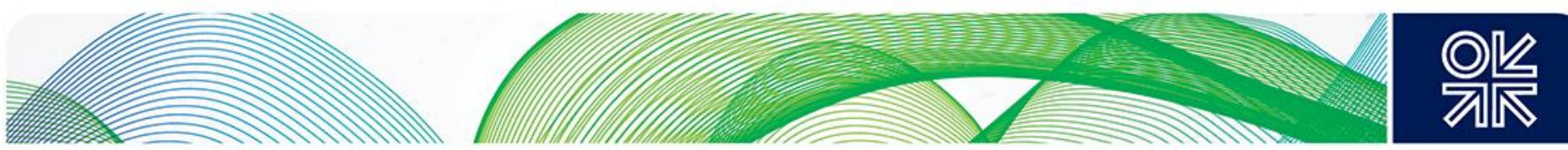

price changes in recent years have a broadly rising trend whilst wholesale prices have exhibited much greater volatility. This issue, and the dangers of taking an over-simplistic approach to the relationship between prompt wholesale prices and prices charged to retail consumers, is addressed further below.

Figure 11: Index of UK residential retail prices and NBP wholesale price in pence/therm

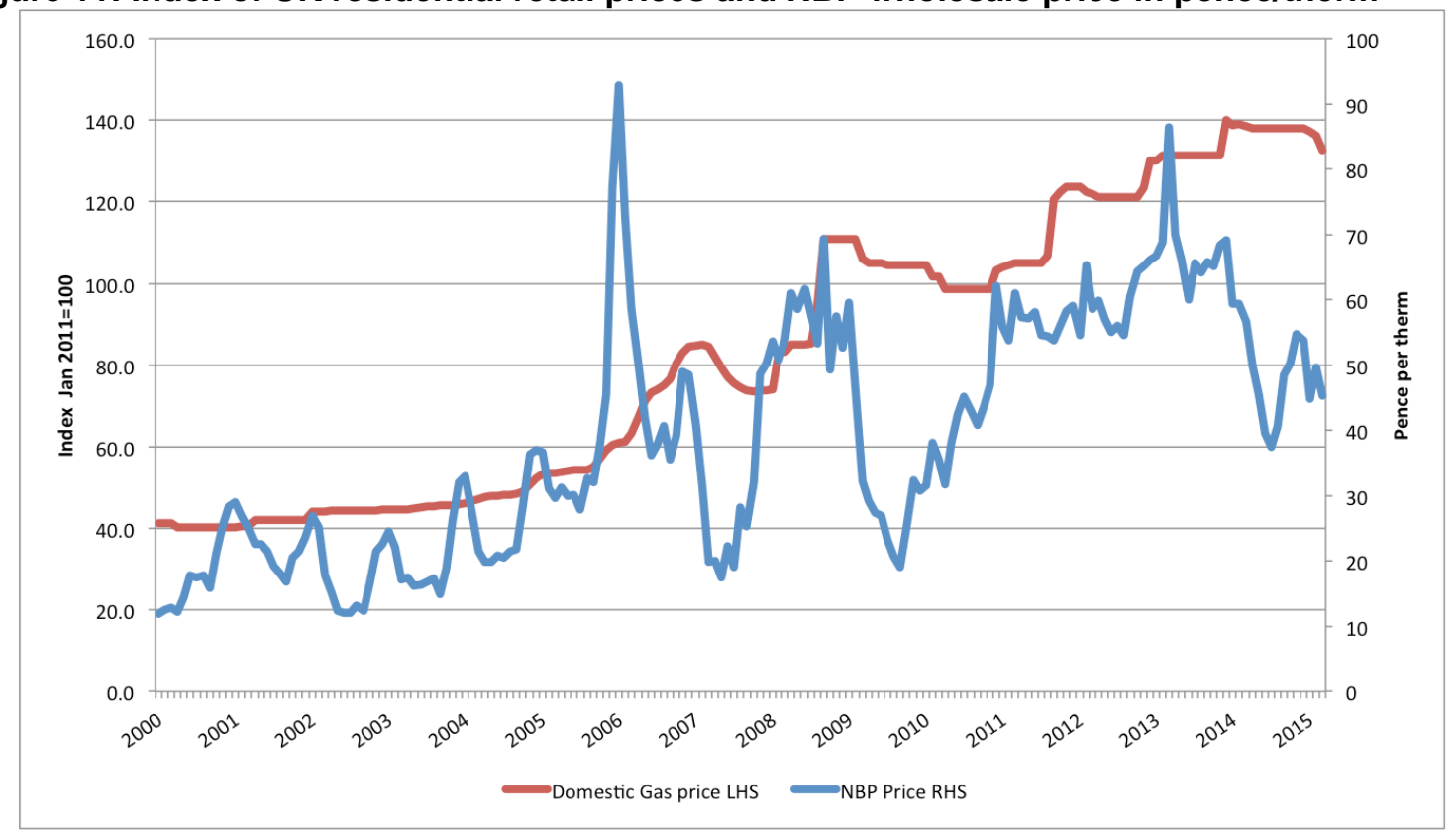

Source: DECC https://www.gov.uk/government/collections/domestic-energy-prices and Platts/Heren. Note: The domestic (i.e. residential) price is indexed where 1 Jan $2011=100$ and is based on an average of the gas companies' tariffs plus butane gas. The NBP price is based on monthly averages.

Retail gas and electricity price controls were completely removed in $2002^{58}$ though energy prices are never far from the headlines and sustained price rises in recent years have increased the pressure on governments to intervene - pressure that they have not been wholly successful in resisting. Whilst average residential gas prices, including taxes, are low by EU standards (amongst the lowest in the EU15 in 2014 according to ACER's monitoring report ${ }^{59}$ ) prices continue to rise ${ }^{60}$. Residential gas and electricity prices rose by $5.1 \%$ and 5.6\% respectively in the year to September 2014 .

The cost of an average annual consumer gas bill in 2014 was estimated by Ofgem to be $£ 700$. This compares with $£ 614$ for an electricity bill and $£ 1,365$ for a dual (i.e. gas plus electricity) fuel bill. The breakdown of prices paid by gas consumers is shown in figure 12. These numbers are derived from Ofgem's supply market indicator $\left(\mathrm{SMI}^{61}\right)$ which, according to the suppliers, tends to overstate their margins. ${ }^{62}$

\footnotetext{
58 Harker \& Waddams Price (2006)

${ }^{59}$ ACER is the Association of European Regulators and now publishes pan-European data. See

http://www.acer.europa.eu/Official_documents/Acts_of_the_Agency/Publication/ACER_Market_Monitoring_Report_2014.pdf

60 See Stern \& Rogers, 2014 page 5 for an illustration of lower UK prices versus those in Germany

61 https://www.ofgem.gov.uk/gas/retail-market/monitoring-data-and-statistics/understanding-energy-prices-great-britain/supply-

market-indicator

62 NERA (2015)
} 

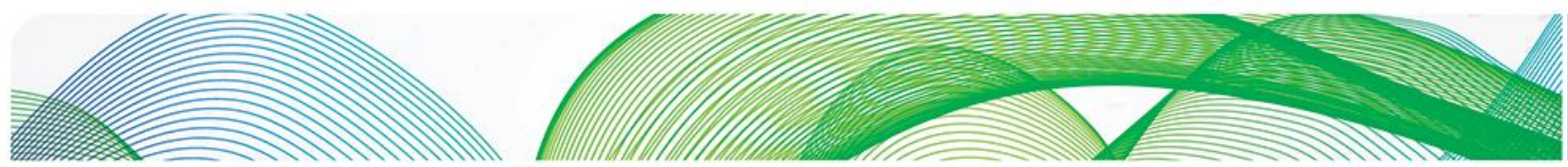

Figure 12: Estimated breakdown for average residential consumer gas bill - 2014

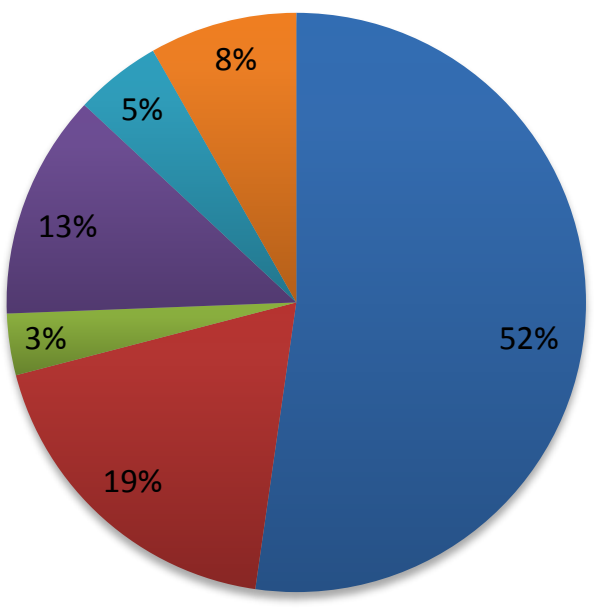

Wholesale costs

Network costs

Environmental and social obligation costs

- Supplier operating costs

VAT

Supplier Margin (pre-tax)

Source: Ofgem Supply Market Indicator https://www.ofgem.gov.uk//publications-and-updates/charts-outlookcosts-make-energy-bills

The key components of the average consumer gas bill are therefore:

- Wholesale gas price - i.e. the commodity price of gas - in 2014 Ofgem estimate that this accounts for $52 \%$ of residential gas bills and around $29 \%$ of average dual fuelled bills,

- Network costs - i.e. the costs of transportation and distribution,

- Suppliers' costs including their profit margin,

- VAT and additional charges imposed by government to cover environmental and social obligations.

Figure 13 shows the CMA analysis of how these components have evolved over recent years for residential gas consumers ${ }^{63}$. 

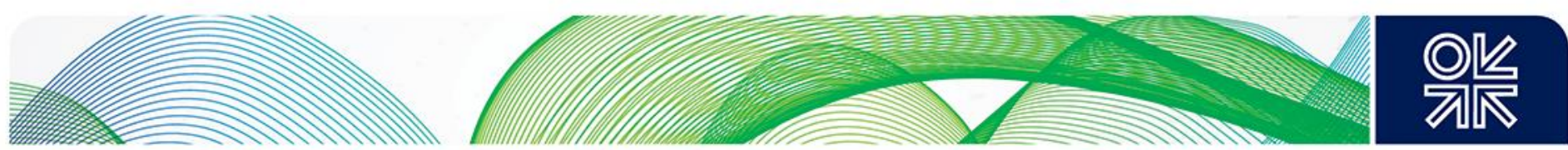

Figure 13: Components of average annual residential gas bill 2007 to $2013(£)$

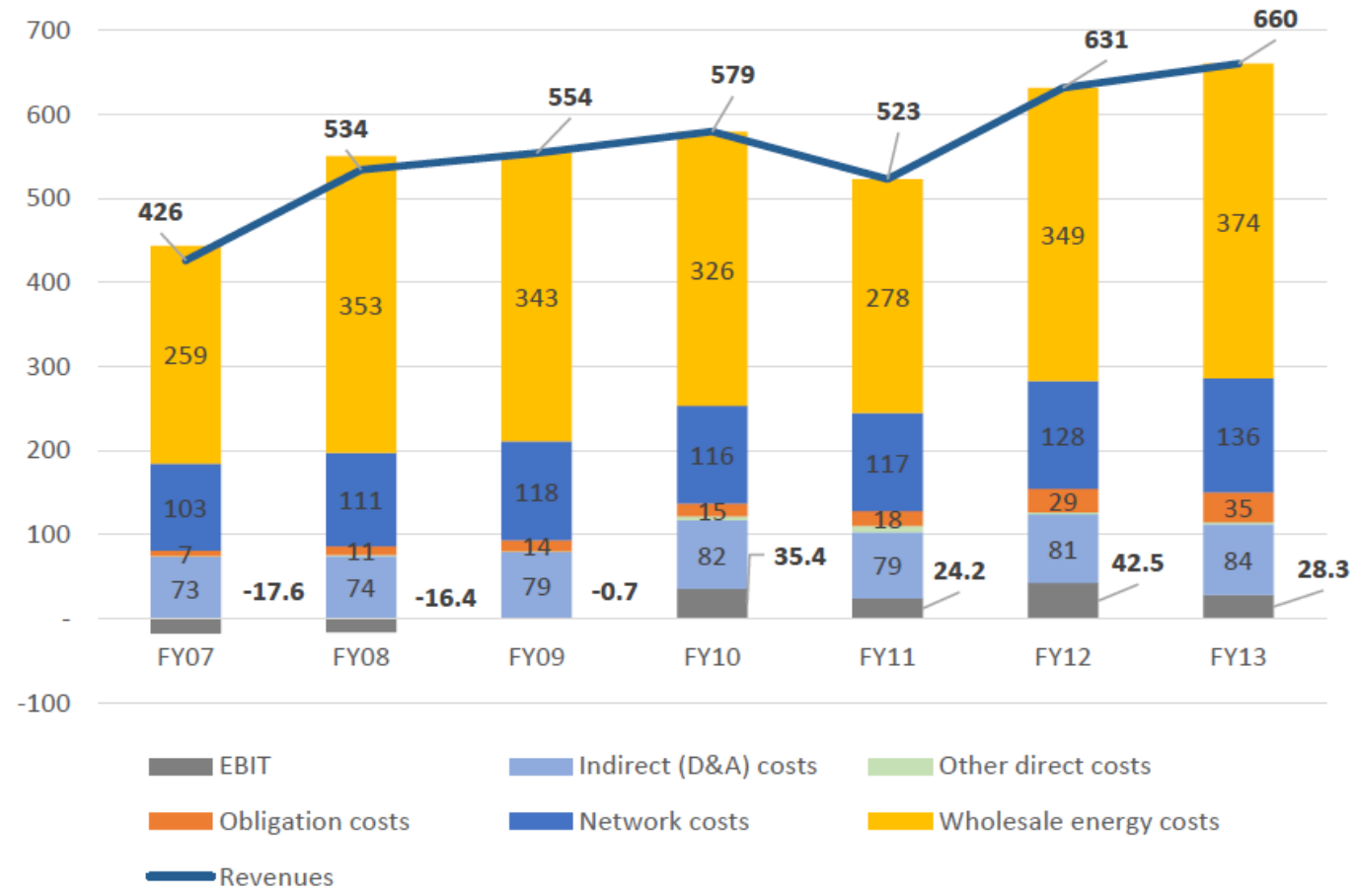

Source: CMA 2015e

Note: EBIT: Earnings Before Interest and Taxation - a commonly used measure of 'profit'. FY refers to financial reporting year ${ }^{64}$

These elements are considered in further detail below.

\subsubsection{Wholesale price formation}

Allsopp and Stern ${ }^{65}$ have demonstrated that for many years the mechanics of wholesale gas price formation were quite different from those of other commodities. This situation began to change, first in the USA in the 1980s and then, as described in Section 3.2, in the UK in the 1990s, when supply and demand fundamentals started to play a stronger role. This trend is also increasingly evident in continental European gas price formation where gas on gas price formation now accounts for $61 \%$ of wholesale volumes. 66

In theory prices in a fully liquid gas market will be set by the cost of the marginal source of supply required to meet demand on any particular day. On this basis it is therefore simply a matter of building a bottom up supply stack for the UK gas market in order of cost. However as Timera (2013) and Stern \& Rogers (2014) note this is no longer appropriate when markets are highly interconnected across a complex range of physical infrastructure where price and flow drivers will vary considerably. The authors have distinguished between flexible and inflexible sources of supply with the former being the key driver in setting prices on hubs. From a UK perspective the supply sources could be broadly allocated into the two categories as follows:

\footnotetext{
${ }^{64}$ This is the reporting year for the companies concerned and equates to the calendar year in which the majority of the reporting months fell.

${ }^{65}$ In Stern ed (2012a)

${ }^{66}$ See IGU (2015)
} 

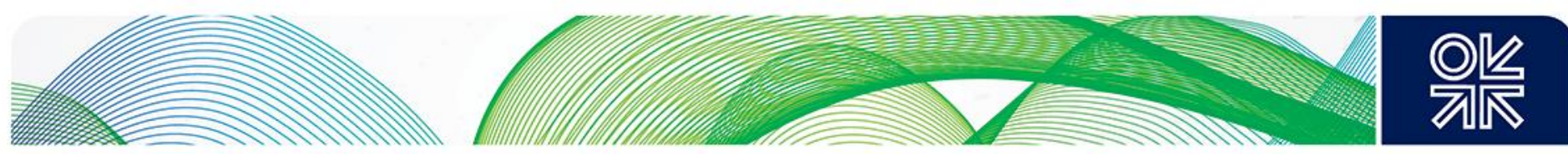

- Inflexible - UKCS production, Norwegian imports ${ }^{67}$ and, to a lesser extent, Dutch imports via BBL

- Flexible - IUK imports, LNG imports which will be a mix of contracted and spot cargoes.

So in broad terms NBP prices will either be set by IUK flows (which could be said to be determined by the availability or otherwise of Russian swing volumes) or LNG, where flows will be primarily determined by dynamics in the Asia Pacific market.

It should be noted that a further crucial determinant of pricing on a day to day basis are withdrawals (or injections) from storage, though the impact on an annual basis is less marked. However, as discussed below, there is an argument that markets with a relatively small proportion of storage such as the UK are more exposed to price shocks. A further factor impacting on the UK is that there is the tendency for more gas to flow from continental markets in the second half of the winter when excess storage volumes become available ${ }^{68}$.

The UK now has a deep and liquid wholesale gas market with prices formed by trading at the NBP hub. ${ }^{69}$ However as noted above it is also the case that UK gas prices are often influenced by prices formed in other markets that are not necessarily so directly impacted by supply and demand fundamentals. So for example continental gas contracts which have price formulae based on lagged oil product prices often influence UK gas prices and arguably have resulted in prices that are higher than they might otherwise have been - particularly prior to 2010 when oil price escalation contracts were more prevalent. ${ }^{70}$ Whilst this feature has led to dissatisfaction in some quarters it is essentially a problem of price level rather than price formation. In other words the problem is that prices are too high, not that the mechanism that derives the prices is flawed. Moves towards a single, market-based price formation mechanism across Europe could help address this issue. ${ }^{71}$

The CMA energy market investigation described below specifically excluded the gas wholesale market from its remit, taking the view that it was functioning well and there were no obvious competition problems. Notwithstanding this view there are still critics of the UK wholesale market including the Parliamentary Select Committee for Energy and Climate Change ${ }^{72}$ and the CMA has recently published a consultative working paper on the subject. ${ }^{73}$ This paper highlighted that some respondents had raised issues with regard to market manipulation, price transparency and concentrated ownership of gas storage capacity. Some independent suppliers in evidence to the $\mathrm{CMA}^{74}$ suggested that for low volume players the costs of supply contracts could be uneconomic. In reviewing these concerns the CMA confirmed its initial view of the wholesale market though it did flag a longer term concern that as the UK's dependence on imported gas from the EU grew it could become more exposed to less competitive conditions elsewhere in Europe.

Separately the All Party Parliamentary Group on Energy Costs published a paper in March $2015^{75}$ on the wholesale gas market. This concluded that the market performed well under the key criteria of ease of entry, liquidity, transparency and number of participants. The Group noted that the UK market was the only European market to meet the ACER criteria for a fully functioning gas market.

\footnotetext{
${ }^{67}$ Stern \& Rogers (2014) note that Norwegian gas production exhibits a seasonal pattern and there is scant evidence that annual production deviates from planned field production other than due to field shut-downs.

68 See Le Fevre (2013)

69 Heather (2010)

${ }^{70}$ IGU 2015)

71 See Stern \& Rogers (2012).

72 see http://www.parliament.uk/business/committees/committees-a-z/commons-select/energy-and-climate-changecommittee/news/chair-reacts-to-cma-statement/

${ }^{73}$ CMA (2015f).

${ }^{74}$ CMA (2015a)

${ }^{75}$ APPGEC (2015)
} 

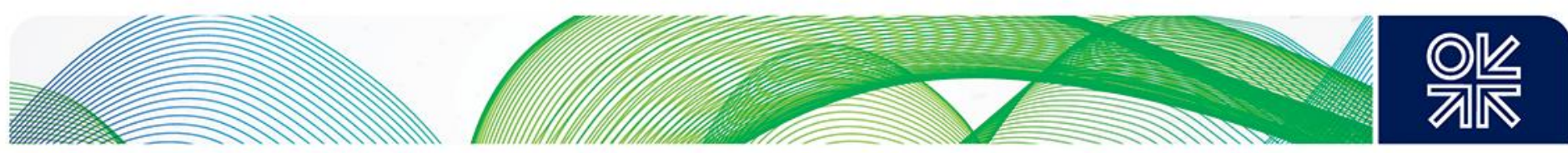

\subsubsection{Network Costs}

The costs of transmission and distribution (undertaken by NG and the GDNOs) have for many years been regulated by the so-called RPI-x approach. This sought to improve efficiency by reducing allowed revenue in real terms whilst using standard of service obligations to maintain or improve quality. This method lead initially to significant reductions in costs charged to consumers, though there have been significant increases in unit costs in recent years as shown in figure 13. Drawbacks with the RPI-x approach included difficulties in setting clear measures of outputs with consequent impacts on quality. In addition there were limited incentives to innovate and a tendency to "front-load" savings at the start of the review period. ${ }^{76}$

In reviewing these problems Ofgem opted for the broader based RIIO framework - Revenue = Incentives + Investment + Outputs ${ }^{77}$ to operate for an eight rather than five year control period in order to improve regulatory certainty. The first determinations were published in $2013^{78}$ and covered gas distribution and a combined control for gas and electricity transmission. The new framework was designed to place greater emphasis on incentivising innovation in investment and promote smarter gas and electricity networks for a low carbon future ${ }^{79}$ - networks that failed to innovate were likely to be penalised. In addition the RIIO reforms included provisions for the indexation of the cost of debt. As Helm (2015b) points out this was important as it removed an area of potential "windfall" outperformance and with it the incentive on Ofgem to intervene within a review period.

Whilst the first review has some way to run the approach has already attracted some criticism. The Parliamentary Select Committee on Energy ${ }^{80}$ reported that whilst the RIIO framework was an improvement in facilitating a more robust negotiating process there was evidence that targets had been set too low and networks were making higher than predicted profits. Whilst Ofgem suggested that it was too early to make a judgment on the overall settlement the Select Committee thought otherwise "We do not think it is in the public interest to wait until the eight-year period is over before determining whether the RIIO framework has met its objectives, and if the price targets have been too lenient." ${ }^{1}$. Government confirmed this view in suggesting some form of mid-term review might be appropriate.

The Select Committee also recommended greater simplicity in network charging methodologies and reduced volatility in charges.

\subsubsection{Environmental and social charges}

There are a range of additional charges imposed by Government that are borne by residential consumers - though most are imposed on electricity rather than gas bills. The most significant of these payments in value terms relate to the electricity renewables levies or low carbon generation charges.

Other payments cover the Carbon Price Floor, Warm Homes discount scheme, smart meters and the Energy Company Obligation (ECO). The three most significant elements are:

- The Carbon Price Floor that taxes generators according to the level of their carbon intensity. It was introduced due to the low and volatile price of carbon under the EU ETS scheme which had resulted in uncertainty for investors in low carbon technologies. It was introduced in 2013 and was set to increase each year from around $£ 7 /$ tonne of carbon dioxide at the outset to $£ 30 /$ tonne in 2020 and $£ 70$ by 2030. In March 2014 the government chose to freeze the CPF at £23/tonne from

\footnotetext{
76 Jenkins (2011)

77 https://www.ofgem.gov.uk/network-regulation-\%E2\%80\%93-riio-model

${ }^{78}$ See https://www.ofgem.gov.uk/network-regulation-riio-model/riio-t1-price-control

79 https://www.ofgem.gov.uk/network-regulation-\%E2\%80\%93-riio-model/riio-t1-price-control

${ }^{80}$ House of Commons (2015)

81 ibid p 13
} 

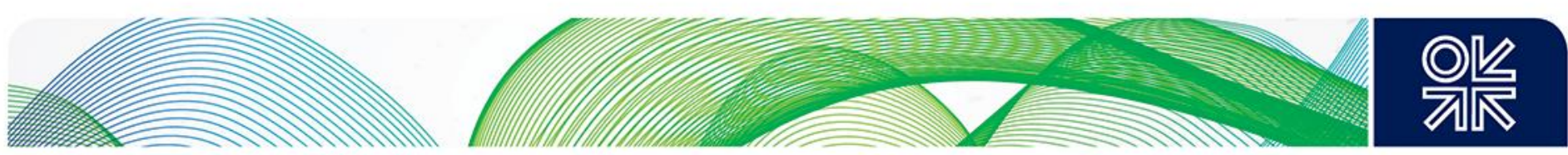

2015/16 onwards $^{82}$. In May 2015 the EU ETS price for carbon was around £5 per tonne so UK generators are paying an additional carbon tax of around £18/tonne.

- The Warm Homes discount scheme (which amounted to £291million in 2013/14) is collected by suppliers and provides a $£ 140$ annual discount to the electricity bills of qualifying consumers.

- ECO places legal obligations on large energy suppliers (greater than 250,000 customer accounts) to deliver energy efficiency measures to residential energy users. ECO payments totalled $£ 1,475$ million (2013 prices) for the period Jan 2013 - March 2014 and will amount to $£ 745$ million annually thereafter. ${ }^{83}$

It should be noted that DECC claim that these polices have saved consumers money in some cases (i.e. compared with the cost of alternative policies) and bills are $6 \%$ lower than they would have been without them.

Industrial consumers also pay the renewables levy as well as payments under the Carbon Price Floor, Climate Change Levy (CCL) and CRC Energy Efficiency Scheme ${ }^{84}$. CCL and CRC amounts paid by commercial and industrial users vary considerably depending on discounts linked to Climate Change Agreements (CCA) or payments linked to the EU Emissions Trading Scheme (ETS) which will apply to large users. However it should be noted that exemption allowances covered by the EU ETS are largely free and the impact on costs has to date not been significant. ${ }^{85}$

The 2014 Committee on Climate Change report on the impact of meeting carbon budgets on energy prices estimates that most of the burden falls on electricity rather than gas prices and accounted for $16 \%$ of electricity prices in the residential sector and $22 \%$ in industry in 2014.86 The CCC estimate that by 2030 these proportions could increase to $33 \%$ and $49 \%$ respectively. A comparison between payments is made in Table 2.

Table 2: Policy cost element of energy prices in 2013

\begin{tabular}{|l|l|l|l|l|}
\hline \multirow{2}{*}{ Additional cost in $\mathrm{p} / \mathrm{kw}$} & \multicolumn{2}{|l|}{ Residential } & \multicolumn{2}{l|}{ Industrial (average user) } \\
\cline { 2 - 5 } & Gas & Electricity & Gas & Electricity \\
\hline Low carbon generation & - & 1.1 & - & 1.1 \\
\hline Carbon Price & - & 0.4 & - & 0.4 \\
\hline ECO & 0.2 & 0.6 & & \\
\hline Smart meters & 0.02 & 0.02 & & \\
\hline Warm home & 0.0 & 0.2 & & 0.4 \\
\hline CRC \& CCL & & & 0.11 & 1.9 \\
\hline Total & 0.26 & 2.32 & 0.11 & 23 \\
\hline As \% of total cost & 5 & 15 & 4 & \\
\hline
\end{tabular}

Source: CCC (2014)

\footnotetext{
${ }^{82}$ https://www.gov.uk/government/uploads/system/uploads/attachment_data/file/293849/TIIN_6002_7047_carbon_price_floor_a nd_other_technical_amendments.pdf

${ }^{83} \overline{D E C C}(2014 d)$

${ }^{84}$ Previously known as the Carbon Reduction Commitment

${ }^{85}$ CCC (2014).

${ }^{86}$ CCC (2014)
} 

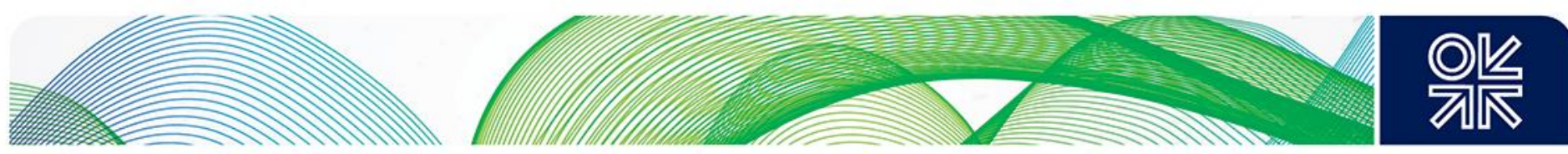

\subsubsection{Suppliers' costs and margins}

The level of profitability of the energy suppliers is also a source of significant political attention and there is evidence of increased profitability in recent years. CMA analysis ${ }^{87}$ shows that total pre-tax and interest earnings (EBIT) for gas and electricity grew from $£ 0.5$ billion in the 2007 financial year to $£ 1.6$ billion in the financial years 2012 and 2013. EBIT margins for residential gas for these years grew from $-4.1 \%$ to $6.7 \%$ and $4.3 \%$ respectively. There is significant variation between margins in the residential and SME sectors as shown in Table 3.

Table 3 Residential and SME gas EBIT margins (\%) for the Big 6

\begin{tabular}{|l|l|l|l|l|l|l|l|}
\hline & $F Y 07$ & $F Y 08$ & $F Y 09$ & $F Y 10$ & $F Y 11$ & $F Y 12$ & $F Y 13$ \\
\hline $\begin{array}{l}\text { Residential } \\
\text { gas }\end{array}$ & -4.1 & -3.1 & -0.1 & 6.1 & 4.6 & 6.7 & 4.3 \\
\hline SME gas & n/a & n/a & 6.5 & 14.4 & 7.7 & 10.8 & 10.9 \\
\hline
\end{tabular}

Source: CMA 2015e Tables 4 and 5

Whilst it might appear from Table 3 that claims of excess supplier profits are overstated it is also the case that the 2014 ACER report says that GB supplier margins (referred to as mark-ups) are amongst the highest in Europe.

Another concern is that under current conditions suppliers are not reducing costs and improving efficiency as quickly as they might. Various studies (Ofgem 2008, IPPR 2012) have concluded that supplier operating costs were not being driven down by competition and there was significant variation in costs between participants. The CMA (2015e) has calculated that unit annual indirect costs (all consumers) had fallen from £83 to £75 over the 7 year period to 2014 though there was considerable variation between companies.

\subsubsection{Retail market functionality}

Concern over prices, standards of service and the impact on vulnerable customers have coalesced to raise questions over the effectiveness of the existing gas and electricity retail market. One particular concern was that the multiplicity of tariffs and charges was confusing customers and impacting particularly harshly on those in fuel poverty ${ }^{88}$.

In response to these concerns Ofgem introduced a Standard Licence Condition on suppliers (SLC $25 A^{89}$ ) in 2009 prohibiting unfair price discrimination, including regional price discrimination. Both Littlechild et al90 and Yarrow ${ }^{91}$ have criticised this move as restricting competition to the detriment of customers whilst increasing supplier profits. Some suppliers have also stated that as a result of these restrictions they have been prevented from offering advantageous terms to vulnerable customers. ${ }^{92}$ This condition lapsed in $2012^{93}$ though CMA (2015a) note that in practice the restrictions remain in place.

In 2013 Ofgem introduced further retail market reforms (Ofgem 2013) that included requirements for suppliers to restrict their offerings to four core tariffs and to develop a single tariff structure comprising a unit rate and a standing charge (though this could be zero). Suppliers were only allowed to offer two cash discounts to customers - one for opting for online billing and one for dual fuel accounts.

\footnotetext{
${ }^{87}$ CMA (2015e)

${ }^{88}$ Households in fuel poverty are those with energy costs that if incurred would leave a residual income below the poverty line. Over $10 \%$ of households were in this category in 2012. (DECC 2014a)

${ }^{89}$ See https://www.ofgem.gov.uk/sites/default/files/docs/2009/10/implementation-of-the-energy-supply-probe-retail-markets.pdf

${ }^{90}$ Littlechild et al (2015)

91 Yarror (2014)

${ }^{92}$ CMA (2015c).

${ }^{93} \mathrm{https}: / /$ www.ofgem.gov.uk/ofgem-publications/74952/decision-standard-condition-25a-gas-and-electricity-supply-licences.pdf
} 

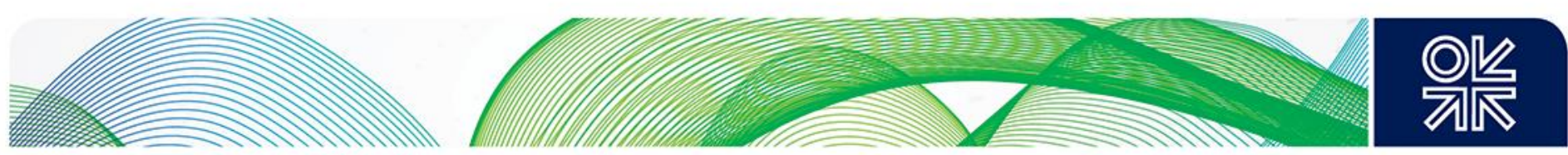

We have seen how the components of retail payments have evolved over recent years and the impact on household bills of these increases is shown in Figure 14. The average gas bill of $£ 685$ in 2013 quoted in this graph compares with a typical electricity bill of $£ 455$.

Figure 14: Change in typical residential gas bill (2004 to 2013)

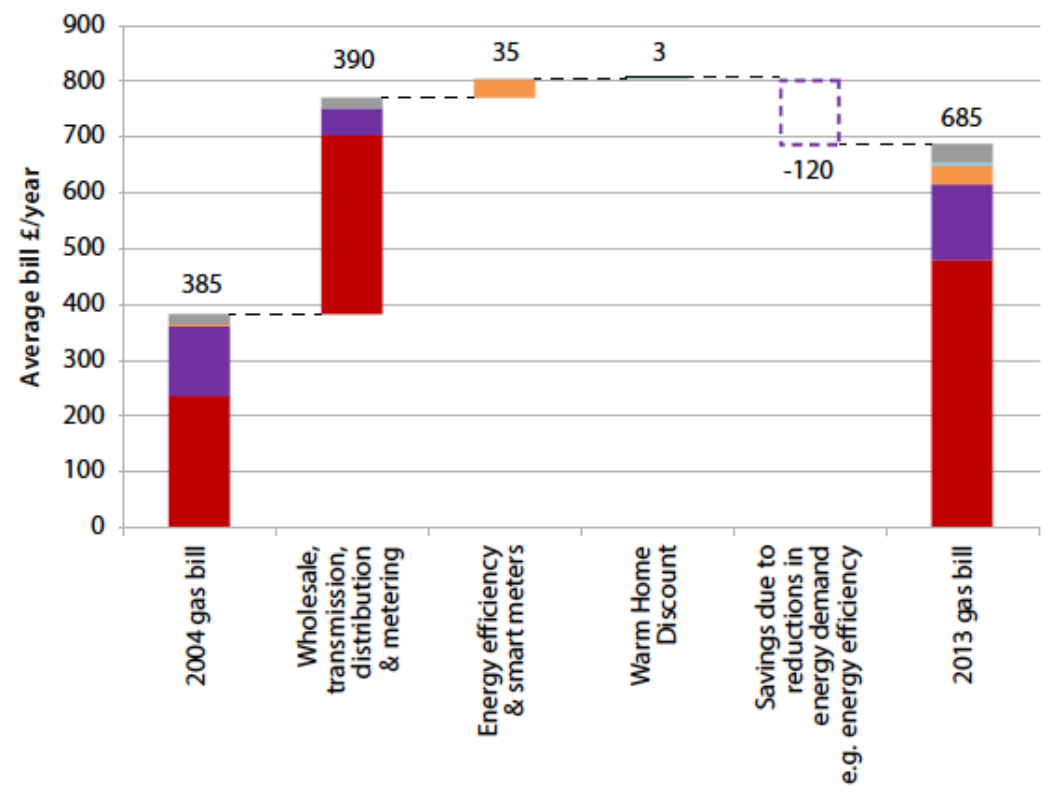

\author{
L-. Savings due to \\ reductions in energy \\ demand e.g. energy \\ efficiency \\ VAT \\ Warm Home Discount \\ Energy efficiency \\ measures \\ Transmission, \\ distribution \& metering \\ Wholesale energy + \\ supplier costs \& margins
}

Source: CCC (2014)

It is clear from Figure 14 that rising wholesale prices are the largest element in increased gas bills. We saw from Figure 11 how NBP prices moved over the period and how these compare with average residential gas prices. There was undoubtedly strong upward pressure on wholesale prices and, as Yarrow (2014) points out, periods of strong upward cost pressure lead certain sections of the public, the media and politicians to ask 'who is to blame and what is to be done about it?' This issue becomes even more pressing when wholesale prices remain static or start to fall and this change is not reflected immediately in prices to consumers.

This relationship between wholesale and retail gas prices is an area which politicians and policy makers either fail to comprehend (or do not wish to) and is inherently difficult to explain to residential end-users. The big 6 energy suppliers, with contracts to supply gas to customers, must manage the risk of price volatility in their supply portfolio in order to achieve a positive margin. This translates into buying gas on the traded market forward curve using a number of different traded contracts for future periods, including years, seasons, months, and days. As time passes the big 6 companies add to th

If they were relying on 'prompt' pricing, they would be significantly exposed if the prompt market price rose significantly above the price level that residential tariff rates had been designed around. On any specific day, the cost of acquiring gas for a big 6 player is the net of tens or possibly hundreds of individual trades, some of which were placed more than a year in the past. It is therefore simplistic and incorrect to assume that their gas acquisition cost is equal to the NBP prompt (day ahead) price. This is illustrated in Figure 15 which shows the relationship between prompt and various forward prices from January 2014 to March 2015. As would be expected, disquiet over prices is most acute during periods when prompt prices exhibit a sustained downward shift from the prevailing level as shown in this graph. 

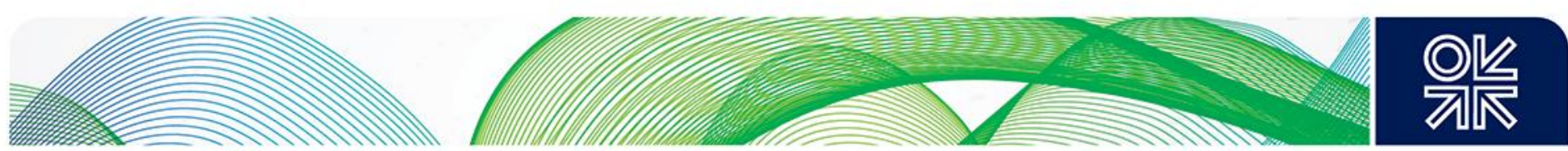

Figure 15: NBP prompt and forward prices January 2014 to March 2015

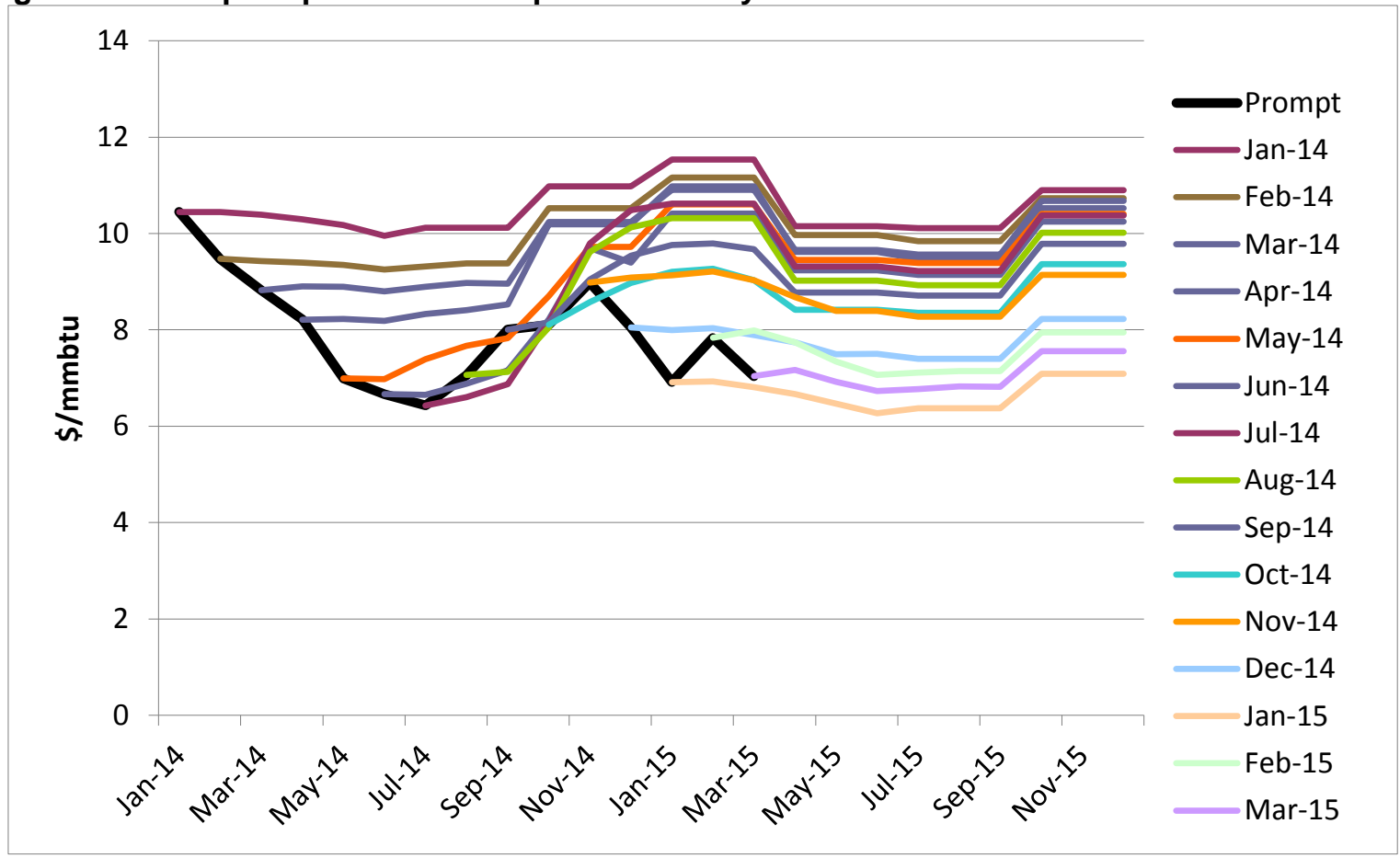

Source: H Rogers and Petroleum Argus

The misunderstanding of this dynamic is arguably the basis upon which much criticism of the big 6 is based. The challenge, which these players have to date failed to overcome, is how to explain these mechanisms to politicians and the general public - particularly in the face of falling wholesale prices. Having lost the benefit of the doubt the major suppliers may also find that explanations will no longer be enough and more concrete measures may be required.

Furthermore Yarrow (2014) suggests Ofgem in 2008 apparently decided to abandon its independent regulatory role and seek to blame suppliers and the market, though at the time Ofgem did not seek a Competition Commission reference and decided instead on the 2009 reforms described above.

However, increasing prices coupled with continuing concerns over a perceived lack of choice and poor service in the competitive energy market has kept the issue of retail energy prices at the forefront of public concerns and emerged as an issue before the 2015 general election. The most notable example was a manifesto promise from Labour to freeze energy prices to 2017 while reforming "the broken energy market ${ }^{94 "}$ "were they to win the 2015 election. Ad hoc intervention was also evidenced by a tweet from Chancellor George Osborne warning energy companies to make sure they pass on any reduction in fuel costs to customers ${ }^{95}$. In response Energy Secretary Ed Davey noted that criticism of energy companies "damages markets, investment and our economy". Davey confirmed his view that competition is the key to driving down energy prices and the importance of the CMA enquiry.

\footnotetext{
${ }^{94} \mathrm{http}: / /$ www.labour.org.uk/page/-/BritainCanBeBetter-TheLabourPartyManifesto2015.pdf page 10

$95 \mathrm{http} / / /$ blogs.platts.com/2015/01/08/uk-utilities-fuelcosts/?WT.mc_id=EnergyBulletin_AllCommodity_Campaign_010815\&WT.tsrc=Eloqua
} 

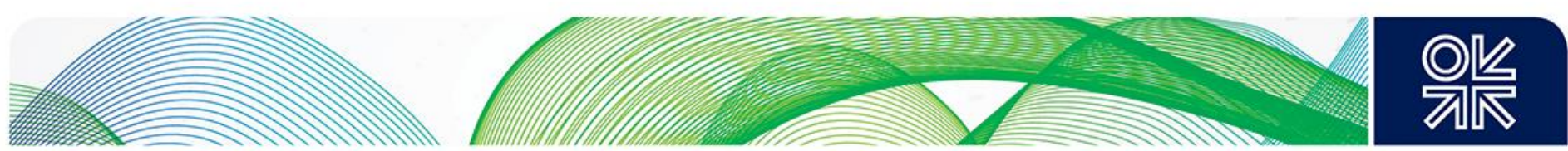

On the regulatory front Ofgem undertook a further market review in $2012^{96}$ and concluded that there are a range of factors preventing effective competition and so contributing to higher prices. These factors were:

- Low levels of activity (e.g. switching) by energy consumers - over $60 \%$ do not recollect ever switching suppliers;

- The big 6 suppliers were charging higher prices to less active consumers and possibly tacitly colluding with each other;

- Vertical integration;

- Barriers to entry.

Ofgem issued a further assessment in March $2014^{97}$ and referred the matter to the Competition and Markets Authority 98 in June 2014. The CMA is due to report by the end of 2015 and produced an interim report in February 2015 which highlighted the following: ${ }^{99}$

- Customers who had failed to switch suppliers were paying on average between £158 and £234 per annum extra;

- Customer complaints continue to increase;

- The CMA had amended their theories of harm ${ }^{100}$ to focus primarily on electricity market issues.

- The broader regulatory framework, including the current system of code governance, acts as a barrier to pro-competitive innovation and change. In particular code governance may be working against new entrants.

- The CMA's initial view that the wholesale gas market was functioning effectively and liquidity and transparency was sufficient was confirmed. The CMA commented specifically on the position of Statoil as "...the one company that might have the ability to raise wholesale prices by withholding output in an exceptionally cold winter". The Authority has concluded that Statoil is unlikely to have the incentive to sustain the output reductions required to raise prices and that the wholesale gas market is unlikely to be at risk.

- Historical incumbency still appears to have an effect on customer behaviour today. For example about $40 \%$ of Centrica's residential gas customers have been served by the company for more than ten years.

- The authority felt that retail market reform and SLC 25A (see above in section 3.6.1.5) may not have worked in the best interests of consumers and might have restricted innovation - though they had not reached a conclusion on this. One small supplier, Utilita, for example claimed that simplification of tariff arrangements meant that its offering that had no standing charge became illegal.

- The authority also highlights the fact that environmental costs fall disproportionately on electricity rather than gas consumption. As a result the residential consumption of electricity attracts a much higher implicit carbon price than the residential consumption of gas. The CMA will examine the implications of this for competition and the viability of electrical heating systems as an alternative to gas.

\footnotetext{
${ }^{96}$ Ofgem (2012c)

97 Ofgem (2014a)

98 The CMA superseded the Competition Commission in April 2014

${ }^{99}$ CMA (2015a)

100 'Theories of harm' are suggested by the CMA as explanations as to how certain market characteristics may be adversely affecting competition and leading to possible adverse outcomes.
} 

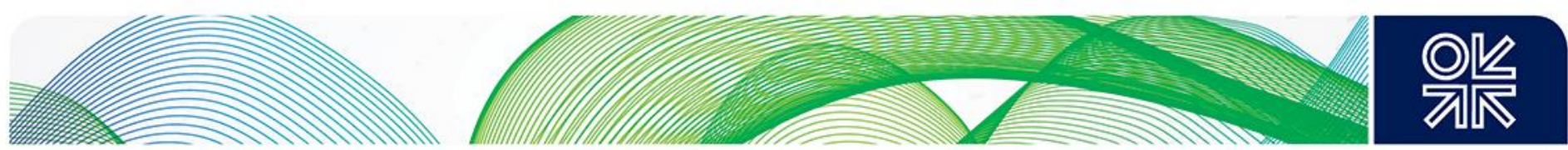

Ahead of the final CMA report the Government has already claimed some success in encouraging new suppliers to enter the market. In October 2014 it reported that there were 19 independent suppliers in the residential retail energy market who together had grown their market share more than ten-fold ${ }^{101}$

Nevertheless there is a body of opinion that remains less convinced that retail market competition will ever be particularly effective - particularly given the homogenous nature of the product. For example Helm (2015) argues that consumer switching has costs as well as benefits to consumers and that there is no opportunity to differentiate between competing products ${ }^{102}$. Since all gas is priced at the NBP consumers are in effect being offered a choice between alternative hedging and margin optimisation strategies and overall differences in the long run are likely to be marginal.

On the other hand with the likelihood of a sustained period of global gas oversupply emerging there could be a move towards sustained lower prices. It could be argued that shifts to lower prices in these conditions are more likely to occur in a market with more rather than fewer players. Lower prices may also remove some of the political heat from the sector and overall it is probably too early to sound the death knell for retail competition in the UK gas sector. It is also probably unrealistic to expect a major increase in competitiveness.

\subsubsection{Environmental and social aspects}

The Government's main environmental and social energy goals were set out in the 2008 Climate Change Act and various pieces of EU legislation. The Act established a legally binding framework to:

- Increase renewable energy levels to $15 \%$ of total UK final energy consumption by 2020 ;

- Reduce greenhouse gas emissions by at least $34 \%$ by 2020 and $80 \%$ by 2050 - both measured from the 1990 baseline. This was to be achieved through a series of 5-year carbon budgets starting in 2008 and these have been enshrined in law for the first 4 carbon budgets (i.e. to 2028) to achieve reductions in emissions in each budget period (relative to 1990 levels) of $23 \%, 29 \%$, $35 \%$ and $50 \%$ respectively. In February 2015 the leaders of the three main parties in Parliament at that time pledged to work together to continue to agree carbon budgets and to end the use of unabated coal for electricity generation; ${ }^{103}$

- Contribute to a $20 \%$ reduction in EU energy consumption by 2020;

- Eliminate fuel poverty as far as reasonably practicable among households in England, Scotland and Northern Ireland by 2016 and in Wales by 2018.

Whilst the implementation of legally binding targets and carbon budgets are aimed at all energy use, much of the focus to date has been on decarbonising the electricity sector. This was to be achieved through the introduction of renewable sources of generation and nuclear power. As demonstrated below the cost of most forms of renewable energy is significantly above that of conventional fossil fuelled generation so the principle agent for incentivising renewables investment has been through various support regimes. These regimes include renewables obligation (RO) ${ }^{104}$, feed in tariffs and most recently Contracts for Difference ${ }^{105}$, which attempt to link support to prevailing market prices. As Table 4 demonstrates, spending under these schemes now exceeds $£ 3$ billion annually though overall commitments are now limited by the so-called Levy Control Framework (LCF) ${ }^{106}$.

\footnotetext{
${ }^{101}$ DECC (2014d).

$102 \mathrm{Helm}$ is also critical of what he sees as the tardiness of suppliers in reducing their standard variable tariff

${ }^{103}$ http://www.green-alliance.org.uk/resources/Leaders Joint Climate Change Agreement.pdf

104 Note that in June 2015 the Government announced it would close the renewables obligation to new onshore wind from 1st April 2016 https://www.gov.uk/government/news/changes-to-onshore-wind-subsidies-protect-investment-and-get-the-best-dealfor-bill-payers

${ }^{105}$ For details see Keay at al (2012)

106 The LCF limits total spending on RO, FIT Warm Homes Discount and CfDs but not Capacity Payments
} 

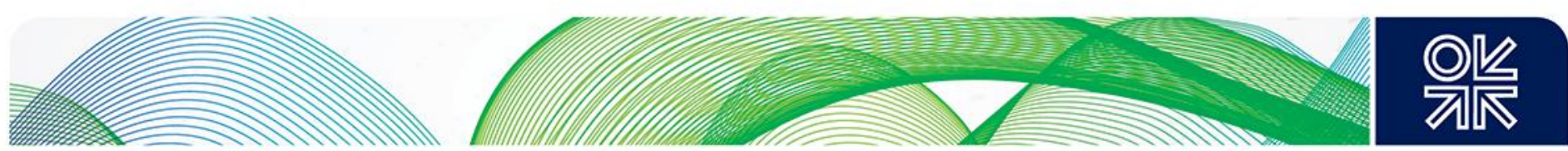

Table 4: Annual spend and outcome for renewable support

\begin{tabular}{|l|l|l|l|l|}
\hline & $2011 / 12$ & $2012 / 13$ & $2013 / 14$ & $2014 / 15$ \\
\hline RO spend (£m) & 1,460 & 1,895 & 2,395 & 2,795 \\
\hline GW Installed & 11.6 & 14.0 & 15.9 & 18.1 \\
\hline TWh Produced & 30.7 & 35.5 & 48.0 & 52.4 \\
\hline \hline FIT Scheme & & & & \\
\hline spend (£m) & 150 & 480 & 590 & 700 \\
\hline GW Installed & 1.1 & 1.8 & 2.7 & 3.6 \\
\hline TWh Produced & 0.5 & 1.7 & 2.6 & 3.6 \\
\hline \hline $\begin{array}{l}\text { Supported renewables } \\
\text { as \% of total } \\
\text { generation }\end{array}$ & 8.6 & 10.2 & 14.4 & 15.3 \\
\hline $\begin{array}{l}\text { Total spend (£m } \\
\text { 2011/12 prices) }\end{array}$ & 1,610 & 2,375 & 2,985 & 3,495 \\
\hline \hline
\end{tabular}

Source: DECC $2014 \mathrm{i}$

The LCF limits increase from $£ 3,300 \mathrm{~m}$ in $2013 / 14$ to $£ 7,600 \mathrm{~m}$ in $2020 / 21$. Poyry forecast that total support costs for low carbon generation could exceed $£ 13$ billion (2012 money) annually, though cost per MWh will gradually fall over time. ${ }^{107}$ The increase in LCF limits reflects the expansion of scope to include the cost of Contracts for Difference which will replace the Renewables Obligation (this is discussed further in 4.3.6). These contracts will include new nuclear build, the first of which is the Hinkley Point C plant. Frontier Economics estimate that this project alone could add a further $£ 1$ billion annually to the LCF budget ${ }^{108}$.

Other elements of environmental legislation with specific impact on the energy - again primarily electricity - sector are two EU directives covering large combustion plant and industrial emissions (see below) and a price floor for carbon. The Energy Act 2013 also gives the Secretary of State power to set a target for the carbon intensity $(\mathrm{Cl})$ of electricity generation. The $\mathrm{Cl}$ of electricity in 2012 was $\left.505 \mathrm{gCO}_{2} / \mathrm{kWh}^{109}\right)$. This was the highest level since 1996 and reflected the greater use of coal-fired generation. Comparative figures for coal and gas (CCGT) fired generation are $910 \mathrm{~g} / \mathrm{kWh}$ and 360 $\mathrm{g} / \mathrm{kWh}$ respectively ${ }^{110}$.

The government approach has been criticized in a number of areas with regard to its impact on the natural gas sector:

- By committing to a fixed percentage of renewables there is an apparent conflation of zero-carbon energy with renewable energy. This could tend to rule out technologies such as carbon capture and storage (CCS) which could in time be competitive with options such as offshore wind.

- The cost of a specific form of renewable energy fails to properly include the cost of back up required to deal with problems of intermittency and all of the required additional infrastructure hook-up costs.

\footnotetext{
107 Poyry (2013).

108 http://www.frontier-economics.com/documents/2015/03/lcp-frontier-economics-next-uk-auctions-renewable-contractsdifference.pdf

109 DECC (2014d)

${ }^{110}$ see http://www.reuk.co.uk/Real-Time-Carbon-Website.htm
} 

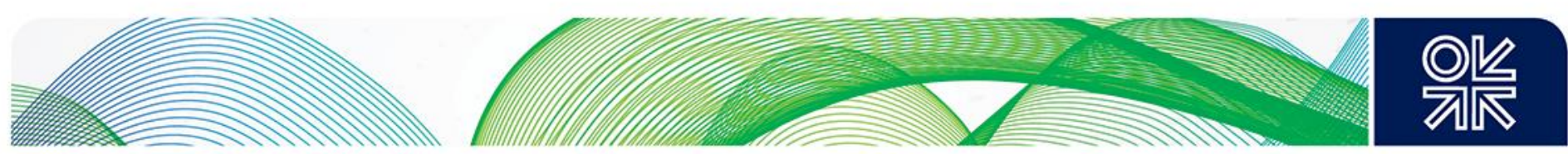

- By failing to distinguish adequately between fossil fuels the environmental advantages of gas over coal have not been recognized - as a result higher gas prices meant that the coal-fired generation share grew from $28 \%$ to $35 \%$ from 2010 to 2013 . The share of gas-fired generation fell from $47 \%$ to $27 \%$ over the same period ${ }^{111}$. There is, however, some evidence that the carbon price floor, which increased in April 2015 and in effect taxes generators according to the level of their carbon intensity, is starting to encourage a switch away from coal in favour of gas ${ }^{112}$.

- There is too much focus on de-carbonising electricity. Whilst Government documents habitually make reference to energy efficiency and the decarbonisation of the heat and transport sectors the latter two have received much less attention.

- The focus on 2050, which implies for example the full decarbonisation of electricity and heat supply by this time, puts the UK in an unnecessarily uncertain and costly position as there is no EU agreement beyond 2030 let alone a global commitment along these lines.

We return to these issues in the following chapter.

\subsubsection{Security of Supply}

As already noted, the decline in UKCS gas production gave rise to a growing import dependency. Whilst a number of new import projects from a range of sources have materialised over the past decade the public perception has grown that the UK gas supply is increasingly exposed to disruption ${ }^{113}$.

A more localised security issue arises from the growing proportion of renewable electricity and the problems that intermittency can cause. The consensus view is that gas-fired generation is the most appropriate form of back-up though as we will see in the next chapter new investments for this purpose may be difficult to justify.

An earlier OIES paper ${ }^{114}$ has looked in detail at the evolution of government policy with regard to security of supply which began with the establishment of the Joint Energy Security of Supply Working Group (JESS) in 2002. This was followed by a regular series of reports and reviews that oscillated between concern and confidence regarding effectiveness of the prevailing arrangements.

More recently the Government started to publish an Annual Energy Statement ${ }^{115}$ that includes an assessment of supply security. In 2012 it also published a Gas Generation Strategy ${ }^{116}$ to address inter alia the issue of providing certainty for investors in gas generation through, for example, legislating for a capacity market in electricity. The generation strategy also noted the potential case for intervention to encourage additional gas storage.

The gas storage issue was also considered at length by Ofgem in $2012^{117}$ though no firm conclusions were reached. Ofgem did note that whilst large scale interruption was very unlikely it was difficult to insulate the GB market from price spikes. It felt however that these spikes could play an important role in attracting gas supply and incentivising gas storage investment.

In September 2013 DECC released its considered view on the case for intervention in the storage sector ${ }^{118}$. The report noted that a recent report commissioned from Redpoint ${ }^{119}$ showed that the cost

\footnotetext{
${ }^{111} \operatorname{DECC}(2014 \mathrm{e})$

112 See http://www.timera-energy.com/gas-plant-competiveness-is-increasing/

${ }^{113}$ For a recent example see "UK gas supplies 'relying on luck', former energy minister Charles Hendry warns" in the Daily Telegraph, 4 January 2015 http://www.telegraph.co.uk/finance/newsbysector/energy/11324543/UK-gas-supplies-relying-on luck-former-energy-minister-Charles-Hendry-warns.html

114 LeFevre (2013)

115 DECC $2012 b$

116 DECC 2012d

117 Ofgem (2012a and 2012b)

118 DECC (2013e)

${ }^{119}$ Redpoint (2013)
} 

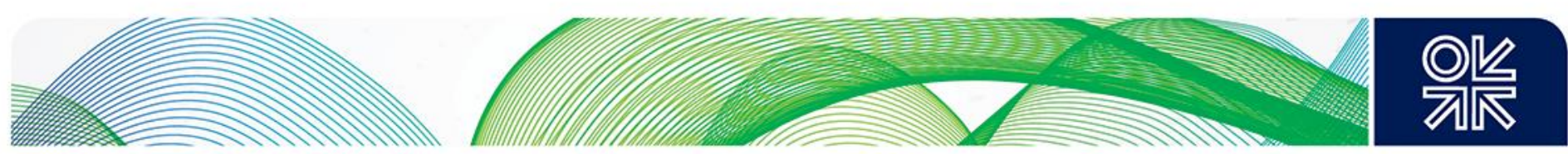

of intervention outweighed the security of supply benefits and that "...Government and consumers would be subsidising investment that large energy companies could pay for themselves". DECC considered that reforms to the cash out procedure, additional capacity contracts and a more effective European gas market would all provide additional support to security of supply and that it was quite likely in addition that new storage would be built with the right market signal.

In its latest statement on the issue ${ }^{120}$ the government defines energy security as "ensuring that consumers have access to the energy services they need at prices that avoid excessive volatility" whilst noting that government strategy is based on competitive energy markets combined with effective regulation to deliver diversity of supply and robust infrastructure for consumers. The report notes that import capacity is nearly double annual gas demand though it recognises the importance of developing new oil and gas fields on the UKCS before existing infrastructure is decommissioned. The importance of shale gas as a potential contributor to energy security is also recognised.

DECC also points to a number of other factors helping to address the supply security challenge:

- Improved EU energy security through implementation of the Third Energy Package (TEP) and projects of common interest (see Yafimava (2013) for details);

- Increased energy efficiency to reduce overall demand;

- Implementation of code changes ${ }^{121}$ which are expected to incentivise gas suppliers to improve the reliability of their suppliers which could also result in infrastructure resilience improvements (See Ofgem (2014b) for details);

- The development of a demand side response mechanism for gas that would compensate large daily metered customers in return for reducing their gas demand

Finally DECC emphasise the importance of investing in the maintenance and reliability of the gas transmission and distribution network noting that for the current RIIO price control period (1 April 2013 to 31 March 2021) Ofgem have agreed $£ 14.4$ billion and $£ 5.5$ billion capital expenditure on the gas distribution and transmission networks respectively.

It is clear that government attitudes to and definitions of energy security have changed significantly over time and the pendulum swings regularly between the temptation to intervene and professed belief in a market based solution. The present resistance to excess price volatility does not sit well with a reliance on competitive energy markets and the case for further action in the area is considered in Chapter 4.

An important feature of government energy policy is how the regulatory framework operates to deliver these objectives. This is considered in section 3.7.

\subsection{Regulation in practice}

In addition to being at the forefront of gas market liberalisation, the UK can also claim to have led in the development of gas market regulation. The Office of Gas Regulation (Ofgas) was created at the privatization of British Gas in 1986 though since then both the office and its remit have undergone a number of transformations.

In its early days the Ofgas remit was focused on holding down prices and improving efficiency of networks. Over time this expanded into increasing the level of competition in gas supply and introducing contestability into areas such as metering and connections. As supply competition grew the regulator progressively reduced direct price control of suppliers.

\footnotetext{
${ }^{120}$ DECC (2014d)

${ }^{121}$ This was known as the Gas Security of Supply Significant Code Review (SCR)
} 

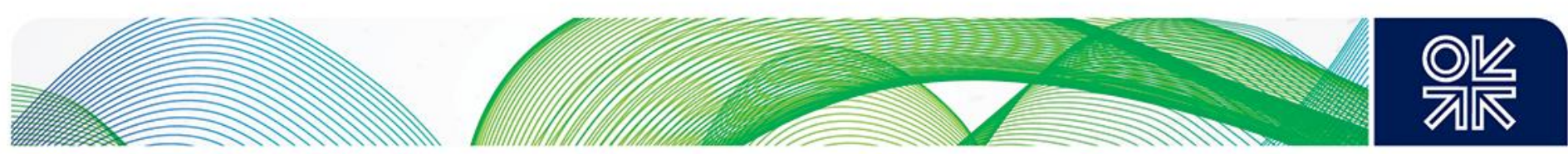

In 1999 Ofgas was merged with the then electricity regulator to form a single energy regulatory authority, the Gas and Electricity Markets Authority (GEMA) with its Office (Ofgem). The merger was designed to introduce an integrated approach to regulating the gas and electricity markets. It is important to remember that whilst Ofgem's remit includes electricity generation it does not extend to upstream gas which is still within the province of DECC though, as noted below, this system is due to change.

As the role of the regulator grew there was a concern that the remit was insufficiently clear and too much at risk of being developed by the whims and interests of the individual charged with running the Office. This led to the establishment of the roles of Chairman and Chief Executive as part of a board with independent directors.

An important principle of regulation is that Ofgem is accountable to Parliament and not government and its regulatory functions are set out in the 1986 Gas Act ${ }^{122}$. These functions are:

- To protect the interests of existing and future consumers - whether by promoting effective competition or other means. These are interests as a whole so include reduction of GHGs and ensuring energy security;

- It must ensure all reasonable demand for gas and electricity are met and;

- That licensees can finance their activities;

- Protection of vulnerable consumers (i.e. disabled, chronically sick, pensionable, low incomes or rural dwellers).

Today the means of regulating the sector is principally through:

- The licensing regime for shippers, suppliers, transporters and other energy businesses which Ofgem administers (in gas these include interconnectors);

- Price control of monopoly areas such as transmission and distribution;

- Supervision, where appropriate, industry codes such as the Network code, Supply Point Administration Agreements (SPAA) and terms for connection to the network.

A further concern from Government when Ofgem was being established was that hitherto the regulator had failed to take sufficient account of environmental and social issues (e.g. fuel poverty). Since 2000 Ofgem has had to have regard to Government guidance on these matters. The latest guidance, issued in $2010^{123}$, is primarily focused on the following areas:

- Access to electricity networks for renewable energy

- Fuel poverty.

Specific references to gas are primarily related to pricing and charging strategies of suppliers (including the charges for prepayment meters) improved resilience and environmental performance of networks and improving incentive mechanisms to encourage gas network extensions to help address fuel poverty.

In 2010-2011 there was a government review (DECC 2011a) of the regulatory framework. This concluded that whilst the arrangements had been largely successful in attracting new investment and providing good value for consumers, the expansion of the remit had complicated the regulatory framework and blurred responsibilities between the regulator and Government. This led to the requirement for a Strategy and Policy Statement (SPS) that would replace the Guidance approach. The Energy Act 2013 required that Ofgem must have regard to the SPS and set out its plans for implementing the SPS on an annual basis.

\footnotetext{
122 http://www.legislation.gov.uk/ukpga/1986/44

${ }^{123}$ DECC 2010 a
} 

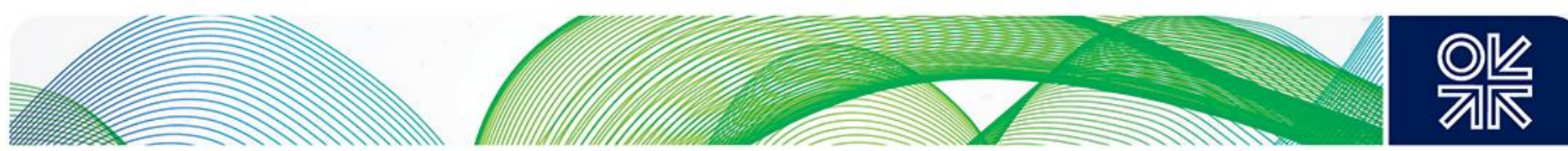

The draft SPS (DECC 2014g) states that the regulator is expected to achieve the following outcomes:

- A competitive energy market that comprises:

- Effective competition with low entry barriers

- Ability to compare prices and switch easily

- High levels of customer service

- Easy to understand energy bills

- Avoidance of disproportionate charges for vulnerable customers

- Low carbon energy delivered at least cost

- Incentives to ensure supply reliability

- Network infrastructure

- Planned and operated to take full account of existing and future needs

- Reliable, resilient and sustainable

- Easy and low cost to connect for both suppliers and consumers.

It is unsurprising that over the years a number of criticisms have been levelled at the regulator and the regulatory framework. The most significant issues from a gas perspective are:

- The separate regulatory regimes for downstream and upstream gas have created significant interface problems and made an integrated approach to security of supply harder.

- Many of the major objectives of regulation have been achieved - unbundling, retail competition etc - but the scope and costs of regulation have not reduced accordingly.

- Ofgem has allowed the requirement to meet statutory obligations regarding introducing contestability to outweigh any consumer benefit. Probably the most egregious example is the introduction of competition in metering which has arguably imposed additional costs and raised barriers to new entrants. It has also increased the cost and complexity of smart meter rollout according to one study by some £3 billion. ${ }^{124}$

- The CMA ${ }^{125}$ has noted that since 2008 Ofgem's interventions have been exceptional. Some have suggested that Ofgem had abandoned the principle of independent regulation and been too willing to point the finger of blame at energy suppliers for higher prices. ${ }^{126}$

- New entrants have claimed that the governance procedures surrounding codes is burdensome and favours existing large incumbents. Ofgem has introduced the concept of the Significant Code Review process which allows it to initiate reviews of complex cross-code and licence issues.

- The CMA interim report (2015a) suggests that frequent interventions by Ofgem, such as the prohibition of price discrimination may have also been damaging.

Perhaps in recognition of some of the above concerns Ofgem has recently launched a very public strategy consultation process. In many respects this was a restatement of the organisation's duties though a need for simplification and trust building was recognized.

\footnotetext{
${ }^{124}$ Frontier (2008)

${ }^{125}$ CMA 2015a

${ }^{126}$ Yarrow (2014)
} 

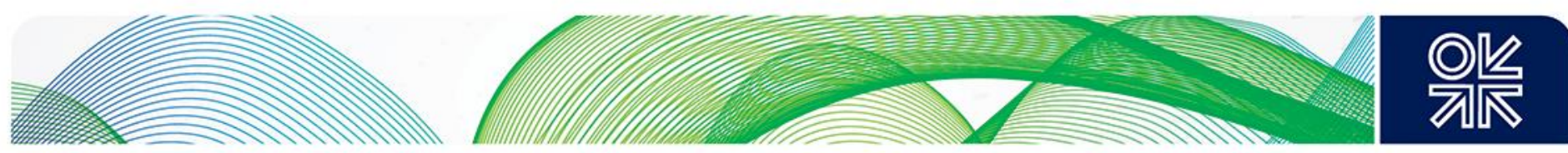

\subsection{The role of EU legislation}

Since 2009 the EU has had a shared competency with member states over energy policy ${ }^{127}$. As the UK market was at the forefront of European liberalization for many years the first two energy packages had very limited consequences for the UK. The Third Energy Package ${ }^{128}$ has required some changes to national legislation primarily related to consumer protection and the role of Ofgem as the National Regulatory Authority ${ }^{129}$.

The other main changes to bring the Uniform Network Code (UNC) into line with EU procedures include:

- A shift in the gas day to begin at 05:00 UK time from 1 October 2015 as opposed to 06:00. This makes the day the same as mainland Europe's gas market.

- Shippers with long-term capacity booked on British interconnectors will be subject to "use it or lose it" (UIOLI) rules.

- the splitting of the Bacton entry point between Interconnector and North Sea supply sources is also under consideration.

The EU has recently agreed on energy and climate change targets for 2030 comprising a $40 \%$ reduction in GHGs from the 1990 level and a 27\% (non-binding) target for renewables and for energy efficiency. Compared with the previous policy, the less prescriptive nature of the new targets together with the agreement to provide more funding for CCS suggests that there is room for the UK Government to be more open minded regarding the ultimate power generation mix. Indeed DECC has agreed in principle that CCS projects will be eligible for the prices guaranteed under the contacts for difference framework ${ }^{130}$.

\subsection{Conclusions on the UK gas market today}

At the end of the last chapter it was suggested that the increased inter-connection with global gas markets has probably been the single most important factor shaping the UK gas market today. This is most evident in the impact on prices, which are no longer determined by internal supply and demand fundamentals, but a range of wider global influences.

Concerns over rising prices - and to a lesser extent security of supply issues associated with growing import dependency - appear to have shaped much of the policy initiatives directed towards the gas sector though there is little evidence of a coherent narrative. Government might argue that there is an over-arching narrative aimed at solving the affordability/environment/security "trilemma" through a commitment to competitive markets wherever possible. However there is little evidence of a careful or consistent consideration of how gas might most effectively help in this regard.

Energy prices at the retail level have become a political issue and the regulator has arguably not helped in informing the debate. Indeed the view of the CMA is that Ofgem must take some responsibility for the present market shortcomings. The relationship between wholesale and retail gas prices and the impact of forward purchases on suppliers' costs has been widely ignored and this is an area where the regulator as well as suppliers could also be more proactive in informing the public and politicians. Despite continued dissatisfaction expressed by politicians and the public, the presence of six competing suppliers plus a growing number of new entrants would be seen as a major success by the standards of many large gas markets. Whether the market will remain sufficiently attractive to

\footnotetext{
127 Under Article 194.

128 See https://www.ofgem.gov.uk/gas/wholesale-market/european-market/eu-legislation for a summary

${ }^{129} \mathrm{https}: / /$ assets.digital.cabinet-office.gov.uk/media/54e755fced915d0cf700000b/Legal_and_regulatory_framework.pdf

130 See Green. A, "CCS - A vital part of future UK energy infrastructure" in Energy World, March 2015
} 

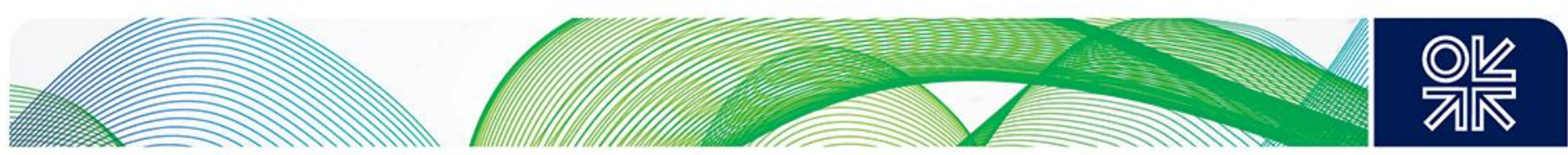

ensure such widespread participation in the future is open to question. Excessive intervention could precipitate the type of consolidation that is evident in sectors such as mobile telephony. Were this to occur in the UK retail energy sector it would present policy makers with a new set of challenges.

One important component of household energy bills is the cost of environmental policies though this is impacting primarily on electricity bills. Government has sought to introduce measures to reduce the cost of low carbon generation but these will continue to require significant government support. Furthermore by failing to distinguish adequately between fossil fuels, the environmental advantages of gas over coal have not been recognized - as a result higher gas prices meant that coal-fired generation has increased its share at the expense of gas.

Security of gas supply remains an important consideration though government attitudes to and definitions of security have changed significantly over time. Generally the temptation to intervene has been resisted in preference to market-based solutions. However, the desire expressed in October 2014 to limit excess price volatility does not sit well with a reliance on competitive energy markets.

The extent to which these conclusions could be shaped by the evolution of the demand and supply characteristics of the GB gas market are considered in the next two chapters.

\section{Outlook for the GB gas market and policy implications - demand}

\subsection{Introduction}

The previous chapter looked at the evolution of the GB gas market and the associated policy framework. This chapter looks to the future regarding demand - the following chapter considers key supply issues. The overall gas demand outlook is assessed and then the two key components demand for power generation and heating - are examined in detail in the context of potential policy developments. This is not to say that other elements of gas demand such as industrial process load or exports are unimportant, only that they will have less relevance from an overall policy perspective.

The chapter then looks at the major supply issues for the GB gas market. These are considered to be indigenous production and overall security of supply as these aspects have the most important implications from a policy perspective.

\subsection{Aggregate demand outlook}

As we have seen, growth in natural gas demand was at its strongest in the 1970s and early 1980s when the share in primary energy consumption grew from $5 \%$ in 1970 to $25 \%$ by 1990 . Overall the share continued to grow to over $40 \%$ by 2010 though it has since dropped back to $36 \%$ in 2013 . Further growth in demand was a feature of most forecasts up to the mid 2000s; since then forecasts have been ranged down.

OIES has undertaken an extensive review of gas demand forecast for Europe to $2030^{131}$ (Honore, 2014). The base case forecast for the UK is shown in figure 16. This forecast projects future demand remaining relatively constant at around $90 \mathrm{bcma}$, based on an anticipated revival in gas-fired power generation as more coal (and old nuclear plant) is retired, offset by efficiency measures in the other sectors.

\footnotetext{
${ }^{131}$ Honore (2014)
} 

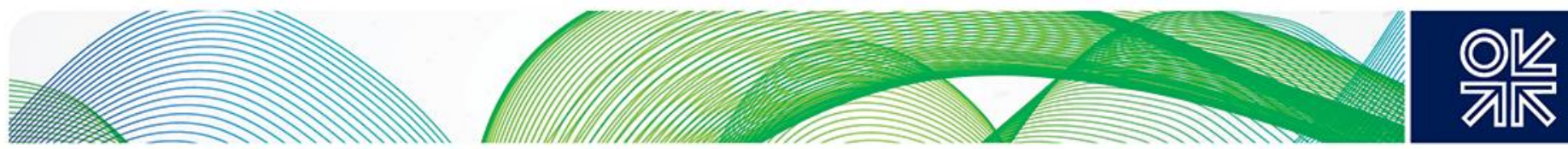

Figure 16: Forecast UK natural gas demand to 2030 (OIES), bcm

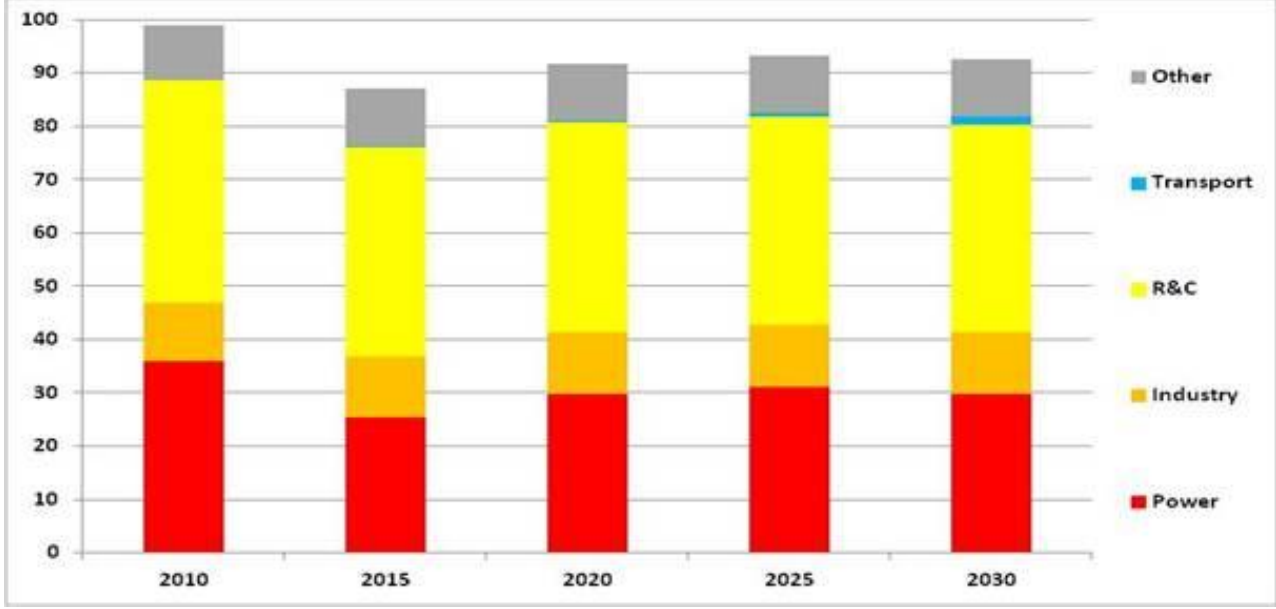

Source: Honore, 2014

National Grid have developed a suite of scenario-based forecasts of future gas demand in GB, which are published in the annual Ten Year Statement and Future Energy Scenarios documents. The latest projections are from December 2014 ${ }^{132}$. The scenario based approach has been developed to reflect the energy "trilemma" described in the previous chapter with particular reference to the potential trade-offs between affordability (i.e. the extent to which money is available) and the degree of emphasis on sustainability. There are four scenarios and they are summarized in figure 17.

Figure 17: National Grid Future Energy Scenarios

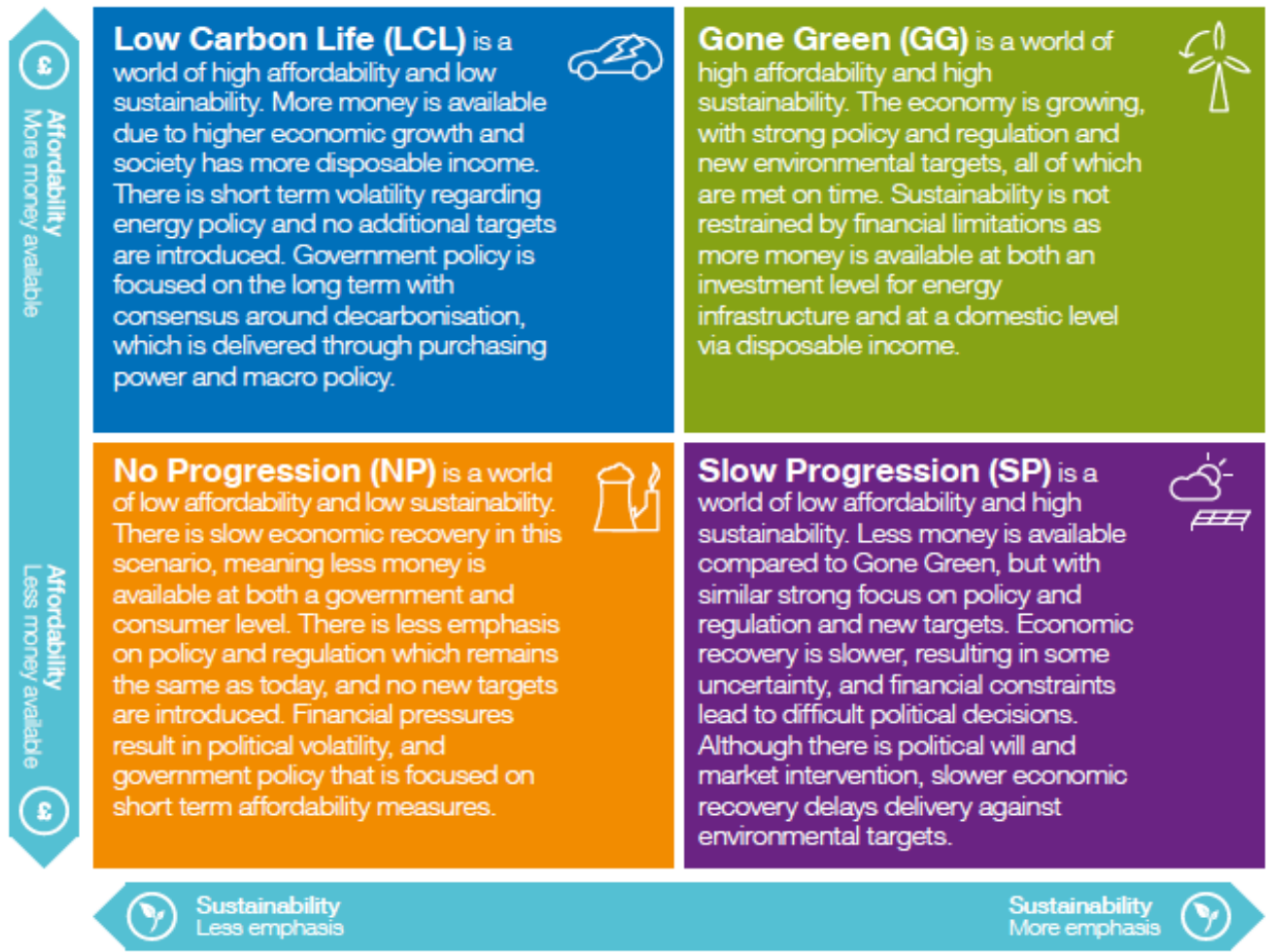

Source: National Grid (2014a)

\footnotetext{
${ }^{132}$ National Grid (2014a and 2014b)
} 

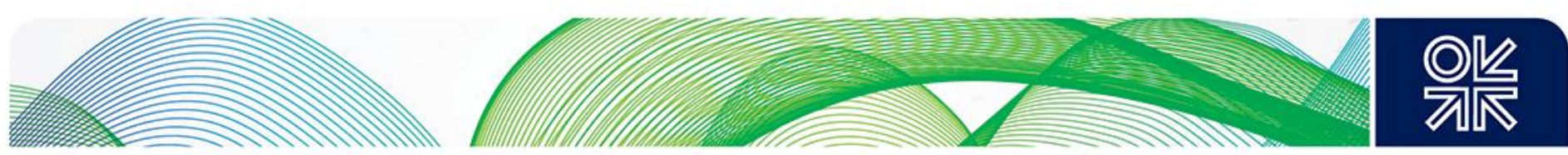

The gas demand forecasts for the four scenarios are shown in figure 18. It can be seen that the two low sustainability scenarios - i.e. No Progression and Low Carbon Life generate forecasts that are some $10 \%$ below those projected by Honore. Slow progression and Gone Green both forecast more sharply declining demand.

Figure 18: Forecast GB natural gas demand to 2035 (excluding exports)

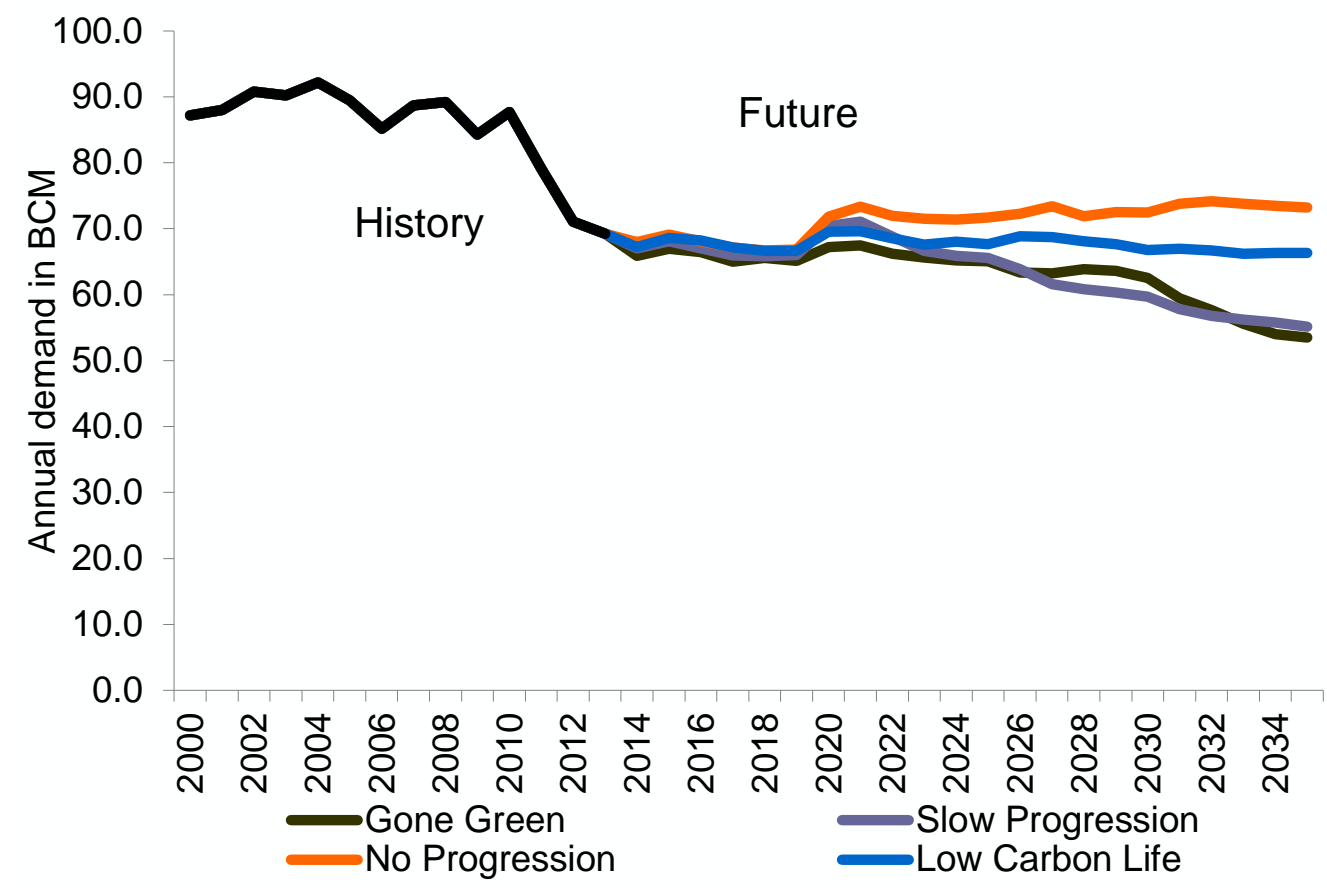

Source: National Grid (2014b)

The overall impact on critical demand characteristics for gas to 2034 under each of the scenarios is shown in table 5.

Table 5: Demand outlook in comparison to 2012 levels

\begin{tabular}{|l|l|l|l|l|l|l|}
\hline Scenario & Aggregate & \multicolumn{3}{|l|}{ Sectoral demand changes by 2020 } & Peak \\
\cline { 3 - 7 } & demand & Power & Residential & I\&C & Exports & demand \\
\hline $\begin{array}{l}\text { No } \\
\text { progression }\end{array}$ & Broadly flat & $+57 \%$ & $-4 \%$ & $-12 \%$ & $-30 \%$ & Stable \\
\hline $\begin{array}{l}\text { Slow } \\
\text { progression }\end{array}$ & $\begin{array}{l}\text { Declining } \\
\text { post 2020 }\end{array}$ & $+51 \%$ & $-5 \%$ & $-9 \%$ & $-21 \%$ & $\begin{array}{l}\text { Falling post } \\
2020\end{array}$ \\
\hline Gone Green & $\begin{array}{l}\text { Declining } \\
\text { post 2030 }\end{array}$ & $+34 \%$ & $-6 \%$ & $-3 \%$ & $+7 \%$ & $\begin{array}{l}\text { Falling post } \\
2020\end{array}$ \\
\hline $\begin{array}{l}\text { Low Carbon } \\
\text { Life }\end{array}$ & Broadly flat & $+38 \%$ & $-5 \%$ & $-5 \%$ & $-16 \%$ & Stable \\
\hline
\end{tabular}

Source: National Grid (2014a)

It should be noted that all scenarios project an increase in gas demand for power generation. The range in sectoral forecasts reflects:

- For power generation demand alternative electricity demand scenarios and mix of generation technology. 

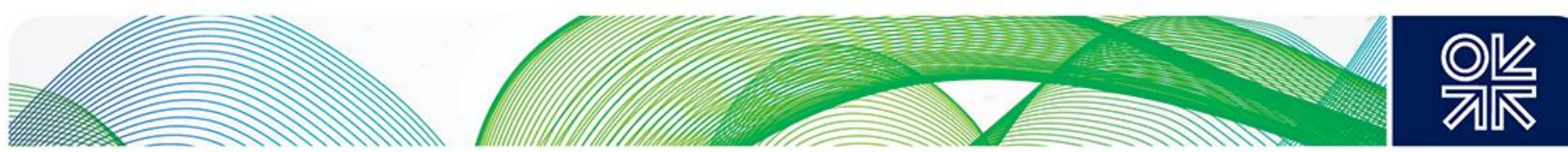

- For residential demand forecasts of alternative housing and boiler energy efficiency assumptions.

- For industrial and commercial (I\&C) demand forecasts of alternative economic growth and energy efficiency assumptions.

- For export forecasts differing levels of demand growth in Ireland ${ }^{133}$ and the availability or otherwise of surplus indigenous production and imported supply for (re-) export to the continent.

The most significant sectors in both policy and demand terms are power and heating (this is the vast majority of residential demand and a significant proportion of I\&C demand). These are considered in more detail on the following sections.

\subsection{Gas demand in the UK electricity sector}

The trends in total energy demand presented in Chapter 2 are mirrored in electricity. Increased prices, economic slowdown and improvements in energy efficiency have resulted in a fall in electricity demand over the last ten years. The historical and scenario based forecasts for GB power demand are shown in Figure 19.

\section{Figure 19: Historical and projected GB power demand}

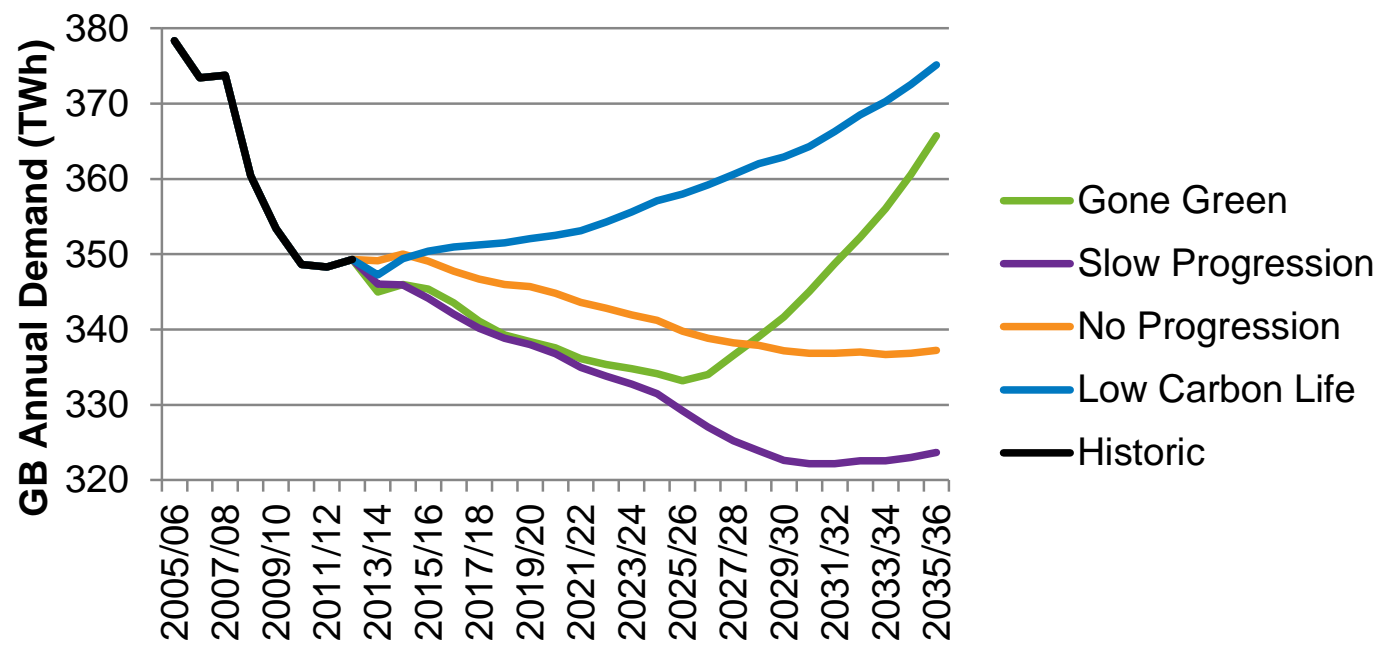

Source: National Grid (2014a). Note: These are GB numbers. Power demand in Northern Ireland was approximately 8 TWh in $2014 .{ }^{134}$

There are a number of aspects to considering the present role of gas in electricity generation. These include the capacity of gas-fired plant relative to total generation capacity, the competitiveness of the plant compared with other sources of power and the extent to which the plant is utilized and the profitability of the plant in marginal terms as measured by the spark spread. These aspects are considered in turn.

\footnotetext{
${ }^{133}$ Plus the impact of the Corrib field that comes on stream in 2015

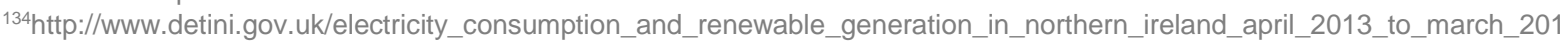
4_-_2.pdf?rev =0
} 

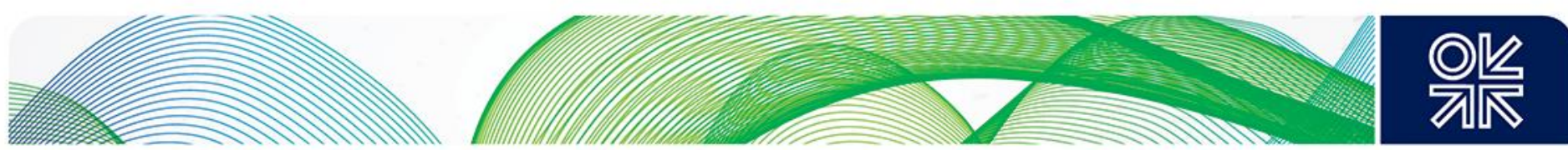

\subsubsection{Gas generation capacity}

Over the last 35 years the sources of electricity generation have become more diversified and changeable. In 1980 over $70 \%$ of power came from coal-fired plant whereas by 2010 this share had fallen to a little over 30\%. Gas-fired power had grown from zero to $40 \%$ of generation of the same period. More recently the share of gas has varied quite significantly from year to year. For example in 2012 the gas and coal shares were $24 \%$ and $44 \%$ respectively, as higher gas prices meant that coal generation was more competitive. The provisional figures for 2014 are 30\% and $29 \%$ respectively reflecting lower wholesale gas prices between June and August, greater call on gas plant to cover nuclear outages in the second half of the year and coal plant closures and conversions ${ }^{135}$.

In May 2014 the UK had over $80 \mathrm{GW}$ of installed electricity capacity ${ }^{136}$. Pumped storage provided another $2.5 \mathrm{GW}$ of capacity and import interconnections with other countries had a capacity of $3 \mathrm{GW}^{137}$. In addition there are a number of generating units classed as "other" power stations (which include CHP facilities plus a number of wind, solar, biomass and biogas plant) which accounted for over $12 \mathrm{GW}$. There is also an element of embedded generation such as micro generation units within individual households - these accounted for $0.7 \%$ of residential power consumption in $2013^{138}$.

The breakdown of this capacity by fuel source is shown in table 6 and figure 20 .

Table 6: Power stations in the UK by source of generation as at May 2014

\begin{tabular}{|c|c|c|c|}
\hline & $\begin{array}{l}\text { Total Capacity } \\
\text { (MW) }\end{array}$ & $\begin{array}{l}\text { Number of } \\
\text { plant }\end{array}$ & $\begin{array}{l}\text { Ave Capacity /plant } \\
\text { (MW) }\end{array}$ \\
\hline CCGT & 29,959 & 38 & 788 \\
\hline Gas (other) & 4,741 & 18 & 263 \\
\hline Gas oil & 1,557 & 27 & 58 \\
\hline Coal & 20,644 & 13 & 1,588 \\
\hline Nuclear & 9,373 & 9 & 1,041 \\
\hline Hydro & 1,592 & 82 & 19 \\
\hline Wind (onshore) & 7,824 & 207 & 38 \\
\hline Wind (offshore) & 4,033 & 23 & 175 \\
\hline Biomass etc. & 671 & $\mathrm{n} / \mathrm{a}$ & $\mathrm{n} / \mathrm{a}$ \\
\hline Total & 80,394 & 417 & 193 \\
\hline
\end{tabular}

Source: DECC Power Stations in the UK in DECC (2014c). Note the table covers stations owned or operated by major power producers and excludes a further $12 \mathrm{GW}$ of renewable and CHP plant. Capacity of plant in N Ireland was 2,630 MW in February $2015^{139}$

\footnotetext{
135 https://www.gov.uk/government/uploads/system/uploads/attachment_data/file/415997/electricity.pdf

${ }^{136}$ DECC Power Stations in the UK table 5.10. This figure is based on stations owned or operated by Major Power Producers and excludes pumped storage, "other power stations" and interconnectors.

137 2GW England-France and 1 GW Netherlands

138 DECC (2014c)

${ }^{139}$ http://www.soni.Itd.uk/media/documents/Operations/CapacityStatements/All\%20Island\%20Generation\%20Capacity\%20State ment\%202015\%20-\%202024.pdf
} 

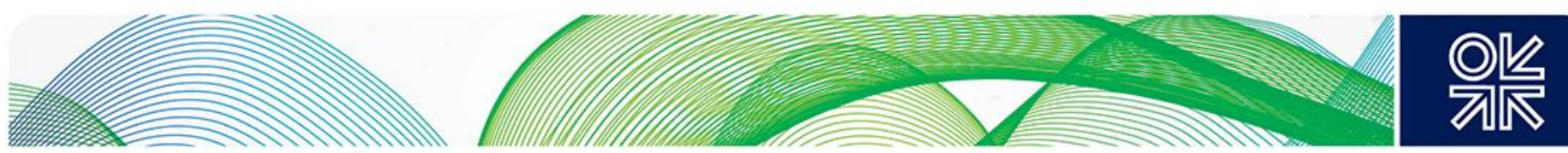

Figure 20: Power generation capacity by source (\%)

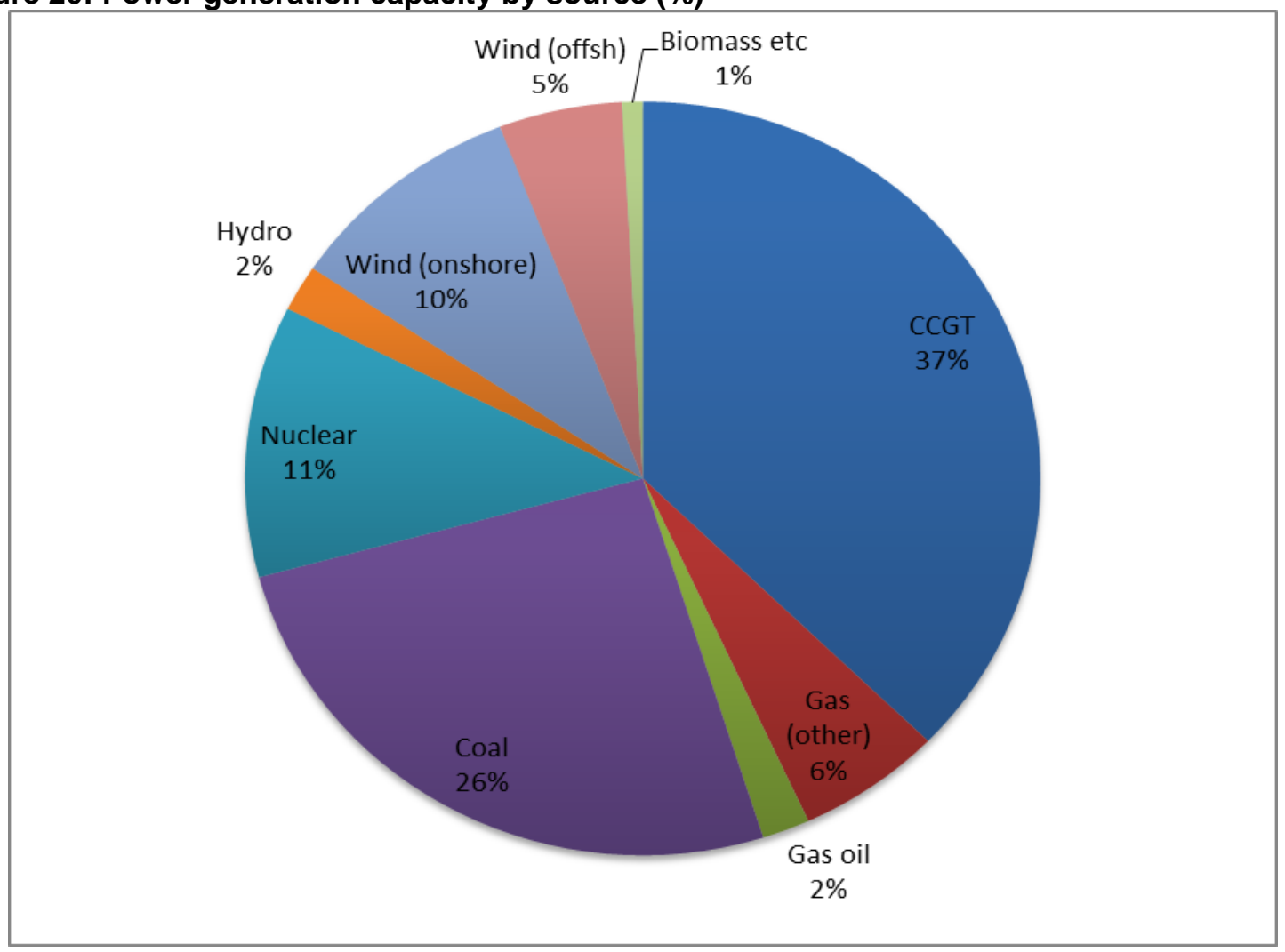

Source: DECC Power Stations in the UK 2014 (See note to table 6)

Whilst gas-fired generation capacity is higher than for other fuels/technologies, coal is still important though two pieces of EU legislation will progressively reduce the amount of coal-fired plant available. These are:

- The Large Combustion Plants Directive ${ }^{140}$ which set 'emission limit values' for the quantity of sulphur dioxide, nitrogen oxides which has resulted in many coal fired power closing;

- The Industrial Emissions directive which has similar requirements and is expected to lead to significant coal fired plant closure by 2020

\subsubsection{Gas generation plant utilisation}

The share of gas in actual generation has fallen significantly in recent years. This is demonstrated in figures 21 and 22 showing the GB power load duration curves for 2009 and 2014.

${ }^{140}$ European Parliament (2001) 

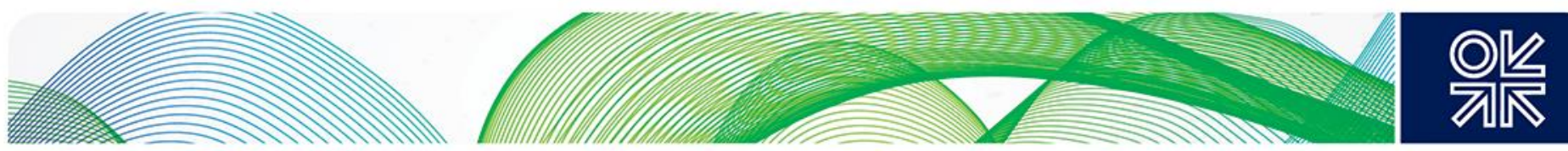

Figure 21: GB power generation load duration curve by source for 2009 (excluding hydro, pumped storage and interconnectors)

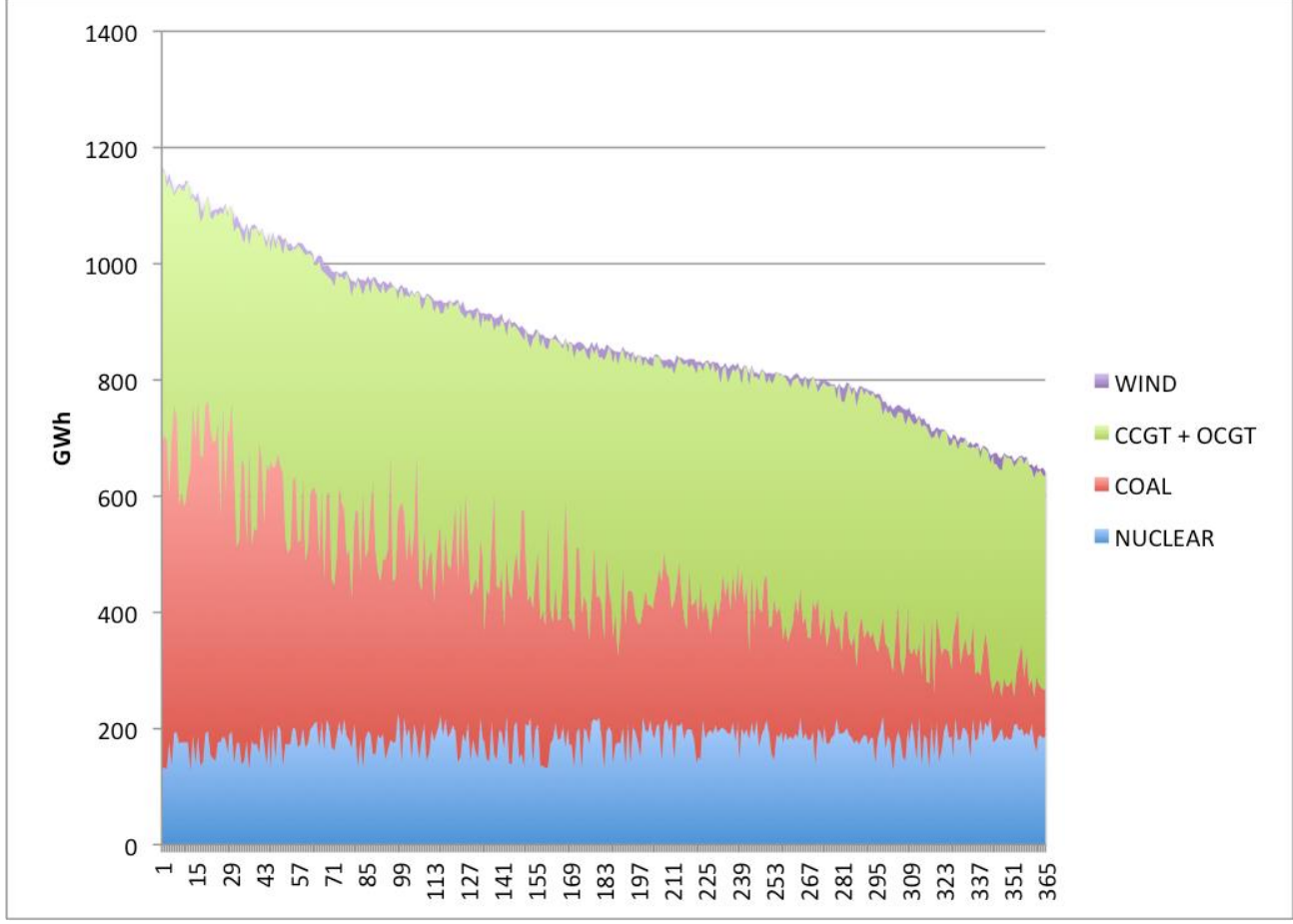

Source: Elexon

Figure 22: GB power generation load duration curve by source for 2014 (excluding hydro, pumped storage and interconnectors)

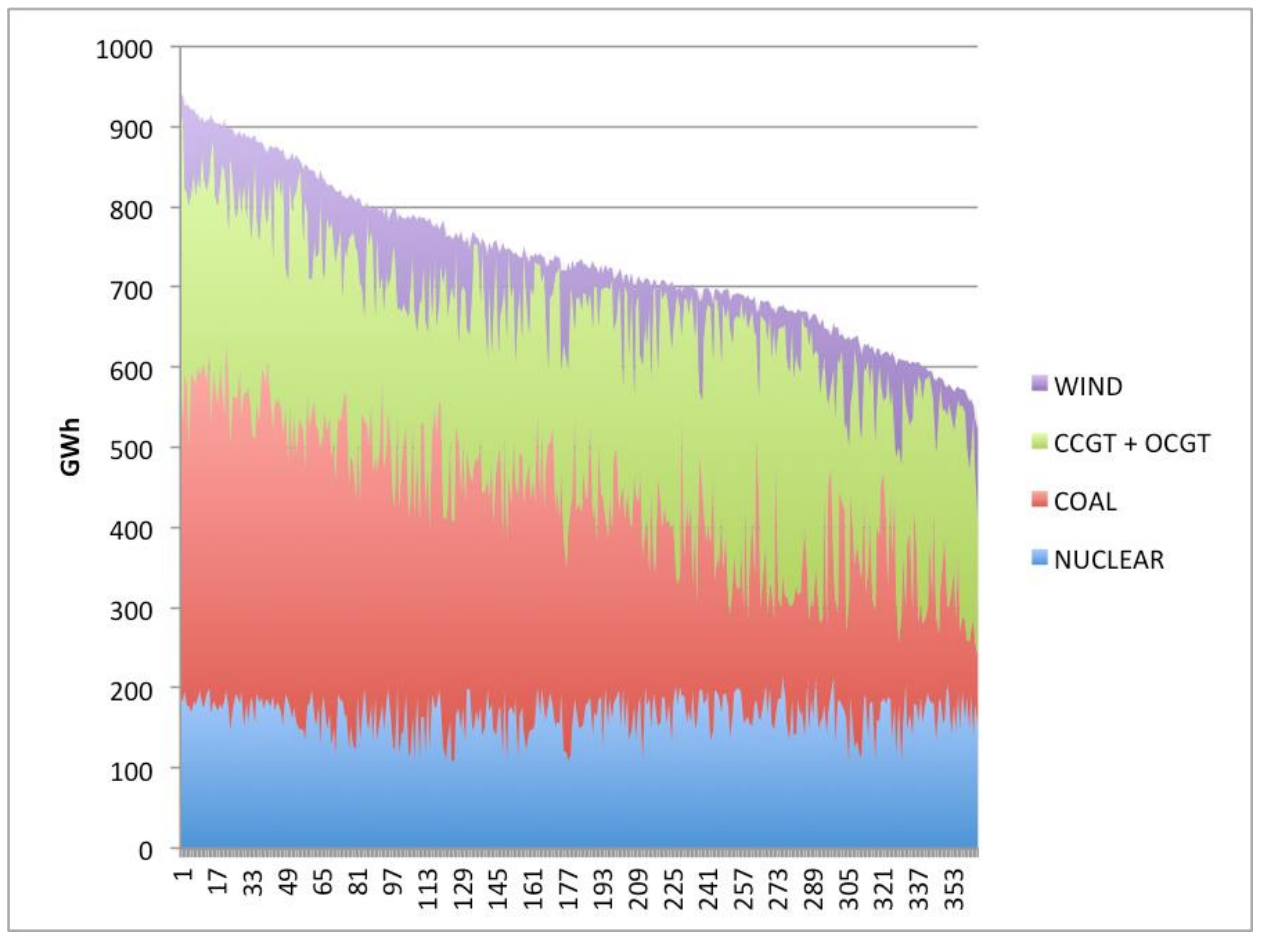

Source: Elexon 

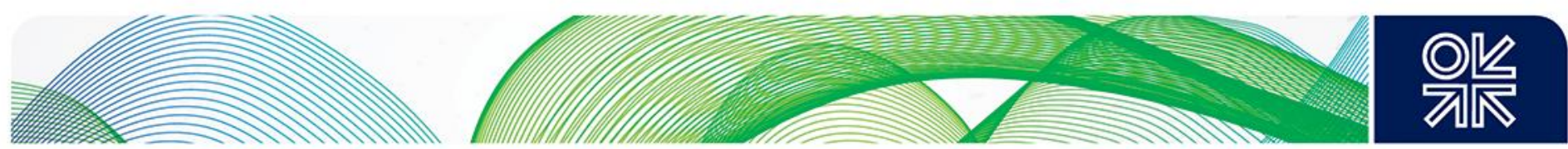

It is noticeable from figures 21 and 22 that the share of gas has both declined and become more volatile $^{141}$. Furthermore gas requirements can still be quite high on days of low electricity demand. The top 10 days of gas-fired power demand in 2014 are shown in table 7 . It should be noted these are days of high demand for gas in power, not necessarily of high power demand. It is immediately clear that high gas requirements can occur at any time of the year.

Table 7: top 10 days of demand for gas in power generation

\begin{tabular}{|c|c|c|c|}
\hline Day & $\begin{array}{c}\text { CCGT + OCGT } \\
\text { generation (GWh) }\end{array}$ & $\begin{array}{c}\text { Total } \\
\text { generation } \\
(\mathrm{GWh})\end{array}$ & Gas as \% of total \\
\hline $09 / 07 / 14$ & 386.8 & 711.6 & $54.4 \%$ \\
\hline $04 / 12 / 14$ & 383.5 & 958.5 & $40.0 \%$ \\
\hline $18 / 07 / 14$ & 372.7 & 705.6 & $52.8 \%$ \\
\hline $08 / 07 / 14$ & 367.9 & 688.1 & $53.5 \%$ \\
\hline $12 / 07 / 14$ & 365.8 & 694.9 & $52.6 \%$ \\
\hline $17 / 07 / 14$ & 364.5 & 697.9 & $52.2 \%$ \\
\hline $25 / 11 / 14$ & 364.0 & 919.3 & $39.6 \%$ \\
\hline $14 / 06 / 14$ & 362.0 & 715.6 & $50.6 \%$ \\
\hline $26 / 11 / 14$ & 359.7 & 909.1 & $39.6 \%$ \\
\hline $16 / 07 / 14$ & 358.4 & 698.6 & $51.3 \%$ \\
\hline
\end{tabular}

Source: Author's analysis of Elexon data

It should also be noted that even on days of very low demand for gas in power it still accounted for at least $10 \%$ of total power generated.

\subsubsection{Generating plant merit order and profitability}

The use of gas-fired generation will be a function of total electricity demand, the availability of renewable energy and the position of gas-fired plant in the merit order. Analysis by the CMA $(2015 \mathrm{~g})$ shows that on a short run marginal cost basis coal is ahead of gas in the merit order. This is shown in figure 23 which indicates that for significant periods the call on some CCGT plants will be very low or zero. The increase in renewable energy - which has a zero marginal cost, so will always run as long as the wind blows or the sun shines - has pushed CCGT down the merit order. This means that much of the gas-fired plant has moved from baseload to peaking plant. Load factors for CCGT plants have fallen from around $80 \%$ in 2000 to less than $30 \%$ in $2013^{142}$. Furthermore the increased intermittency from renewables requires greater cycling of despatchable plant - including a switch from combined cycle to open cycle generation for some gas plant - and therefore higher costs.

${ }^{141}$ One factor behind this increased volatility is the rise in embedded (mainly small scale solar) generation which could produce $50 \mathrm{GWh}$ on a bright summer's day

142 DECC (2014e) 

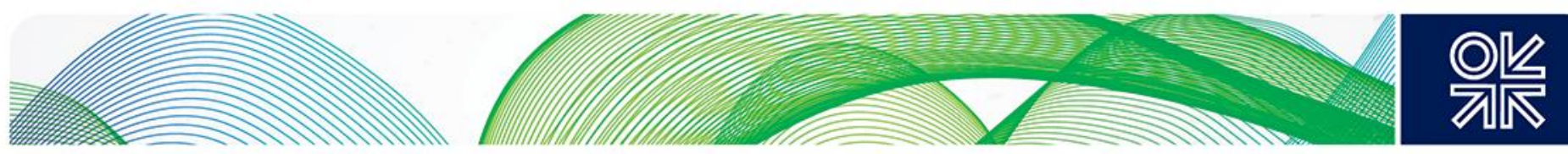

Figure 23: Merit order of GB electricity generators, as at $\mathbf{3 1 . 1 0 . 1 3}$

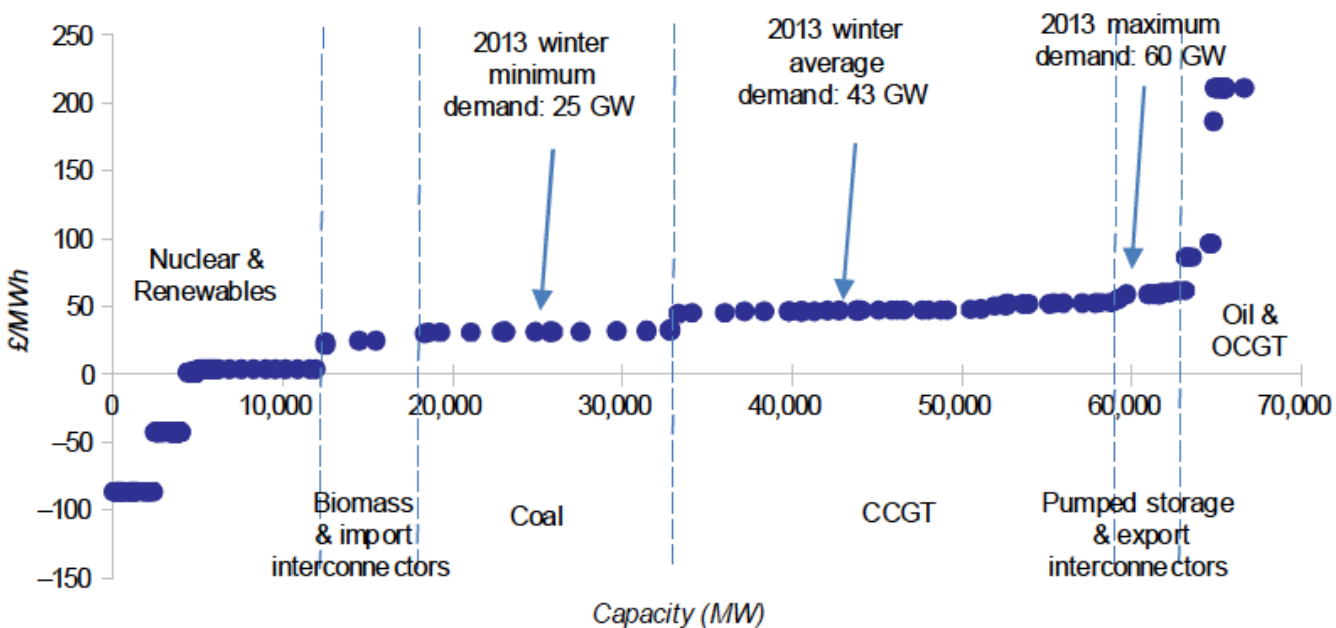

Source: CMA (2015g)

The merit order position will in turn depend primarily on the comparative cost of gas fired generation versus coal fired generation and as we have already noted since 2011 low coal prices in relation to gas prices have tended to favour coal fired power. The carbon price floor and lower gas prices could alter the position and this appears to be the case during the summer of 2014. Figure 24 shows the day ahead gas price and spark spread ${ }^{143}$ for 2014 . Gas prices fell in July and the spark spread increased. It can be seen from table 7 that gas-fired power was a particularly high proportion of the total in July.

\section{Figure 24: Day ahead gas price and spark spread for selected days in 2014}

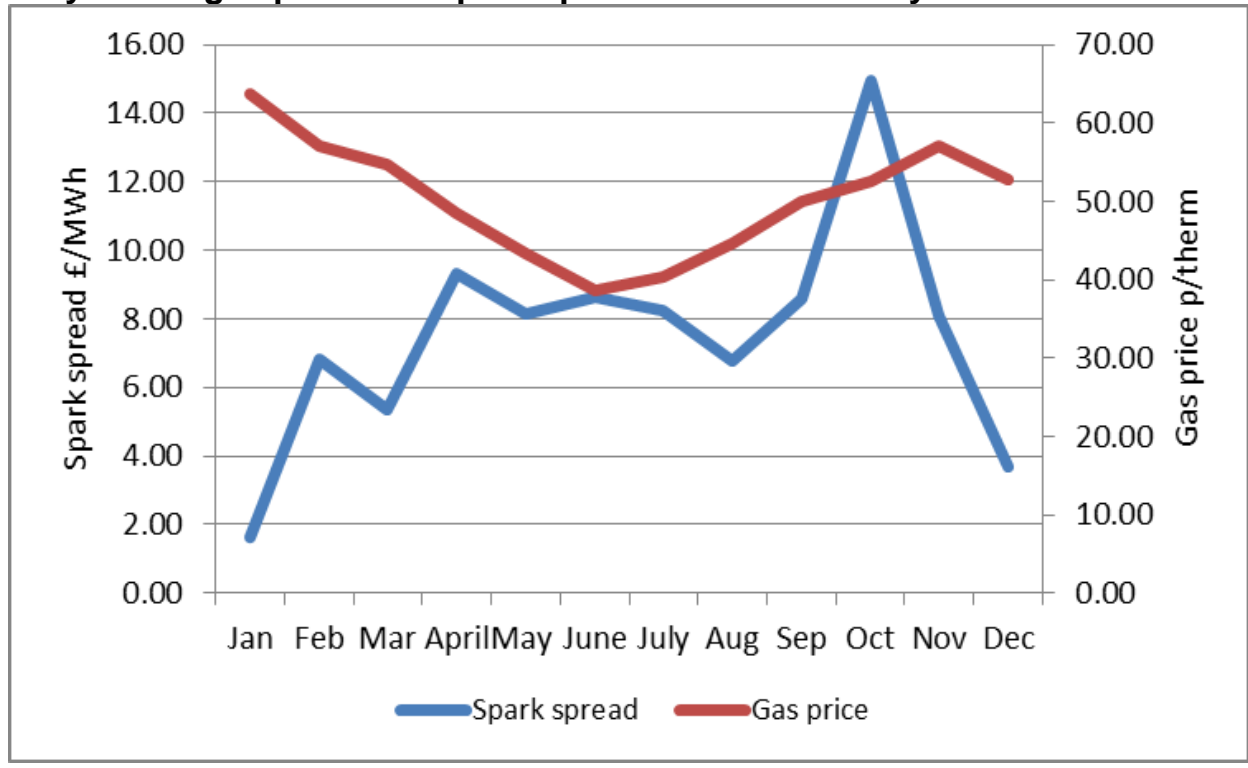

Source: Petroleum Argus

\footnotetext{
${ }^{143}$ See Appendix B for explanation of the gas spark spread calculation
} 

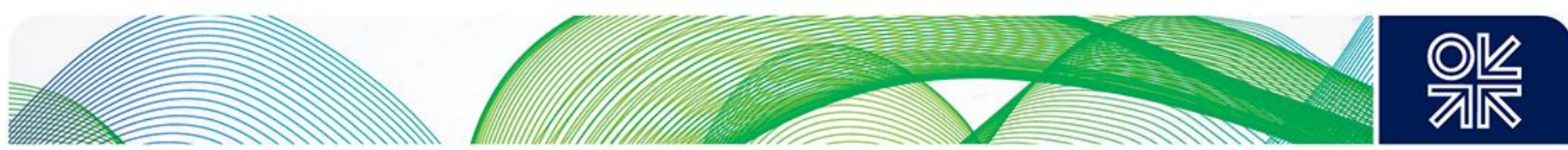

Analysis by Timera Energy (2015b) shows that in July 2014 newer (52\% efficient) gas plant had a short run marginal cost of $£ 40 / M W h$ whilst $36 \%$ efficient coal-fired plant had a SRMC of around $£ 42 / \mathrm{MWh}$. The difference was primarily due to the higher cost of carbon in the UK (as a result of the price floor) outweighing the lower cost of coal. In July 2014 the UK carbon tax as a result of the price floor was £9/tonne and this increased to £18/tonne on 1 April, 2015.

Clearly the efficiency of the gas-fired power plant is a crucial consideration. In order to differentiate within the otherwise 'generic' CCGT category, Timera Energy (2014a) suggest dividing the UK CCGT fleet into three tranches of plant based on year of first operation that each account for approximately $10 \mathrm{GW}$ of capacity. These three categories are:

- Recently built very efficient and flexible plant (efficiency around 52\%);

- Plant built at the beginning of the 2000s which has average efficiency (around 49\%) and flexibility;

- Plant that is 20 to 25 years old that is relatively inefficient (around $47 \%$ ) and inflexible.

This categorization can be seen in figure 25, which shows the distribution of gas-fired power plant by year of commissioning. The utilization levels of plant in each of these categories will vary significantly and the older plant is still unlikely to be competitive in present market conditions.

Figure 25: Year of commissioning of UK CCGT electricity generators

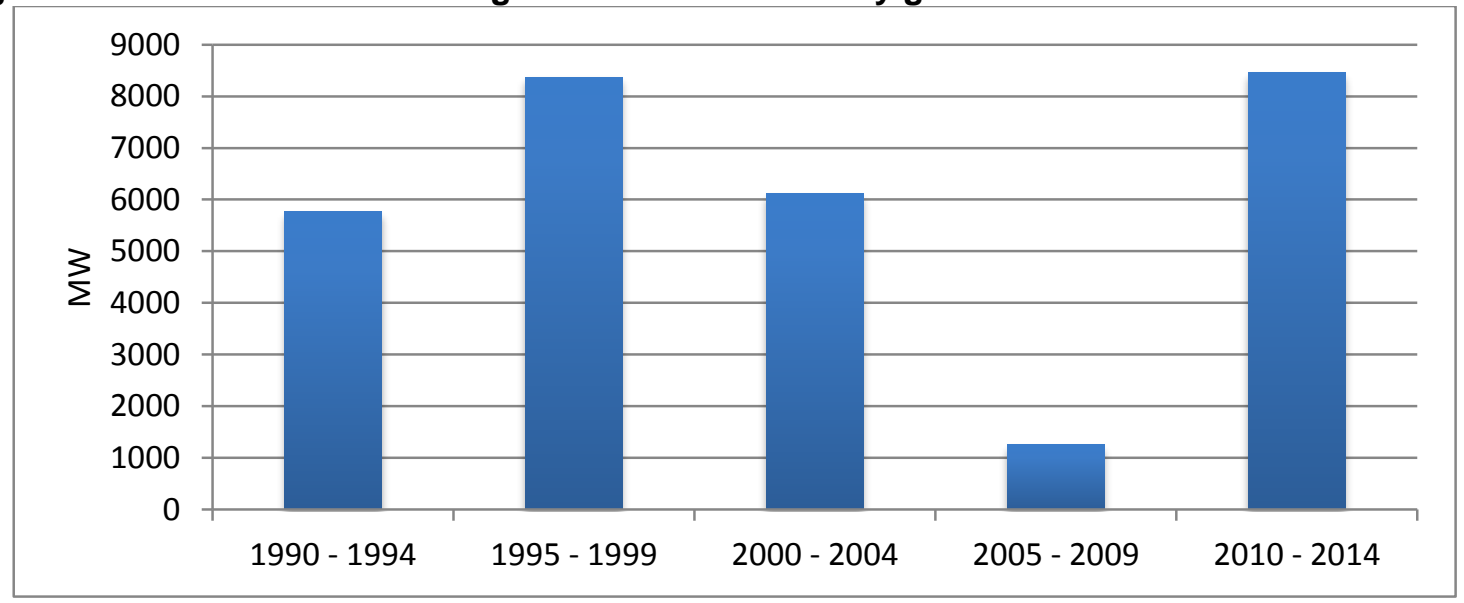

Source: Author's analysis of DECC Power Stations in the UK. Note 1990-1994 includes the Peterhead CCGT plant that came on stream in 1980 .

\subsubsection{The challenges facing gas-fired power}

There are a number of conclusions that can be drawn from this analysis:

- Despite the superior environmental performance of gas in H1 2015 market conditions the power sector will favour coal over gas in most cases. Some coal plant has been retired but the remaining capacity is likely to be in place for some years.

- Some gas-fired power will always be required but a significant proportion of the fleet will run at very low utilisation levels. Around $10 \mathrm{GW}$ of first generation CCGT capacity has been largely offline since $2012^{144}$ and a number of closures have been announced ${ }^{145}$.

\footnotetext{
144 Timera (2014a)

${ }^{145}$ Barking, Brigg, Killingholme
} 

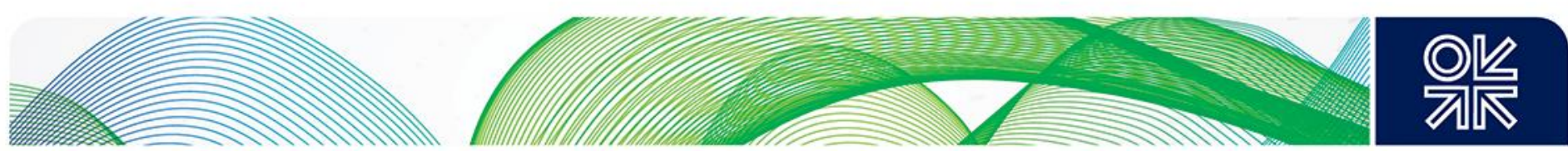

- The price of electricity is likely to be set by gas-fired plant but due to the level of competition, margins will be constrained and marginal profitability of the plant (spark spread) will primarily depend on gas prices.

- The Q1 2015 level of gas prices means that the spark spread for the most efficient base load gasfired plant is in the range $£ 4-5 / \mathrm{MWh}$. This compares with the margin required to justify investment in new gas-fired capacity, which is in the region of $£ 13 / \mathrm{MWh} .{ }^{146}$

- The increase in carbon price support on April 12015 and the decline in gas prices that began in summer 2014 (with further falls possible) suggests that the competitive position of gas could improve vis a vis coal. However whether this leads to an increase in spark spreads or a change in the price setting role of CCGT plant ${ }^{147}$ or both remains to be seen. It should be noted that coal prices have declined from 2014 to 2015.

In the short term planned plant closures and disruptions have led to a reduction in supply margins during peak demand periods. Since the end of 2012 nearly 10GW of plant has either been closed or mothballed whilst fires and nuclear outages have led to further temporary shutdowns. This has led to the development of incentives to generators to keep some plant on standby (the supplemental balancing reserve) and payments to large users for switching off during periods of high demand (the demand-side balancing reserve).

These measures alone are unlikely to be sufficient to make new (or even existing) gas-fired plant attractive so a longer term solution has been to develop a capacity market whereby generators will be paid to have plants available if required to ensure security of electricity supply.

\subsubsection{The GB power capacity market}

The first capacity auction took place in December 2014 (see Appendix A for more details). Nearly $65 \mathrm{GW}$ of capacity entered the auction which procured $49.3 \mathrm{GW}$ of capacity $(75.8 \%$ of the amount bid and around $61 \%$ of total generating capacity) at a clearing price of $£ 19.40 / \mathrm{kW}$. Only $2.8 \mathrm{GW}(5.3 \%)$ of the amount procured was new capacity.

According to Timera Energy this price was around $50 \%$ below market expectations ${ }^{148}$. A total of 15.7 GW of capacity exited the auction above the clearing price of which $8.4 \mathrm{GW}$ was existing coal and CCGT plants - the remainder being new build (mainly CCGT) generating capacity. In their review of the auction Timera note that plant that failed to secure a capacity agreement could be in a precarious position $^{149}$.

Indeed some of the projects (e.g. the 450MW South Hook CHP project) have since been put on hold ${ }^{150}$ whilst Centrica have announced the closure of its Brigg and Killingholme power stations ${ }^{151}$. However, other project promoters remain upbeat despite missing out - for example Intergen's Spalding and Gateway projects remain on track whilst Carlton Power is entering its Thorpe Marsh CCGT project into the second auction to be held later in $2015^{152}$.

The breakdown of plant securing capacity agreements is shown by technology in Table 8 .

\footnotetext{
146 Timera (2014a)

147 If coal- fired plant were to become the marginal plant the cost of carbon price support would fall more heavily on consumers. Sandbag (http://www.sandbag.org.uk/site media/pdfs/reports/Comparing carbon price instruments.pdf) estimate the charge would increase from $€ 10 / M W h$ for gas to $€ 22.5 / M W h$ for coal

148 Timera (2015a)

149 http://www.timera-energy.com/uk-power/implications-of-the-1st-uk-capacity-auction/

150 http://www.Ingworldnews.com/south-hook-chp-project-put-onhold/?utm source=emark\&utm medium=email\&utm campaign=Daily\%20update \%20LNG\%20World\%20News \%2C $\% 202015$ 02-05\&uid=21190

151 http://www.centrica.com/files/presentations/2015/prelims/index.asp

152 http://www.icis.com/resources/news/2015/03/23/9870129/uk-ccgt-developers-upbeat-despite-early-auction-failure/?
} 

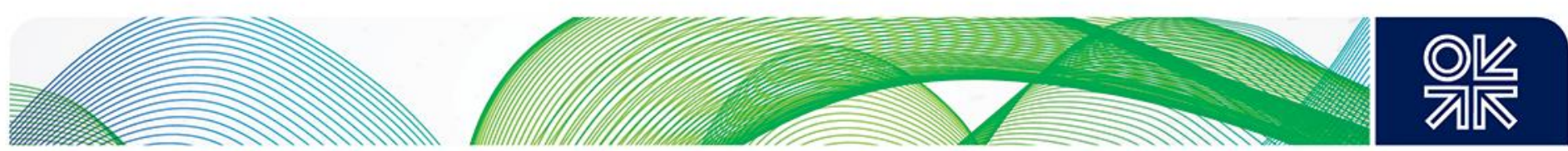

Table 8: Generating plant securing capacity agreements, December 2014

\begin{tabular}{|l|c|c|c|c|}
\hline Technology type & $\begin{array}{l}\text { Capacity } \\
\text { (GW) }\end{array}$ & $\begin{array}{l}\text { Capacity } \\
(\%)\end{array}$ & $\begin{array}{l}\text { Number } \\
\text { of } \\
\text { CMUs }\end{array}$ & $\begin{array}{l}\text { Number } \\
\text { of CMUs } \\
(\%)\end{array}$ \\
\hline CCGT & 22.3 & 45.2 & 47 & 15.4 \\
\hline CHP \& autogeneration & 4.2 & 8.6 & 36 & 11.8 \\
\hline Coal/Biomass & 9.2 & 18.7 & 29 & 9.5 \\
\hline DSR & 0.2 & 0.4 & 15 & 4.9 \\
\hline Hydro & 0.7 & 1.4 & 29 & 9.5 \\
\hline Nuclear & 7.9 & 16.0 & 16 & 5.2 \\
\hline OCGT and Reciprocating Engines & 2.1 & 4.3 & 121 & 39.5 \\
\hline Storage & 2.7 & 5.5 & 13 & 4.3 \\
\hline Total & 49.3 & 100 & 306 & 100 \\
\hline
\end{tabular}

Source: National Grid (2015)

It should be noted that many of the contracts awarded are for just one year so it is dangerous to draw too many long term conclusions. Nevertheless the overall view is that the capacity price is insufficiently high to justify new build alone and the fact that some unsuccessful coal and gas plant may close could cause further short-term capacity problems.

\subsubsection{Longer term power requirements}

Figure 19 demonstrates that there are a wide range of possible future requirements for electricity and within these different demand scenarios there will be alternative permutations of generation technologies. The 'contracts for difference' regime has been introduced to provide appropriate incentives for long-term investments in low carbon generation (including nuclear). However, due to the timing of these investments, the retirement of older coal- and gas-fired plant and the intermittency problems of renewables, additional fossil-fuelled plant will almost certainly be required. Most of this requirement is expected to be met by new CCGT plant though gas- and coal-fired CCS schemes could also play a role.

There are three key issues in considering the future shape of low carbon generation.

- The pace of deployment of alternative technologies which will depend primarily on technology and policy issues,

- The overall financial support required which is a function of the levelised cost of electricity $\left(\mathrm{LCOE}^{154}\right)$ for each technology and the CfD strike price,

- The level of back up that will be required to deal with intermittency. National Grid (2014a) assume annual average load factors of $28 \%, 38 \%$ and $11 \%$ for onshore wind, offshore wind and solar PV respectively.

Poyry (2013) in their report to the Climate Change Commission (CCC) provided comprehensive analysis of the likely deployment timescales and costs of five low carbon technologies for power generation:

- Onshore wind

- Offshore wind

- Nuclear

\footnotetext{
${ }^{153} \mathrm{CMU}=$ capacity market unit. This is the particular resource or demand side resource participating in the capacity market. For more detail see https://www.energy-uk.org.uk/files/docs/Policies/Capacity\%20Market/capacity market user support guide.pdf ${ }^{154}$ The LCOE takes account of capital and operating costs plus developer's rate of return adjusted to reflect the potential for costs to change over time as the technology matures
} 

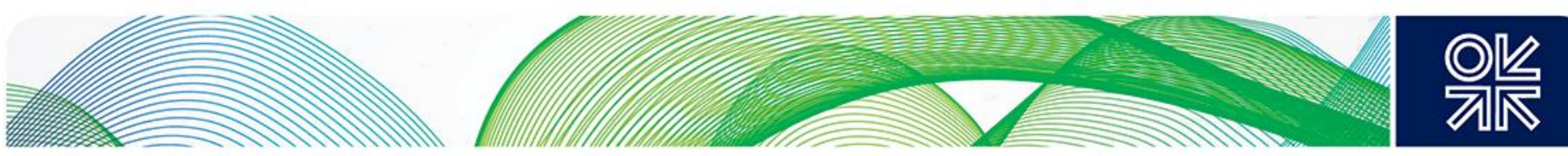

- $\quad$ CCS (based on coal or gas)

- Conversion of existing coal-fired generation to run in biomass

These are shown in tables 9 and 10. Table 9 shows that low carbon technologies could in total amount to some $90 \mathrm{GW}$ of generating capacity by 2030

Table 9: Alternative low carbon generation technologies - projected deployment

\begin{tabular}{|l|l|l|l|l|}
\hline \multirow{2}{*}{ Technology } & \multicolumn{2}{|l|}{ Project deployment in GW } & Key constraints \\
\cline { 2 - 5 } & 2013 & 2020 & 2030 & \\
\hline Offshore wind & 3 & $12-15$ & $25-40$ & $\begin{array}{l}\text { Construction finance, supply } \\
\text { chain capacity }\end{array}$ \\
\hline Onshore wind & 5 & 15 & 25 & Planning \\
\hline New Nuclear & 0 & 0 & 16 & $\begin{array}{l}\text { Number of developers and } \\
\text { construction finance }\end{array}$ \\
\hline $\begin{array}{l}\text { Biomass } \\
\text { conversion }\end{array}$ & 0 & 0.6 & 10 & $\begin{array}{l}\text { Implementation of pre- } \\
\text { commercial plants }\end{array}$ \\
\hline
\end{tabular}

Source: Poyry 2013

Table 10 gives an indication of levelised cost estimates undertaken by DECC (2013a) for projects by year of commissioning. It should be emphasized that the CfD strike prices for individual projects are likely to differ from these more generalised cost estimates ${ }^{155}$ and this is reflected in the results from the first round of CfD auctions held in January/February 2015. The prices from the successful bids are also shown in table 10. The two offshore wind projects are below the levelised cost estimates whilst the onshore wind numbers are within the levelised cost range. Most noticeable however is the low price bid by large scale solar projects. It remains to be seen whether these projects will materialise.

Table 10: Alternative generation technologies - cost estimates ( $£ / M W h$ )

\begin{tabular}{|c|c|c|c|c|}
\hline \multirow[t]{2}{*}{ Technology } & \multicolumn{2}{|c|}{ Levelised cost in } & \multirow{2}{*}{$\begin{array}{l}\text { Cfd } \\
\text { Auction } \\
\text { price } \\
(2015) \\
\end{array}$} & \multirow[t]{2}{*}{ Comments } \\
\hline & Current & 2030 & & \\
\hline Offshore wind & $131-208$ & $90-141$ & $114-120$ & $\begin{array}{l}\text { A more recent study (Frontier 2014) } \\
\text { puts the } 2030 \text { figure at } £ 104 / \mathrm{MWh}\end{array}$ \\
\hline Onshore wind & $75-115$ & $69-104$ & $79-82$ & \\
\hline New Nuclear & $79-102$ & $67-89$ & $\mathrm{n} / \mathrm{a}$ & $\begin{array}{l}\text { Current is next generation built in } \\
2020 \text { 's }\end{array}$ \\
\hline CCS & - & $93-118$ & $\mathrm{n} / \mathrm{a}$ & CCGT with CCS post combustion \\
\hline Biomass conversion & $106-107$ & 105 & 80 & $\begin{array}{l}2030 \text { figure from Frontier 2014. CfD } \\
\text { figure is energy from waste with CHP }\end{array}$ \\
\hline Large scale solar & 114-131 & $66-74$ & $50-79$ & \\
\hline CCGT & $73-75$ & $85-88$ & $\mathrm{n} / \mathrm{a}$ & $\begin{array}{l}2013 \text { gas and carbon price } \\
\text { assumptions }\end{array}$ \\
\hline
\end{tabular}

Source: Poyry (2013). DECC (2013a) and DECC (2015b)

${ }^{155}$ See Poyry (2013) p 82 for a detailed explanation

July 2015: The Role of Gas in UK Energy Policy 

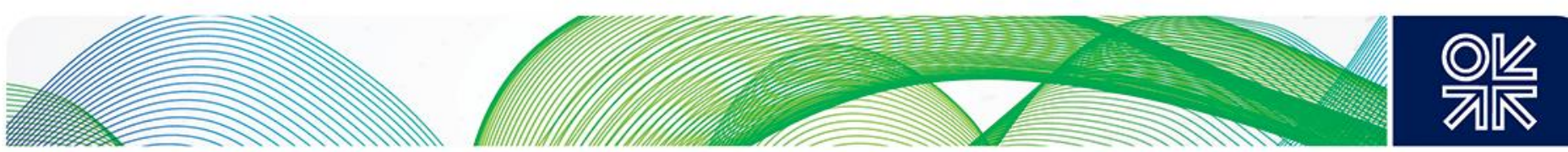

In table 10 the levelised CCGT costs are based on the DECC central case that sees gas prices rise in real terms from $63 \mathrm{p} /$ therm $\left(\$ 9.70 / \mathrm{mmbtu}^{156}\right)$ to $74 \mathrm{p} /$ therm $(\$ 11.40 / \mathrm{mmbtu})$ by $2030^{157}$ and carbon prices increasing to $£ 76 /$ tonne by 2030 . Levelised costs for a low gas price (just over $40 \mathrm{p} /$ therm $\$ 6.20 / \mathrm{mmbtu}$ long term) and carbon price scenario are some £20/MWh lower for the CCGT case. Removing the carbon price impact brings the CCGT costs down to $555 / \mathrm{MWh}^{158}$. DECC's updated fuel price projections ${ }^{159}$ show gas prices oscillating around $60 \mathrm{p} /$ therm $(\$ 9.24 / \mathrm{mmbtu})$ to 2020 then increasing to $76 \mathrm{p} /$ therm $(\$ 11.70 / \mathrm{mmbtu})$ by 2030 . A more recent study $(\mathrm{ETI}, 2015 \mathrm{a})$ suggests that CCS costs could be below £90/MWh by 2030 though a practical demonstration of CCS will be required to validate this number.

Gas-fired power is likely to remain competitive under most price scenarios and is the most likely choice for backing up intermittent renewables - though CCS based on gas- or coal-fired generation could play an increasing role in time; particularly if it is linked to enhanced oil recovery projects.

Table 11 shows the gas-fired capacity that could be required under different National Grid scenarios and the amount of power this would generate (recorded as $30.76 \mathrm{GW}$ and $73.7 \mathrm{TWh}$ respectively by NG in 2013/14).

Table 11: Long term gas-fired power capacity and output by scenario

\begin{tabular}{|l|l|l|l|l|l|l|l|l|}
\hline Scenario & \multicolumn{2}{|l|}{$\begin{array}{l}\text { Capacity 2025/6 } \\
\text { GW }\end{array}$} & \multicolumn{2}{|l|}{$\begin{array}{l}\text { Output 2025/6 } \\
\text { TWh }\end{array}$} & \multicolumn{2}{l|}{$\begin{array}{l}\text { Capaity 2035/6 } \\
\text { MW }\end{array}$} & \multicolumn{2}{l|}{$\begin{array}{l}\text { Output 2035/6 } \\
\text { MW }\end{array}$} \\
\cline { 2 - 8 } & $\begin{array}{l}\text { Gas } \\
\text { fired }\end{array}$ & Total & $\begin{array}{l}\text { Gas } \\
\text { fired }\end{array}$ & Total & $\begin{array}{l}\text { Gas } \\
\text { fired }\end{array}$ & Total & $\begin{array}{l}\text { Gas } \\
\text { fired }\end{array}$ & Total \\
\hline $\begin{array}{l}\text { No } \\
\text { Progression }\end{array}$ & 39.6 & 99.9 & 138.9 & 340.9 & 43.2 & 105.0 & $\begin{array}{l}159.1 \\
0.0\end{array}$ & 339.2 \\
\hline $\begin{array}{l}\text { Slow } \\
\text { Progression }\end{array}$ & 38.7 & 114.3 & 103.7 & 334.2 & 34.3 & 130.1 & $\begin{array}{l}54.3 \\
6.3\end{array}$ & 330.9 \\
\hline Gone Green & 36.1 & 127.7 & 101.3 & 357.7 & 31.9 & 162.9 & $\begin{array}{l}54.0 \\
31.3\end{array}$ & 423.9 \\
\hline $\begin{array}{l}\text { Low Carbon } \\
\text { Life }\end{array}$ & 32.2 & 121.8 & 83.3 & 368.8 & 24.6 & 138.1 & $\begin{array}{l}54.1 \\
47.1\end{array}$ & 405.6 \\
\hline
\end{tabular}

Source: National Grid (2014a)

Note: figures in italics in the $2035 / 6$ column show forecast additional gas CCS power output

Gas demand for power generation for each of the scenarios compared to 2013 is shown in table 12 which has been derived from the 2014 Ten Year Statement. ${ }^{160}$ This shows that it is only under the Slow Progression scenario that gas demand for power generation falls below its present level as there is a reduction in conventional gas-fired output and no compensating increase in CCS-based generation.

\footnotetext{
${ }^{156}$ At May 2015 average exchange rate of $\$ 1.54=£ 1.00$

157 DECC (2013d)

158 Roulstone (2014)

$159 \operatorname{DECC}(2014 d)$

${ }^{160}$ National Grid (2014b)
} 

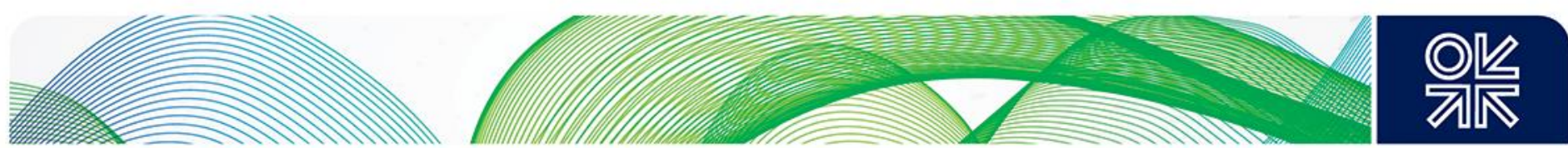

Table 12: Gas demand for gas-fired power by NG scenario $(\mathrm{bcm})$

\begin{tabular}{|c|c|c|c|c|}
\hline Scenario & \multicolumn{1}{|l|}{2013} & 2020 & 2025 & 2035 \\
\hline $\begin{array}{c}\text { Slow } \\
\text { Progression }\end{array}$ & 12.9 & 19.4 & 16.5 & 8.7 \\
\hline Gone Green & 12.9 & 15.6 & 15.9 & 13.9 \\
\hline $\begin{array}{c}\text { Low Carbon } \\
\text { Life }\end{array}$ & 12.9 & 17.6 & 17.1 & 17.5 \\
\hline
\end{tabular}

Source: NG 2014b

It is clear substantial amounts of gas-fired capacity are expected to be required though utilisation levels could continue to fall. However new gas-fired generation is presently not very profitable. For example Timera Energy (2014a) calculate that the required margin to justify investment in new gasfired capacity is in the region of $£ 13 / \mathrm{MW}$, some way above the prevailing spark spreads shown in figure 24.

There is clearly uncertainty over the future role of gas in this sector. Other factors that are adding to the uncertainty include:

- The rise in embedded generation. The advent of feed-in tariffs for small scale low carbon generation in April 2010 has resulted in over 600,000 households and businesses generating electricity by September 2014 - mainly through solar photo voltaic installations. ${ }^{161}$ Total solar capacity is now some $5 \mathrm{GW}$.

- How peak power demand will evolve. Average cold spell peak power demand has fallen from 65 GW in 2005/6 to around 60 GW in 2013/4 (this is a continuation of a trend due to recession and increases in embedded generation) and could either continue to fall or grow again for example as a result of the electrification of transport.

There is also a major risk for the consumer that capacity which has intermittent generation continues to be added but reliability falls. Excess capacity is therefore required at significantly greater overall cost. For example in 2013/14 total capacity was 91GW against the predicted average cold spell requirement of 60GW. By 2035/36 under the gone green scenario the numbers are 163GW and 68GW respectively. A study commissioned by Centrica (2014) estimates that a cost optimized buildout would result in higher utilization for CCGT but lower overall capacity of $88 \mathrm{GW}$ against a policy forecast of $129 \mathrm{GW}$.

There is also significant uncertainty over what if any role Carbon Capture and Storage could play. Rogers (2012) points out that the technology components have been available and reliably utilised in the refining, processing and EOR sectors for decades -the main barriers are commercial and regulatory. An EU directive issued in 2009 established a legal framework for geological storage of carbon as well as the capture and transportation component of the technology. It also contained provision for half of the emission trading scheme (ETS) revenues to be used to finance CCS projects ${ }^{162}$. This move clearly failed to gain traction - not least because of the low level of ETS revenues but also uncertainty over how the directive would work in practice. A very limited number of demonstration projects have survived - in November 2014 these were White Rose and Peterhead in

\footnotetext{
${ }^{161} \operatorname{DECC}(2014 d)$

${ }^{162}$ European Parliament (2009)
} 

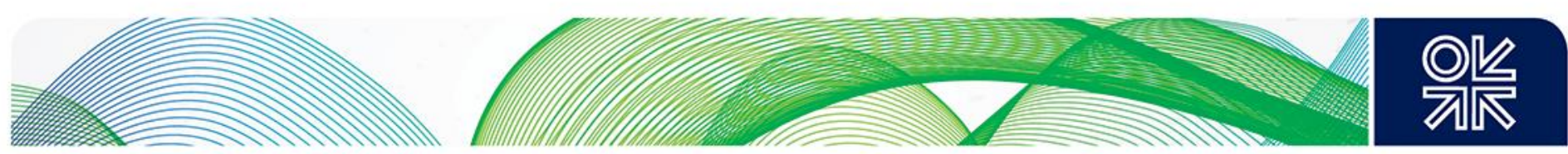

the UK and the ROAD project in the Netherlands. The Commission has, however, agreed to provide further funding for demonstration projects post 2020

The UK Government has also provided some support for CCS as set out in a Road Map published in 2012 though there remains the sense that it is less favoured than other low carbon approaches as it in some ways provides a "let off" for fossil fuels. Sherman (2013) notes that full CCS would result in huge amounts of $\mathrm{CO}_{2}$ to be stored though depleted oil and gas reservoirs present the most attractive option and the technology could be attractive for "hard to decarbonise" industries such as steel and concrete.

The Carbon Capture and Storage Policy Scoping Document (DECC 2014h) summarised the following actions:

- Future CfD contract allocations will include consideration of CCS projects;

- DECC will engage with developers on the design of generic CCS projects;

- Developing appropriate financing options;

- Assessing alternative transportation and storage options;

- Determining the extent to which enhanced oil recovery could enhance the prospects for $\mathrm{CO}_{2}$ storage options.

Given the extensive availability of depleted offshore oil and gas fields, widespread infrastructure and scope for enhanced oil recovery (EOR) in the North Sea163 there should be significant scope for developing a viable suite of CCS projects. A recent report from the Energy Technologies Institute (ETI, 2015b) indicates that it is both feasible and affordable to establish a $10 \mathrm{GW}$-scale CCS sector capturing around 50 million tonnes of $\mathrm{CO} 2$ by 2030 in the UK.

As shown in table 12 even if the upper ranges of renewable generation capacity are met by 2030 the level of dispatchable as opposed to intermittent power is such that CCGT will continue to play a role with or without CCS.

\subsection{The role of gas in the UK heat sector}

Energy for heat accounts for $48 \%$ of total energy demand in the UK ${ }^{164}$ and is the single largest requirement for energy. Natural gas remains the fuel of choice to heat homes. Around $81 \%$ of the 450 $\mathrm{TWh} / \mathrm{y}$ of residential heat is through gas central heating, which was present in 22.5 million homes in 2010.

UK gas consumers buy 1.5 million residential gas boilers annually (the largest market in W. Europe) of which only $2 \%$ are low carbon ${ }^{165}$, whereas for Germany the figure is $20 \%{ }^{166}$. Given that households account for $25 \%$ of UK's greenhouse gas (GHG) emissions and $40 \%$ of its final energy use, a key challenge for policy makers seeking to meet the 2050 GHG reduction target relates to the decarbonisation of residential space and water heating. There are a range of options but simply electrifying the heating network is unlikely to be one of them. Figure 26 compares the recent levels of energy demand for heat and electricity with the former rising to between 5 or 6 times the energy equivalent of the latter on days of high heat demand. Wilson et al (2014) estimate that moving $30 \%$ of NDM (non-daily metered usersi.e. residential and small I\&C) heat demand to resistive heating almost

\footnotetext{
${ }^{163}$ By using $\mathrm{CO}_{2}$ to maintain reservoir pressure

164 DECC (2014d)

${ }^{165}$ A low carbon gas boiler would typically comprise a condensing boiler coupled with additional technology such as gas absorption heat pumps - see http://www.remeha.co.uk/tag/low-carbon/page/2

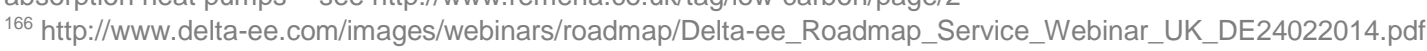



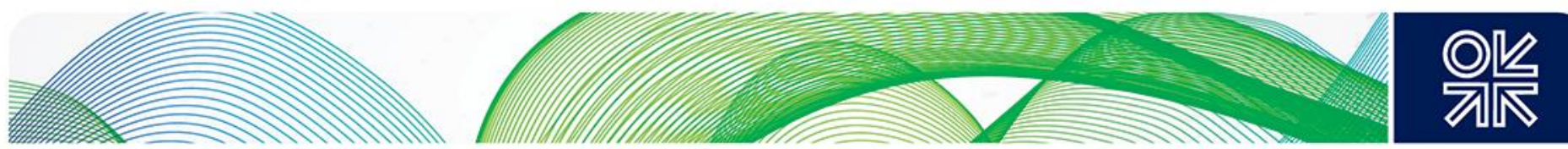

doubles daily electrical demand during high demand periods. Even if this proportion were to switch to heat pumps it would still increase daily electrical demand by $25 \%$.

\section{Figure 26: Half hourly heat and electricity demand in 2010}

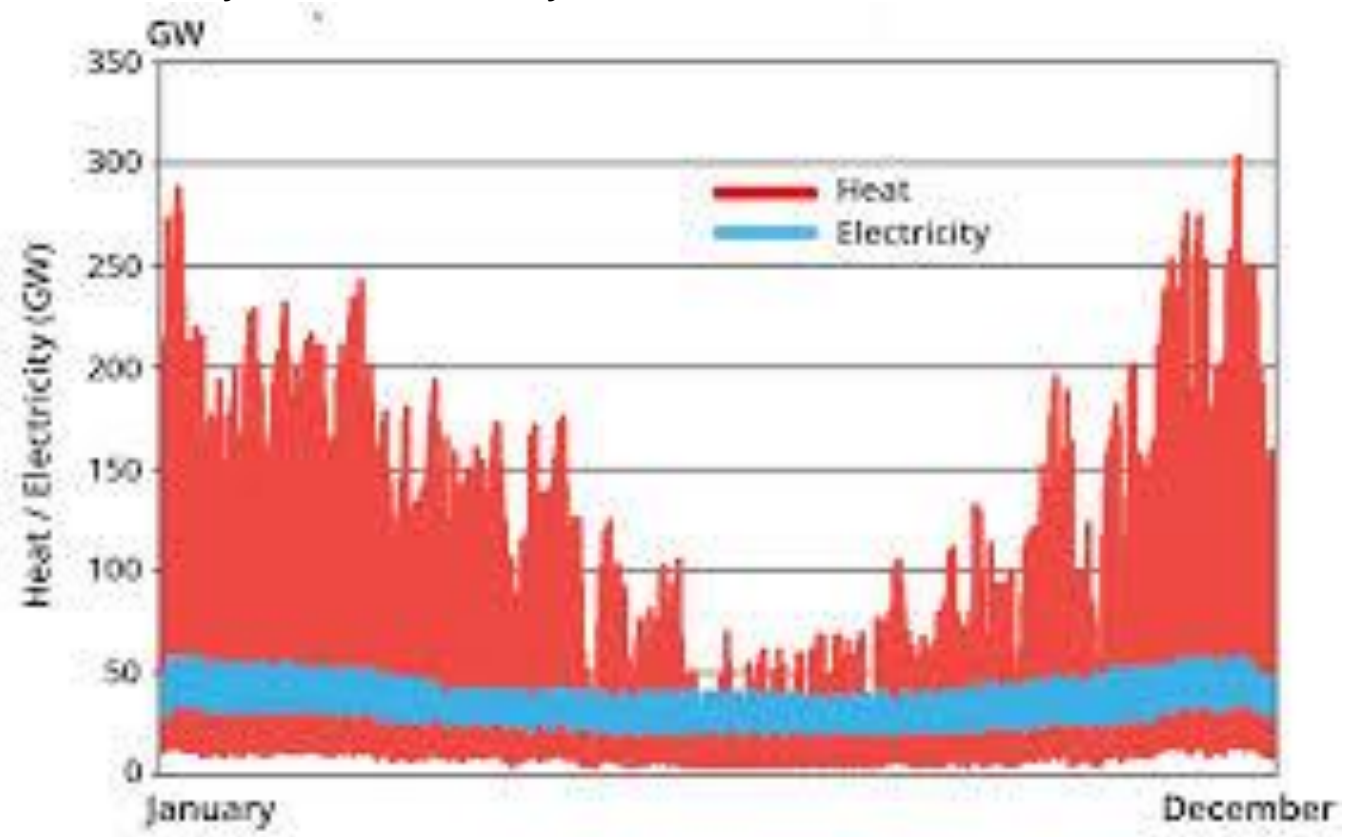

Source: DECC (2015a), Courtesy of Imperial College

The Government published a Renewable Energy Strategy (RES) in 2009 that suggested renewable heat could account for $12 \%$ of UK heat demand by 2020 . The main policy initiative is the Renewable Heat incentive launched in 2011 which provides financial support to bridge the gap between the cost of fossil fuel heat sources and renewable heat alternatives such as biomass, biomethane, heat pumps and solar. DECC (2013c) estimates that the scheme could support 5.2 - 7.4TWh of renewable heat by the end of $2015 / 16$. There are separate schemes for industrial and residential consumers and the latter is primarily targeted at those who are not connected to the gas network, as it is recognised that homes "without mains gas have the most potential to save on fuel bills and decrease carbon emissions"167.

Take up of the industrial scheme had not met expectations in $2013^{168}$ - apart from biomass - and the main reason was that the $\mathrm{RHI}$ tariffs underestimated the full costs of deployment. The tariffs have been increased though issues regarding the sustainability of biomass have cast further doubts on the scheme. There is a concern that the present approach could actually increase overall emissions.

Despite this major challenge there is still a widespread expectation that by 2050 heat demand will be largely met by non-gas sources. Figure 27 shows a number of long term forecasts with comparison to today. It should be noted that the NG forecast is under the gone green scenario which assumes a large scale switch to heat pumps. 

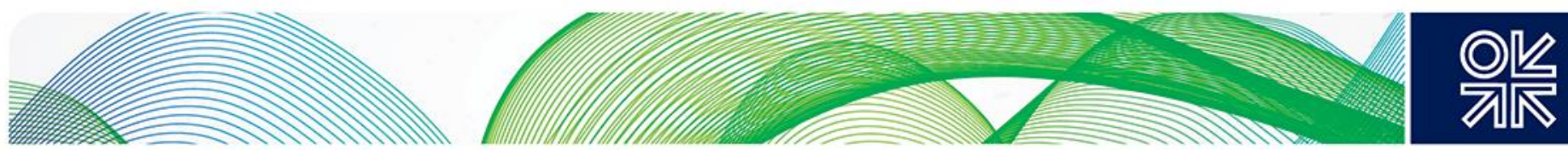

Figure 27: Forecasts of sources of heat provision in 2050 compared to 2014

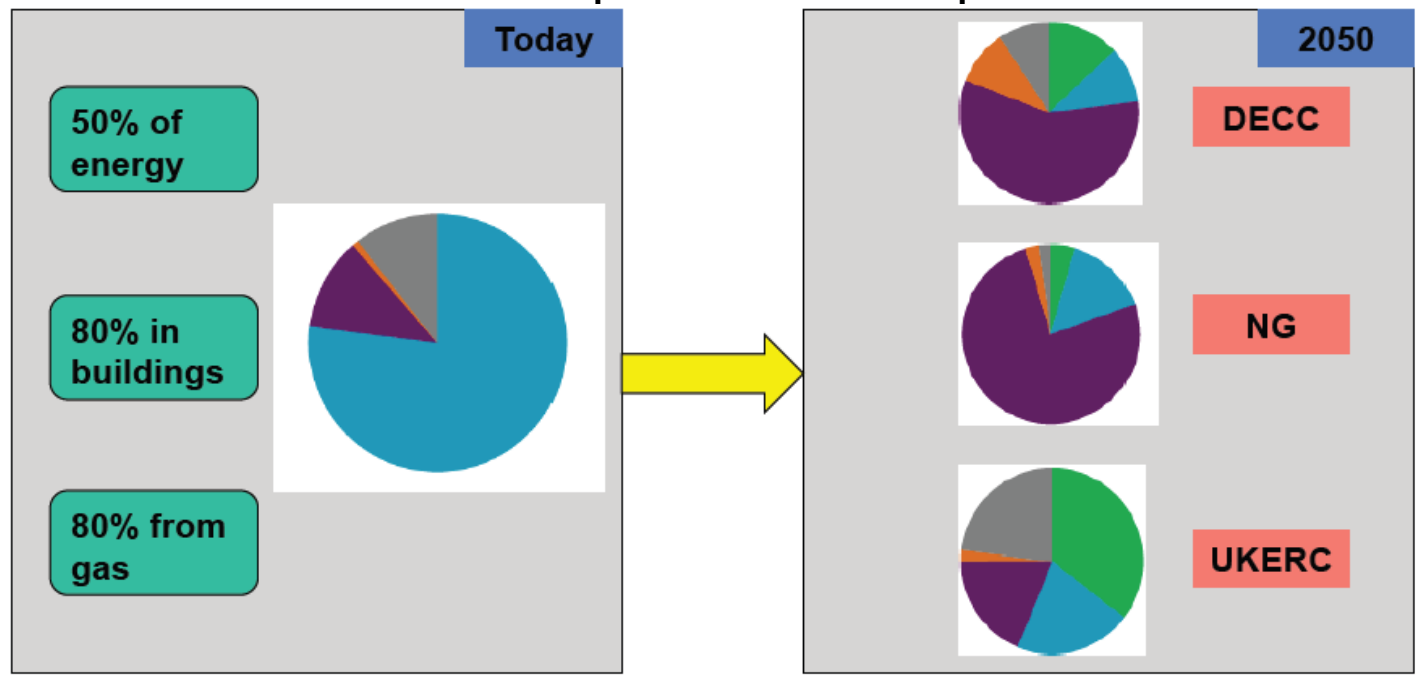

$\square$ Efficiency $\square$ Gas $\square$ Electricity $\square$ District heat $\quad$ Other

Source: Carbon Connect. Note NG forecast is based on their Gone Green Scenario

Leaving aside the electrification of heat provision, which seems largely impractical given the present configuration of the power network and housing stock in the UK, and without a major breakthrough in residential battery technology, decarbonising the heat sector could be achieved through a number of strategies:

- Development of heat networks - this is often referred to as district heating. Unlike many European countries the UK has relatively limited heat network provision. There are currently some 2,000 heat networks in the UK but these account for only $2 \%$ of overall heating demand. However DECC has estimated that by $203014 \%$ of UK heat demand could be cost effectively met by heat networks and that this figure could increase to $43 \%$ by 2050 (2014 Annual Energy Statement ${ }^{169}$ ). Centrica (2014) estimate city centre residential and commercial district heating could account for 3 to 3.5 million city centre connections by 2030 (equivalent to between 30 and 50 TWh of heat).

- Air source and ground source heat pumps - these are still not cost effective in most cases though could work well with new generation hybrid gas boilers

- Biomass boilers - these are unlikely to be practical for most households.

- Replacing the building stock with highly energy efficient homes and offices - clearly a sensible approach but one with very high costs and extended timescales. ETI (2015b) estimate that $90 \%$ of the UK's present housing stock will still be in use by 2050.

- Improving the efficiency/carbon impact of the existing system.

This last option still appears to contain the greatest potential in the short term. There have been significant improvements in energy efficiency in heating. These include:

- Improved boilers - condensing boilers (that are now mandatory under the 2005 Building regulations). Centrica notes that there are still over 3 million old boilers which are less than $70 \%$

${ }^{169}$ DECC (2014i) 

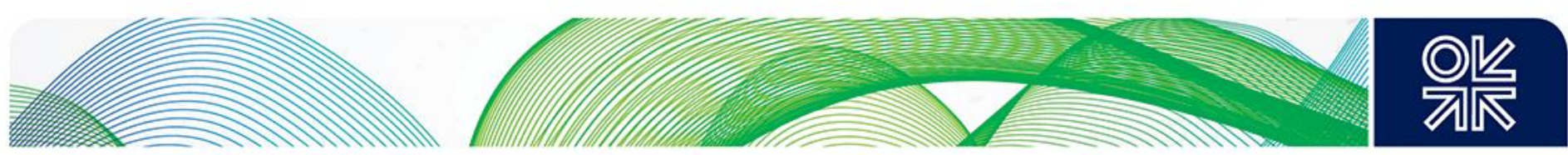

efficient while DECC calculate that every year the increase in the number of condensing boilers saves an additional $0.7 \mathrm{MTCO}_{2}$ tonnes of carbon. There were nearly 12 million of these boilers installed by the end of 2012 so the scope for further savings is still significant.

- Higher efficiency for hot water - from better boilers and improved systems.

- Increased insulation - cavity wall insulation can reduce gas consumption by around $14 \% .67 \%$ of all homes now have this type of insulation.

- Reduced indoor temperatures - the average household temperature peaked at $18.50 \mathrm{C}$ in 2005 and has declined by around $10 \mathrm{C}$ since 170 .

The Committee on Climate Change estimate ${ }^{171}$ that these and other measures could reduce consumption across all households by an average of $1,115 \mathrm{KWh}$ per annum. The average temperature adjusted consumption per household in 2013 was $14,829 \mathrm{KWh}$ of gas and $4,170 \mathrm{KWh}$ of electricity ${ }^{172}$. A Friends of the Earth paper ${ }^{173}$ argues that a more dramatic reduction in gas demand for home heating is possible through radical measures to improve efficiency. These measures could reduce residential gas demand by $40 \%$.

Centrica (2014) expect that gas is likely to continue to heat around $80 \%$ of UK households well into the 2030s. National Grid scenarios other than Gone Green all project continuing high levels of gas demand for heating.

Analysis commissioned by Centrica ${ }^{174}$ indicates that to deliver around 100 TWh of renewable heat by 2020 (equivalent to approximately one third of residential gas demand in that year) would require all of the following:

- $10 \%$ of industrial process heat to come from biomass;

- between 100,000 and 200,000 homes and businesses per year to connect to a district heating network;

- and between 50,000 and 250,000 non-residential heat pump installations

DECC acknowledge that for a long time there was no clear strategic vision for the development of heat networks in the UK ${ }^{175}$ though it claims to have fixed this problem and has established a Heat Networks Delivery Unit (HNDU) which combines grant funding with expert guidance.

DECC believes that heat networks can become the UK's third piece of significant energy infrastructure, after the gas and electricity grids, though one has to question at what cost. Some models show technical potential to supply as much as $43 \%$ of heat demand for buildings through networks by $2050^{176}$ but again this leaves a major proportion of heat requirements that presumably will still need to be met from gas and hence ensures a significant role for gas for at least 20 years. It is also unclear how these heat networks will be energised and given that they will almost certainly involve a combination of heat and power generation there will inevitably be a loss of flexibility. As Mackay (2014) points out a CHP system is not very flexible in the mix of electricity and delivers heat only to the places it's connected to, whereas condensing boilers can be placed anywhere with a gas main.

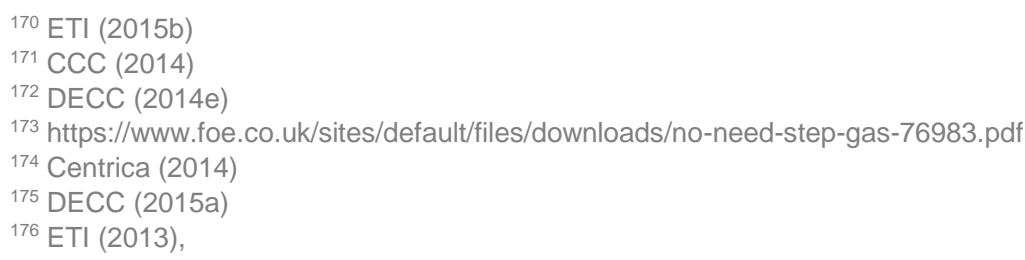



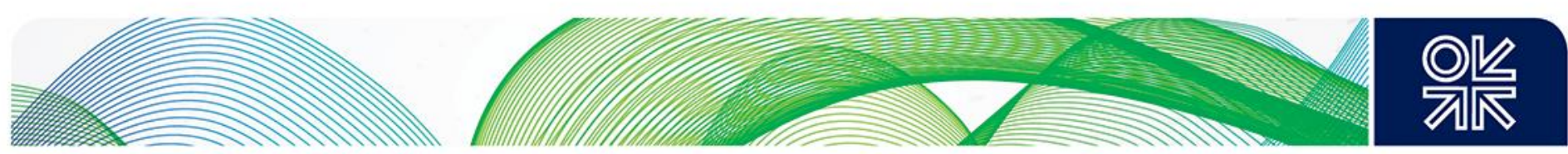

More recently ETI (2015b) have argued for the development of a two solution approach with local schemes using heat networks (partly based on gas with CCS) and individual homes using electric heat (from a mix of heat pumps and resistive heating) combined with a $£ 100$ billion programme to reduce heat demand in 7 million homes through major efficiency improvements. This could deliver a low carbon heating solution though the scale of the undertaking is clear with the need for 26 million homes requiring a "significant level of attention" over a 25 year period.

Amongst the many challenges facing such a large scale approach is that there is little evident consumer demand for a switch from their present very flexible form of heat provision and it will be a major task to convince consumers that the cost and disruption is justified. The issue of replacing gas used for cooking will also need to be addressed. Overall it would appear to make little sense to duplicate the existing gas distribution network though there may be scope for selective development of heat networks that work within the existing distribution envelope. It is also sensible to pursue all other measures to improve the efficiency and carbon impact of gas supply and utilisation in this sector. A financially feasible route to completely decarbonising heat is not yet apparent.

\subsection{Conclusions on the demand outlook for the GB gas market and the policy implications}

Overall there is little doubt that natural gas will play a key role in UK energy supply at least until 2030 and probably longer. In power generation, despite the wide range of possible levels of demand and generation mix, gas fired power will continue to feature in a critical capacity:

- As a provider of both base load and back up to intermittent generation, especially renewables;

- In setting electricity prices.

Furthermore, the balance of probability, given continuing high costs of renewable energy versus the medium term (i.e. to 2020) outlook for gas prices, more concerted efforts to restrict coal-fired generation, extended timescales for large scale nuclear and the emergence of viable CCS schemes, is that the share of gas will be at least as large as it is in 2015 for the next 15 years.

It is a similar picture in the heat market. Gas will continue to be the most dominant fuel until well into the 2030s. Beyond this it is far from certain that heat networks can be developed on the scale and efficiency required to make them a viable alternative, though this is an area that will receive increasing technical and commercial attention from policy makers.

It is therefore essential that policy makers recognise and plan for the continuing large scale presence of gas in the energy mix. The danger is that without this recognition the gas-related components of the portfolio may not be available when required. This is a particular issue for new generation gasfired power plant where, as Bassi et al (2013) argue, natural gas should be used to the greatest value in the move towards decarbonisation. The recent capacity auctions do not appear to have incentivised any additional projects and this could create a gap in requirements unless the market dynamics shift in favour of gas.

\section{Outlook for the GB gas market and policy implications - supply}

\subsection{Introduction}

The previous chapter looked at the future in terms of demand. This chapter considers key supply issues for the GB gas market within the existing policy framework. The main focus is on indigenous production and overall security of supply as these aspects have the most important implications from a policy perspective. 

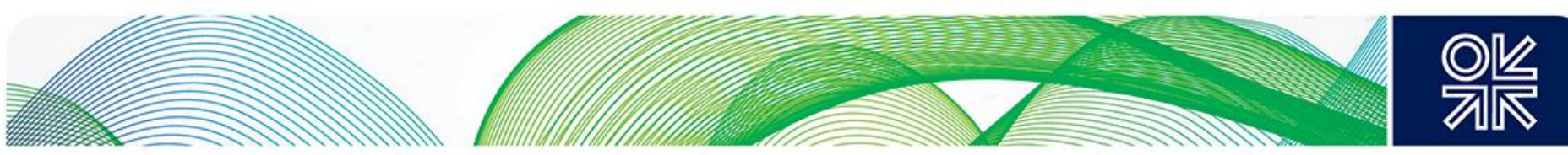

\subsection{Indigenous gas production - UKCS}

Gas production from the UKCS peaked in 2000 and has been declining at around 10\%/year since 2003. Decline has eased in recent years and, with new developments coming onstream, production may continue to fall but at a lower rate. The UKCS is one of the most mature offshore basins in the world though there are still a number of frontier provinces such as West of Shetland with potential whilst the scope for further recovery from already developed plays is still significant.

Table 13 shows the latest estimates of gas reserves in the UKCS. It is notable that at 2014 rates of production proven reserves would be depleted within 6.6 years

Table 13: Estimates of UK gas reserves as at 31/12/13 (bcm)

\begin{tabular}{|l|l|l|l|l|}
\hline Location & Proven & Probable & Possible & Maximum \\
\hline SNS NAG & $92(92)$ & $57(49)$ & $58(53)$ & $207(194)$ \\
\hline Other NAG & $22(22)$ & $11(10)$ & $4(4)$ & $37(36)$ \\
\hline Gas from condensate fields & $97(97)$ & $119(57)$ & $92(65)$ & $308(220)$ \\
\hline Associated gas & $31(31)$ & $25(15)$ & $43(39)$ & $99(85)$ \\
\hline Total & $241(241)$ & $211(131)$ & $198(161)$ & $650(534)$ \\
\hline $\begin{array}{l}\% \text { of Estimated Ultimate } \\
\text { Recovery (EUR) yet to be } \\
\text { produced }\end{array}$ & $8.9 \%$ & $100 \%$ & $100 \%$ & $20.9 \%$ \\
\hline
\end{tabular}

Source: DECC 2014j

Note: Figures in brackets are those reserves that are in production or under development, NAG - non associated gas

The UKCS has faced a number of challenges in addition to those besetting a mature province. Foremost of these have been the high cost of operation, poor coordination and cooperation between the myriad players and since 2002 a relatively unattractive (and volatile) fiscal regime. These problems have been exacerbated by the recent fall in oil and, to a lesser extent, gas prices.

Despite the high costs in the sector many existing and potential offshore gas developments are likely to be profitable even at relatively low gas prices. This is demonstrated in figure 28 .

Figure 28: New development breakeven (levelised) costs for selected UK gas sources

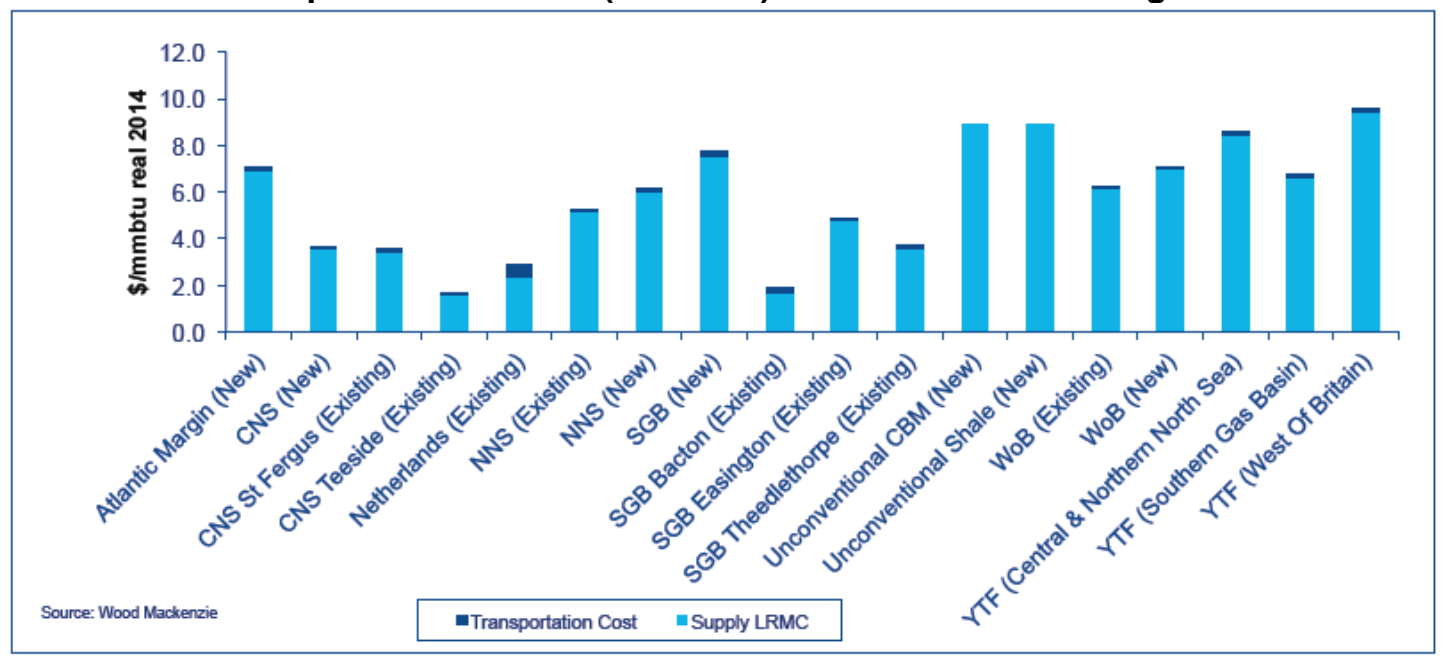

Note: $\$ 6 / \mathrm{mmbtu}$ is equivalent to 39p/therm at May 2015 exchange rate of $\$ 1=£ 1.54$ For more information on conversion factors see Appendix B. 

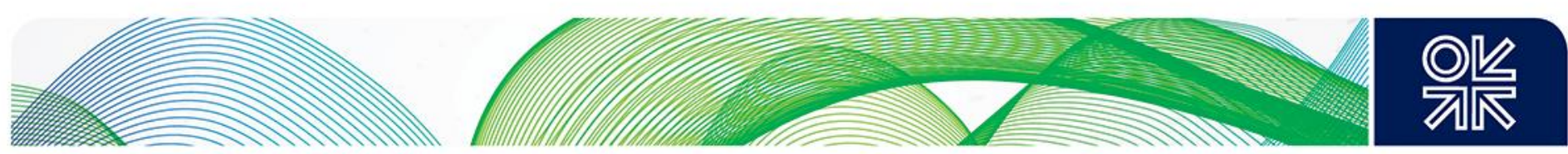

Whilst there have been some surges in investment; high costs, poor fiscal regime and (more recently) falling gas prices have caused a significant slump in activity.

Traditionally the UK offshore sector was characterised by light touch regulation though as production and activity has declined greater attention has been paid to means whereby Government intervention might help. The PILOT scheme ${ }^{177}$ whereby government and industry have worked in partnership has been running for some years and whilst it has had some success in, for example, the sharing of information there has been a sense that it has failed to deal with the major issues such as gaining access to existing infrastructure which still remains a significant obstacle for new, marginal developments.

In recognition of the issues DECC commissioned the Wood review in 2013. In its 2014 report $^{178}$ it recommended a more cohesive approach from Government, industry and regulators towards a shared objective of "Maximising Economic Recovery (MER) for the UK". Towards this end the review recommended the establishment of a new regulatory body with greater powers to facilitate MER, a more collaborative approach amongst industry participants and the introduction of strategies to address key issues such as infrastructure, technology, regional development and asset stewardship.

The Review noted a particular concern regarding the gas prone Southern North Sea (SNS). This region was vulnerable to rapid decline though with some continuing potential from new fields such as Cygnus and Tolmount. Wood claims the region is in danger of premature contraction and decommissioning and in urgent need of a coordinated development plan to avoid this. Particular problems for the region include:

- Relative lack of attractiveness of gas versus oil (though this was when comparative prices were $\$ 60 / \mathrm{bpe}{ }^{179}$ for gas $v \$ 105 / \mathrm{bbl}$ for oil so the recent fall in oil price may have closed this gap somewhat;

- Undifferentiated tax regime between oil and gas which makes gas less attractive - marginal tax rate for gas in the UK is $81 \%$ versus $50 \%$ in the Netherlands;

- Access to infrastructure at competitive rates

Comparison with the Netherlands also shows that UK gas production rates in the SNS have fallen more sharply even though reserves are higher.

The Oil and Gas Authority (OGA) has been established and will be vested as a Government Company in 2016 - timing that many have criticised as being overly tardy. One of the key issues it will have to tackle is that of access to infrastructure - a particularly important detail for many gas projects.

\subsubsection{Access to UKCS infrastructure}

The traditional development model in the North Sea was for oil and gas pipelines to be developed and owned by operators as required, usually as the export facilities for typically early, large field developments. As the number of later, typically smaller discoveries increased, it became apparent that it was necessary (and beneficial) to make infrastructure available to third parties. This was generally achieved on an ad hoc basis involving bi-lateral negotiations between infrastructure owners and new field developers.

Some pipeline systems (e.g. CATS ${ }^{180}$ ) were developed and structured to make access relatively easy with standard terms and conditions, though in many other cases there was dissatisfaction that access was not being made available in a fair and transparent manner.

\footnotetext{
${ }^{177}$ For details see http://www.oilandgasuk.co.uk/PILOT.cfm

${ }^{178}$ Wood (2014)

${ }^{179}$ bpe - barrel of petroleum equivalent

180 http://www.bp.com/en/global/north-sea-infrastructure/Infrastructure/Terminals/CATS.html
} 

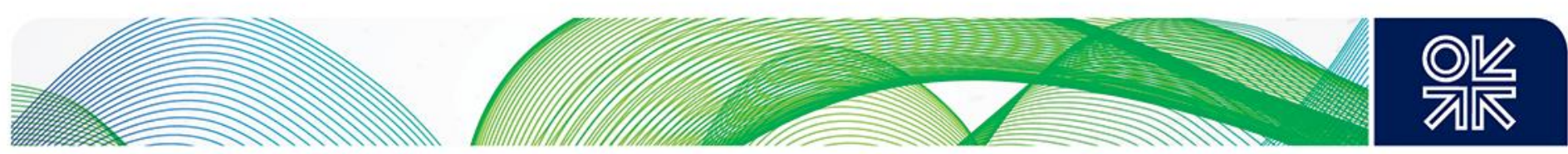

In 2002 Government pressed the industry to choose between regulated access or a voluntary industry code for negotiated access developed within existing legislation. Unsurprisingly the industry opted for the latter and the Infrastructure Code of Practice ${ }^{181}$ (ICOP) was introduced in 2004. This was seen as a preferred alternative to formal regulation though legal rights to seek access were in place and the Secretary of State for Department of Energy and Climate Change had powers under the Petroleum Act (1998) to settle disputes relating to access to infrastructure by determining that access be provided and on what terms. In practice these powers were rarely called upon even though, as recognised by the 2014 Wood review new developments continue to be constrained through failure to gain access to existing infrastructure.

Wood points out that there is a fundamental mismatch between the interests of the two parties:

- The facilities owner for whom third party processing is of little economic value whilst presenting the possibility of reducing capacity for its own developments and increasing operational risk;

- The new developer has limited bargaining power and faces delays in seeking to deal with all of the issues.

To deal with these issues Wood recommends:

- The OGA should work with government and industry to develop coherent plans for existing and infrastructure with appropriate returns;

- Infrastructure should be included within the asset stewardship process and regional infrastructure plans developed;

- The Regulator should make greater use of the legal powers available to resolve disputes regarding access to infrastructure;

- Consideration should be given to measures to reduce tariffs - infrastructure should not be treated as a high margin activity. PRT has been removed from tariff income though it is still subject to the supplementary charge - any reduction in taxation should be passed on to users;

- Measures to establish dedicated transport and processing companies should be considered. This could be along the lines of NOGAT BV in the Netherlands and could apply to both existing and new facilities.

There are also some practical problems with granting access. For example in declining fields the volumes of liquids that need processing may remain stable though the proportion of hydrocarbons is displaced by increased water. So spare capacity is not always available. There were plans to include elements of the Wood recommendations in the 2015 Infrastructure Bill though these were removed following lobbying from the industry. It seems that whilst all parties agree what needs to be done individual commercial interests continue to dominate.

\subsubsection{UKCS fiscal regime}

A major criticism of Government policy has been the "punitive" and excessive changeability of the fiscal regime. Tax rates were relatively low up to the early 2000s. Analysis by Boue and Wright (2010) in which they describe the UKCS fiscal regime as non-proprietorial - in other words it is designed to maximise economic recovery of reserves as opposed to government take - shows fiscal revenues per boe falling from $57 \%$ in 1986 to $16 \%$ in 1999 . Boue and Wright criticise the failure of this change. In their view government take was relaxed without achieving a 'quid pro quo' from the industry in the form of increased exploration and investment activity. However, this analysis may not fully reflect the dynamics of a maturing petroleum province where production from existing fields is declining, new discoveries are smaller and unit operating and development costs are increasing.

${ }^{181}$ See http://www.oilandgasuk.co.uk/knowledgecentre/InfrastructureCodeofPractice.cfm 

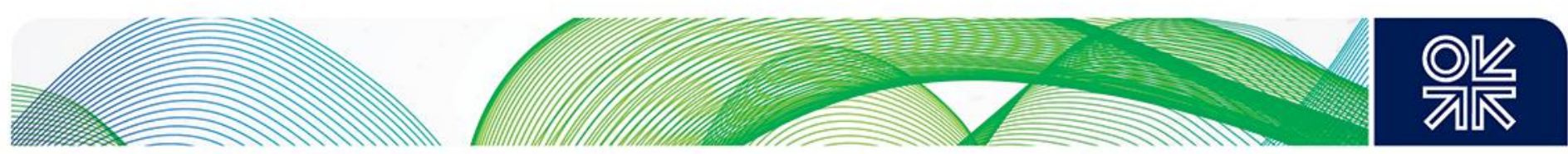

Furthermore UKCS gas production was maintained to 2002 despite successive forecasts of decline. In the early 1990s the average reserves of new fields starting production was in the region of $60 \mathrm{bcm}$. This increased to over $100 \mathrm{bcm}$ by 1994 (NG Transco 2002 TYS) and this higher level was maintained for some 5 years. It was only in 1998 that new developments were insufficient to match the growing levels of demand.

The fiscal position was tightened in 2002 and up to 2010 marginal tax rates per boe have been in the region of $50 \%$ for post- 1993 fields and $70 \%$ for pre-1993 fields. Following the tax change in 2011 the marginal rate increased to $81 \%$ on the oldest fields and $61 \%$ for post-1993 fields. ${ }^{182}$ Incentives were put in place to assist shallow fields and small fields and this has been particularly directed at gas, though the industry claims the requirements are excessively bureaucratic. Following extensive industry lobbying the 2015 Budget contained a number of provisions to simplify and improve the fiscal regime resulting in a fall in marginal rates to $50 \%$ for post-1993 fields and $67.5 \%$ for pre-1993 fields ${ }^{183}$.

One clear impact of the 2011 tax rise has been a fall in exploration activity and the most recent report from UK Oil \& Gas (2015) shows that in 2014 only 14 exploration wells were drilled with between 8 to 13 exploration wells anticipated for 2015 . The report notes that fiscal terms and oil price falls are the main reasons for the decline and that prospectivity is still considered to be high - particularly in the Central North Sea. The 2015 budget did include provisions for £20 million support in 2015-16 for surveys of under-explored areas though this is not expected to have a major impact.

Looking ahead, ICIS forecast that UKCS gas production is set to rise in 2015 due to the start-up of Total's Laggan-Tormore and Engie's (formerly GDF Suez) Cygnus fields ${ }^{184}$. Government also continues to encourage new developments in the UKCS and the 28th Offshore Licensing Round was launched in April 2014. Whilst over 170 applications were made for more than 350 blocks and 134 licenses granted UKOG have noted that the work programme commitments were primarily based on the obtaining or re-processing of seismic data and the number of wells proposed was disappointingly low ${ }^{185}$.

Experience from other mature production provinces such as the USA suggests that tail production can be prolonged much beyond initial estimates of field abandonment. This arises for a number of reasons:

- Initial abandonment pressures are often simply engineering assumptions that take no account of economics. As fields come close to these pressures it is often the case that marginal investments can prolong production levels significantly and profitably;

- Surplus pipeline capacity (ullage) is more readily available - though due to increasing water-cut, oil processing facilities may need expanding;

- Operators may be keen to prolong production to postpone abandonment costs;

- Technological developments such as horizontal drilling may allow recoveries to be enhanced.

A counter argument however is that where production is offshore in a high cost environment the operating costs of the production platform must be covered by its producing wells. Once this is not the case the field is abandoned. Onshore USA producing wells do not have to carry such a high fixed operating cost burden and so can continue at lower rates.

\footnotetext{
182 Scottish Government (2011)

${ }^{183}$ For details see http://www.woodmac.com/public/media-centre/12526863

$184 \mathrm{http} / / /$ www.icis.com/resources/news/2015/01/05/9849921/2015-outlook-politics-and-regulation-to-reshape-british-gasmarket/?cmpid=NLC|ENER|CHEEN-2015-0107-GLOB\&sfid=70120000000taAQ

${ }^{185} \mathrm{http}: / /$ www.oilandgasuk.co.uk/news/news.cfm/newsid/1104
} 

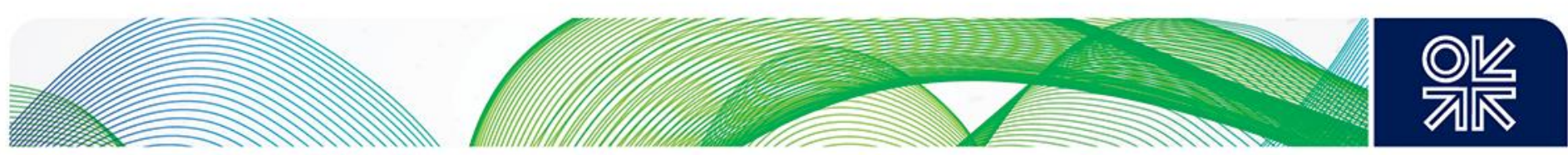

However, probably the biggest challenge facing the UKCS is the sharp decline in oil prices. This is a concern for three reasons.

- The oil price fall has led to some reductions in regional gas prices linked contractually to oil. This has lowered the arbitrage ceiling on hub based gas prices such as the NBP which are in any case depressed due to stagnant demand and an anticipated surge in new LNG supply between 2015 and 2020. This has called into question the viability of some existing fields.

- Many future gas producing developments are primarily driven by the presence of oil and condensate and so may be deferred or cancelled.

- Offshore labour costs may prove hard to reduce due to the difficulty of re-negotiating terms and conditions that were granted during times of high oil prices.

Some commentators ${ }^{186}$ have suggested that, while some developments may be postponed overall, the impact of lower gas prices should not be too damaging. A mixture of cost cutting, new technologies and improved fiscal terms could redress the balance and overall the long term level of UKCS production is unlikely to change significantly as result of the price situation. Furthermore, if gas prices do fall further and remain low for a sustained period this would be as a result of a continuing surplus of low cost gas from around the world. Under these circumstances it may make more sense from a government point of view to import these cheaper supplies and preserve UKCS reserves for future periods of higher prices (and higher government take).

Others are less sanguine. Sir lan Wood estimates that at an oil price of $\$ 50 /$ barrel $40 \%$ of UKCS fields are losing money ${ }^{187}$. There is a real concern that this may accelerate decommissioning and remove critical elements of offshore infrastructure creating a so-called technical and economic domino effect leading to earlier de-commissioning of other infrastructure and making the prospects for new developments much tougher. ${ }^{188}$ This has led some to call for the creation of a state backed North Sea investment fund to maintain and upgrade essential infrastructure and possibly underwrite the financing of fields during periods of low prices that would otherwise be shut in ${ }^{189}$.

There is also a security of supply aspect. It is noteworthy that whilst the UKCS contribution to UK energy security is often mentioned in broad terms there appears to be little recognition of the specific additional advantages that indigenous gas reserves provide. It could be argued that oil security is of less concern as the commodity is both more readily available through international trading and more easily stored. As noted above gas security of supply is subject to a great range of technical, commercial and geo-political considerations and there is a case for this to be particularly recognized in terms of UKCS gas reserves and production. Identifying measures (fiscal and otherwise) that particularly target this aspect deserve further examination. One option would be to develop some form of security of supply rebate to apply to existing and planned gas developments as a way of maintaining a role for UKCS gas in meeting future demands. This type of measure could also be used to make winter production more attractive (versus summer production) in order to prolong the number of years during which UKCS gas can contribute to seasonal demands.

\subsubsection{Onshore}

Until relatively recently the future prospectivity of UK onshore hydrocarbons was considered to be low. The two largest discoveries were Wytch Farm (primarily oil) and Saltfleetby with recoverable gas reserves of $1.4 \mathrm{bcm}$ and $2.1 \mathrm{bcm}$ respectively. All other discoveries to date have recoverable reserves

\footnotetext{
${ }^{186}$ See for example http://pwc.blogs.com/scotland/2015/02/can-the-uk-oil-gas-industry-find-opportunities-in-adversity-.html

187 http://knowledge.energyinst.org/Energy-Matrix/product?product=87449

188 OGA (2015)

189 See for example http://blogs.ft.com/nick-butler/2015/02/22/dont-abandon-the-northsea/?ftcamp=crm/email/2015223/nbe/CompaniesBySector/product
} 

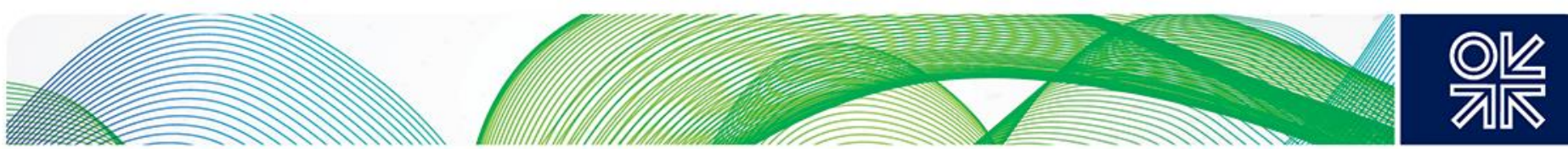

of less than $0.5 \mathrm{bcm}^{190}$. Onshore gas production has been falling steadily and in 2013 was just 11 million $\mathrm{m}^{3}-0.03 \%$ of that produced offshore ${ }^{191}$.

This perspective has been radically altered by the transformational impact of shale gas exploitation in the USA. The prospect of a similar bonanza in the UK has excited a great deal of interest - and opposition - though to date activity has been limited. It is not the intention of this paper to debate the merits or otherwise of shale gas exploitation in the UK ${ }^{192}$ though given the attention the topic has received in the media and elsewhere the prospects for shale gas need to be considered.

The British Geological Society (BGS) have undertaken an extensive survey of shale gas prospects ${ }^{193}$. Figure 29 shows the regions that might have potential, though BGS suggests that northern England may be the most prospective as it bears the greatest similarities to US shales.

Figure 29: Outcrop of main black shale formations in UK and selected oil and gas wells and gas fields

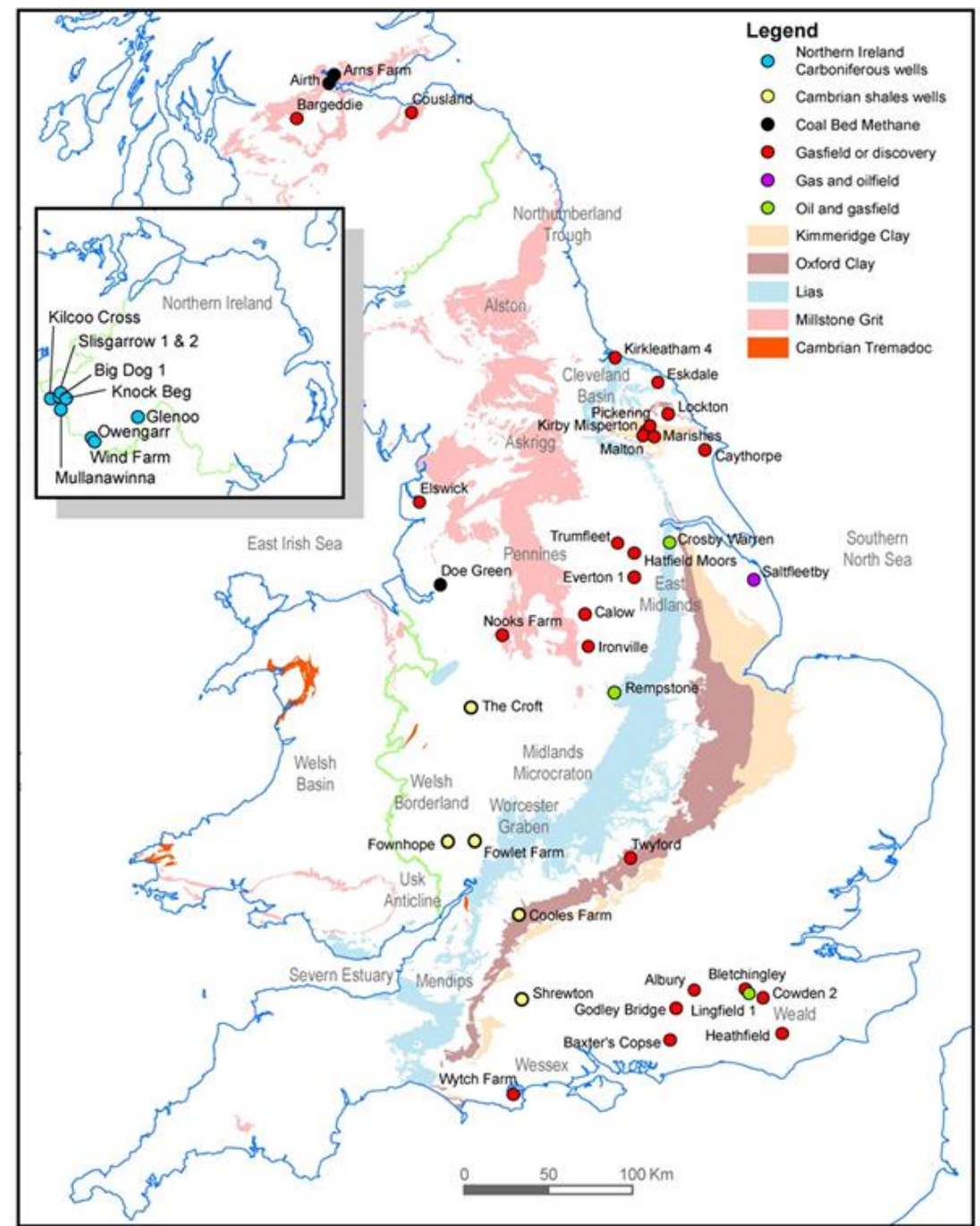

Source: British Geological Survey http://www.bgs.ac.uk/research/energy/shaleGas/howMuch.html

\footnotetext{
190 DECC (2013f)

${ }^{191}$ DECC (2014k)

192 See Bassi et al, (2013)

${ }^{193}$ Andrews, (2013)
} 

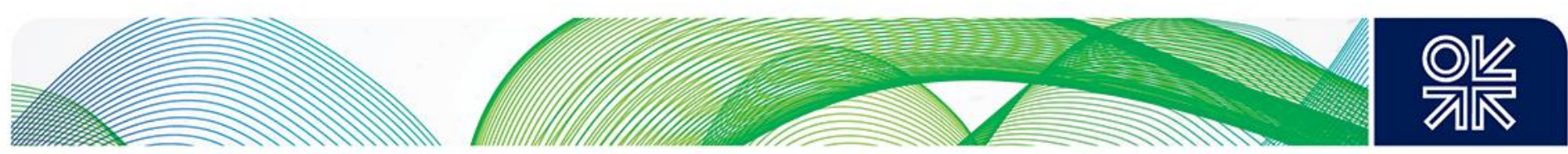

Because of the lack of data from wells drilled, estimates of resources are based on applying a range of recovery rates to assumed levels of gas in place. As a result there is a wide range of resource, reserve and production estimates. For example:

- BGS have developed a central estimate of $37.6 \mathrm{tcm}$ of gas in place (GIP) for the Bowland shale ${ }^{194}$. BGS state it is presently not possible to develop a reserves estimate.

- Cuadrilla estimate there is $5.7 \mathrm{tcm}$ GIP in the Bowland shale. ${ }^{195}$

- Ricardo AEA, commissioned by the Environment Agency and reported in Rural Community Policy Unit (2014), estimate that a high US-style scenario of 12,500 producing wells (with a peak drilling rate of 1,100/year) could generate $80 \mathrm{bcm}$ peak production across the UK, with mid and low scenarios producing $10 \mathrm{bcm}$ and $1 \mathrm{bcm}$ at peak respectively

- NG's latest estimate ${ }^{196}$ is for 2025 and 2030 production of between zero and $17 \mathrm{bcm}$ and zero and $32 \mathrm{bcm}$ respectively

- An IOD report (2013) aggregated the various exploration company estimates to 8.7 tcm to which they then applied recovery rates ranging between 5 and $25 \%$.

As Rogers (2013) points out, the conclusions drawn from these estimates regarding production are overly simplistic. He notes that the number of wells drilled in Pennsylvania alone has grown from zero to over 2,000/year in 2011 - a huge number by UK standards. In addition rapid production decline rates means that a large number of extra wells is needed year after year to maintain production levels. Recent studies in the US ${ }^{197}$ also point to the need to drill a large number of wells in order to understand where the most prospective areas are. Finding these "sweet spots" is not simply a matter of studying seismic and well log data - drilling is the only answer.

Speaking in November 2014 Paul Stevens of Chatham House noted that shale provinces seemed to be highly differentiated and a great deal of highly specific research and development is required to determine the best approach to recovering reserves. He noted that ExxonMobil pulled out of Poland because the US technology did not work there and another approach was required ${ }^{198}$.

This all adds up to the fact that large numbers wells are required and a great deal of expenditure before it is possible make a realistic estimate of potential resources. This in turn raises the question of public acceptance. Leaving aside the objections to the hydraulic fracturing process, any on-shore activity will require significantly higher vehicle movements (HGV traffic) and other disruptions. Hartley (2014) estimates the drilling and fracturing phase for a typical well takes around 3 to 4 months and will involve 200 truck movements, the 84 month production phase requires another 400 truck movements. Some of this impact might be mitigated by drilling multiple wells from a single well pad and there is no doubt that successful shale development could provide a much needed boost for some communities. Nevertheless it would appear at present that the initiative is with those that want to block shale developments and so timescales could be extended.

The Government has recognised these issues and has pursued a number of initiatives:

- Fiscal encouragement

- Local support - communities can keep $100 \%$ of business rates, this could be worth up to $£ 1.7$ million/year for a typical site ${ }^{199}$

\footnotetext{
194 The Bowland basin broadly corresponds to the Millstone Grit sequence in NW England shown in figure 29

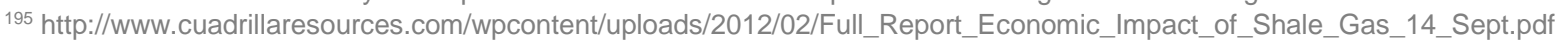

${ }^{196}$ National Grid (2014a)

197 Ikonikova et al, (2014)

198 http://www.naturalgaseurope.com/ukerc-uk-shale-rhetoric-reality
}

199 https://www.gov.uk/government/news/local-councils-to-receive-millions-in-business-rates-from-shale-gas-developments 

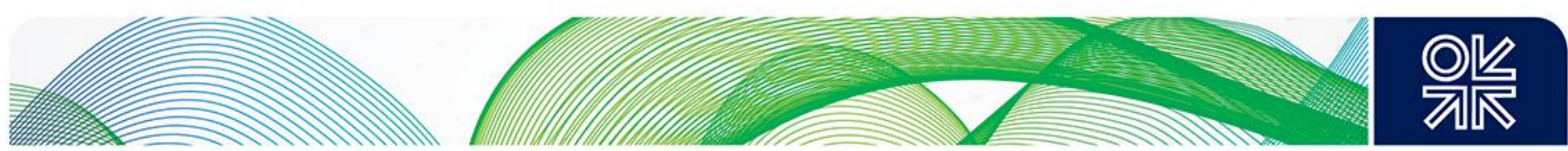

- The recently passed Infrastructure Act (UK Government 2015) - this excludes Scotland - has provisions to allow underground access for shale gas and oil and deep geothermal underground drilling. Though amendments have restricted the application to National Parks.

- To try to overcome the issue of the extended process in gaining regulatory approval DECC has published a regulatory roadmap ${ }^{200}$ covering exploration though it has yet to develop a regulatory regime for full production.

Progress on the ground remains slow. The Scottish Government has introduced a moratorium on granting consents for shale gas and coalbed methane developments while further research and a public consultation was carried out. ${ }^{201}$ Cuadrilla Resources, one of the most active shale companies, had its planning application to undertake further seismic and pressure monitoring work at a previously drilled well turned down by Lancashire County Council ${ }^{202}$ though planning officers subsequently recommended approval in June 2015 for one well to be drilled203.

Another company, Ineos, has taken a proactive approach to development and plans to use shale gas produced in its petro-chemical plant. As an incentive to gain support from local communities it has announced that it will give $6 \%$ of the revenues to those living above its shale gas operations.

The consensus view is that any appreciable impact from shale production is at least ten years away and even then there is a wide range of possible outcomes as evidenced by the National Grid (2014a) forecasts shown above.

There is the possibility of increased supplies from bio-methane. There are already 360 biogas plants in the UK ${ }^{204}$ and this number is set to increase. Volumes are relatively small, though some estimates suggest output could exceed 7 TWh annually $(0.7 \mathrm{bcm})$ by $2020^{205}$ and the environmental benefits of biogas are significant.

\subsection{Security of supply and the role of gas storage}

The other major area of consideration on the supply side is that of security of supply. As we have noted the growing dependence on imported gas plus some major supply scares both internally and internationally ${ }^{206}$ mean that the subject remains an important consideration for policy makers.

There are two main components to gas security. The ability to meet demands on a peak day and over extended periods of high demand. The peak day position and how it has evolved in recent years in shown in table 14.

\footnotetext{
$200 \operatorname{DECC}(2013 e)$

201 http://www.bbc.co.uk/news/uk-scotland-31554251

202 http://www.cuadrillaresources.com/news/cuadrilla-news/article/statement-from-cuadrilla-resources-regarding-grange-hillofficers-recommendation/

203 This was subsequently refused by Lancashire county council on 24 June 2015

204 Energy World April, 2015, "Europe's biogas industry reports strong growth"

205 http://www.cngservices.co.uk/assets/Uploads/2-Presentation-Day-1-15th-June-2015.pdf

${ }^{206}$ See Le Fevre (2013)
} 

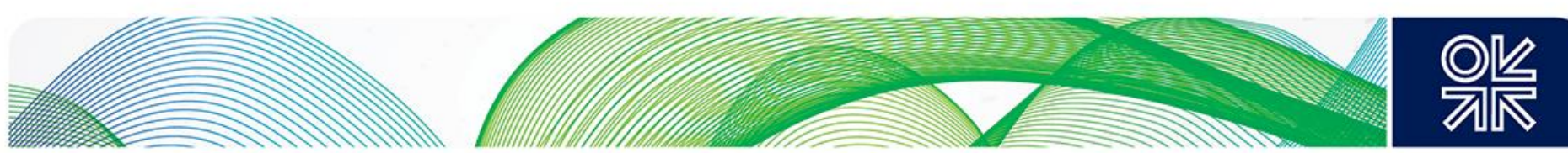

Table 14: Forecast maximum peak day supply $\&$ demand ${ }^{207}$

\begin{tabular}{|l|l|l|l|l|l|l|l|}
\hline Source & \multicolumn{2}{|l|}{$2005 / 6$} & \multicolumn{2}{l|}{$2009 / 10$} & \multicolumn{2}{l|}{$2012 / 13$} & $2014 / 15$ \\
\hline & Mcm/d & $\%$ & Mcm/d & $\%$ & Mcm/d & $\%$ & Mcm/d \\
\hline UKCS & 327 & 63.9 & 183 & 33.9 & 137 & 26.0 & $76-109$ \\
\hline Norway & - & & 118 & 21.9 & 115 & 21.9 & $60-130$ \\
\hline Continent & 48 & 9.4 & 55 & 10.2 & 66 & 12.5 & $10-119$ \\
\hline $\begin{array}{l}\text { LNG } \\
\text { imports }\end{array}$ & 17 & 3.3 & 60 & 11.1 & 100 & 19.0 & $8-100$ \\
\hline Storage & 120 & 23.4 & 124 & 23.0 & 108 & 20.5 & $0-136$ \\
\hline Total & 512 & 100 & 540 & 100 & 526 & 100 & $154-595$ \\
\hline $\begin{array}{l}\text { Forecast } \\
\text { peak day }\end{array}$ & $540^{208}$ & 105.5 & 502 & 93.0 & 516 & 98.1 & 500 \\
\hline
\end{tabular}

Source: National Grid Winter Outlooks and author's calculations. Note actual performance may exceed forecast levels on some occasions

There are two particular points that emerge from Table 14. Firstly in 2014/15 there was a significant surplus of total daily capacity over the forecast peak day demand. Secondly it has become increasingly unclear where the gas will come from on any particular day. Hence the range of production figures shown in the final column. This means that the National Grid system has to become increasingly flexible to deal with a wide range of potential supply configurations.

It is also clear from Table 14 that storage remains an important contributor to meeting high demand requirements. An assessment of current storage working capacity and deliverability is shown in Table 15. It is important to note that the daily deliverability figures are in the main based on assessments published by NG in the Ten Year Statement ${ }^{209}$. These numbers are generally maxima and in practice daily deliverability will be below these levels. NG's latest assessment from the 2014/15 Winter Outlook (shown in table 14) is for an assumed maximum total deliverability of $136 \mathrm{mmcm} /$ day. The table also shows the theoretical capacity and delivery of the three LNG terminals by way of comparison.

\footnotetext{
${ }^{207}$ Norwegian imports are included within UKCS for 2005/6, Continent comprises IUK and BBL

208 Based on cold weather analysis - NG assume demand side response would suppress demand to match supplies - see http://www.nationalgrid.com/NR/rdonlyres/B9DC52C9-0F4E-4C83-9F5F-41A7822C5B80/4988/WORautumn2007.pdf

${ }^{209}$ National Grid (2014b)
} 

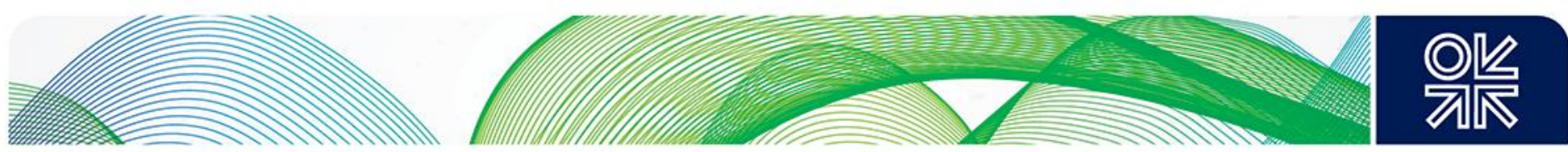

Table 15: Existing storage facilities

\begin{tabular}{|c|c|c|c|c|c|}
\hline Facility & Owner & Type & Location & $\begin{array}{c}\text { Working } \\
\text { Capacity } \\
\mathrm{mcm}^{210}\end{array}$ & $\begin{array}{c}\text { Delivery } \\
\mathrm{Mcm} / \mathrm{d}\end{array}$ \\
\hline Rough & Centrica & Depleted field & $\begin{array}{c}\text { Offshore } \\
\text { Easington }\end{array}$ & 3,660 & 41 \\
\hline Hatfield Moor & Scottish Power & Depleted field & Yorkshire & 70 & 2 \\
\hline Humbly Grove & Star Energy & Depleted field & Hampshire & 252 & 7 \\
\hline Aldbrough & SSE/Statoil & Salt Cavity & Yorkshire & 300 & 40 \\
\hline Holford & E.On & Salt Cavity & Cheshire & 220 & 22 \\
\hline Hill Top Farm & EdF & Salt Cavity & Cheshire & 44 & 5 \\
\hline Hole House & EDF Trading & Salt Cavity & Cheshire & 42 & 11 \\
\hline Hornsea & SSE & Salt Cavity & Yorkshire & 300 & 18 \\
\hline Stublach & Storengy (GdF & Salt Cavity & Cheshire & 125 & 11 \\
\hline Avonmouth & National Grid & LNG & $\begin{array}{c}\text { Avon \& } \\
\text { Somerset }\end{array}$ & 49 & 13 \\
\hline Total & Various & & $\begin{array}{c}\text { Grain, } \\
\text { Milford } \\
\text { Haven }\end{array}$ & 1,700 & 100 \\
\hline LNG Terminals & & & 5,064 & 170 \\
\hline
\end{tabular}

Source: National Grid Ten Year Statement, 2014 p 34 and Storage and LNG Operator Information as at March 2014 at http://www2.nationalgrid.com/uk/Industry-information/gas-transmission-operational-data/supplementaryreports/

The levels of storage capacity shown in Table 15 are expected to increase in the coming years as expansion underway at the Hill Top Farm and Stublach facilities continues. These could add a further $14 \mathrm{mmcm} /$ day of deliverability by 2017 .

However a number of storage projects that have planning permission have either been put on hold or cancelled. Those cancelled include the Baird, Caythorpe, Gateway and Portland projects which together represent a potential storage capacity of $7.4 \mathrm{bcm}$. A number of other projects such as Deborah, Islandmagee (in Northern Ireland) and Saltfleetby are presently proposed ${ }^{211}$ but the combination of low seasonal spreads, static demand and lack of government funding suggest that any immediate progress in this sector is unlikely.

Furthermore existing storage is under some threat:

- Centrica Storage (CSL) announced ${ }^{212}$ a halt to capacity sales for the 2015/16 storage year in the Rough facility following the identification of a potential technical issue during a routine inspection that would limit the amount of stock in the Rough reservoir to a range of 29TWh to 32TWh (2.7 to $3.0 \mathrm{bcm}$ ) compared to the 2014 maximum of $41.1 \mathrm{TWh}(3.9 \mathrm{bcm})$. CSL subsequently confirmed on 2 June 2015 that the restriction would last at least until September 2015. It also stated it was applying to DECC for permission to reduce the lower limit of gas production in order to increase the licensed capability of Rough by approximately 4.5TWh (i.e. total reservoir volume would be

\footnotetext{
Actual levels of storage can exceed these numbers

${ }^{211}$ See National Grid (2014b) for a full list

212 http://www.centrica-sl.co.uk/index.asp?pageid=564
} 

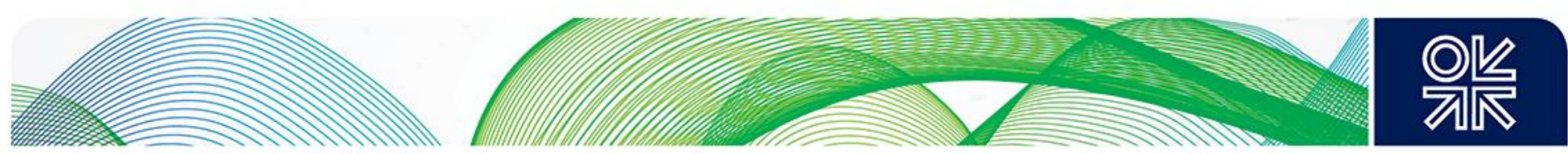

between 33.5 and $36.5 \mathrm{TWh}$ or 3.2 to $3.5 \mathrm{bcm}$ ). It also announced a new operating regime whereby the withdrawal capability (and contractual entitlement) will reduce once the storage stock is below half-full, and reduces to less than $50 \%$ of the current rate when the facility is empty 213 .

- SSE have announced that deliverability at its Hornsea salt cavity storage facility will be reduced by $6 \mathrm{mcm} / \mathrm{d}$ to $12 \mathrm{mcm} / \mathrm{d}$ by mothballing the older withdrawal plant. SSE blamed the challenging economic environment for gas storage and the impact of the Valuation Office Agency decision to effectively double business rates for most gas storage facilities ${ }^{214}$

The Rough announcement could have implications for the ability of the GB system to withstand a prolonged period of high demand. Figure 30 shows an indicative representation of deliverability against duration for existing storage.

\section{Figure 30: Storage deliverability $\mathbf{v}$ days of storage available}

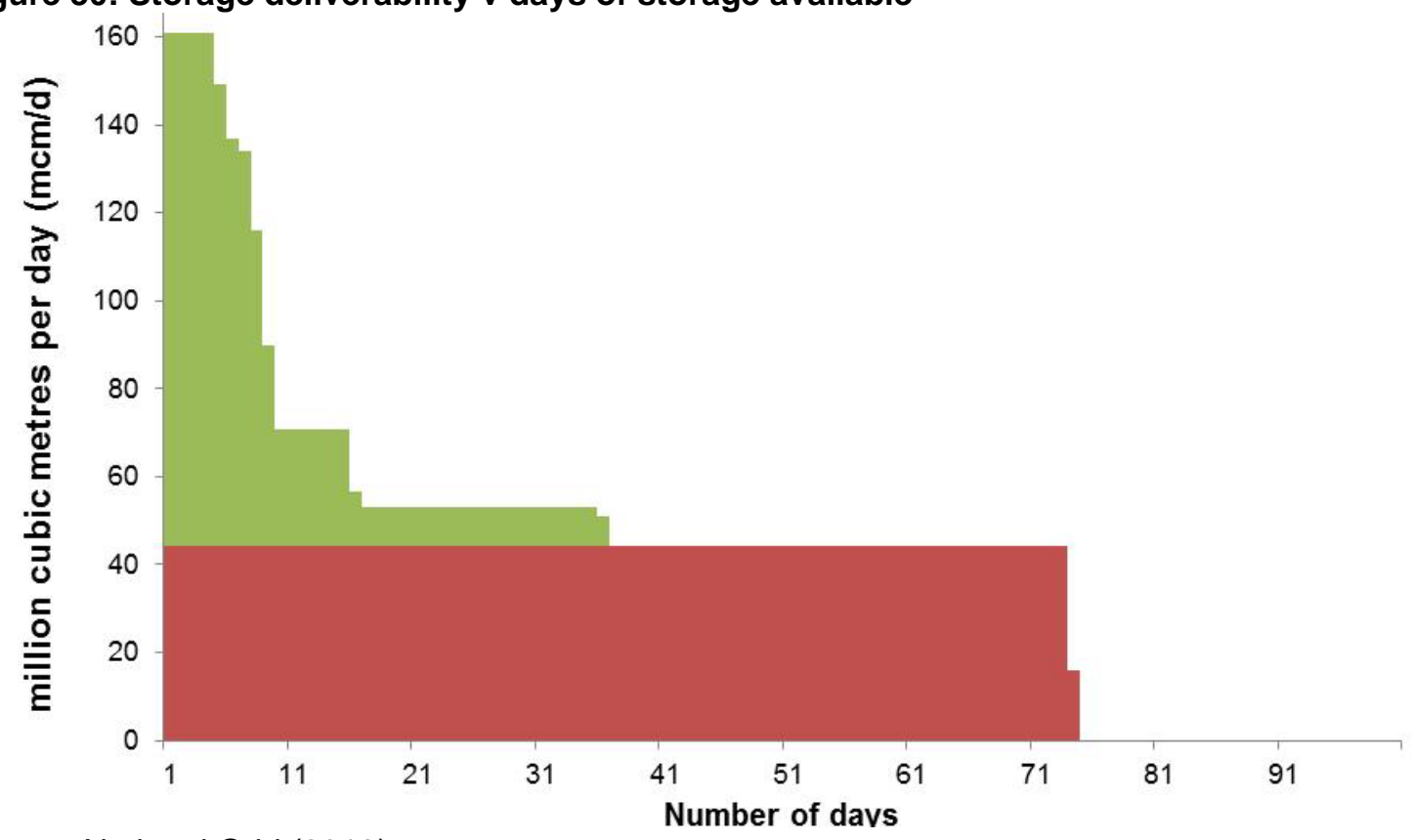

Source: National Grid (2013)

The loss of one third of Rough capacity could restrict deliverability to around 50 days at maximum flow rates though withdrawal rates are likely to fall well before stocks near depletion. The reduced flow rates as the facility depletes could also have an impact during an extended winter with high demands. It should however be noted that the days of deliverability for some of the other storage sites can be extended by rapid recycling (i.e. injection) during the winter period.

The lack of new build storage combined with the relatively low level of storage compared to other large gas consuming countries such as Germany and France continues to be a source of concern in some quarters. The OIES paper on gas storage (Le Fevre, 2013) examined the reasons for the relatively low level of gas storage developments in GB and concluded that the prime commercial reason was the relative collapse in summer-winter spreads and the associated fall in price volatility at the NBP trading hub.

The paper also concluded that contribution to flexibility from existing and planned fast cycle storage, LNG imports, Norwegian pipeline imports and continental imports via IUK and BBL had to date demonstrated a sufficient degree of responsiveness to deal with a range of supply and demand

\footnotetext{
213 http://www.centrica-sl.co.uk/index.asp?pageid=624

214 http://www.platts.com/latest-news/natural-gas/emea/sse-mothballs-33-of-uks-hornsea-gas-storage-withdrawal-

21201819?wt.mc_id=energybulletin_allcommodity_campaign_032615\&wt.tsrc=eloqua
} 

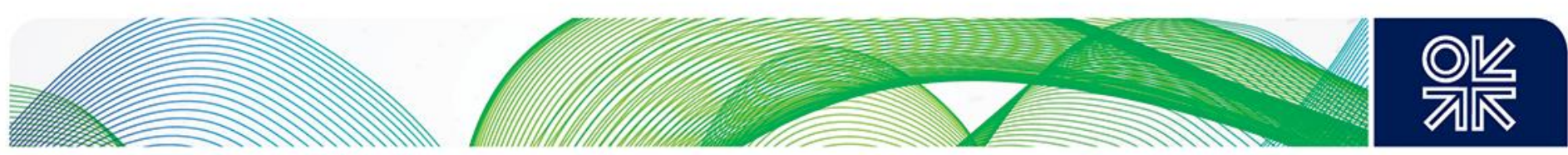

events. However it was also noted that with the likelihood of a growing dependence on imports GB could become increasingly exposed to high impact/low probability events which, by definition, the market is unable to price, though the impact is most likely to be in the form of (perhaps sharply) increased prices rather than interruptions to firm supplies. This was evident in the spring of 2013 when UK storage was virtually empty and a temporary disruption to IUK flows resulted in a brief but significant price spike (DECC 2014b). Even so the multiplicity of import options gives the UK market a great deal of resilience. A recent Europe wide security of supply study 215 indicates that even with a 9 month embargo of all Russian exports to Europe, UK gas volumes would be unaffected though prices would clearly rise.

Le Fevre (2013) demonstrated that there is plentiful storage capacity in NW Europe and more storage projects are being built such as the Bergermeer depleted field in the Netherlands. The move away from oil indexation in continental gas contracts and the growth of European trading hubs can only benefit the UK as gas flows become more responsive to price signals and infrastructure such as gas storage becomes more market orientated. Full market opening in countries such as Germany and France could lead to the conclusion that rather than the UK being exposed from too little storage these countries, to which the UK is well linked via IUK and BBL pipelines, are exposed to too much.

It is therefore difficult in the present conditions to make a case for state help to build more gas storage in the UK. Whilst the relative cost of funding new seasonal/strategic storage for the UK would be minor compared to the overall level of future energy investments the damage to the investment climate caused by ill-considered intervention could be much greater. In addition to the impact on commercial storage, intervention of this nature could make the GB market less attractive for other suppliers. LNG marketers may downgrade the UK as an option as the possibility for large returns during periods of tight supply no longer exist. Certain measures taken to improve security of supply could therefore have the opposite effect.

Furthermore security of gas supply is not a matter for storage alone and it is important to take a holistic view of alternative supply sources together with their level of responsiveness and robustness. Bradshaw et al (2014) notes that most gas supply emergencies are as a result of technical problems in either midstream or upstream facilities. Table 16 seeks to recognise these factors by providing an overview of the main sources of supply together with a commentary on their assessed level of responsiveness and longer term robustness. 

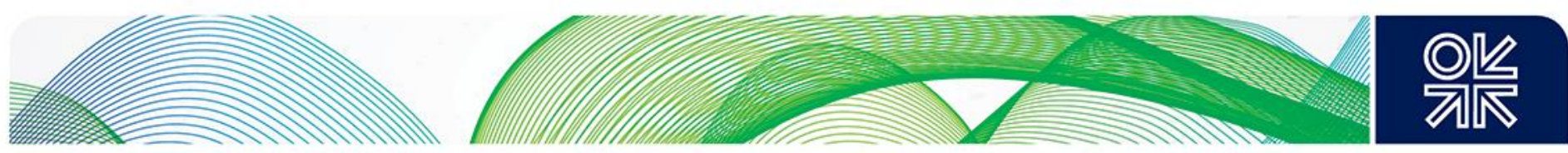

Table 16: Main GB supply sources; responsiveness and robustness

\begin{tabular}{|l|l|l|}
\hline Source & Short term responsiveness & Longer term robustness \\
\hline UKCS & $\begin{array}{l}\text { Very limited - usually producing at } \\
\text { maximum year round. }\end{array}$ & $\begin{array}{l}\text { Present projections suggest } \\
\text { decline in output post 2020. }\end{array}$ \\
\hline Norway & $\begin{array}{l}\text { Significant seasonal swing and the } \\
\text { potential to ramp up production further } \\
\text { though competing demands from } \\
\text { continent may restrict this. }\end{array}$ & $\begin{array}{l}\text { Present projections suggest } \\
\text { decline in output post 2020 } \\
\text { under some scenarios. }\end{array}$ \\
\hline Continent & $\begin{array}{l}\text { Both BBL and IUK show seasonal } \\
\text { swing, IUK in particular which typically } \\
\text { switches from export to import in the } \\
\text { winter and has shown an ability to flow } \\
\text { at very high levels at relatively short } \\
\text { notice. }\end{array}$ & $\begin{array}{l}\text { Main concerns relate to } \\
\text { restrictions on Groningen } \\
\text { production and the status of } \\
\text { IUK capacity post 2018 when } \\
\text { existing contracts expire. }\end{array}$ \\
\hline LNG imports & $\begin{array}{l}\text { If stocks are available at terminals } \\
\text { supplies can ramp up quickly. Diverting } \\
\text { additional cargoes has much longer lead } \\
\text { times. }\end{array}$ & $\begin{array}{l}\text { Can expand capacity at } \\
\text { Grain216 and other projects } \\
\text { are proposed. }\end{array}$ \\
\hline Storage & $\begin{array}{l}\text { Designed for seasonal and peak } \\
\text { demand response. Fast-cycle storage } \\
\text { likely to inject and withdraw throughout } \\
\text { the winter. }\end{array}$ & $\begin{array}{l}\text { Questions over Rough and } \\
\text { Hornsea and how many new } \\
\text { projects will actually } \\
\text { complete. }\end{array}$ \\
\hline $\begin{array}{l}\text { Contractually based interruption of large } \\
\text { users has played an important role } \\
\text { During periods of very high demand. } \\
\text { response is underway. }\end{array}$ & $\begin{array}{l}\text { Too early to say whether this } \\
\text { will have a major long term } \\
\text { impact. }\end{array}$ \\
\hline
\end{tabular}

Source: Author's analysis

The level of responsiveness assessed in Table 16 confirms that in the short term there are a range of options though longer term there are a number of potential concerns. Norwegian production could start to decline post 2020 unless there is a concerted effort to invest in infrastructure accessing the more northerly gas fields. IUK have begun to market long term capacity contracts from 2018 when the existing 20 year contracts expire ${ }^{217}$. If there is insufficient interest in buying capacity from Belgium to Bacton the existing capacity could be downgraded thereby reducing responsiveness to demand increases from this critical source. As noted above some of the gas storage facilities are starting to show signs of wear and the possibility of partial decommissioning is of concern. Restrictions on output from the giant Groningen field in response to the earthquake ${ }^{218}$ risk is another example of the type of disruption that can occur. However up to May 2015 this was having a minor impact on prices and none on supplies.

There are also a range of external factors that need to be considered from a security of supply perspective. Developments such as:

- A major increase in forecast gas demands

\footnotetext{
${ }^{216}$ Grain Phase 4 has all consents in place though FID is awaiting market requirements. See P Carter presentation http://www.eua.org.uk/sites/default/files/Phil-Carter.pdf 217 http://www.interconnector.com/media/96237/20150204 - 2018 capacity sales - launch event presentation.pdf 218 http://www.reuters.com/article/2015/02/18/netherlands-gas-gasterra-idUSL5N0VS1IV20150218
} 

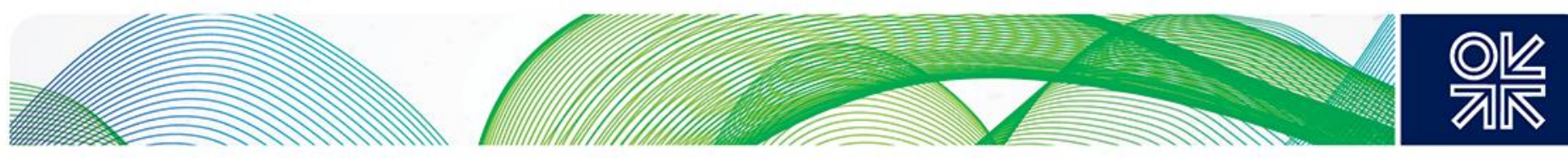

- A material change in the global availability of LNG supply

- A significant reduction in the capability or capacity of existing storage and interconnectors

- A reduction in the pace of liberalisation of the NW European gas market

- An appreciable widening of price spreads that did not stimulate new storage investments

would all require a re-appraisal of the supply outlook. Table 17 assesses the present state for each of the above criteria.

\section{Table 17: External factors meriting a review of supply security}

\begin{tabular}{|l|l|}
\hline Criteria & Outlook \\
\hline A major increase in forecast gas demand & $\begin{array}{l}\text { Both annual and peak forecasts remain stable } \\
\text { or falling }\end{array}$ \\
\hline $\begin{array}{l}\text { A material change in the global availability of } \\
\text { LNG supply }\end{array}$ & $\begin{array}{l}\text { Global surplus likely to develop but } \\
\text { uncertainty over whether this will persist }\end{array}$ \\
\hline $\begin{array}{l}\text { A reduction in the pace of liberalisation of } \\
\text { the NW European gas market }\end{array}$ & $\begin{array}{l}\text { Some aspects of the Energy Union could run } \\
\text { counter to market opening objectives }\end{array}$ \\
\hline $\begin{array}{l}\text { An appreciable widening of price spreads } \\
\text { that did not stimulate new storage } \\
\text { investments }\end{array}$ & $\begin{array}{l}\text { Seasonal spreads have widened sporadically } \\
\text { but overall remain low }\end{array}$ \\
& $\begin{array}{l}\text { evidence of a structural recovery that can be } \\
\text { observed in forward market pricing }\end{array}$ \\
\hline
\end{tabular}

Source: Author's analysis

Overall it would appear that the main risk to supply security arises from existing assets being decommissioned either because there is insufficient demand or the cost of refurbishment cannot be justified - or a combination of the two factors. This is a particular aspect of markets characterised by falling demand. As the utilisation of infrastructure elements declines, unit costs increase. Whilst there may not be case for intervention in the present circumstances it would be unwise to be complacent.

Government and Ofgem should consider whether there is a case for guaranteeing rate of return for certain critical pieces of supply infrastructure as well as continuing to monitor the long term situation regarding both markets and supply outlook.

\subsection{Conclusions on the supply outlook for the GB gas market and the policy implications}

It was argued in previous chapters that the transition caused by the decline of domestic gas production and loss of self-sufficiency has probably been the single most important factor shaping the UK gas market.

UKCS gas production has been falling for some 10 years though is presently on a plateau. There is of course an element of inevitability in that all hydrocarbon provinces will in time decline as the remaining prospectivity is in smaller high cost fields and unit costs will correspondingly increase. The joint challenge to Government and industry is to optimize the use of infrastructure to encourage maximum resource recovery through regulatory and fiscal tools. Steps are being taken to this end though decline cannot be postponed forever. The sudden fall in oil and gas prices has added further weight to the problem and it is far from clear whether the underlying cost base can be reduced sufficiently either to support planned new developments or to avoid early abandonment of old producing fields and still potentially useful infrastructure.

\footnotetext{
219 See Stern and Rogers (2014)

${ }^{220}$ Centrica report both 2014 and 2015 spreads in the region of $6-10$ p/therm $(\$ 1.0$ -

1.5/mmbtu)http://www.centrica.com/files/presentations/2015/prelims/content/zoom.asp?id=18

221 Timera (2015a)
} 

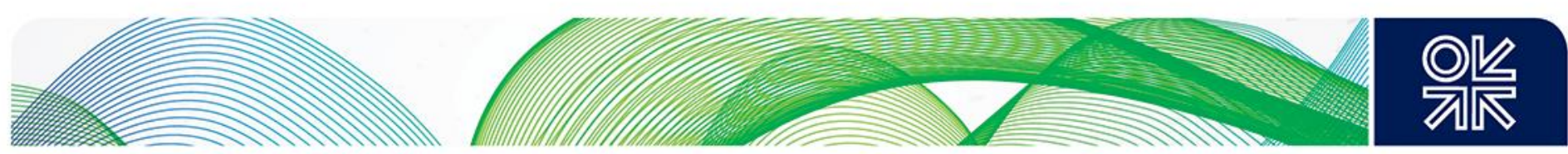

Nevertheless the UKCS could continue to play an important role in UK gas supply for many years to come - particularly if seasonal swing could be increased. Greater attention to how this might work within a more holistic approach to security of supply should be an important aspect of policy in this sector.

Shale gas may also come to play a role in time though it is not possible to make a valid assessment until more wells have been drilled and any appreciable impact is at least five and probably ten years away. Furthermore such an impact will only happen if reserves are proven and it is shown to be possible to drill and frack between 100 and 300 wells/year for a sustained period.

The UK market is well placed to take gas from a range of sources and the infrastructure is in place to allow this. Ensuring that the UK remains an attractive destination for gas exporters remains a key policy objective. Interconnections with the continental gas markets are also important components of the supply matrix and can be particularly important during periods of peak demand as they link the UK market to those in North West continental Europe which have high volumes of gas storage. Ensuring the necessary physical and commercial elements remain robust for these interconnections is also vital. The case for intervention to encourage more storage to be built remains difficult to make though continued monitoring of all aspects of gas security of supply remains important.

\section{Conclusions}

\subsection{The case for a "national strategy for natural gas"}

This study has sought to answer two key questions:

- How has UK energy policy impacted on the gas sector?

- Is there a case for an integrated natural gas strategy for the UK? Or to put it another way does the absence of such a strategy pose particular risks to the energy sector and the wider UK economy.

\subsubsection{Policy impacts on the gas sector}

In addressing the first question the study has initially considered how the gas market has evolved in the context of the overall UK energy market. It is clear that whilst absolute levels of gas demand have fallen the fuel is still the most important component in the UK's energy mix (48\% of non-transport consumption in 2013). Gas plays a vital role in residential heating and power generation and is also crucial in many industries.

On the supply front the range of sources (both pipeline gas and LNG) has grown dramatically in recent years as domestic production has fallen and the paper has argued that this transition from an enclosed self-sufficient market to one exposed to the cycles of global gas supply and demand has probably been the single most important factor shaping the UK gas market today.

In looking in greater detail at today's market the study has reached the following conclusions:

- The shift from self-sufficiency is most evident in the impact on prices, which are no longer determined by internal supply and demand fundamentals, but by a range of wider global influences.

- Concerns over rising prices - and to a lesser extent security of supply issues associated with growing import dependency -have shaped much of the policy initiatives directed towards the gas sector though there is little evidence of a coherent approach or specific objectives. The exposure to lower gas prices through increased global supply (as witnessed in 2015) has not been widely recognised as a positive aspect of having an open market.

- Government has sought to develop an over-arching narrative aimed at solving the affordability/environment/security "trilemma" through a commitment to competitive markets wherever possible. Leaving aside the issue of whether the "trilemma" is resolvable or the explicit 

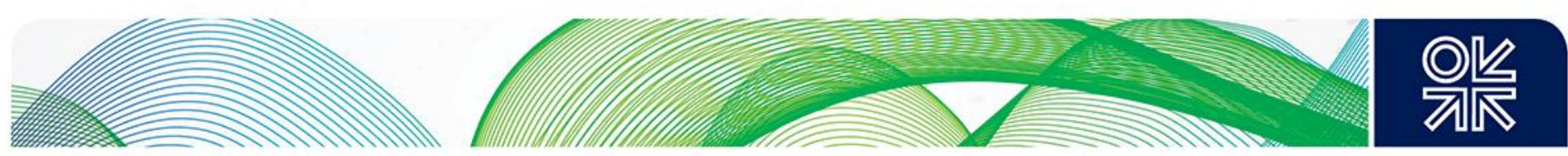

role that markets should play if it is, there is little evidence of a careful or consistent consideration of how gas might most effectively play a role in this regard.

- Energy prices at the retail level have become a political issue and both the regulator and suppliers have failed to adequately articulate the relationship between wholesale and retail gas prices and the impact of forward purchases on suppliers' costs. The focus on supplier profits - whether justified or not - has led some to call for control of their prices and/or margins.

- By some measures an energy market with six competing suppliers plus a growing number of new entrants could be seen as a success but this continued level of participation should not be taken for granted. Excessive intervention could precipitate further consolidation that is evident in sectors such as mobile telephony. Were this to occur in the UK retail energy sector it would present policy makers with a new set of challenges.

- One important component of household energy bills is the cost of environmental policies though this impacts primarily on electricity bills. Government has sought to introduce measures to reduce the cost of low carbon generation but the costs are still well above wholesale market levels. Furthermore by failing to distinguish adequately between different fossil fuels the environmental advantages of gas over coal have not been sufficiently realised - as a result higher gas prices relative to coal have meant that the share of coal-fired generation has increased at the expense of gas. The increased impact of the carbon price floor may, however, make gas more attractive

- Security of gas supply remains an important consideration though government attitudes to and definitions of security have changed significantly over time. Generally the temptation to intervene has been resisted in preference to market-based solutions. However, the recently expressed desire to limit excess price volatility does not sit well with a reliance on competitive energy markets.

The study then examined the extent to which the above conclusions could be shaped by the evolution of the demand and supply characteristics of the GB gas market.

In terms of gas demand the study concluded that there is little doubt that natural gas will play a key role on UK energy supply for many years to come. In power generation, despite the wide range of possible levels of demand and generation mix, gas-fired power will continue to feature in a critical capacity:

- As a provider of both base load and back up for intermittent renewable generation;

- In setting electricity prices.

Furthermore, given:

- The continuing need for support schemes for renewable energy,

- The outlook for gas prices to 2020 which are below present projections from Government,

- The possibility of more concerted efforts to restrict coal fired generation,

- Extended lead-times and the need for support schemes for large scale nuclear and

- The predicted potential for viable CCS schemes that could be more cost effective than offshore wind,

the balance of probability is that the share of gas in power generation will be at least as large as it was in 2014 up to 2035.

The picture is similar in the heat market. Gas will continue to be the most dominant fuel for the next 15 to 20 years. Beyond then it is far from certain that heat networks can be developed on the scale and with the efficiency required to make them a viable alternative not least due to the massive expansion of local residential distribution networks and household equipment this would entail. It is not clear that the costs, logistical challenges and degree of compulsion this would require are either affordable or acceptable. However, this is an area that will receive increasing technical and 

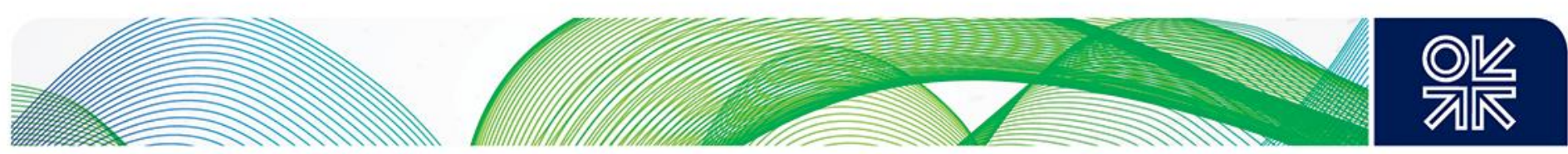

commercial attention from policy makers and the gas sector needs to adopt a more proactive strategy if it is to continue to play a major role in serving the heat market in the future.

On the supply side:

- The UKCS is a mature province and the decline of gas production is inevitable whilst remaining prospectivity is in smaller high cost fields and unit costs will correspondingly increase. The joint challenge of Government and industry is to optimize the use of infrastructure to encourage maximum resource recovery through regulatory and fiscal tools. Steps are being taken to this end though further decline cannot be postponed forever. The sudden fall in oil and gas prices has added further to the problem and it is far from clear whether the underlying cost base can be reduced sufficiently either to support planned new developments or to avoid early abandonment of old producing fields and infrastructure. Nevertheless the UKCS could provide at least $20 \%$ of UK gas supply to 2035 and possibly beyond.

- Indigenous shale gas may also come to play a role in time though it is not possible to make a valid assessment until more wells have been drilled and the economic viability of reserves has been established; any appreciable impact is probably 10 years away or until such time as it proves possible to drill 100-300 wells/year without major regulatory or environmental obstacles.

- The UK market is well placed to take gas from a range of sources and the infrastructure is present to allow this: ensuring the UK remains an attractive destination for gas exporters therefore remains a key policy objective.

- Interconnections with the continental gas markets are also important components of the supply matrix and can be particularly important during periods of peak demand. Ensuring the necessary physical and commercial elements remain robust for these interconnections is also vital.

- The case for intervention to encourage more storage to be built remains difficult to make though continued monitoring of all aspects of gas security of supply remains important.

\subsubsection{A national strategy}

The GB gas market is a complex set of interactions and whilst a long-term future for gas is not assured it should continue to play a key role in the provision of heat and power in the UK for many years to come. There is the danger that policy initiatives aimed at a particular part of the energy chain will fail to address the specific needs and opportunities presented by natural gas. It is therefore essential that policy makers recognise and plan for the continuing large scale presence of gas in the energy mix.

There is the risk that without this recognition, the lead times involved may mean the gas-related components of the portfolio are not available when required. This is a particularly pressing issue for new generation gas-fired power plant. The recent capacity auctions have not incentivised any additional projects and this could lead to inadequate reserve margins of reliable generation unless the market dynamics shift in favour of gas. In this context it should be noted that the lead time for new CCGTs, including planning and approval, is between 4 and 8 years ${ }^{222}$.

It is therefore suggested that the development of an integrated natural gas strategy for the UK would go some way to addressing the challenges of the trilemma whilst reducing risks to the energy sector and the wider UK economy. Developing such a strategy would not involve a major change in direction or the establishment of a new task force or regulatory body. It would rather be a requirement for all government departments and agencies to consider policy implications where they are relevant to the natural gas sector. The advantages of such an approach include:

- A more cost effective approach to transitioning towards a low carbon economy;

\footnotetext{
${ }^{222}$ https://www.gov.uk/government/uploads/system/uploads/attachment data/file/315717/coal and gas assumptions.PDF table 3
} 

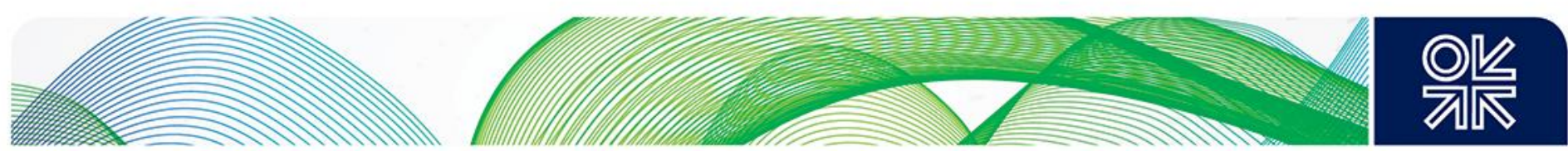

- Avoiding a supply crunch in the power market arising from, for example, delays to new nuclear plant combined with a sudden loss of existing facilities:

- The opportunity to develop a more reasoned, evidence based, approach to the gas retail market that maintains its attractiveness to existing and new suppliers.

The following sections give some examples of how a national strategy for gas might work in practice for each "trilemma" objective.

\subsubsection{Price and affordability}

We have seen that wholesale gas prices are primarily shaped by global market developments and this state of affairs is likely to continue. As a result prices will rise and fall in line with supply and demand fundamentals. A combination of slack demand in Europe and reduced rates of demand growth in Asia coupled with a looming surplus of LNG on global markets will put major downward pressure on UK wholesale prices in 2015 and beyond. This of course does not mean prices will stay low forever though the current consensus is that they will remain so at least until 2020.

The most important policy choice should be to ensure that no measures damage the transparency and liquidity of the wholesale market as it is these features that make the UK an attractive destination for gas. The availability of excess import capacity with the continued option to export to the continent is another important element of this attractiveness.

It is also the case that managing UKCS production in a way that maximizes output at periods of high demand could potentially help to reduce (though not remove) price spikes.

It remains to be seen whether the CMA might recommend measures that would lead to a reduction in retail prices. In any event retail prices are likely to continue to be a focus for political intervention and transparency on costs wherever possible will by crucial. There is a valid argument that having six major suppliers is not a bad outcome and there is scant evidence that either excessive consolidation or a single buyer model leads to long term benefits for consumers. A move to control supplier margins could lead to a more risk averse purchasing policy that could raise prices.

Nevertheless if the expected gas supply surplus does lead to major price falls it will be important for this to be reflected (and publically recognised as resulting) in lower retail prices. This may also provide opportunities for new entrants and policies that lower commercial barriers to entry should be pursued as a matter of urgency.

We have noted that falling demand will lead to increases in unit costs and charges for fixed assets. This is one factor behind the increase in unit transportation costs. If the very low gas demand forecasts do materialise the regulator and industry will need to work closely together to ensure the trade-offs between asset integrity, cost and efficiency are managed effectively. The risks associated with large scale asset stranding would need to be recognised and dealt with.

\subsubsection{Environmental sustainability}

In the electricity generation sector we have noted the superior environmental performance of gasover coal-fired plant however the latter are generally higher up the merit order. Measures to move coal down the power generation merit order (or close these plant down) in favour of existing gas-fired power would appear to have limited risk from a policy perspective - particularly if it were to prevent the decommissioning of relatively new CCGT plant. The carbon price floor should play a role in this regard, depending on the level of the floor compared with the relative prices of gas and coal.

There have been faltering moves to increase the level of commitment to carbon capture and storage (CCS). Even under the relatively high DECC price projections CCS could be competitive with offshore wind and presents fewer technical and commercial risks with potential upside from enhanced oil recovery. This technology should gain further support - particularly at sustained lower gas prices.

Moves to decarbonise heat should in the first instance focus on non-gas supply areas. Government should make explicit the recognition that there is a long term role for gas in heat provision and put 

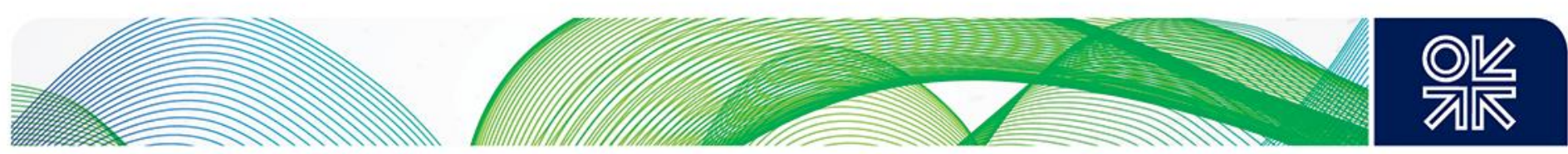

renewed effort into making this supply chain more environmentally friendly. This could include additional measures to encourage the use of biogas, removal of old inefficient boilers, continued investments in home insulation and using smart meters and big data techniques to target measures at particularly energy inefficient buildings.

\subsubsection{Security of Supply}

Some continue to argue that the UK is dangerously exposed to supply-side shocks due to a combination of import dependency and low levels of storage. However, the present outlook for supply security is less alarming due to lower demand and more than adequate supplies - though there is no room for complacency.

This paper has argued for the adoption of a holistic approach to gas supply security that in particular recognizes the continuing role of UKCS supplies. To this end the Treasury should work with DECC and the new Oil and Gas Authority to develop measures that provide appropriate incentives for the continuation of existing production and the bringing forward of new production of gas. This could include a "security of supply" rebate that applies to new developments of UKCS gas as well as incentives that encourage winter versus summer production. Traditionally UKCS gas has been produced at a relatively constant rate thought the year. If the existing level of delivery of around 100$120 \mathrm{mcm} /$ day were to be sustained for the next 10 to 15 years through restricting production during the summer months this could provide a major contribution to supply security as well as potentially mitigating some price spikes. Some however might see such an initiative as an explicit 'subsidy' to UKCS production and therefore its likelihood of success is debateable.

The government has agreed to implement the measures recommended in the Wood review and this is to be welcomed. One particular aspect the Oil and Gas Authority should be pursuing as a matter of urgency is a review of measures to improve access to infrastructure. The Wood Review did not rule out some form of open access regime and the OGA should call on Ofgem's expertise in this area to progress matters.

Close attention should be paid to the status of IUK and the Rough and Hornsea storage facilities. There is a danger that decommissioning critical assets due to poor profitability may merit some form of intervention, though this should be done on a holistic basis that compares the costs and benefit of all of the alternatives. It would not appear that the case against intervention to encourage new storage investment has changed though the case needs continuing evaluation. In any event it could be argued that the recent problems with Rough demonstrate the potential vulnerability of large offshore underground storage which in turn suggests that on-shore fast cycle facilities or additional LNG storage tanks at existing terminals are probably a more cost effective solution.

Finally the importance of a holistic approach by government departments and agencies is also vital. To take one example, the decision of the Valuation Office Agency to increase business rates on gas storage with no apparent recognition of the security of supply implications seems particularly illjudged.

\subsection{Other issues and considerations}

The approach of this paper has been to look in detail at the critical elements of gas demand and supply from an analytical and policy perspective. In doing so it is hoped that some common misconceptions can be laid to rest - or at least that a more nuanced understanding is required. The broad conclusions that can be drawn include the following:

- It is untrue to claim that the gas wholesale market is "rigged";

- Gas prices are cyclical and subject to volatility but will not keep rising forever, and indeed may remain at the lower levels witnessed in 2015 for some while;

- Gas will continue to play a critical role in power generation for many years; 

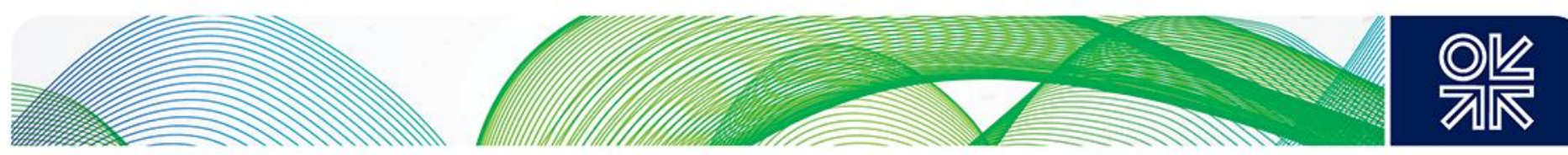

- Gas as a fuel for heat will likewise be essential for many years;

- UKCS gas production may not keep declining;

- The UK is not dangerously exposed due to import dependency and low levels of storage;

- Indigenous shale production is many years from making any significant contribution to energy supply.

The paper has also sought to answer some subsidiary questions:

1) How far has the consensus regarding the legitimacy of a privatised, market-led energy market eroded in the face of public concerns over prices, profits and the effectiveness of competition and supply security?

2) How might policy evolve given concern over the effectiveness of markets and government intervention to reduce carbon emissions and what are the implications for the gas sector?

3) What role is gas likely to play in this future environment and what might be the impact of other factors such as indigenous shale gas or abundant international supplies?

As stated in the introduction, given the breadth of these subsidiary questions, the paper does not aim to provide definitive answers/solutions, but has sought to illustrate the dimensions of the issues and the dangers inherent in pursuing dogmatic approaches which ignore the economic and physical realities of energy systems and the timescales over which material change is possible.

So it is clear that there is less consensus on the viability of a market-led energy framework than hitherto - if indeed such consensus ever existed. However it is in electricity where most of the interventionist activity is occurring where according to Atherton (2014) it is impossible for any power station to be built unless the government underwrites the economics. It is quite possible that if the financial burden of low carbon energy continues to mount a further re-appraisal may occur. A return to more market based policies to encourage gas-fired generation investments could emerge.

There should be little doubt that there will be a role for gas for the next two decades at least and the gas industry needs to ensure it can play this role effectively. The critical challenge for policy makers is to identify the ways in which the role can be integrated positively and effectively within the broader energy framework to ensure an equitable outcome for the industry and an optimal solution for consumers and taxpayers. 


\section{Appendix A}

\section{Gas fired power plant and the capacity auctions}

This appendix provides further detail of gas power generation capacity in the UK and the impact of the recent capacity auctions. Table A1 provides a listing of CCGT plant in operation as at May 2014.

Table A1: Gas fired power plant in UK as at May 2014

\begin{tabular}{|c|c|c|c|}
\hline Name & Type & Size (MW) & Year of operation \\
\hline Peterhead (1) & CCGT & 1180 & 1980 \\
\hline Glanford Brigg (2) & CCGT & 150 & 1993 \\
\hline Peterborough (2) & CCGT & 240 & 1993 \\
\hline Corby & CCGT & 401 & 1993 \\
\hline Killingholme & CCGT & 900 & 1993 \\
\hline Rye House & CCGT & 715 & 1993 \\
\hline Barking & CCGT & 1000 & 1994 \\
\hline Killingholme & CCGT & 665 & 1994 \\
\hline Deeside & CCGT & 515 & 1994 \\
\hline Little Barford & CCGT & 720 & 1995 \\
\hline South Humber Bank & CCGT & 1310 & 1996 \\
\hline Connahs Quay & CCGT & 1380 & 1996 \\
\hline Barry (2) & CCGT & 140 & 1998 \\
\hline Thornhill & CCGT & 50 & 1998 \\
\hline Rocksavage & CCGT & 810 & 1998 \\
\hline Didcot B & CCGT & 1470 & 1998 \\
\hline Seabank 1 & CCGT & 812 & 1998 \\
\hline Cottam Development Centre & CCGT & 395 & 1999 \\
\hline Enfield & CCGT & 408 & 1999 \\
\hline Sandbach & CCGT & 56 & 1999 \\
\hline Sutton Bridge & CCGT & 819 & 1999 \\
\hline Saltend * & CCGT & 1200 & 2000 \\
\hline Damhead Creek & CCGT & 805 & 2000 \\
\hline Shoreham & CCGT & 420 & 2000 \\
\hline Seabank 2 & CCGT & 410 & 2000 \\
\hline Coryton & CCGT & 800 & 2001 \\
\hline Great Yarmouth & CCGT & 420 & 2001 \\
\hline Baglan Bay & CCGT & 510 & 2002 \\
\hline Castleford & CCGT & 56 & 2002 \\
\hline Ballylumford C & CCGT & 616 & 2003 \\
\hline Spalding & CCGT & 880 & 2004 \\
\hline Coolkeeragh & CCGT & 408 & 2005 \\
\hline Marchwood & CCGT & 842 & 2009 \\
\hline Langage & CCGT & 905 & 2010 \\
\hline Severn & CCGT & 848 & 2010 \\
\hline Grain & CCGT & 1365 & 2010 \\
\hline Staythorpe C & CCGT & 1748 & 2010 \\
\hline West Burton CCGT & CCGT & 1410 & 2012 \\
\hline
\end{tabular}



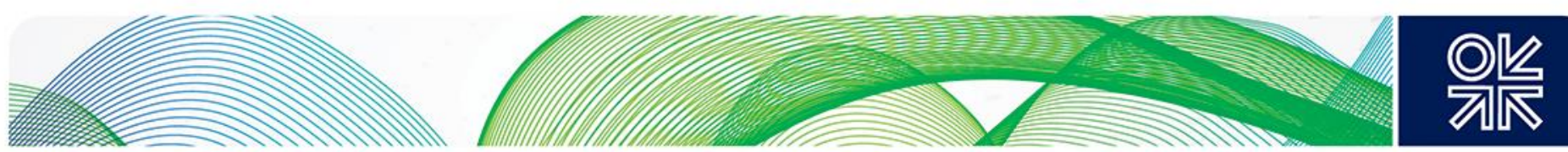

\begin{tabular}{|l|l|r|l|}
\hline Pembroke & CCGT & 2180 & 2012 \\
\hline Ballylumford B & gas & 540 & 1968 \\
\hline Knapton & gas & 40 & 1994 \\
\hline Fellside * & gas & 180 & 1995 \\
\hline Pilkington - Greengate * & gas & 10 & 1998 \\
\hline Bridgewater District Energy & gas & 10 & 2000 \\
\hline Sevington District Energy & gas & 10 & 2000 \\
\hline Solutia District Energy & gas & 10 & 2000 \\
\hline $\begin{array}{l}\text { Barkantine Heat \& Power } \\
\text { Company * }\end{array}$ & & 1 & 2000 \\
\hline London Heat \& Power & gas & 9 & 2000 \\
\hline Company * & gas & 10 & 2002 \\
\hline Aberdare District Energy & gas & 10 & 2002 \\
\hline Chippenham & gas & 1240 & 2004 \\
\hline VPI Immingham * & gas & 42 & 2005 \\
\hline Wilton GT2 * & gas & 2,286 & \\
\hline $\begin{array}{l}\text { CHP schemes other than } \\
\text { major power producers and }\end{array}$ & mainly gas & 238 & 1952 \\
\hline Wilton Power Station & gas/coal/oil & 15 & 1995 \\
\hline Thames Valley Power * & gas/gas oil & 45 & 1998 \\
\hline Burghfield & gas/oil & 45 & 1998 \\
\hline Chickerell & gas/oil & & \\
\hline
\end{tabular}

Source: DUKES, www.powerstationeffects.co.uk/pdf/UK-OperationalPlantsMay2004.pdf Notes:

(1): Total capacity is $1,840 \mathrm{MW}$ but because of transmission constraints only 1,180 MW can be used at any one time.

(2): Capacity reduced in 2013, with these stations typically now operating as Open Cycle Gas Turbines ${ }^{*} \mathrm{CHP}$ plant

\section{GB Capacity auction}

The first capacity auction took place in December 2014. Nearly 65GW of capacity entered the auction which procured $49.3 \mathrm{GW}$ of capacity $(75.8 \%$ of the amount bid and around $61 \%$ of total generating capacity) at a clearing price of $£ 19.40 / \mathrm{kW}$. Only $2.8 \mathrm{GW}(5.3 \%)$ of the amounts procured was new capacity.

According to Timera Energy ${ }^{223}$ this price was around $50 \%$ below market expectations .A total of 15.7 GW of capacity exited the auction above the clearing price of which $8.4 \mathrm{GW}$ was existing coal and CCGT plants - the remainder being new build (mainly CCGT) generating capacity. Amongst those in the latter category was the $400 \mathrm{MW}$ Carrington facility (already under construction), Centrica's 325 MW Kings Lynn A, Intergen's Spalding expansion and Gateway EC projects (1685 MW in total), Scottish power Damhead Creek 2 (1056MW), South Hook CHP (450 MW), SSE Abernedd (440 MW), Thorpe March Power Itd projects (1056 MW). 

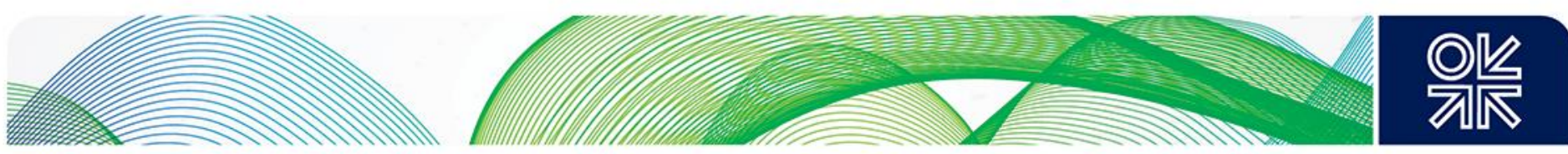

In their review of the first capacity auction Timera note that plant that failed to secure a capacity agreement could be in a precarious position ${ }^{224}$. Indeed some of the projects (e.g. the 450MW South Hook CHP project) have since been put on hold ${ }^{225}$ whilst Centrica have announced the closure of its Brigg and Killingholme power stations 226 . However other project promoters remain upbeat despite missing out - for example Intergen's Spalding and Gateway projects remain on track whilst Carlton Power is entering its Thorpe Marsh CCGT project into the second auction to be held in late $2015^{227}$.

The breakdown of plant securing capacity agreements is shown by technology in table A2.

Table A2: Generating plant securing capacity agreements, December 2014

\begin{tabular}{|l|c|c|c|c|}
\hline Technology type & $\begin{array}{l}\text { Capacity } \\
\text { (GW) }\end{array}$ & $\begin{array}{l}\text { Capacity } \\
(\%)\end{array}$ & $\begin{array}{l}\text { Number } \\
\text { of CMUs }\end{array}$ & $\begin{array}{l}\text { Number } \\
\text { of CMUs } \\
(\%)\end{array}$ \\
\hline CCGT & 22.3 & 45.2 & 47 & 15.4 \\
\hline CHP \& autogeneration & 4.2 & 8.6 & 36 & 11.8 \\
\hline Coal/Biomass & 9.2 & 18.7 & 29 & 9.5 \\
\hline DSR & 0.2 & 0.4 & 15 & 4.9 \\
\hline Hydro & 0.7 & 1.4 & 29 & 9.5 \\
\hline Nuclear & 7.9 & 16.0 & 16 & 5.2 \\
\hline OCGT and Reciprocating Engines & 2.1 & 4.3 & 121 & 39.5 \\
\hline Storage & 2.7 & 5.5 & 13 & 4.3 \\
\hline Total & 49.3 & 100 & 306 & 100 \\
\hline
\end{tabular}

Source: National Grid (2015)

Note: $\mathrm{CMU}=$ Capacity market unit

\footnotetext{
${ }^{224}$ http://www.timera-energy.com/uk-power/implications-of-the-1st-uk-capacity-auction/ see also https://www.frontiereconomics.com/documents/2015/01/lcp-frontier-economics-review-first-gb-capacity-auction.pdf

225 http://www.Ingworldnews.com/south-hook-chp-project-put-on-

hold/?utm source=emark\&utm medium=email\&utm campaign=Daily\%20update\%20LNG\%20World\%20News\%2C\%20201502-05\&uid=21190

${ }^{226} \mathrm{http} / / /$ www.centrica.com/files/presentations/2015/prelims/index.asp

227 http://www.icis.com/resources/news/2015/03/23/9870129/uk-ccgt-developers-upbeat-despite-early-auction-failure/?
} 

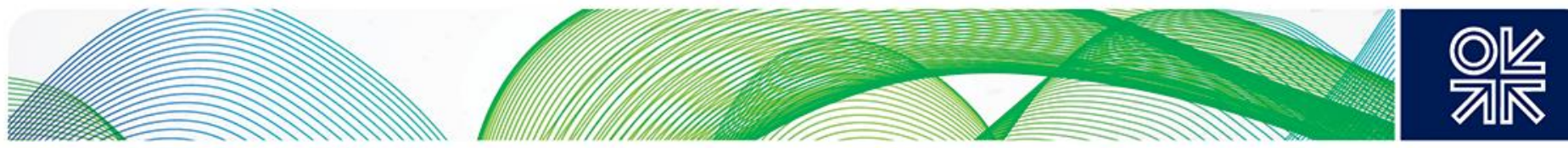

Figure A1 shows the supply/demand position resulting from the auction for 2018/19 capacity.

Figure A1: Supply demand curves for 2018/19 capacity

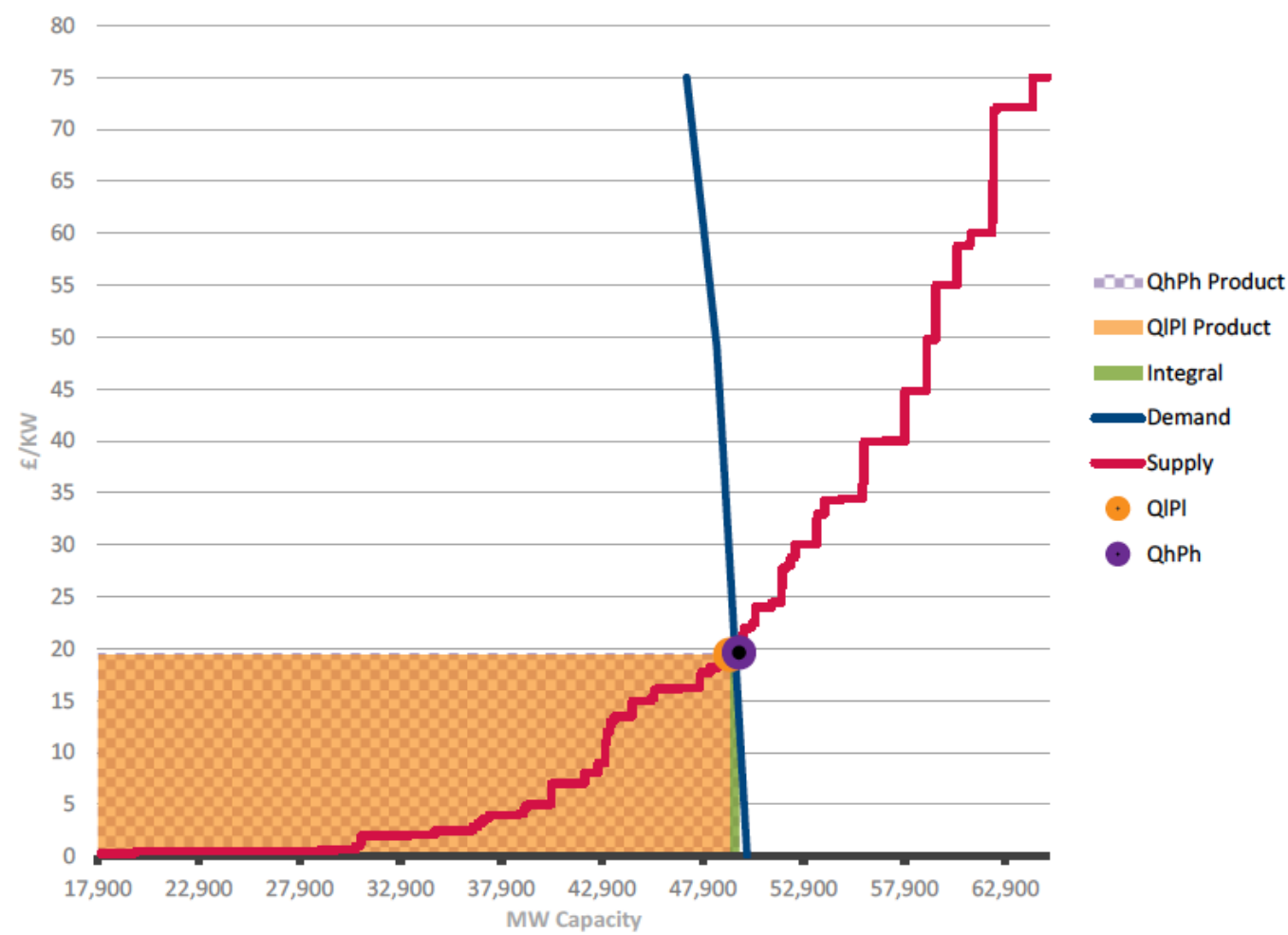

Source: National Grid (2015)

It should be noted that many of the contracts awarded are for just one year so it is dangerous to draw too many long term conclusions. Nevertheless the view is that price is insufficiently high to justify new build alone and at present spark spread outlook there is insufficient upside to precipitate a surge in new investment. The fact that some coal and gas plant was unsuccessful may lead to some of this plant closing - indeed Centrica subsequently announced the closure of its Brigg and Killingholme power stations 228 (which may cause short term capacity problems and require further action along the lines of the SBR) but again unlikely to make a big difference to overall requirements for new build CCGT - though some plant may move up the merit order. 

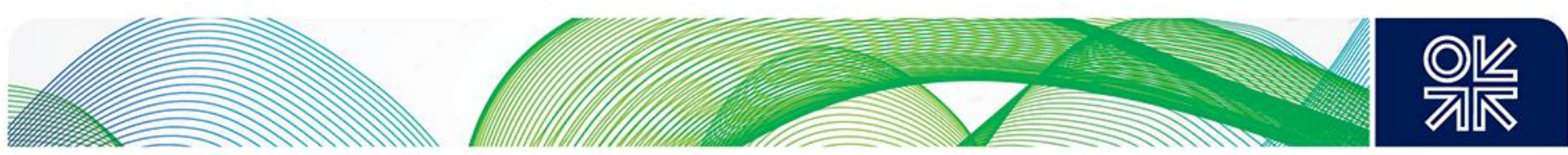

Table A3: Capacity bids in excess of $50 \mathrm{MW}$ that exited the auction

\begin{tabular}{|l|l|l|l|l|}
\hline Type & Status & Capacity & Name & Owner \\
\hline CCGT & $\begin{array}{l}\text { Under } \\
\text { construction }\end{array}$ & 400 & Carrington & Carrington \\
\hline CCGT & New build & 400 & Carrington & Carrington \\
\hline CCGT & Existing & 142 & Barry BRGG & Centrica \\
\hline CCGT & Refurbishment & 220 & BRYP & Centrica \\
\hline CCGT & New build & 326 & $\begin{array}{l}\text { Kings Lynn } \\
\text { KLYN-A }\end{array}$ & Centrica \\
\hline CCGT & Existing & 231 & Peterborough & Centrica \\
\hline CCGT & Existing & 598 & Killingholme & Centrica \\
\hline & New build & 55 & $\begin{array}{l}\text { Danish Power } \\
\text { Service }\end{array}$ & Danish Power \\
Service
\end{tabular}

${ }^{*}$ Other units at this location were successful

Source: National Grid (2015)

Helm (2015) has described the capacity market as a "complex mess" that has excluded large amounts of investment (i.e. renewables) from the auctions resulting in consumers probably paying several hundred million pounds more than necessary. Others have criticised the capacity market concept as a solution to yesterday's problems. Developments in smart grids, new products (such as 15 minute electricity) and greater cross border integration could help reduce peaks and diversify supplies. The fact that new generation capacity can obtain contracts of up to fifteen years as opposed to demand-side response (DSR) options limited to a one year contract has in the word of Tim Yeo (chair of the parliamentary energy and climate change select committee) "encouraged the construction of expensive new power stations" at the expense of "cheaper and greener alternatives"229. 

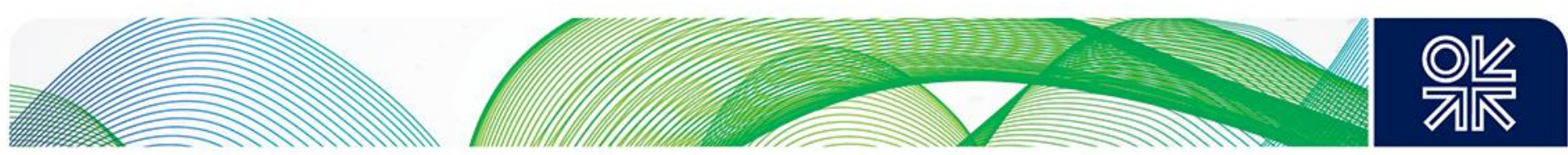

Newbery and Grubb (2014) have pointed out that the UK capacity regime has been developed in isolation from other European markets though the GB electricity market is becoming increasingly interconnected. Indeed the capacity regime can undermine the interconnection investment.

\section{Appendix B}

\section{Units and conversion factors}

In general the units used by the source material are stated. Where conversions have been undertaken the rates used are as follows:

1. TWh to $\mathrm{BCM}$ at a calorific value of $38.1 \mathrm{MJ} / \mathrm{m}^{3}$. Therefore $10 \mathrm{TWh}=0.94 \mathrm{BCM}$ of natural gas.

2. Gas price data is generally provided in $\$ / \mathrm{mmbtu}$ or converted to this unit at the prevailing exchange rate. So to convert from $\mathrm{p} /$ therm to $\$ / \mathrm{mmbtu}$ (where $1 \mathrm{mmbtu}=10$ therms) multiply by exchange rate and divide by 10 . So $50 p$ per therm at an exchange rate of $£ 1=\$ 1.6$ is (50 $x 1.6) / 10=\$ 8 / \mathrm{mmbtu}$. Exchange rates are based on period averages from http://www.oanda.com/currency/historical-rates/

3. Power price data is generally provided in $£ / \mathrm{MWh}$ - this includes spark spread information. To convert from $£ / \mathrm{MWh}$ to $\mathrm{p} /$ therm (where $1 \mathrm{MWh}=34.12$ therms) multiply by 100 and divide by 34.12. So $£ 5$ (which is the prevailing spark spread value) is $(5 \times 100) / 34.12=14.7 \mathrm{p} /$ therm.

4. The spark spread - which is an indicator of generator economics - data has been sourced from Argus unless stated otherwise. The spread is calculated from the cost of generating power (from coal or gas) less the price of the power sold. The cost of power will be a function of the commodity cost and the efficiency of the generating unit. The UK unadjusted spark spread is calculated assuming a $49.13 \%$ efficiency for gas-fired power and a $38 \%$ efficiency for coal-fired power (the coal spark spread is referred to as the dark spread). So if gas costs $50 \mathrm{p} /$ therm $(50 / 100 / 29.31 \times 1000)=£ 17.06 / \mathrm{MWh})$ and the power is sold at $£ 45.70$, at the efficiency of $49.13 \%$ the spark spread is $45.7-(17.06 / 0.4913)=£ 10.98 / \mathrm{MWh}$. The spreads can then be emissions adjusted to derive a clean spark spread and a clean dark spread for gas and coal respectively. The adjustment is made using an appropriate emissions price and emissions factors of $0.897 \mathrm{t} / \mathrm{MWh}$ for coal and $0.411 \mathrm{t} / \mathrm{MWh}$ for gas.

5. Household prices are generally in p/kWh. 1 therm is equal to $29.31 \mathrm{kWh}$. 

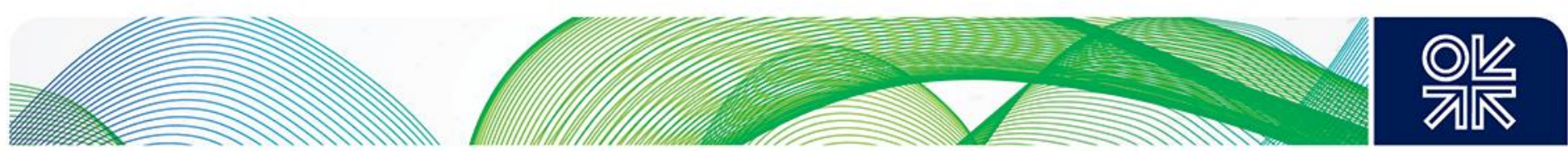

\section{Glossary}

1 in 20 Peak Day: The level of daily demand that, in a long series of winters, would be exceeded in one out of 20 winters, with each winter counted only once.

ACER: Agency for the Cooperation of Energy Regulators, an EU Agency created by the Third Energy Package in March 2011 to further progress on the completion of the internal energy market in gas and electricity. It is based in Ljubljana, Slovenia with its own staff and resources.

Aquifer storage: Underground gas storage facility in a non hydrocarbon bearing aquifer.

Asset Stranding: Assets which have subsequently become either not used or under-used as compared with initial expectations.

Bacton-Zeebrugge Interconnector: see IUK

Baumgarten: Austrian gas hub.

BBL: Balgzand (Holland) to Bacton (UK) pipeline, import capacity $53 \mathrm{mcm} / \mathrm{d}$.

Bbl: barrel (of oil)

$\mathrm{Bcm}$ : one billion cubic metres.

Bcma: one billion cubic metres per annum.

Bpe: barrel of petroleum equivalent

Biogas- gas produced from the anaerobic digestion of organic matter such as animal manure, sewage, and municipal solid waste.

Biomass - any organic material which has stored sunlight in the form of chemical energy. As a fuel it may include wood, wood waste, straw, manure, sugarcane, and many other by-products from a variety of agricultural processes.

Biomethane - Biogas which is upgraded to vehicle fuel quality.

Carbon price floor (CPF): The CPF which came into effect on 1 April 2013 is made up of the price of $\mathrm{CO}_{2}$ from the EU Emissions Trading System (EU ETS) and the Carbon Price Support (CPS) rate per $\mathrm{tCO}_{2}$ which is a UK-only additional payment levied on fossil fuel power generators. The CPF increased in April 2015.

CATS: The UK offshore sub-sea Central Area Transmission System, a 223 mile pipeline from the Central North Sea to the CATS processing terminal in Teesside on the North East coast of England.

CC: UK Competition Commission (now superseded by the CMA).

CCGT: Combined cycle gas turbine power station.

CCS: Carbon capture and storage (CCS) is a three stage process involving (1) capturing $\mathrm{CO}_{2}$ emissions from power stations or other industrial sources; (2) transporting the $\mathrm{CO}_{2}$, usually by pipelines, to storage points; and (3) storing it safely (e.g. in depleted oil and gas fields).

CEER: The Council of European Energy Regulators association of Europe's national regulators of electricity and gas at EU and international level for cooperation and exchange of best practice.

Centrica: The demerged part of British Gas plc that owns the GB supply business, the Morecambe Bay gas fields and the Rough storage facility. 

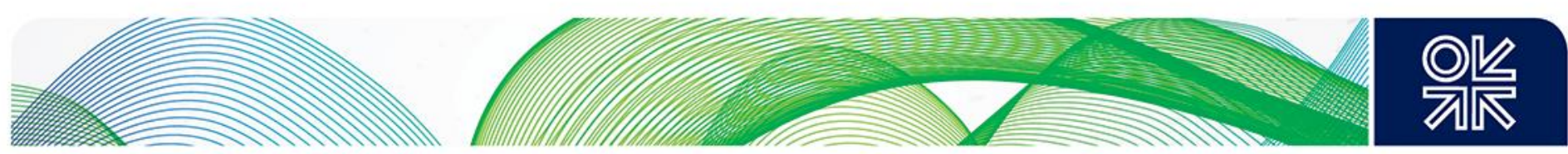

CERT: Carbon Emissions Reduction Target - The CERT programme replaced the Energy Efficiency Commitment 2005-2008 as the UK government's domestic efficiency obligation on energy suppliers. It sets an obligation on energy suppliers to reduce $\mathrm{CO}_{2}$ emissions by promoting energy efficiency and micro renewables to domestic energy users.

CHP: Combined heat and power - the simultaneous generation of usable heat and power (usually electricity) in a single process, thereby leading to reductions in the amount of wasted heat.

Clean Spark spread: See Appendix B

CMA: Competition and Markets Authority - formed in 2013 through the amalgamation of the Competition Commission and the Office of Fair Trading (OFT)

CMU: Capacity market unit. This is the particular generating resource or demand side resource participating in the GB electricity capacity market auction.

Contracts for difference (CfDs): A CfD is a private law contract between a low carbon electricity generator and the Low Carbon Contracts Company (LCCC), a government-owned company. A generator party to a CfD is paid the difference between the 'strike price' - a price for electricity reflecting the cost of investing in a particular low carbon technology - and the 'reference price'-a measure of the average market price for electricity in the GB market.

Conventional Gas: Natural gas produced from an underground reservoir other than shale gas, tight gas or coal bed methane.

Crown Estates: Organisation established by Act of Parliament to manage property owned by the Crown which includes almost all of the seabed around the UK.

CSL: Centrica Storage Ltd.

CSO (Customer Service Obligations): See PSO.

Cycle rate: Also called turnover. The number of times in a year that a storage facility could be filled and emptied. This is a theoretical measure used to demonstrate the relative flexibility of a storage facility. In this report cycle rates have been calculated as follows: (365-14)/(days to fill working volume + days to empty working volume) where 14 represents the number of days the facility is unavailable for routine maintenance.

DECC: UK government Department of Energy and Climate Change.

Depleted field storage: Underground gas storage facility located in a hydrocarbon bearing reservoir.

DM: Daily metered gas consumer - normally very large users such as power stations.

DSM: Demand side management (also referred to as load management) is any mechanism that allows a customer's electricity demand to be intelligently managed in response to events on the power system. Such events would include lack of network capacity or insufficient generation. Similar arrangements can apply for gas.

DSR: Demand Side response - fuel switching by consumers in response to higher gas prices or shipper/transporter initiated interruption.

DTI: UK government Department of Trade and Industry - now superseded by DECC.

DUKES - Digest of |UK Energy Statistics.

EFET: The European Federation of Energy Traders.

ENA: The Energy Networks Association - a trade body that represents the gas and electricity transmission and distribution companies in the UK.

ENTSOG: The European Network of Transmission System Operators for Gas manages and coordinates TSO activities regarding the functioning of the internal market and cross-border trade for gas. 

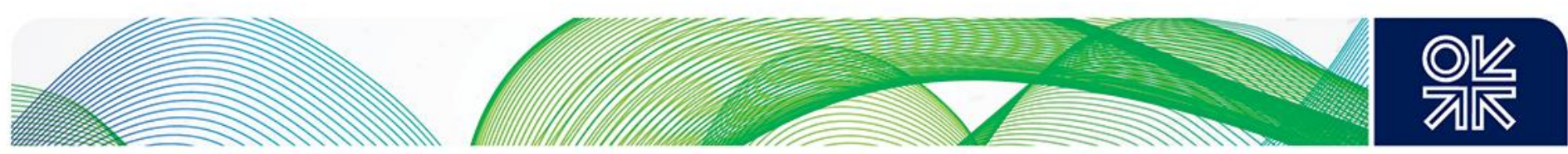

EOR: Enhanced oil recovery - range of techniques to increase oil recovery from hydrocarbon reservoirs.

ERGEG: European Regulators Group for Electricity and Gas - now superseded by CEER and ACER.

EU Emissions Trading System: A cap and trade system under which participating EU Member States allow qualifying $\mathrm{CO}_{2}$ emitting installations to trade $\mathrm{CO}_{2}$ permits. The number of $\mathrm{CO}_{2}$ permits are limited by agreed caps on $\mathrm{CO}_{2}$ emissions at the Member State level.

Extrinsic value: The price of an option minus its intrinsic value.

Fast cycle storage: Storage that is able to switch from injection to withdrawal and vice versa quickly typically salt cavern facilities.

FES: Future energy scenarios - a set of scenarios produced by NG annually describing possible future levels of gas and electricity supply and demand.

FID: Final Investment Decision: usually in the context of a gas project, this is the joint decision on the part of the investment companies and any state entities to proceed with the full development of a project through to commercial operation.

FITs: Feed in tariffs - the price per unit of electricity that a utility or supplier has to pay for renewable electricity from private generators. These are used to encourage distributed renewable generation through private generators.

Forward curves: The predetermined delivery prices for gas to be paid at defined dates in the future.

Fuel poverty: A fuel poor household is defined as one that needs to spend $10 \%$ or more of their household income on all fuel use in order to maintain a satisfactory heating regime.

Gas Forum: The body that represents the view of gas shippers and suppliers active in GB

GBA: Gas balancing alert - issued by NG to provide a signal to the market that demand-side reduction and/or additional supplies may be required to avoid the risk of entering into a Network Gas Supply Emergency. The trigger level will be based on the NSS (non-storage supplies) plus all storage sites with 2 or more days of deliverability.

GDE Gas deficit emergency -a form of Gas Supply Emergency which occurs if there is insufficient gas available in the NTS to maintain a national supply / demand balance.

GDNO: Gas distribution network operator - GDNs transport gas from the NTS to final consumers and to connected system exit points. There are currently eight GDNs in Great Britain which comprise twelve local distribution zones (LDZs).

GSMR: Gas Safety Management Regulations.

GHG: Greenhouse Gas.

GT: Gas transporter.

GTS: Gas Transportation Services - the Dutch gas TSO.

GW: Gigawatt, i.e. 1 billion watts.

GwH: Gigawatt hour; a unit of energy equivalent to a Gigawatt of power over the duration of one hour. HSE: Health \& Safety Executive.

I\&C Demand: Industrial and commercial gas demand - i.e. non-residential/household demand

IEA: International Energy Agency.

IFA: Interconnexion France Angleterre, electricity interconnector between England and France.

Infrastructure Planning Commission: See Planning Inspectorate 

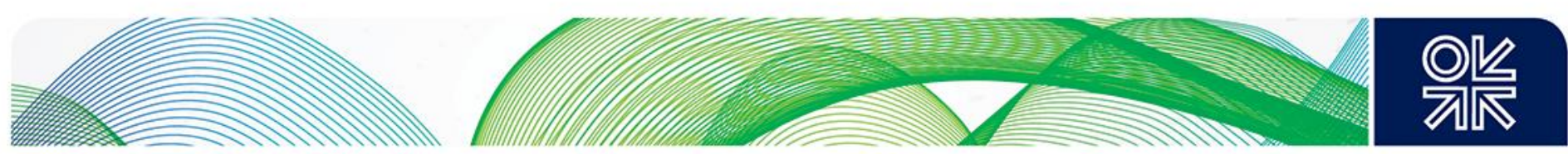

Interconnector: A physical link which allows for the transfer of gas or electricity across borders.

Intrinsic Value: - The actual value of a company or an asset based on an underlying perception of its true value including all aspects of the business, in terms of both tangible and intangible factors. In the case of storage usually based on the value gained from injecting (cheaper) gas in the summer and withdrawing (more expensive) gas in the winter - i.e. exploiting the seasonal spread.

IRR: Internal Rate of Return.

IUK: the shorthand name for the Bacton (UK) to Zeebrugge (Belgium) bi-directional gas pipeline. Import capacity (to the UK) 25.5 bcma, export capacity 20 bcma.

JESS: Joint Energy Security of Supply Working Group.

KWh: Kilowatt hour

Langeled: The 725 mile pipeline from the Nyhamna terminal in Norway via the Sleipner Riser platform in the North Sea to Easington Gas Terminal in England. Its capacity is 25.8 bcma.

Large Combustion Plant Directive: the LCPD aims to reduce acidification, ground level ozone and particles throughout Europe by controlling emissions of sulphur dioxide and nitrogen oxides and dust from large combustion plants. Member States can choose to meet the obligations by either complying with emission limits or limiting the remaining operating life of plant whose emissions exceed these limits.

LDC: Load duration curve, formed by ranking daily gas supply data (or power generation supply) from the highest demand day to the lowest demand day in any given year.

Levy Control Framework (LCF): Established in 2011-12 the LCF places limits on the aggregate amount levied from consumers by energy suppliers to implement Government policy. Some elements are excluded - see http://www.nao.org.uk/report/levy-control-framework-2/

LNG Terminal: Facility for importing ship borne LNG. Normally the LNG is stored at the terminal before regasification and injection into the transmission system.

LNG: Liquefied natural gas, natural gas liquefied by cooling to minus 162 degrees Centigrade.

LNGs or LNG storage (also called LNG Peak Shaver): a gas storage facility which provides high output of natural gas albeit for a short duration. The facility extracts natural gas from the transmission grid, liquefies it and stores it in an insulated vessel. When gas is required to meet peak loads the LNG is regasified and injected into the transmission system. Note this definition does not include storage tanks at $L N G$ regasification terminals.

LRS: Long range storage - The Rough facility in GB.

mcm; million cubic metres.

$\mathrm{mcm} /$ day: Million cubic metres per day.

Mmbtu: Million British thermal units.

MRS: Mid range storage - All storage in GB apart from Rough and LNG storage.

MWh: A unit of energy equivalent to a Megawatt of power over the duration of one hour.

NBP: the UK"s National Balancing Point: a virtual point (hub) in the National Transmission System where gas trades are deemed to occur. It is also used as shorthand for the UK spot gas price.

NDM: Non daily metered gas consumer - normally domestic and small industrial and commercial $(I \& C)$.

NEC: Network Emergency Coordinator - NG holds this role. 

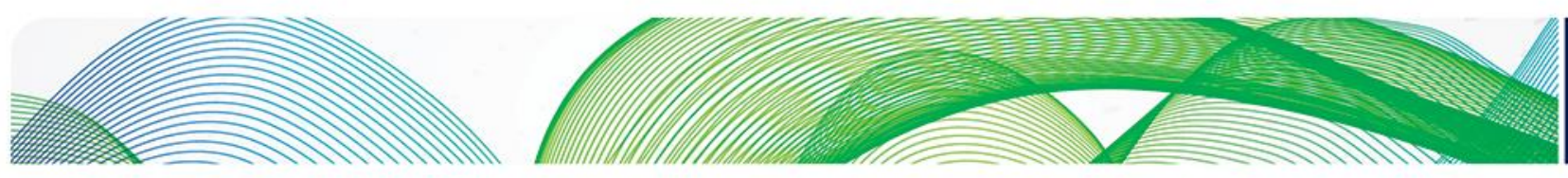

Network Gas Supply Emergency: A 'supply emergency' as defined under the Gas Safety Management Regulations (GSMR Reg 2.1) means an emergency endangering persons and arising from a loss of pressure in a network or part thereof.

NG: National Grid plc.

NGG: National Grid Gas, a wholly owned subsidiary of NG. NGG is the gas transporter (GT) licence holder for the North West, West Midlands, East England and London GDNs. NGG also holds the GT licence for the gas transmission system.

NOx: A mixture of various nitrogen oxides as emitted by combustion sources.

NPV: Net Present Value.

NSS: Non Storage supply - i.e. gas supplies to GB market from UKCS, Norway, IUK, BBL and LNG imports.

NTS: The National Transmission System - GB's high pressure gas grid owned and operated by NGG.

OCGT: Open Cycle Gas Turbine. The open cycle gas turbine is the most basic gas turbine unit. The working fluid does not circulate through the system, therefore it is not a true cycle. It consists of a compressor, a combustion chamber and a gas turbine. The compressor and the gas turbine are mounted on the same shaft.

Ofgas: GB gas regulator replaced by Ofgem.

Ofgem: The Office of Gas and Electricity Markets, the GB gas and electricity regulator.

Operating Expenditure (Opex): The costs of the day to day operation of the network such as staff costs, repairs and maintenance expenditures, and overheads.

Oil Indexed Gas Prices: gas prices within long term contracts which are determined by formulae containing rolling averages of crude oil or defined oil product prices.

Planning Inspectorate: UK body set up under the Planning Act 2008 responsible, inter alia, for national infrastructure planning, enforcement appeals and reporting on planning applications called in for decision. Replaced the Infrastructure Planning Commission.

PM - particulate matter - microscopic emissions from diesel engines that have been shown to cause breathing difficulties and to have a carcinogenic effect.

Price control: The process whereby the regulator sets targets and allowed revenues for network companies. The characteristics and mechanisms of this price control are developed by the regulator in the price control review period depending on network company performance over the last control period and predicted expenditure in the next.

PSO (Public Service Obligations): Directive 2003/55/EC of the European Parliament and of the Council of 26 June 2003 concerning common rules for the internal market in natural gas provides for the possibility for Member States to impose public service obligations to guarantee security of supply, economic and social cohesion objectives, regularity, quality and price of the gas supply and protection of the environment.

RAV: regulated asset value.

RHI: The Renewable Heat Incentive - a government environmental programme designed to provide long-term financial support to renewable heat installations to encourage the uptake of renewable heat.

RIIO: Revenue = Incentives + Innovation + Outputs. The price control framework applied by Ofgem to onshore transmission and distribution of gas and electricity.

RPI-X: A form of price control applied to network monopolies. Each company is given a revenue allowance in the first year of each control period. The price control then specifies that in each subsequent year the allowance will reduce by ' $X$ ' per cent in real terms. 

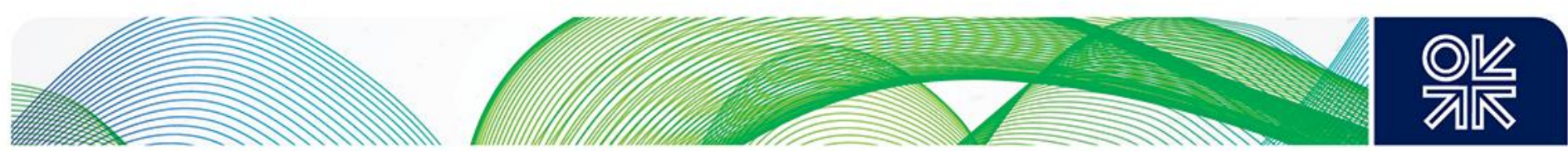

Salt cavern storage: Underground gas storage facilities contained in salt caverns

SBGI: Society of British Gas Industries.

SBU: storage bundled unit containing an appropriate mix of the three elements - injection, storage and withdrawal - typically designed to provide a single unit of delivery.

SCR: Significant Code Review.

Seasonal Normal temperature (SNT): Temperature expected on average each day forecast by NG. It is updated every few years to include the most recent years' data and to include climate change.

Seasonal spread: The difference between the purchase price of gas in the summer and the sales price in the following winter at any one point in time.

Seasonal storage: Storage that is capable of delivering gas at maximum rates for extended periods typically in excess of 90 days. These facilities will have high working volumes and will normally be in either depleted fields or aquifers.

Shale Gas: natural gas formed in fine-grained shale rock (called gas shales) with low permeability in which gas has been adsorbed by clay particles or is held within minute pores and micro fractures.

SND: Seasonal Normal Demand. Demand occurring at Seasonal Normal Temperatures.

Spark spread: See Appendix B

SO: System operator - responsible for the day to day operation of the gas grid (NG in GB).

SRS: Short range storage - LNG Storage in GB.

SSE: Scottish and Southern Energy.

SSO: storage system operator.

Storage Inventory: See Working Capacity

Strategic storage: Gas that is stored for use only in case of an emergency which would be a clearly defined set of circumstances.

Ten Year Statement: Annual planning document issued by NG.

Therm: Imperial unit of energy used in GB gas pricing - 1 therm is equal to $29.3071 \mathrm{kWh}$.

Third Package (Third Internal Energy Market Legislative Package) - An important element in the implementation of the internal EU energy market with particular emphasis on the need for better coordination between European network operators and continuing co-ordination between regulators at that level.

Tight Gas: natural gas formed in sandstone or carbonate (called tight gas sands) with low permeability which prevents the gas from flowing naturally.

Top Up: Additional storage booked by Transco/NG if necessary to maintain supply security. The top up regime was discontinued in 2004.

TPA: Third Party Access - in the context of storage there is regulated - rTPA - or negotiated third party access - nTPA.

Transco: The gas transportation arm of British Gas plc - subsequently unbundled into Lattice plc before merging with National Grid Plc (NG) in 2002.

TSO: Transmission System Operator.

TTF: Title Transfer Facility - the Dutch trading hub.

Turnover: See cycle rate.

TWh: A unit of energy equivalent to a Terawatt of power over the duration of one hour. 

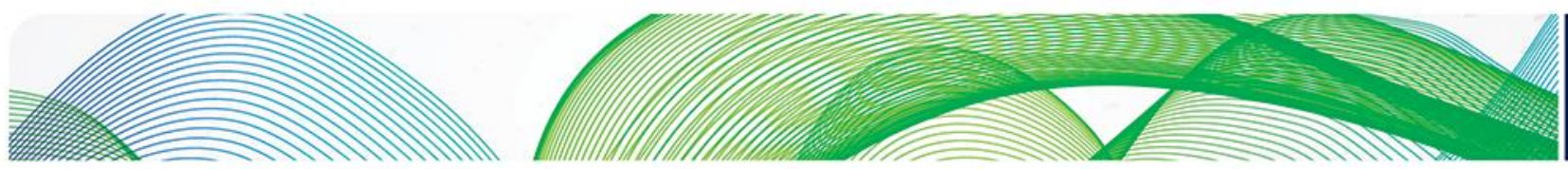

\section{이조}

UIOLI: Use It or Lose It - usually refers to booked but unused (pipeline or storage) capacity that can be offered to the market in the short term

UGS: Underground gas storage

UKCS: The UK Continental Shelf

UNC: Uniform Network Code - this replaced National Grid Gas's Network Code on 1 May 2005 as the contractual framework for the NTS, GDNs and system users.

VoLL: Value of Lost Load - the amount in pence per kWh that gas consumers would pay to avoid supply interruptions.

Working Gas: the quantity of gas that is normally injected and withdrawn in any one year in a storage facility. Working gas is distinct from "cushion gas" which is only withdrawn from storage when a storage site is decommissioned.

Working volume: Capacity of a storage facility to hold working gas. 

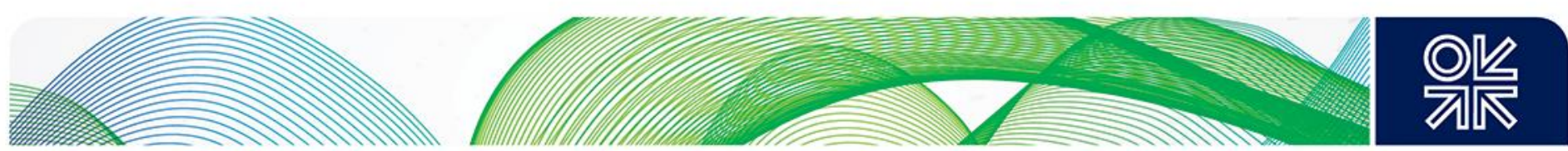

\section{References}

ACER, 2014 Annual report on the results of monitoring the internal electricity and natural gas markets in 2013, ACER, December 2014

http://www.acer.europa.eu/Official documents/Acts of the Agency/Publication/ACER Market Monit oring Report 2014.pdf

AEA-|Ricardo (2013) Projections of CHP capacity and use to 2030, A Report for DECC Ricardo-AEA /R/ED56126 Issue Number 1.2 Date 20/03/2013,

https://www.gov.uk/government/uploads/system/uploads/attachment data/file/191543/Projections of CHP capacity use to 2030 2204.pdf

Andrews, I.J. (2013), The Carboniferous Bowland Shale gas study: geology and resource estimation, British Geological Society/DECC, London 2013

https://www.gov.uk/government/uploads/system/uploads/attachment data/file/226874/BGS DECC B owlandGasReport MAIN REPORT.pdf

APPGEC (2015), Wholesale gas Market, All Party Parliamentary Group on Energy Costs, March 2015 https://gallery.mailchimp.com/b6ac32ebdf72e70921b025526/files/APPGEC Wholesale Gas Market Report final v3.pdf

Atherton, P. (2014) Liberum insight on energy policy and utilities, Spectator Energy Conference, December 2014

Bassi et al (2013), A UK "dash" for smart gas, The Centre for Climate Change Economics and Policy (CCCEP), March 2013, http://www.cccep.ac.uk/Publications/Policy/docs/PB-uk-dash-for-smartgas.pdf

BIS (2011), Principles for Economic Regulation, Department for Business, Innovation and Skills, April 2011, https://www.gov.uk/government/uploads/system/uploads/attachment data/file/31623/11-795principles-for-economic-regulation.pdf

Boue J. C. and Wright P. (2010), A Requiem for the UK's Petroleum Fiscal Regime in Rutledge I. and Wright P. (eds) UK Energy Policy and the End of Market Fundamentalism, OIES, 2010

http://www.oxfordenergy.org/shop/uk-energy-policy-and-the-end-of-market-fundamentalism/

BP (2015), World Energy Statistics 2015, BP, June 2015

http://www.bp.com/en/global/corporate/about-bp/energy-economics/statistical-review-of-worldenergy.html

Bradshaw et al (2014), Bradshaw, M., Bridge, G., Bouzarovski, S., Watson, J. and Dutton, J. The UK's Global Gas Challenge - Research Report (UKERC: London).

CCC (2014) Energy prices and bills - impacts of meeting carbon budgets, Committee on Climate Change, December 2014 http://www.theccc.org.uk/wp-content/uploads/2014/12/Energy-Prices-andBills-report-v11-WEB.pdf 

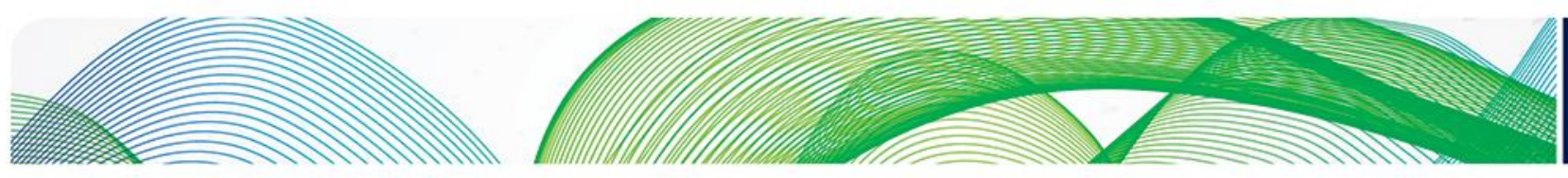

Centrica (2014), Energy Choices for the UK,

http://www.centrica.com/files/pdf/energy choices report.pdf

CMA (2015a) Energy Markets Investigation, Updated Issues Statement, Competition and Markets Authority, February 2014, https://assets.digital.cabinet-

office.gov.uk/media/54e378a3ed915d0cf7000001/Updated Issues Statement.pdf

CMA (2015b), Energy Markets Investigation, Case studies on barriers to entry and expansion in the retail energy supply: profit margin analysis, 18 February 2015 https://assets.digital.cabinet-

office.gov.uk/media/54e378c7e5274a4511000012/Retail barriers to entry and expansion.pdf

CMA (2015c), Energy Markets Investigation, The pricing strategies of the 6 large energy firms, 2 March 2015 https://assets.digital.cabinet-office.gov.uk/media/54f48e7840f0b61427000009/Retail pricing strategies.pdf

CMA (2015d), Energy Markets Investigation, Descriptive statistics Generation \& Trading, 6 March 2015 https://assets.digital.cabinet-

office.gov.uk/media/54f9c76740f0b61407000007/Descriptive statistics generation and trading.pdf

CMA (2015e), Energy Markets Investigation, Profitability of retail supply of energy in GB: profit margin analysis, 10 March 2015 https://assets.digital.cabinet-

office.gov.uk/media/55070c2040f0b613e6000015/Profitability of retail energy supply.pdf

CMA (2015f), Energy Markets Investigation, Gas Wholesale Market, 10 March 2015

https://assets.digital.cabinet-

office.gov.uk/media/54ff238040f0b6140700000c/Gas wholesale market.pdf

CMA (2015g) Energy Markets Investigation, Analysis of Generation Profitability, 25 February 2015

https://assets.digital.cabinet-

office.gov.uk/media/54edfeb540f0b61427000001/Generation profitability.pdf

DECC (2009), The UK Renewable Energy Strategy, Department of Energy and Climate Change, CM 7686, July 2009,

https://www.gov.uk/government/uploads/system/uploads/attachment data/file/228866/7686.pdf

DECC (2010a), SOCIAL AND ENVIRONMENTAL GUIDANCE TO THE GAS AND ELECTRICITY MARKETS AUTHORITY, Department of Energy and climate change, 2010 https://www.ofgem.gov.uk/ofgem-publications/74203/file37517.pdf

DECC (2011a) Ofgem Review, Final report, Department of Energy and Climate Change, July 2011 https://www.gov.uk/government/uploads/system/uploads/attachment data/file/48134/2151-ofgemreview-final-report.pdf

DECC (2011b) The Carbon Plan: delivering our low carbon future, Department of Energy and Climate Change, Dec 2011;

https://www.gov.uk/government/uploads/system/uploads/attachment data/file/47613/3702-the-

carbon-plan-delivering-our-low-carbon-future.pdf 

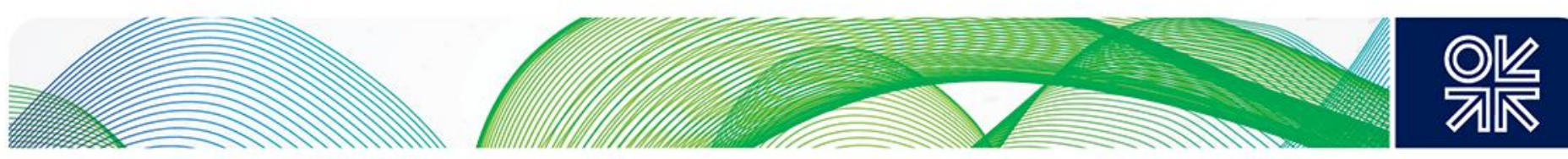

DECC (2012a), Energy Bill (HC Bill 100), November 2012,

http://www.publications.parliament.uk/pa/bills/cbill/2012-2013/0100/cbill 2012-20130100 en 1.htm

DECC (2012b), Annual Energy Statement, Department of Energy and Climate Change, Nov 2012 https://www.gov.uk/government/uploads/system/uploads/attachment data/file/65633/7086-annualenergy-statement-2012.pdf

DECC (2012c), Energy Security Strategy, Department of Energy and Climate Change, Nov 2012 https://www.gov.uk/government/uploads/system/uploads/attachment data/file/65643/7101-energysecurity-strategy.pdf

DECC (2012d), Gas Generation Strategy, Department of Energy and Climate Change, Dec 2012 https://www.gov.uk/government/publications/gas-generation-strategy

DECC (2013a) Electricity Generation Costs 2013 Department of Energy and Climate Change, July 2013

https://www.gov.uk/government/uploads/system/uploads/attachment data/file/223940/DECC Electrici ty Generation Costs for publication - 2407 13.pdf

DECC (2013b), DECC Fossil Fuel Price Projections Department of Energy and Climate Change, July 2013

https://www.gov.uk/government/uploads/system/uploads/attachment data/file/212521/130718 decc-

fossil-fuel-price-projections.pdf

DECC (2013c) RHI Tariff Review, Scheme Extensions and Budget Management, Impact Assessment, Department of Energy and Climate Change 24 September 2013,

https://www.gov.uk/government/uploads/system/uploads/attachment data/file/263580/lmpact Assess ment RHI Tariff Review Extensions and Budget Management Dec 2013.pdf

DECC (2013d), DECC Fossil Fuel Price Projections Department of Energy and Climate Change,

October 2014

https://www.gov.uk/government/uploads/system/uploads/attachment data/file/360598/DECC $2014 \mathrm{f}$ ossil fuel price projections.pdf

DECC (2013e) Onshore oil and gas exploration in the UK: regulation and best practice, Department of Energy and Climate Change, Dec 2013

https://www.gov.uk/government/uploads/system/uploads/attachment_data/file/265988/Onshore_UK_o il_and_gas_exploration_England_Dec13_contents.pdf

DECC (2013f), The hydrocarbon prospectivity of Britain's onshore basins, DECC 2013, https://www.gov.uk/government/uploads/system/uploads/attachment data/file/367284/UK onshore 2 $\underline{013 . p d f}$

DECC (2014a): Annual Fuel Poverty Statistics Report, 2014, Department of Energy and Climate Change 14 June 2014

https://www.gov.uk/government/uploads/system/uploads/attachment data/file/319280/Fuel Poverty $\underline{\text { Report Final.pdf }}$ 

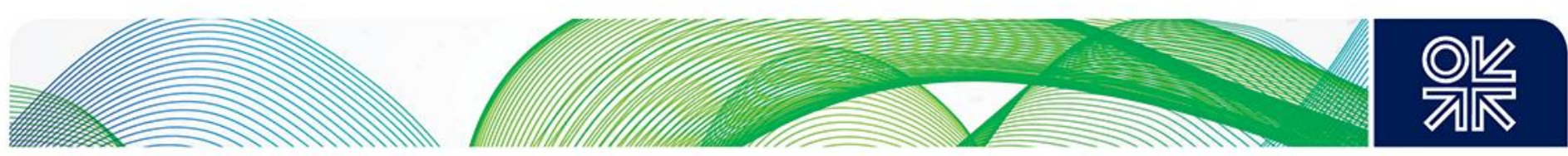

DECC (2014b), UK Risk Assessment on Security of Gas Supply, DECC June 2014 https://www.gov.uk/government/uploads/system/uploads/attachment data/file/318466/gas risk asses sment.pdf

DECC (2014c), Digest of UK Energy statistics (DUKES), July 2014

https://www.gov.uk/government/statistics/electricity-chapter-5-digest-of-united-kingdom-energystatistics-dukes

DECC (2014d), 2014 Government GHG Conversion Factors for Company Reporting, July 2014 http://www.ukconversionfactorscarbonsmart.co.uk/documents/2014\%20Emission\%20Factor\%20Meth odology\%20Paper FINAL-4Jul14.pdf

DECC (2014e) Energy Consumption in the UK (2014), Department of Energy and Climate Change 31 July 2014

https://www.gov.uk/government/uploads/system/uploads/attachment data/file/338662/ecuk chapter 3 domestic factsheet.pdf

DECC, (2014f) Gas since 1882, https://www.gov.uk/government/statistical-data-sets/historical-gasdata-gas-production-and-consumption-and-fuel-input-1882-to-2011

DECC (2014g), Strategy and Policy Statement - Consultation on the draft statement, Department of Energy and Climate Change August 2014

https://www.gov.uk/government/uploads/system/uploads/attachment data/file/343314/SPS consultati on paper.pdf

DECC (2014h), Next Steps in CCS: Policy Scoping Document, August 2014,

https://www.gov.uk/government/uploads/system/uploads/attachment_data/file/341995/Final_Version_ Policy_Scoping_Document_PSD.pdf

DECC (2014i), Annual Energy Statement 2014, Department of Energy and Climate Change October 2014

https://www.gov.uk/government/uploads/system/uploads/attachment data/file/371387/43586 Cm 89 $\underline{45 \text { accessible.pdf }}$

DECC (2014j), UK Gas Reserves and Estimated Ultimate recovery, 2014, https://www.gov.uk/government/uploads/system/uploads/attachment data/file/326978/UK Gas Rese rves and EUR 2014.pdf

DECC (2014k), Gross Gas Production since 1991, https://www.gov.uk/oil-and-gas-uk-field-data

DECC (2015a), Delivering UK Energy Investment: Networks, Department of Energy and Climate Change January 2015,

https://www.gov.uk/government/uploads/system/uploads/attachment data/file/394509/DECC Energy Investment Report WEB.pdf

DECC (2015b), CFD Auction Allocation Round One - a breakdown of the outcome by technology, year and clearing price, February 2015

https://www.gov.uk/government/uploads/system/uploads/attachment data/file/407465/Breakdown inf ormation on CFD auctions.pdf 

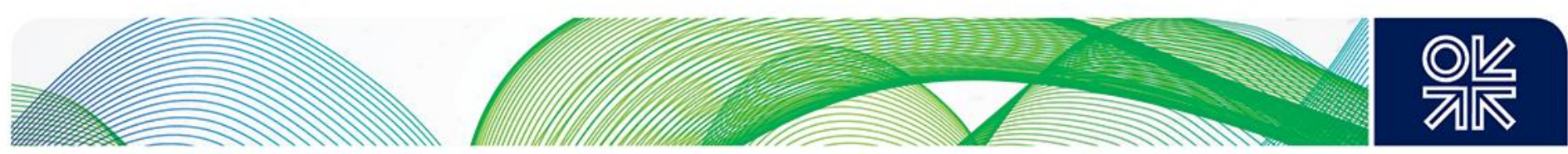

DECC (2015c), Strategy and Policy Statement - Review of Responses, Department of Energy and Climate Change, March, 2015

2015https://www.gov.uk/government/uploads/system/uploads/attachment data/file/418683/SPS Sum mary of reponses.pdf

Elkins, J, (2010), Natural Gas in the UK, An Industry in Search of a policy, OIES, NG 40 http://www.oxfordenergy.org/wpcms/wp-content/uploads/2010/11/NG40-

NaturalGasinTheUkAnIndustryInSearchofAPolicy-JohnElkins-2010.pdf

ETI, (2013), Macro Distributed Energy Project Report, Energy Technologies Institute, March 2013, http://www.eti.co.uk/wp-content/uploads/2014/03/ETI_Macro_Distributed_Energy_Report_-

21_March_2013_2.pdf

ETI (2015a), Carbon capture and storage: Building the UK carbon capture and storage sector by 2030 -Scenarios and actions, Energy Technologies Institute, March 2015, http://www.eti.co.uk/wpcontent/uploads/2015/03/CCS-Building-the-UK-carbon-capture-and-storage-sector-by-2013.pdf

ETI (2015b), Smart Systems and Heat: Decarbonising Heat for UK Homes, Energy Technologies Institute, March 2015, http://www.eti.co.uk/wp-content/uploads/2015/03/Smart-Systems-and-HeatDecarbonising-Heat-for-UK-Homes-.pdf

EWI (2014), An Embargo of Russian Gas and Security of Supply in Europe, Institute of Energy Economics at the University of Cologne (EWI), October 2014, http://www.ewi.unikoeln.de/fileadmin/user upload/Publikationen/Studien/Politik und Gesellschaft/2014/201409 An Embargo of Russian Gas and Security of Supply in Europe 0610.pdf

European Parliament (2001) Directive 2001/80/EC of the European Parliament and of the European Council of 23 October 2001 http://www.eea.europa.eu/policy-documents/directive-2001-80-ec-large

European Parliament (2009), DIRECTIVE 2009/31/EC OF THE EUROPEAN PARLIAMENT AND OF THE COUNCIL of 23 April 2009 on the geological storage of carbon dioxide and amending Council Directive 85/337/EEC, http://eur-lex.europa.eu/legal-content/EN/TXT/?uri=CELEX:32009L0031

Frontier (2008), Less is more, Frontier Economics Bulletin, January 2008, https://www.frontiereconomics.com/documents/2014/06/less-is-more-frontier-bulletin.pdf

Frontier (2014), The relative system cost of biomass and offshore wind- An independent report commissioned by Drax, Frontier Economics, November 2014

http://www.businessgreen.com/digital assets/8305/Frontier report on offshore wind and biomass report.pdf

Harker M \& Waddams Price C (2006), Introducing Competition and Deregulating the British Domestic Energy Markets: a Legal and Economic Discussion, CCP Working Paper 06-20, November 2006 http://competitionpolicy.ac.uk/documents/8158338/8256117/CCP+Working+Paper+06-20.pdf

Hartley, R., (2014) Shale gas development: US experience - UK application, Presentation to Energy Institute, London 10 December 2014, https://www.energyinst.org/filegrab/?ref=3307\&f=el-shale-gas10-dec-2014-ppt.pdf 

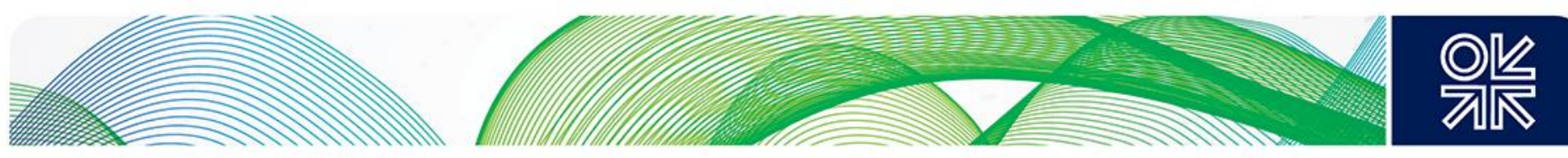

Heather (2010), The Evolution and Functioning of the Traded Gas Market in Britain, P. Heather, OIES, NG 44, http://www.oxfordenergy.org/2010/08/the-evolution-and-functioning-of-the-traded-gasmarket-in-britain/

Helm D. (2004), Energy, the state and the market: British Energy policy since 1979, http://www.dieterhelm.co.uk/node/611

Helm D. (2015), Competition in the British electricity sector: a set of practical reforms, Energy Futures Network Paper No. 8 Dieter Helm 9th February 2015

http://www.dieterhelm.co.uk/sites/default/files/Competition\%20in\%20the\%20British\%20electricity\%20 $\underline{\text { sector.pdf }}$

Helm D. (2015b), Regulatory credibility and the irresistible urge to meddle, Dieter Helm, 16th April 2015 http://www.dieterhelm.co.uk/node/1403

Honore, A. (2014), The Outlook for Natural Gas Demand in Europe, OIES June 2014 http://www.oxfordenergy.org/wpcms/wp-content/uploads/2014/06/NG-87.pdf

House of Commons (2015) Energy and Climate Change Committee Energy network costs: transparent and fair? Sixth Report of Session 2014-15, House of Commons, February 2015 http://www.publications.parliament.uk/pa/cm201415/cmselect/cmenergy/386/386.pdf

IGU (2015), Wholesale Gas Price Survey, 2015 Edition, International Gas union, May 2015, http://www.igu.org/sites/default/files/node-page-

field file/IGU\%20Whole\%20Sale\%20Gas\%20Price\%20Survey\%20Report\%20\%202015\%20Edition.p $\underline{\mathrm{df}}$

Ikonikova et al (2014), Profitability of Shale gas drilling: A Case Study of the Fayetteville Shale play, Bureau of Economic Geology, University of Texas http://www.sciencedirect.com/science/article/pii/S0360544214014236

IOD (2013), Getting shale gas working, Institute of Directors, Infrastructure for Business Report, 6 , 2013 http://www.igasplc.com/media/3067/iod-getting-shale-gas-working-main-report.pdf

IPPR (2012), The True Cost of Energy, Institute for Public Policy Research, April 2012, http://www.ippr.org/files/images/media/files/publication/2012/04/true-cost-ofenergy Apr2012 9040.pdf?noredirect=1

Jenkins, C. (2011), RIIO Economics - Examining the economics underlying Ofgem's new regulatory framework, Centre for Competition and Regulatory Policy Winter Workshop, February 2011, http://www.city.ac.uk/ data/assets/pdf file/0011/80939/Jenkins RIIO-Economics draft-paperFINAL.pdf

Keay et al (2012), Keay, M.,Rhys J. and Robinson D, Decarbonisaiton of the electricity industry- is there still a place for markets?, OIES, Oxford, 9 November 2012,

http://www.oxfordenergy.org/wpcms/wp-content/uploads/2012/11/EL-9.pdf 

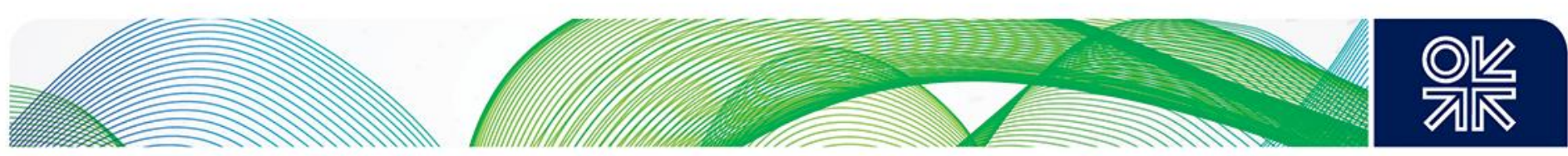

Kopp, S-D., (2015) Politics, Markets and EU Gas Supply Security http://www.springer.com/gp/book/9783658083236

Le Fevre, C. (2013), Gas Storage in Great Britain, OIES NG72, January 2013 http://www.oxfordenergy.org/wpcms/wp-content/uploads/2013/01/NG-72.pdf

Littlechild et al (2015) Submission to CMA on updated Issues statement, 24 February 2015, https://assets.digital.cabinet-

office.gov.uk/media/54f8757540f0b61407000005/Stephen Littlechild and others response to updat ed issues statement.pdf

Mackay David JC (2014), Sustainable Energy - Without the hot air, UIT Cambridge, 2008. ISBN 9780-9544529-3-3. Available free online

, http://www.withouthotair.com/

Moss \& Buckley (2014), Competition in British business energy supply markets An independent assessment for Energy UK, Cornwall Energy, April 2014 https://www.energy-

uk.org.uk/publication.html?task=file. download\&id=3296

National Grid (2008): Winter Consultation report, 2008/9 A review of winter 2007/8 \& preliminary outlook for winter 2008/9 June 2008

http://www.ofgem.gov.uk/Markets/WhIMkts/Custandlndustry/winout2008/Documents1/Winter\%200utl ook\%20Consultation\%20Report\%20(June).pdf

National Grid (2009): Winter Outlook report, 2009/10 Outlook for winter 2009/10 October 2009 http://www2.nationalgrid.com/UK/Industry-information/Future-of-Energy/FES/Winter-Outlook/

National Grid (2013): Gas Transportation Ten Year Statement 2013, December 2013, http://www2.nationalgrid.com/UK/Industry-information/Future-of-Energy/Gas-ten-yearstatement/Current-statement/

National Grid (2014a): UK Future Energy Scenarios, July 2014, http://www2.nationalgrid.com/uk/industry-information/future-of-energy/future-energy-scenarios/

National Grid (2014b): Gas Transportation Ten Year Statement 2014, December 2014, http://www2.nationalgrid.com/UK/Industry-information/Future-of-Energy/Gas-Ten-Year-Statement/

National Grid (2015): Final Auction Results: t-4 Capacity Market Auction 2014, https://www.emrdeliverybody.com/Capacity\%20Markets\%20Document\%20Library/T4\%202014\%20Final\%20Auction\%20Results\%20Report.pdf

Nera (2015), Energy Supply Margins: Commentary on Ofgem's SMI, Prepared for Energy UK, 29 January 2015, http://www.energy-uk.org.uk/publication.html?task=file.download\&id=5008

Newbery and Grubb (2014), The Final Hurdle? Security of Supply, the Capacity Mechanism and the role of interconnectors, David Newbery Based on EPRG WP1412 EPRG Winter Seminar Cambridge, 14th Dec 2014

http://www.eprg.group.cam.ac.uk 

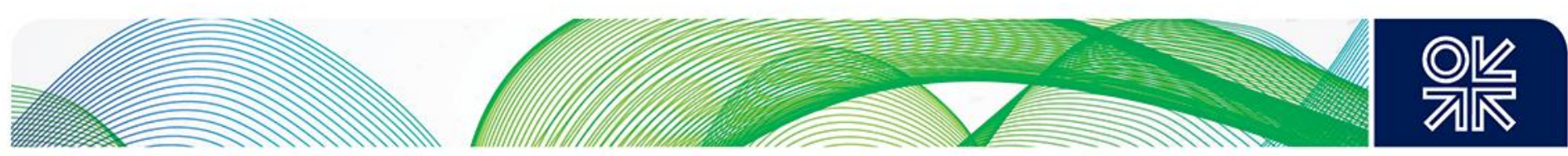

Ofgem (2008) Energy Supply Probe Summary of initial findings and remedies, 6 October 2008, https://www.ofgem.gov.uk/sites/default/files/docs/2008/10/probe summary.pdf

Ofgem (2009) Regulating Energy Networks for the Future: RPI-X@20 History of Energy Network Regulation, Ofgem, 27 February 2009, https://www.ofgem.gov.uk/ofgem-

publications/51984/supporting-paper-history-energy-network-regulation-final.pdf

Ofgem (2012a), Gas Security of Supply Report, November 2012

http://www.ofgem.gov.uk/Markets/WhlMkts/monitoring-energy-security/gas-security-of-supplyreport/Documents1/Gas\%20SoS\%20Report.pdf

Ofgem (2012b), Gas Security of Supply Report, Further measures design appendix November 2012 http://www.ofgem.gov.uk/Markets/WhIMkts/monitoring-energy-security/gas-securityof-supply-report/Documents 1/Gas\%20SoS\%20Report\%20-

\%20Further\%20Measures\%20Appendix.pdf

Ofgem (2012c), The Retail Market Review - Updated domestic proposals, October 2012, https://www.ofgem.gov.uk/sites/default/files/docs/2012/10/the-retail-market-review---updateddomestic-proposals.pdf

Ofgem (2013), The Retail Market Review - Implementation of Simpler Tariff Choices and Clearer Information, August 2013, https://www.ofgem.gov.uk/sites/default/files/docs/decisions/the retail market review implementation of simpler tariff choices and clearer information.pdf

Ofgem (2014a), State of the market assessment, March 2014 https://www.ofgem.gov.uk/ofgempublications/86804/assessmentdocumentpublished.pdf

Ofgem (2014b), Gas Security of Supply Significant Code Review

: Conclusions, 23 September 2014,

https://www.ofgem.gov.uk/sites/default/files/docs/2014/09/gas_scr_final_decision.pdf

Ofgem (2015), Making a difference for Consumers, Strategy presentation, 22 January 2015, https://www.ofgem.gov.uk/ofgem-publications/92597/strategystakeholderevent-22januarydnpresentation-textversion.pdf

OGA (2015), Oil and Gas Authority, Call to Action: The OGA Commission 2015

https://www.gov.uk/government/uploads/system/uploads/attachment data/file/406680/Call to Action - The OGA Commission 2015.pdf

Oil and Gas UK (2015), Activity Survey 2015,

http://www.oilandgasuk.co.uk/Health_Safety_Report.cfm

Parsons Brinckerhoff (2014), Coal and Gas Assumptions: Report for DECC, March 2014 https://www.gov.uk/government/uploads/system/uploads/attachment_data/file/315717/coal_and_gas_ assumptions.PDF

Pirani, Stern and Yafimava, (2009); The Russo-Ukrainian gas dispute of January 2009: a comprehensive assessment; Oxford Institute for Energy Studies, February 2009 

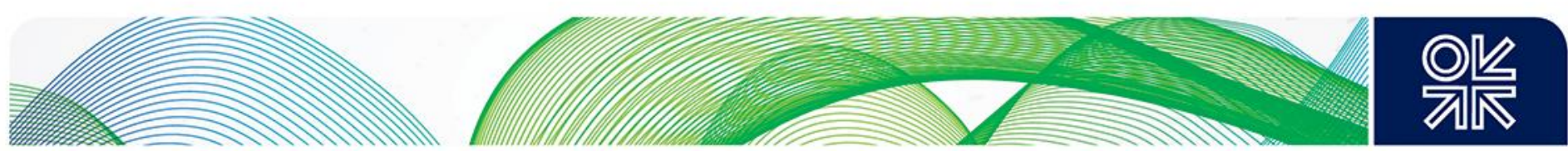

NG 27, http://www.oxfordenergy.org/wpcms/wp-content/uploads/2010/11/NG27-

TheRussoUkrainianGasDisputeofJanuary2009AComprehensiveAssessmentJonathanSternSimonPiraniKatjaYafimava-2009.pdf

Pöyry (2013) Technology Supply Curves for Low Carbon Generation. A report to the Committee on climate change, June 2013, http://www.theccc.org.uk/wp-content/uploads/2013/05/325 Technologysupply-curves-v5.pdf

Redpoint (2013), The impact of gas market interventions on energy security, A report for DECC from Redpoint Energy, July 2013, https://www.gov.uk/government/uploads/system/uploads/attachment data/file/236757/DECC FI Fina I report 09072013.pdf

Rogers H, (2011), The Impact of Import Dependency and Wind Generation on UK Gas Demand and Security of Supply to 2025; Oxford Institute for Energy Studies, July, 2011, NG 54 http://www.oxfordenergy.org/2011/08/the-impact-of-import-dependency-and-wind-generation-on-ukgas-demand-and-security-of-supply-to-2025-2/

Rogers H, (2012), Gas with CCS in the UK - Waiting for Godot?; Oxford Institute for Energy Studies, September, 2012, http://www.oxfordenergy.org/2012/09/gas-with-ccs-in-the-uk-waiting-for-godot/

Rogers, H. (2013), UK Shale Gas - Hypre, Reality and difficult questions , Oxford Energy Comment, July 2013, http://www.oxfordenergy.org/wpcms/wp-content/uploads/2013/07/UK-Shale-Gas-GPC1.pdf

Roulstone (2014), Transformative Change in Energy How can Nuclear beat Gas? Tony Roulstone Cambridge Nuclear Energy Centre June 2014

www.energy.ox.ac.uk/wordpress/wp-content/uploads/2014/10/Roulstone.pdf

Rural Community Policy Unit (2014), Shale Gas Rural Economy Impacts March 2014, https://www.gov.uk/government/uploads/system/uploads/attachment_data/file/408977/RFI6751_Draft _Shale_Gas_Rural_economy_impact_paper.pdf

Rutledge and Wright (2010), UK Energy Policy and the End of Market Fundamentalism, OIES, 2010

Scottish Government (2011), UK Continental Shelf Tax Regime - Options for Reform, June 2011, http://www.gov.scot/resource/doc/919/0121778.pdf

Sherman, E. (2013), Four Challenges for CCS, Avaialble on GreenPeace websaite http://www.greenpeace.org.uk/newsdesk/energy/analysis/four-challenges-ccs

Stern, J.P. (ed.) (2012a). The Pricing of Internationally Traded Gas, Oxford: OIES/OUP. https://www.oxfordenergy.org/shop/the-pricing-of-internationally-traded-gas-ed-jonathan-p-stern/

Stern, J.P. (2012b). 'The Pricing of Internationally Traded Gas: an historical survey', in Stern (2012), Chapter 2, pp. 40-84.

https://www.oxfordenergy.org/shop/the-pricing-of-internationally-traded-gas-ed-jonathan-p-stern/

Stern, J. and Rogers, H. (2012). 'The Transition to Hub-Based Gas Pricing in Continental Europe', in Stern, J.P. (ed.), The Pricing of Internationally Traded Gas, Oxford: OIES, Chapter 4, pp.145-177. http://www.oxfordenergy.org/shop/the-pricing-of-internationally-traded-gas-ed-jonathan-p-stern/ 

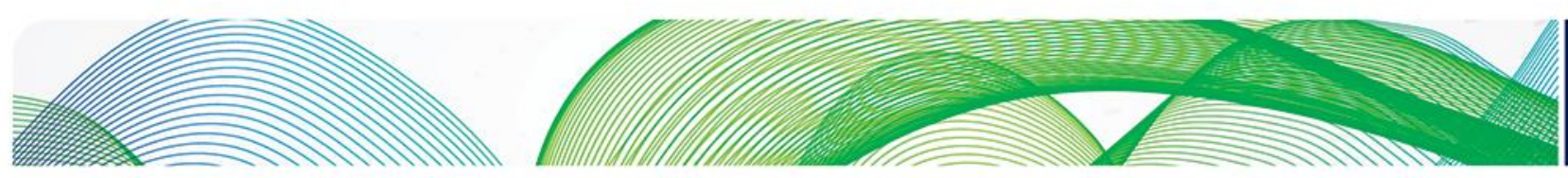

Stern J. and Rogers. H. (2014) The Dynamics of a Liberalised European Gas Market: Key determinants of hub prices, and roles and risks of major players, OIES December 2014 http://www.oxfordenergy.org/2014/12/dynamics-liberalised-european-gas-market-key-determinantshub-prices-roles-risks-major-players/

Timera Energy (2013), `A Framework for Understanding European Hub Pricing', http://www.timeraenergy.com/a-framework-for-understanding-european-gas-hub-pricing/ Timera Energy (2015a) Market benchmark for gas flexibility Value, Timera Energy, February 2015http://www.timera-energy.com/uk-gas/market-benchmark-for-gas-flexibility-value/

Timera Energy (2015b) Gas plant competiveness is increasing, Timera Energy, April 2015 http://www.timera-energy.com/gas-plant-competiveness-is-increasing/

Transco (2000) Ten Year Statement, December 2000

UK Government (2008), Climate Change Act 2008, http://www.legislation.gov.uk/ukpga/2008/27/contents

UK Government (2013), Energy Act 2013, http://www.legislation.gov.uk/ukpga/2013/32/contents/enacted/data.htm

UK Government (2015), Infrastructure Act 2015, http://services.parliament.uk/bills/201415/infrastructure/documents.html

UK Oil \& Gas (2015), Activity Survey 2015, http://cld.bz/Yst721r\#6

Walker A (2011), LNG Today, Tomorrow and beyond, presentation to World LNG Summit, Rome 14 November, 2011

Wilson I et al (2014) Historical daily gas and electrical energy flows through Great Britain's transmission networks and the decarbonisation of domestic heat, published via the University of Strathclyde,

https://pure.strath.ac.uk/portal/files/30735961/Wilson_IAG_et_al_Pure_Historical_daily_gas_and_elec trical_energy_flows_through_Great_Britains_..._domestic_heat_Oct_2013.pdf

Wood, I. (2014), UKCS Maximising Recovery Review: Final report (“The Wood Review”), Sir lan Wood, February 2014,

http://www.woodreview.co.uk/documents/UKCS\%20Maximising\%20Recovery\%20Review\%20FINAL \%2072pp\%20locked.pdf

Wright P (2006), Gas Prices in the UK, Markets and Insecurity of Supply, Philip Wright, OIES, OUP 2006 http://www.oxfordenergy.org/shop/gas-prices-in-the-uk-markets-and-insecurity-of-supply/

Yafimava K., 2013, The EU Third Package for Gas and the Gas Target Model: Major contentious issues inside and outside the EU, OIES, NG 75, April 2013, http://www.oxfordenergy.org/wpcms/wpcontent/uploads/2013/04/NG-75.pdf 

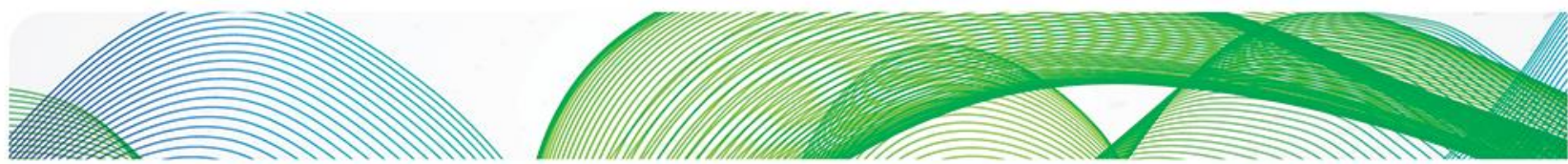

\section{ORe}

Yarrow G, (2014), Energy Market Investigation, Response to the CMA's Statement of Issues, 18 August 2014, https://assets.digital.cabinet-

office.gov.uk/media/53f1c32fe5274a48c400000f/George Yarrow response to IS.pdf 